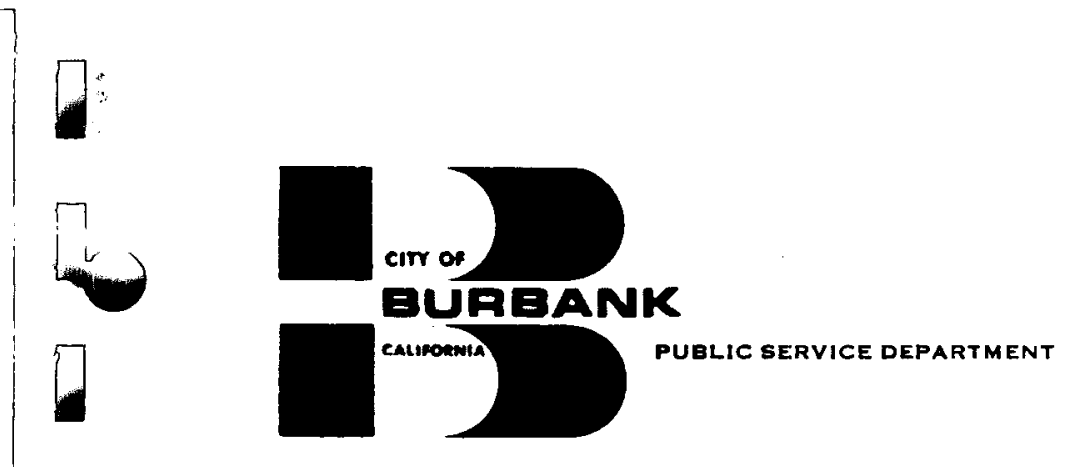

\title{
SYSTEM DESIGN VERIFICATION OF A HYBRID GEOTHERMAL/COAL FIRED POWER PLANT
}

\author{
Prepared for the \\ UNITED STATES DEPARTMENT OF ENERGY \\ DIVISION OF GEOTHERMAL ENERGY \\ Under Grant Extension No. EG-77-G-03-1572 \\ PRIME CONTRACTOR: CITY OF BURBANK
}

Project No. 5805

September 1978

The Ralph M. Parsons Company DISCLAIMER
This book was prepared as an account of work sponsored by an agency of the United States Government.
Neither the United Siates Government nor any agency thereof, nor any of their employees, makes any warranty, express or implied, or assumes any legal liability or responsibility for the accuracy, completeness, or usefulness of any intormation, apparatus, product, or process disclosed, or rejresents that its use would nor intringe privately awned rights. Reference herein to any specific commercial product, process, or service by irade narne, trade mark, manufacturer, or otherwise, does
not necessarily constitute or imply its endorsement, recomrendation, or favoring by the United

Engineers / Constructors

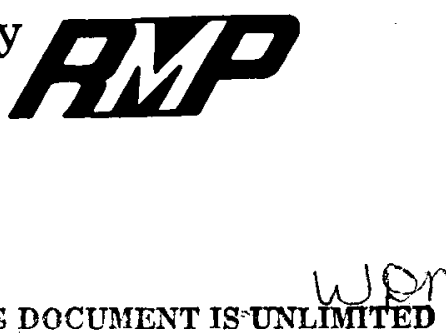




\section{DISCLAIMER}

This report was prepared as an account of work sponsored by an agency of the United States Government. Neither the United States Government nor any agency Thereof, nor any of their employees, makes any warranty, express or implied, or assumes any legal liability or responsibility for the accuracy, completeness, or usefulness of any information, apparatus, product, or process disclosed, or represents that its use would not infringe privately owned rights. Reference herein to any specific commercial product, process, or service by trade name, trademark, manufacturer, or otherwise does not necessarily constitute or imply its endorsement, recommendation, or favoring by the United States Government or any agency thereof. The views and opinions of authors expressed herein do not necessarily state or reflect those of the United States Government or any agency thereof. 


\section{DISCLAIMER}

Portions of this document may be illegible in electronic image products. Images are produced from the best available original document. 
The Ralph M. Parsons Company makes no warranty or representation, expressed or implied, with respect to the accuracy, completeness, or usefulness of the information contained herein, or that the use of any information, apparatus, method, or process disclosed herein may not infringe. privately owned rights; nor does it assume any liabilities with respect to the use of, or for damages resulting from the use of, any such information, apparatus, method, or process. 


\begin{abstract}
Geothermal power plants using hot geothermal steam to drive turbine generators for electric power generation have been built and operated for a number of years. However, with respect to the extraction of available work from the geothermal fluids, the efficiencies of existing plants are low.

A relatively new concept for the use of hot geothermal fluids in conventional type fossil-fired power plants was introduced in 1975. This hybrid plant utilizes geothermal fluid for feedwater heating. With respect to the extraction of available work from the geothermal fluids, this cycle is approximately two times as efficient as the all geothermal plant. This conclusion was reached in the "Site Specific Analysis of Hybrid Geothermal/Fossil Power Plants" prepared by the City of Burbank and published in June 1977. That report further concluded that the hybrid plant is both feasible and economical compared with a well sited conventional coal fired power plant.
\end{abstract}

The System Design Verification Study, conducted by The Ralph M. Parsons Company for the City of Burbank and presented in this report, verifies the technical and economic feasibility of the hybrid plant. This report is comprised of a conceptual design, cost estimate, and economic analysis of a one-unit $715 \mathrm{MW}$ hybrid geothermal/coal fired power plant. In addition to the use of geothermal fluid for feedwater heating, this report also investigates its use for additional power generation, condensate and cooling tower makeup water, coal beneficiation, air preheating, flue gas reheating and plant space heating requirements. An engineering and construction schedule for the hybrid plant is also included. 


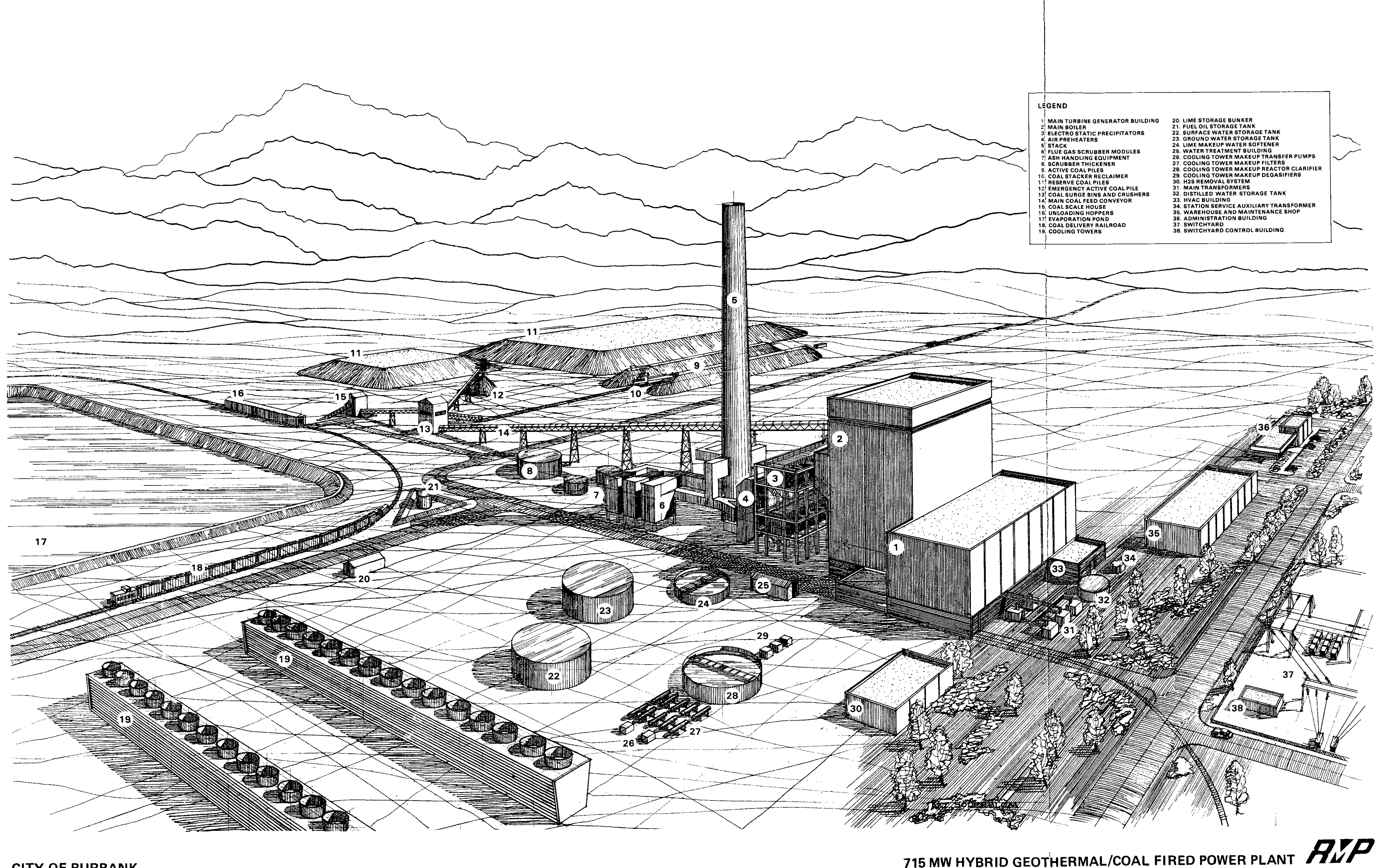


CONTENTS

ABSTRACT

SECTION 1 - SUMMARY AND CONCLUSIONS

1.1 Introduction $1-1$

1.2 Scope of Study $1-3$

1.3 Study Criterion $1-5$

1.4 Description of Power Plant 1-5

1.5 Description of Geothermal Feedwater Heating 1-6

1.6 Description of Additional Investigations $1-7$

1.7 Cost Estimates and Schedule 1-12

1.8 Economic Analysis $1-14$

1.9 Conclusions 1-16

SECTION 2 - FEEDWATER HEATING

2.1 General Discussion 2-1

2.2 Geothermal Resource 2-2

2.3 Heat Balance $2-4$

2.4 Design Effects of Geothermal Feedwater Heating 2-7

2.5 Alternative Feedwater Heating Arrangements 2-10

2.6 Potential Problem Areas 2-13

SECTION 3 - PLANT DESCRIPTION

3.1 General Description 3-1

3.2 Main Boiler 3-2

3.3 Draft System $3-5$

3.4 Emission Control System 3-8

3.5 Coal and Limestone Handling Systems 3-11

3.6 Ash Handling Systems 3-15

3.7 Turbine Generator Unit 3-17

3.8 Hot and Cold Brine System 3-19

3.9 Feedwater and Condensate System 3-21

3.10 Main and Reheat Steam System 3-26

3.11 Bleed Steam System 3-28

3.12 Heater Vents and Drains Systems 3-31

3.13 Circulating Water System 3-33

$3.14 \mathrm{H}_{2} \mathrm{~S}$ Removal System 3-34

3.15 Electrical System $3-36$

3.16 Outline Specifications of Major Equipment $3-40$ 
SECTION 4 - MAKEUP WATER

4.1 General Discussion

$4-1$

4.2 Condensate Makeup Water

$4-2$

4.3 Cooling Tower Makeup Water

4-8

4. 4 Summary

4-12

SECTION 5 - ADDITIONAL POWER

5.1 General Discussion

5.2 Alternatives Considered

$5-1$

5.3

Heat Balance

5.4

System Descriptions

$5-4$

5.5

Out line Specifications of Major Equipment

$5-7$

5.6 Summary

$5-10$

$5-19$

SECTION $6-$ COAL BENEFICIATION

6.1 General Discussion

6-1

6.2 Alternatives Considered

$6-2$

6.3 Selection Criteria

$6-4$

6.4 System Descriptions

$6-8$

6.5 Outline Specifications for Major Equipment

$6-11$

6.6

Conclusions

$6-19$

SECTION 7 - OTHER GEOTHERMAL USES

7.1 General Discussion

$7-1$

7.2 Air Preheating

7.3 Flue Gas Reheating

$7-1$

7.4 Plant Space Heating

$7-2$

7.5 Summary

$7-4$

$7-7$

SECTION 8 - COST ESTIMATES AND SCHEDULE

8.1 Cost Estimate and Schedule Criteria

8-1

8.2 Cost Estimate

$8-2$

8.3 Schedule

$8-18$ 


\section{CONTENTS}

(continued)

Page

SECTION 9 - ECONOMIC ANALYSIS

9.1 General Discussion

9-1

9.2 Geothermal Feedwater Heating

$9-2$

9.3 Makeup Water and Other Geothermal Uses

9-6

9.4 Additional Power

9-9

9.5

Coal Beneficiation

$9-10$

SECTION 10- DRAWINGS

10.1 Description of Drawings 10-1 
SECTION 1

SUMMARY AND CONCLUSIONS

\subsection{INTRODUCTION}

This "System Design Verification of a Hybrid Geothermal/Coal Fired Power Plant" was performed by The Ralph M. Parsons Company to verify the results of an earlier report. The earlier report published by the city of Burbank in June 1977 entitled "Site Specific Analysis of Hybrid Geothermal/ Fossil Power Plants" was prepared for the Energy Research and Development Administration, Division of Geothermal Energy. That report covers the analysis and modifications required to convert a conventional 750 megawatt coal fired power plant to a hybrid geothermal/coal fired power plant.

The Intermountain Power Project (IPP) plant was selected as the coal fired reference power plant for the present study since it was also the reference plant used in the City of Burbank Report described above. In addition, the Roosevelt Hot Springs site was used as the geothermal resource in this study.

The hybrid geothermal/coal fired power plant is defined as a conventional coal fired power plant utilizing hydrothermal energy from a geothermal source. In this study the use of geothermal fluids for feedwater heating was considered or referred to as the base case. Other uses for geothermal fluid in the hybrid plant were added to the scope of this study as additional conceptual engineering investigations and their uses are described in Sections 4 through 7 . The additional investigations for using geothermal fluids included makeup water, additional power, coal beneficiation, air preheating, flue gas reheating, and plant space heating.

The City of Burbank Report analyzed four potential sites for the location of the hybrid power plant. These were: 
- Roosevelt Hot Springs, Beaver County, Ut ah

- Coso Hot Springs, Inyo County, California

- East Mesa, Imperial County, California

- Long Valley, Mono County, California

Mathematical and computer modeling techniques were employed by the City of Burbank to determine plant overall heat rates, cycle characteristics, operation, and maintenance. Cost estimates, including total installed capital costs, operating costs, maintenance costs, labor, etc. were prepared for each site listed above. Costs were included for power generation, DC conversion, transmission, and $A C$ conversion. The Roosevelt Hot Springs site resulted in the most economical selection based on total cost per kilowatt hour of power generation delivered to Victorville, California and referenced to overall costs for the life of the plant. A conceptual design, from which more accurate estimates could be made for total installed plant costs, was not undertaken by the City of Burbank.

This system design verification study performed by Parsons was based on modifying the IPP coal fired plant to a hybrid geothermal/coal fired power plant. Considerable data generated in the Intermountain Power Project Preliminary Engineering and Feasibility Study dated October 1976 was used as the basis for this system design verification study. Conceptual engineering was performed on those systems that would be affected by the change to the hybrid concept. An economic analysis was performed to determine overall cost of power production in mills per kilowatt hour. A conceptual design cost estimate prepared by Parsons for the hybrid plant was used as the basis of the economic analysis. Other factors influencing the overall power production costs include:

(1) Cost of the geothermal wells, piping, operation, maintenance, etc. 


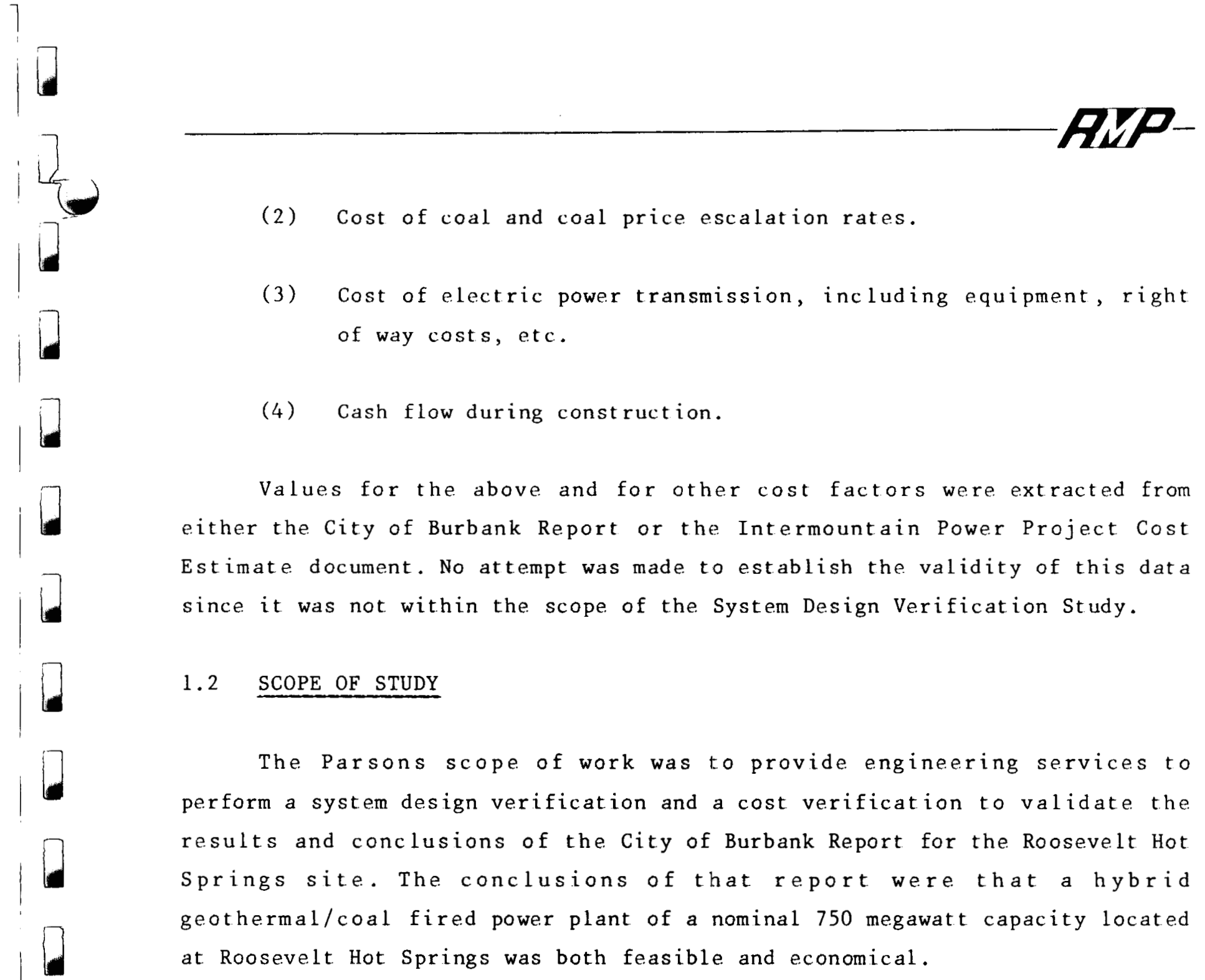

The Parsons work included the following:

(1) Prepare a detailed heat balance for a hybrid power plant using the IPP preliminary design as a reference base.

(2) Modify IPP general arrangement drawings, flow diagrams, and piping line diagrams to reflect the hybrid plant concept, or prepare new drawings as required.

(3) Prepare a cost estimate for the hybrid plant using supporting data from the IPP cost estmate document and the City of Burbank Report for equipment and structures not affected by the geothermal process. 
(4) Perform overall economic analyses of the hybrid plant.

(5) Prepare a design and construction schedule for the hybrid plant.

(6) Investigate beneficiation of coal using geothermal fluid for reduction of ash and sulfur content.

(7) Determine feasibility of using geothermal fluids as a source of makeup water for condensate and cooling tower makeup.

(8) Investigate the use of geothermal fluid for additional power generation .

(9) Investigate other uses for utilizing heat from geothermal fluids.

The City of Burbank Report was based on using geothermal fluids for feedwater heating only. However, the City of Burbank Report also recommended that other uses of geothermal heat should be investigated. Therefore, in order to verify and validate the results of the report, Parsons base case study is also based on using geothermal fluids for feedwater heating only. However, the results of the additional engineering investigation as 1 isted in Items 6 through 9 above are documented in this report and are analyzed separately.

The engineering of the hybrid plant systems and modification of affected IPP systems and equipment in the power plant are conceptual in nature. Cost estimates are budgetary and represent order-of-magnitude prices based on conceptual outline specifications for new equipment and systems, and on the IPP cost estimate for the other plant systems not affected by the hybrid plant design.

The IPP plant consists of four 750 MW units. One 715 MW hybrid geothermal/coal fired generating unit comprises the hybrid plant. However, some of the drawings presented in Section 10 show more than one unit. Since the IPP plant is designed for four units, selected drawings contained 
information on one, two, or four units. On those drawings where more than one unit is shown, the impact of the hybrid design was indicated on each unit. However, the cost estimate and economic analysis are based on a single unit plant .

\subsection{STUDY CRITERION}

The criterion for the system design verification is to establish the optimum use of geothermal feedwater heating for energy production based on modifying the Intermountain Power Project $750 \mathrm{MW}$ conventional pulverized coal fired generating unit at a specific site. Results of the report, in turn, are expected to verify the estimated cost of power generation in the City of Burbank Report.

Conceptual designs are based on environmental regulations, safety, and legal requirements at the time (1976) of the IPP Report. Performance characteristics of all equipment and systems are specified to use state of the art equipment.

Environmental considerations derived from the introduction of potentially toxic or undesirable substances, contained in the geothermal fluid, to within the plant boundary limits are examined and solutions to these considerations presented. For example, it is anticipated that the geothermal resource contains hydrogen sulfide $\left(\mathrm{H}_{2} \mathrm{~S}\right)$. An $\mathrm{H}_{2} \mathrm{~S}$ removal system is presented in Section 3 which is designed to remove expected quantities of $\mathrm{H}_{2} \mathrm{~S}$ from piping and equipment vents in the geothermal fluid systems.

\subsection{DESCRIPTION OF POWER PLANT}

The IPP power plant consists of four units each rated at 820 MW gross electric output. This System Design Verification Study examines only one unit. The heat balance calculations for the turbine generator set indicates that the total electric output from the hybrid plant will be 780 MW gross. The reduction in total output was dictated by the maximum steam flow 
limitation in the low pressure turbine exhaust stages. Since extraction steam from the intermediate pressure and low pressure turbines was virtually eliminated, nearly all the intermediate pressure turbine steam flow must flow through the low pressure turbines. Total feedwater flow was reduced accordingly to prevent exceeding the low pressure turbine maximum flow limitations.

The steam generator for the hybrid plant is a conventional pulverized coal fired boiler rated at $4,543,000 \mathrm{lb} / \mathrm{hr}$ main steam flow at $1000 \mathrm{~F}, 2487$ psia, and $4,489,000 \mathrm{lb} / \mathrm{hr}$ reheat steam flow at $1000 \mathrm{~F}$ and $444 \mathrm{psia}$. Turbine generator throttle conditions are 1000F/1000F, 2400 psi. Condenser back pressure is assumed to be $1.84 / 2.85$ inches $\mathrm{Hg}$ as in the IPP plant. Eight stages of feedwater heating are employed. Feedwater Heaters $1,2,3,5,6$, and 7 are geothermal fluid-to-feedwater heat exchangers. Heater 4 is a deaerating direct contact feedwater heater, and Feedwater Heater 8 is a conventional extraction steam type tube and shell feedwater heater with desuperheating, condensing and subcooling surfaces. Heater 7 in the IPP plant design is, in this study, Heater 8 which is identical to the one selected for the all coal fired plant. Installation of this heater ensures that feedwater temperature to the boiler will very closely approximate that of the IPP plant design.

The circulating water system is a closed loop utilizing wet mechanical draft counterflow type cooling towers as shown on drawings in section 10 and as described in section 3.

The hybrid plant, like the IPP plant, is designed to include complete coal and limestone handling systems, emissions control, cleanup, and disposal systems, including electrostatic precipitators and 1 imestone throwaway type. $\mathrm{SO}_{2}$ scrubbers.

\subsection{DESCRIPTION OF GEOTHERMAL FEEDWATER HEATING}

The condensate and feedwater system in the hybrid plant employs one conventional shell and tube extraction steam-type feedwater heater with 
desuperheating, condensing, and subcooling heat transfer surfaces; one deaerating type direct contact feedwater heater using extraction steam from the cold reheat line; and six geothermal shell and tube type feedwater heaters utilizing hot geothermal fluid for feedwater heating. The major contribution of heat to the feedwater is provided by the geothermal heaters, Feedwater Heaters $1,2,3,5,6$, and 7 .

The deaerator, Heater 4, has been designed for adequate removal of noncondensible gases from the feedwater. Feedwater Heater 8 , a conventional extraction steam type, is designed to operate with only a minimum heat transfer duty under normal design conditions, but has the capacity to assume. greater heat loads when required. Its primary function is to maintain constant feedwater temperature entering the boiler, particularly in the event the geothermal fluid source temperature drops below design conditions or one or more geothermal heaters are removed from service. Under these conditions, the turbine extraction steam flow will increase to compensate for the decrease in feedwater temperature entering the heater.

The geothermal feedwater heaters are the shell and tube type utilizing the straight tube design for ease of maintenance and cleaning. Geothermal fluid flows inside the tubes and feedwater is on the shell side. A single heater train is provided and each heater is equipped with a bypass for selective removal from service for maintenance or in the event of a malfunction.

\subsection{DESCRIPTION OF ADDITIONAL INVESTIGATIONS}

A number of additional engineering investigations were performed by Parsons in addition to the use of geothermal fluid for feedwater heating. A summary of these investigations is provided in the following paragraphs. 


\subsubsection{MAKEUP WATER}

The advantages of using spent geothermal fluids for makeup water are significant since the quantity of raw water to be purchased in an area where ground and surface water is both scarce and costly is considerably reduced. Likewise, spent geothermal fluid that is not used for makeup water must be reinjected into the ground at additional cost.

Spent geothermal fluid can be used for both condensate makeup water and for cooling tower makeup water. Average continuous makeup water requirements at full load for the hybrid plant are estimated at 50,000 pounds per hour for condensate makeup and 4,500,000 to 5,200,000 pounds per hour for cooling tower makeup. The total geothermal fluid flow at full load is $4,600,000$ pounds per hour.

\subsubsection{Condensate Makeup Water}

Four alternative concepts were analyzed for providing condensate makeup water from the spent geothermal fluid. Of the four concepts examined the one with the lowest overall cycle heat rate, the most efficient use of geothermal energy, low capital and operating costs, and purest condensate makeup water was selected.

The concept selected uses cold geothermal fluid from the discharge of Feedwater Heater 1 , and is evaporated in a conventional type evaporator system. Steam from the evaporator is condensed in an additional low pressure feedwater heater. The condensate is then pumped through a mixed bed demineralizer to remove any solids, such as silica or other impurities, carried over from the evaporator. The discharge of the demineralizer is then sent to the main condenser hotwell.

\subsubsection{Cooling Tower Makeup Water}

Three alternatives were analyzed for providing cooling tower makeup water from the spent geothermal fluid. The concept selected was 
on the basis of meeting cooling tower makeup water purity requirements, cost of equipment and installation, operating and maintenance costs.

The alternative selected uses cold geothermal fluid from the discharge of Feedwater Heater 1 , which is then passed through a pressure reducing station and a degasifier, and introduced into a reactor clarifier. Chemicals are injected into the reactor clarifier to remove 90 percent of the silica from the fluid. The geothermal fluid is then passed through gravity filters and introduced into the cooling towers.

\subsubsection{ADDITIONAL POWER}

The most efficient use of geothermal heat for power generation is to use geothermal fluid for feedwater heating in a hybrid geothermal/coal fired power plant. The geothermal efficiency of a hybrid plant is approximately twice that obtained in most all-geothermal plants. Consequently, for an area like Roosevelt Hot Springs, where large quantities of coal are economically available for use in a hybrid plant, a base loaded all geothermal plant is not desirable. However, it is desirable to maintain geothermal well production at system capacity to obtain an acceptable rate of return on the capital cost of the wells and geothermal piping systems. Constant flow is also desirable from an operating and maintenance standpoint.

of the four alternatives for additional power examined in the study, the most feasible concept is an all geothermal plant operated in conjunction with the hybrid plant. When the hybrid plant is at full rated load all the geothermal fluid is used for feedwater heating. When the hybrid plant is at less than full rated load, excess geothermal fluid is flashed for power generation in the all geothermal plant. Thus, under all normal operating conditions the geothermal fluid flow is held constant and at maximum system capacity. 
1.6.3 COAL BENEFICIATION

Normally, if the run-of-mine coal is dirty and contains extraneous rubble, it is given a simple wash treatement at the mine and shipped. In the case of coals in the western part of the United States, this is generally dispensed with since the run-of-mine coal is quite clean. More complex treatments to coal in order to effect significant improvements in its characteristics, such as ash reduction or sulfur removal, are referred to as beneficiation.

Coal beneficiation to remove both ash and sulfur is essentially a two part process. Processes that are effective in the removal of ash are not particularly effective in the removal of sulfur. Processes that are effective in the removal of sulfur are not effective in the removal of ash. Therefore, in order to accomplish both, a combination process would be more practical.

In order to achieve mainly ash reduction, the two beneficiation processes considered were the wet physical separation process using water as the media and the heavy media process. The heavy media process is more expensive both in capital and operating costs than the wet physical separation process. Therefore, the first process mentioned is considered the more desirable. Both of the processes are in commerical use.

The chemical cleaning processes reviewed for sulfur removal are all in the developmental stage. Thus, there is no actual commercial operational experience. The six developmental processes reviewed all purport to remove 100 percent of the pyritic sulfur and little or none of the organic sulfur.

The western coals, bituminous and sub-bituminous, are generally appreciably lower in sulfur and ash content than eastern coals. Since this study is based on the power plant located in the Roosevelt Hot Springs area, 
review of Utah coal analyses indicated that sulfur and ash content are low. Therefore, beneficiation can be considered advantageous for only a portion of the boiler feed coals. Spent geothermal fluid can be used as the water media for wet physical coal beneficiation, and can be used either hot or cold.

The reduction of ash through beneficiation of only the high ash coal, or coal containing above 9 percent ash would appear desirable. This would amount to approximately one-third of the coal. Accordingly, a coal beneficiation system, using the wet physical separation process, having a capacity of approximately 3,000 tons per day, should reduce the ash content of coal deliveries having over 8 to 9 percent ash to a range of 6 to 7 percent. The pyrites sulfur of the high ash coal would also be partially removed in the coal beneficiation processing.

\subsubsection{OTHER GEOTHERMAL USES}

Geothermal energy may be utilized in the hybrid geothermal/coal fired power plant for combustion air preheating, flue gas reheating and plant space heating. Concepts were developed for each of these applications because significant savings in coal consumption occur when using geothermal energy in lieu of conventional energy sources for these systems.

The total contribution of geothermal heat in the hybrid plant for air preheating, flue gas reheating and plant space heating may vary between 181,000,000 Btu per hour and 241,000,000 Btu per hour, depending upon the outside air temperature. Total geothermal fluid flow in the three systems varies between 120,000 and 155,000 pounds per hour. The heat input to the hybrid plant resulting from these systems is equivalent to a savings in coal of between 8 and 10.5 tons per hour which converts to an approximate annual costs savings of $\$ 1,000,000$ to $\$ 1,400,000$ based on 1976 coal cost figures. 


\subsection{COST ESTIMATES AND SCHEDULE}

The cost estimate for the overall plant using geothermal feedwater heating, as the base case, is described separately from the cost estimates where geothermal fluids are used for other purposes in the power plant. This was done to permit more direct comparisons with the findings in the City of Burbank Report. The basis for the conceptual design cost estimates, items that are included, and those excluded are described in section 8 .

\subsubsection{COST ESTIMATE - GEOTHERMAL FEEDWATER HEATING}

The conceptual design capital cost estimate for a 715 MW (net) hybrid geothermal/coal fired power plant with geothermal feedwater heating is $\$ 385,841,000$ in 1976 dollars. This estimate, which does not include the cost of geothermal wells, compares to an estimated capital cost of $\$ 361,065,000$ published in the June 1977 City of Burbank Report. The difference between the two estimates of $\$ 24,776,000$, or approximately 7 percent, is primarily due to the distribution of common facilities costs identified in the IPP cost estimate.

The IPP cost estimate was for a four unit 3000 megawatt power plant. Costs of facilities common to all four units were identified in the cost estimate. The City of Burbank Report assumed that the equivalent cost of common facilities for a one unit plant of 750 megawatts was 25 percent of that for a 3000 megawatt plant.

The Parsons cost estimate for "common facilities" is included in the costs presented in Section 8, Table 8-1 entitled Cost Estimate Summary. Each common facility in the IPP report was considered on its individual characteristics to determine an appropriate scaling factor which was then applied to the IPP cost estimate number. 


\subsubsection{COST ESTIMATE - OTHER GEOTHERMAL SYSTEMS}

\subsubsection{Makeup Water}

The capital cost estimate for providing condensate and cooling tower makeup water from geothermal fluid is $\$ 2,720,000$, in 1976 dollars. This estimate is in addition to capital costs estimated for conventional makeup water systems for the base case hybrid plant.

\subsubsection{Additional Power}

The capital cost estimate for the all geothermal plant, termed "additional power" is $\$ 30,432,000$, in 1976 dollars. This estimate includes cost savings resulting from common systems between the hybrid and all geothermal plants.

\subsubsection{Coal Beneficiation}

The capital cost estimate of the coal beneficiation system is in the range between $\$ 9,000,000$ and $\$ 11,000,000$. A more accurate assessment of costs could be made based on a definite known coal analyses range.

\subsubsection{Other Geothermal Uses}

The capital cost estimate for providing combustion air preheating, flue gas reheating, and plant space heating by hot geothermal fluid is $\$ 300,000$, in 1976 dollars. This estimate is in addition to capital costs estimated for conventional systems for the base case hybrid plant. 


\subsection{ECONOMIC ANALYSIS}

The economic analysis for the hybrid power plant using geothermal feedwater heating, as the base case, is described separately from the economic analysis where geothermal fluids are used for other purposes in the power plant. This was done again to permit more direct comparisons with the findings in the City of Burbank Report. The detailed economic analysis is described in Section 9.

\subsubsection{ECONOMIC ANALYSIS - GEOTHERMAL FEEDWATER HEATING}

Economic analysis by Parsons of the hybrid geothermal/coal fired power plant with geothermal feedwater heating consisted of determining the estimated annual costs for capital, operating and maintenance, fuel, cooling water and transmission. These annual costs, expressed in 1976 dollars for both average annual costs and base year (1976) costs, are presented in equivalent mills per kilowatt hour in Tables 9-1 and 9-2 in Section 9. Table. 9-1 entitled "Annual Cost Summary for a 715 MW Hybrid Plant" shows that the total base year cost for power at Victorville, California is $\$ 99,327,000$ in January, 1976 dollars, or an equivalent of 18.69 mills per kilowatt hour. Average annul costs during the plant economic life, also expressed in January 1976 dollars, in Table 9-2 are estimated at $\$ 109,829,000$ or an equivalent energy cost of $20.67 \mathrm{mills}$ per kilowat hour.

The City of Burbank Report estimated the base year cost of power at $18.042 \mathrm{mills}$ per kilowatt hour and the average annual cost at 20.46 mills per kilowatt hour. When compared to these values the Parsons estimate for base year and average annual costs is 3.6 percent and 1.0 percent higher, respectively. These differences are within the accuracy 1 imits of the capital, operating and maintenance, and fuel cost estimates developed in this report. 


\subsubsection{ECONOMIC ANALYSIS - OTHER GEOTHERMAL SYSTEMS}

The economic analysis for geothermal makeup water, combustion air preheating, flue gas reheating and plant space heating was conducted separately from the analysis for additional power, since of all these geothermal systems, the additional power all geothermal plant was the only system to increase the total energy costs.

Tables $9-3$ and $9-4$ are annual cost comparison summaries for base year (1976) energy costs and average annual costs in 1976 dollars, respectively. Case 1 is the energy cost breakdown for the base case hybrid plant. Case 2 includes the base case hybrid plant plus the addition of geothermal makeup water, air preheating, flue gas reheating and plant space heating systems. Case 3 includes Case 2 plus additional power.

As discussed in Paragraph 1.8.1, the total energy costs for Case 1 are estimated at 18.69 and $20.67 \mathrm{mills}$ per kilowatt hour for base year (1976) cost and average annual cost, respectively. The corresponding total energy costs for Case 2, however, reduce to 18.36 and $20.13 \mathrm{mills}$ per kilowatt hour. This reduction is primarily due to cost savings in makeup water and coal savings from the use of geothermal heat for air preheating, flue gas reheating, and plant space heating.

Total energy costs increase when the cost of the additional power all geothermal plant is included in the estimate. Total energy costs for Case 3 are estimated at 18.84 and $20.29 \mathrm{mills}$ per kilowat hour respective base year (1976) and average annul costs as compared to corresponding Case 2 costs of 18.36 and 20.13 .

\subsubsection{ECONOMIC ANALYSIS - COAL BENEFICIATION}

The cost of coal beneficiation for Roosevelt Hot Springs, Utah, is estimated at $\$ 1.43$ per ton of beneficiated coal in Base Year (1976) costs and $\$ 1.14$ per ton in average annual costs in 1976 dollars. This includes 
capital, operating, and maintenance costs. This cost is in addition to the cost of coal delivered to the site and is in 1976 do11ars. Assuming an 85 percent capacity factor for the coal beneficiating system and the availability of corresponding amounts of coal which would require beneficiation to maintain the system at process capacity, this would amount to an additional first year coal cost of $\$ 1,350,000$ and $\$ 1,060,000$ expressed in Base Year (1976) and average annual costs, respectively.

\subsection{CONCLUSIONS}

Conclusions drawn from the results of this System Design Verification study are discussed in the following paragraphs. The conclusions presented in Paragraph 1.9.1, below, are limited to the application of geothermal heat for feedwater heating only. Subsequent paragraphs include the impact of additional geothermal power, coal beneficiation, makeup water, and other geothermal uses such as for air preheating, flue gas reheating, and plant space heating .

\subsubsection{GEOTHERMAL FEEDWATER HEATING}

\subsubsection{Alternative Feedwater Heating Arrangements}

Two feedwater heating arrangements were examined in detail. One arrangement utilizes the 1 iquid dominated geothermal fluid resource in liquid-to-1iquid feedwater heaters, whereas the other arrangement includes a series of flash tanks and feedwater heaters in a cascading system. The former arrangement uses sensible heat transfer while the latter uses latent heat transfer. Selection of the most desirable arrangement is dependent on site specific parameters. For Roosevelt Hot Springs, the liquid-to-liquid (sensible heat transfer) arrangement is selected on the basis of overall economics and efficiency of utilization of the geothermal resource. Generally, moderately saline geothermal fluids favor this arrangement, whereas highly saline geothermal fluids favor the flash tank arrangement on the basis of reliability, operation, maintenance, and capital costs. 
In addition to consideration of geothermal feedwater heating arrangements, variations in the thermodynamic properties of the geothermal fluid or permanent degradation of the resource may affect the operation of the plant. One extraction steam type heater at the top of the feedwater train maintains constant feedwater temperature entering the steam generator in the event of cycling geothermal fluid temperatures, geothermal feedwater heater outages, and geothermal well outages.

\subsubsection{Geothermal Heat Contribution}

The conceptual design of the geothermal feedwater heating cycle resulted in a total geothermal heat contribution to the feedwater of 24 percent, or 20 percent of the total energy consumed in the plant. Additional contribution of geothermal heat is discussed in Paragraphs $1.9 .2,1.9 .3$ and 1.9 .5 .

\subsubsection{Resource Utilization Efficiency}

The hybrid plant utilizes the geothermal energy much more efficiently than present concepts for all geothermal plants, with respect to the extraction of available work from the geothermal fluid. The overall geothermal efficiency of the hybrid plant is approximately 80 percent. Overall efficiencies of all geothermal plants range from 40 to 55 percent.

\subsubsection{Plant Heat Rate}

The net heat rate for the hybrid plant is 9124 Btu per kilowatt hour whereas the net heat rate of the IPP unit is 8250 Btu per kilowat hour. The heat rate for the hybrid plant would be improved with optimization of turbine, condenser, and cooling tower designs. In the context of this report, net heat rate is defined as the sum of the total Btu/hr extracted from the geothermal fluid and the total Btu/hr generated from coal combustion divided by the net kilowatt output at the bussbar. It is 
anticipated that subsequent to optimization of the hybrid plant, total energy costs would be lower than those presented in Paragraph 1.9.1.6. Additionally, the low available energy of the geothermal fluid makes the heat rate appear high, whereas the true efficiency of the hybrid plant would be about the same as a conventional plant.

\subsubsection{Cost Estimate}

The total constructed cost of the hybrid plant is estimated at $\$ 385,841,000$ in 1976 dollars. This cost is 7 percent higher than that estimated in the City of Burbank Report. The difference is primarily due to the method used to distribute "common facilities" costs provided in the four unit IPP cost estimate to a one unit hybrid plant estimate.

\subsubsection{Energy Cost}

Total energy cost for power at Victorville for the hybrid plant is estimated at $18.69 \mathrm{mills}$ per kilowatt hour, expressed in base year 1976 dollars, and 20.67 mills per kilowatt hour based on average annual costs in 1976 dollars. These energy cost figures are 3.6 and 1.0 percent higher respectively than those estimated in the City of Burbank Report. These differences are within the accuracy of the capital, operating and maintenance, and fuel cost estimates developed in this report. Total energy costs expressed as base year 1976 costs or average annual costs in 1976 dollars for both the Parsons and the Burbank estimates for the hybrid plant are lower than the Burbank estimate for all coal fired plant located at Roosevelt Hot Springs. The hybrid plant is therefore, economically and technically feasible on the basis of lower total energy costs. Also only existing technology is required for construction of the hybrid plant.

\subsubsection{Fuel Savings}

Annual fuel consumption for the hybrid plant is 1,933,000 tons of coal. Coal consumption for an all coal fired plant of the 
same generating capacity as the hybrid plant, with the same heat rate calculated by IPP, is estimated at 2,185,000 tons per year. Therefore, an estimated net coal savings of 252,000 tons per year or 13 percent would be realized with the hybrid plant.

\subsubsection{Site Location}

Site selection alternatives for the hybrid plant depend entirely on the location of suitable known geothermal resource areas (KGRA's). Normally, the hybrid plant should be located within one mile of the geothermal wells since transport of hot geothermal fluid over large distances is impractical. Site selection between suitable alternatives, however, is governed by economic factors. The dominant factor on which site selection is governed is the cost of coal. The hybrid plant located at Roosevelt Hot Springs is economically competitive with a well sited all coal fired power plant.

Other factors which influence the overall criteria for site selection include the thermodynamic properties of the geothermal fluid as well as the concentration of total dissolved solids and noncondensible gases, chemistry, and $\mathrm{pH}$.

\section{$1.9 .1 .9 \quad \mathrm{H}_{2}$ S Removal System}

Removal of elemental sulfur from noncondensible gases present in the geothermal fluid can be accomplished with one of several existing processes. A conceptual design of an $\mathrm{H}_{2} \mathrm{~S}$ removal system is included in this report for removal of all but $10 \mathrm{ppm}_{2} \mathrm{~S}$ in the vent gas stream. 


\subsubsection{MAKEUP WATER}

Spent geothermal fluid in a hybrid geothermal/coal fired power plant can be most advantageously used for both condensate makeup water and for cooling tower makeup water. The use of this spent geothermal fluid will most significantly reduce the quantity and cost of raw water required from ground and surface water sources. It also eliminates the need for reinjection of this fluid into the ground at extra cost.

\subsubsection{Cost Estimate and Economic Analysis}

The estimated cost of $\$ 2,720,000$ for providing geothermal makeup water to the hybrid plant is more than compensated by savings in the cost of fresh raw water makeup that would be required in a conventional plant. Consequently the total energy cost for the hybrid plant with geothermal makeup water systems is lower than for the base case hybrid plant. Therefore, it is concluded that the hybrid geothermal/coal fired power plant should include the geothermal makeup water systems described in Section 4.

\subsubsection{ADDITIONAL POWER}

The most feasible concept for using geothermal heat for additional power generation is an all geothermal plant operated in conjunction with the hybrid geothermal/coal fired power plant. Although it is desirable to maintain geothermal well production at system capacity for a number of reasons as explained previously, the low capacity factor for the all geothermal plant imposes a cost penalty on the hybrid plant which overrides the cost benefit from utilizing geothermal heat for power production. As a result, without further indepth studies, the use of geothermal heat for additional power generation is not economically feasible when compared to the hybrid plant. 


\subsubsection{COAL BENEFICIATION}

The desirability and economic feasibility of coal beneficiation is highly dependent on the coal characteristics, the site location, and applicable emission standards to be met. Furthermore, in a hybrid geothermal/coal fired power plant, the geothermal fluids will have a bearing on the feasibility of coal beneficiation along with the fact that the power plant is located remote from the coal source. As a result, no reliable assessment of the cost and benefits from coal beneficiation can be made on the basis of generic studies or generalized analysis as it relates to a specific situation.

\subsubsection{OTHER GEOTHERMAL USES}

The use of geothermal energy in the hybrid geothermal/coal fired power plant may be utilized to good advantage for combustion air preheating, flue gas reheating, and for plant space heating. The estimated additional capital cost of $\$ 300,000$ for providing these other systems is more than compensated by savings in the cost of coal that would be consumed in a conventional plant for these services. Consequently, the total energy cost for the hybrid plant with these other systems is lower than for the base case hybrid plant. Therefore, it is concluded that the hybrid geothermal/coal fired power plant should include the geothermal combustion air preheating, flue gas reheating and plant space heating systems described in section 7. 
SECTION 2

FEEDWATER HEATING

\subsection{GENERAL DISCUSSION}

The concept of the hybrid fossil-geothermal power plant is based on the theory developed at Brown University by Professors Ronald Di Pippo, Joseph Kestin, and H. Ezzat Khalifa. Based on this theory the City of Burbank undertook the task of determining the economic viability of a hybrid power plant under contract to the Energy Research and Development Administration, Division of Geothermal Energy. The objectives of the study, limited to the use of geothermal fluids for feedwater heating only, were to:

- Develop the analytical techniques for rough parametric design of hybrid geothermal/fossil fuel plants for various geothermal resource characteristics

- Develop the analytical techniques for approximate evaluation of hybrid geothermal/fossil fuel plants for given hydrothermal resource characteristics, fossil fuel location, consumer locale, plant size, and environmental restraints

- Evaluate the merits of a hybrid geothermal/fossil fuel plant for each of four known geothermal resource areas (KGRA's):

- Roosevelt Hot Springs, Beaver County, Utah

- Coso Hot Springs, Inyo County, California

- East Mesa, Imperial County, California

- Long Valley, Mono County, California 
- Prepare a preliminary plan for implementing the use of geothermal energy in hybrid cycle plants.

In order to perform their study, the City of Burbank selected the Intermountain Power Project (IPP) plant as the all coal fired reference. plant. The data needed was extracted from the IPP Preliminary Engineering and Feasibility study dated October, 1976, hereafter referred to as the IPP Report.

The results of the City of Burbank study were presented in the report entitled "Site-Specific Analysis of Hybrid Geothermal/Fossil Power P1ants" dated June 1977, hereafter referred to as the City of Burbank Report.

The Ralph M. Parsons Company, under contract to the City of Burbank, was requested to perform sufficient conceptual engineering investigations to corroborate the results and conclusions described in the City of Burbank Report. The scope of the work is described briefly in Paragraph 1.2. The study was to be based on one $750 \mathrm{MW}$ unit of the IPP plant located at Roosevelt Hot Springs. In order to verify the results of the City of Burbank Report, the work was divided into two parts. The first part was to use geothermal fluids for feedwater heating only. The second part was to investigate other uses for geothermal fluids in the power plant.

\subsection{GEOTHERMAL RESOURCE}

The geothermal resource, considered in this system design verification study as the source of hydrothermal energy for the hybrid geothermal/coal fired power plant, is Roosevelt Hot Springs. Roosevelt Hot Springs is located in Beaver County, about 12 miles northeast of Milford and about 20 miles northwest of Beaver, Utah. It is one of the two known geothermal resource areas (KGRA's) in Utah that were originally defined on geologic evidence by the United States Geological Survey. 
Documentation of geothermal exploratory findings have been reviewed by the City of Burbank and is described in their report. These findings indicate the following:

(1) Geothermal energy in usable form for generation of electric power and for feedwater heating is available in a number of KGRA's, including Roosevelt Hot Springs, Utah. In this report, it is concluded that when all ramifications of a hybrid power plant are considered, including design, construction, operation, maintenance, electric power transmission, coal supply, etc., Roosevelt Hot Springs proves to provide the lowest cost of electrical power to the Southern California area.

(2) Exploratory wells indicate that Roosevelt Hot Springs is a large source of hydrothermal energy, capable of high volume delivery of hot geothermal fluid to a hybrid power plant for many years.

(3) High silica content nearer the surface, found in early geothermal fluid analyses, indicated the possibility of a marked increase in temperature with depth. More recent drilling by Phillips Petroleum Company, Thermal Power Company, and others confirm the existence of this temperature gradient and show available temperature gradients ranging from 2.5 to $26.8 \mathrm{~F}$ per 100 feet. According to the United States Geological Survey, one of the Phillips Petroleum exploratory wells (54-3) was drilled to 2728 feet and had initial flows of one million pounds per hour of which 25 percent was steam and 75 percent was water. Reservoir pressure was reported at 500 psi at grade level.

A more detailed discussion of the geothermal resource at Roosevelt Hot Springs, including the geology, hot spring deposits, structure, field development, costs and water chemistry may be found in the supporting documents of the City of Burbank Report. Table 2-1 is a compilation of sample analyses of geothermal brine in the Roosevelt Hot Springs KGRA. 
For the purpose of this study, the Roosevelt Hot Springs resource is assumed to contain adequate geothermal fluid to meet the flow requirements for the hybrid geothermal/coal fired power plant, as described in Sections 1 and 3. Furthermore, the thermodynamic properties of the fluid have been assumed to be $475 \mathrm{~F}, 459.9$ Btu per pound mass (saturated liquid) at the plant battery limit. However, moderate variations in these conditions will not have a significant impact on the overall installed cost of the plant. A more indepth evaluation of this subject will be undertaken during the preliminary engineering design phase of the hybrid plant.

\subsection{HEAT BALANCE}

Parsons work was initiated with the calculation of revised heat and mass balances based on heat balances contained in the IPP Report.

For this study the same IPP steam turbine generator was utilized substituting geothermal feedwater heating for extraction heating as initially shown for 100 percent fossil operation. In order to determine the amount of heat that could be absorbed by the feedwater from geothermal fluids as well as maximum capability of the turbine generator, a maximum exhaust flow of 992,000 pounds per hour was assumed for each low pressure turbine element. A two-pressure-level condenser shown in the IPP Report was retained for this analysis.

In order to establish the quantity of heat that could be absorbed by the feedwater train, heat and mass flow calculations were performed for the following cases:

(1) A11 IPP extraction type Feedwater Heaters 1 through 7 were removed from service and replaced by geothermal heaters.

(2) Feedwater Heater 7 would be on extraction steam with remaining feedwater heating by geothermal fluid. 


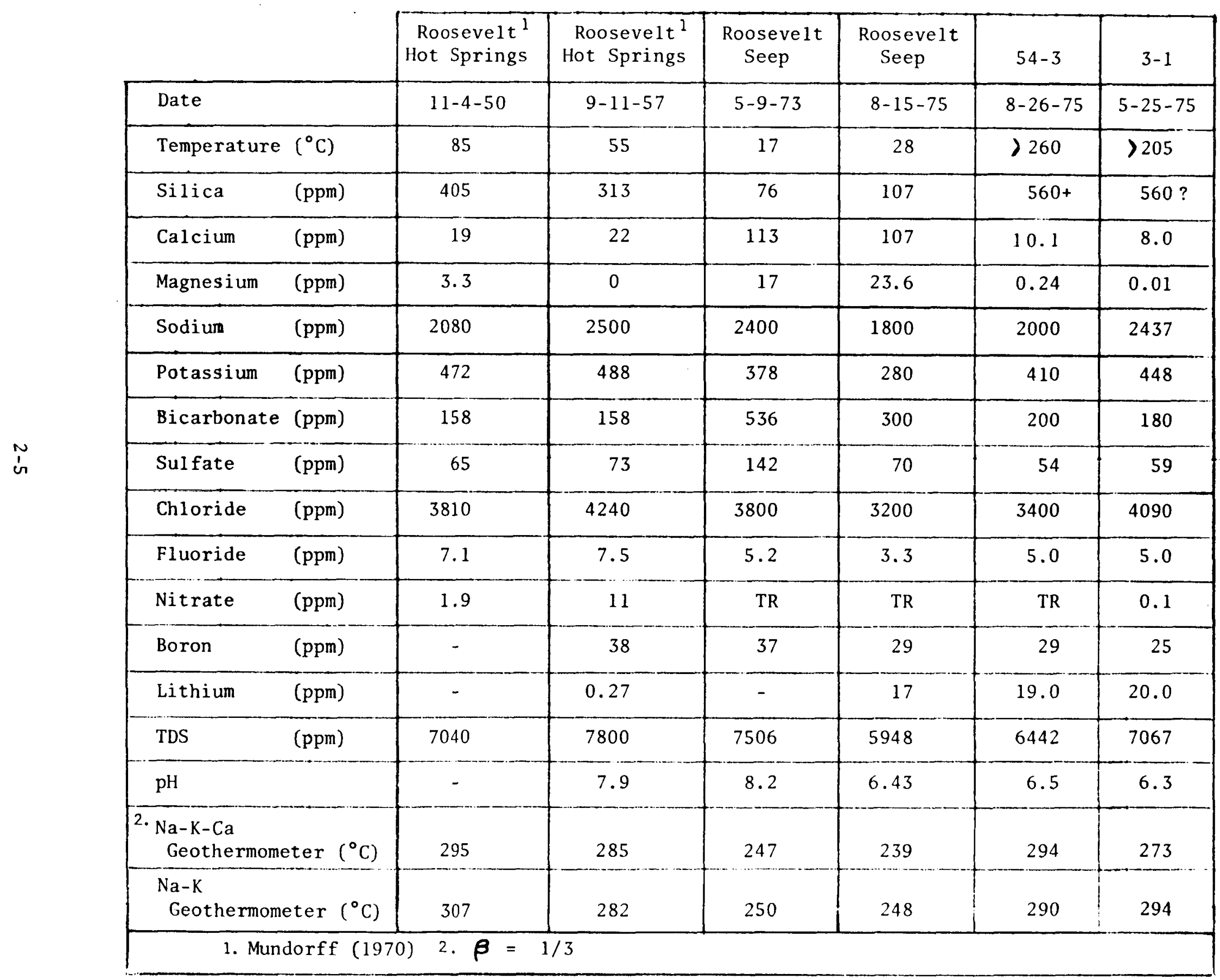


(3) Feedwater Heaters 6 and 7 would be on extraction steam with the balance of feedwater heat by geothermal fluid.

(4) Feedwater Heaters 5, 6 and 7 would be on extraction with the balance of feedwater heating by geothermal fluids.

Calculations were made assuming a constant feedwater temperature to the boiler at $480 \mathrm{~F}$, the same as for the original IPP heat balance, and no extraction for station auxiliary drivers. Calculations were repeated using maximum steam for station auxiliaries in order to determine the effect on station performance using steam drives for the auxiliaries.

Heat balance calculations were prepared to determine the generating capability of the turbine generator and the corresponding geothermal heat that could be absorbed for Cases 1 and 4 listed above. In addition, the quantity of geothermal heat that could be absorbed with and without extraction steam for auxiliary drives was calculated. Some basic results and conclusions are:

(1) Substitution of geothermal feedwater heating for regenerative feedwater heating by steam extraction reduces the maximum output capability of a steam turbine or multi-stage steam turbine arrangement designed for use in conventional regenerative cycles. This occurs because the output capability of any steam turbine is limited by the maximum steam flow which can be passed through the low pressure end. Elimination of extraction requires reduction of steam flow through the high pressure stages in order to maintain the flow at the low pressure end within allowable limits. This reduction in flow through the high pressure stages reduces turbine power output.

(2) The effect described in Item 1 above can be mitigated by maximizing extraction for auxiliary steam drives. 
The heat and mass flow balance study indicates that for geothermal fluid at approximately $460 \mathrm{~F}$, the best cycle is to use one feedwater heater on extraction steam with the balance of heat provided by geothermal fluids and with maximum utilization of extraction steam for auxiliary drives. This is covered by Case 2 of the initial analysis. For the purpose of comparing heat rates for the various cases under consideration, gross heat rate without extraction steam for auxiliaries, net heat rate with extraction steam for auxiliaries and gross heat rate assuming electric drive auxiliaries were calculated for Cases 1 through 4 . The results indicate the value of using extraction steam for the large auxiliary drives particularly when geothermal heat is available for heating feedwater.

As a result of the above analysis, a detailed heat balance was prepared to show expected flows, heat rate, and fuel consumption using Case 2 with extraction steam for auxiliaries as a basis. The heat cycle and heat balance are shown on Drawings ME-1 and ME-2, respectively in Section 10 .

\subsection{DESIGN EFFECTS OF GEOTHERMAL FEEDWATER HEATING}

The design effects of using geothermal fluids for feedwater heating in an all coal fired power plant are considerable. The changes and modifications required affect a number of systems along with many major pieces of equipment. These are briefly discussed in the subsequent paragraphs. Section 3 provides the basis and description of the hybrid plant as modified from the IPP all coal fired plant.

\subsubsection{MAIN BOILER}

The introduction of geothermal heat input to the condensate and feedwater systems results in a decrease in the total heat input contribution of the boiler to the cycle. Additionally, the total plant rated capacity is reduced as a result of the flow limitation in the low pressure turbines, as discussed previously. Consequently, the main boiler was resized in accordance with a lower coal consumption rate to reflect the hybrid parameters. 


\subsubsection{DRAFT SYSTEM}

Draft system sizing calculations were performed to reflect the reduction in capacity discussed in Paragraph 2.4.1. Ducts were resized to maintain draft losses identical to those in the IPP design.

\subsubsection{MAIN EMISSION CONTROL, COAL HANDLING AND ASH HANDLING SYSTEMS}

These systems were resized to reflect the impact of the hybrid design on coal consumption, as well as particulate, $\mathrm{so}_{2}$, and ash production. Drawings for these systems in Section 10 show a 3000 MW four unit plant. The economic analysis, however, reflects the costs of a single unit plant .

\subsubsection{TURBINE GENERATOR UNIT}

The steam turbine for the hybrid plant is comprised of one high pressure turbine, one two-flow intermediate pressure turbine, and two two-flow low pressure turbines on the same shaft having 33.5 inch last stage blades. Replacement of conventional feedwater heaters, designed for the IPP plant, with geothermal feedwater heaters in the hybrid configuration has resulted in the elimination of six feedwater heater extraction points. The only turbine extraction steam being used for feedwater heating in the hybrid configuration is cold reheat for the deaerator, Heater 4, and for Heater 8 which was Heater 7 in the IPP plant design.

Low pressure turbine choke velocity limitations resulted in a reduction in unit capacity. In the interest of continuity between the IPP plant design and that of the hybrid plant, turbine and condenser configurations have been retained, thus no attempt was made in this study to optimize the turbine and condenser design. As discussed above, removal of extractions in the intermediate pressure and low pressure turbine sections resulted in increased flow in the low pressure turbines. Thus, limitations in low pressure turbine flow are responsible for the reduction in unit power output capacity. 


\subsubsection{HOT AND COLD BRINE SYSTEM}

The hot and cold brine system will be designed so that the pressure of geothermal brine in the feedwater heaters is maintained lower than the pressure of the feedwater and condensate under all plant operating conditions. Consequently, leaks in the tube and shell geothermal heat exchangers will not result in contamination of the feedwater and a subsequent unit trip. Rather, in the event of a leak, the flow will be from the feedwater (she11) side to the geothermal brine (tube) side. The geothermal brine will flow through the tube side of all geothermal feedwater heaters to facilitate maintenance and cleaning and to improve plant reliability.

\subsubsection{CONDENSATE AND FEEDWATER, MAIN AND REHEAT STEAM, BLEED STEAM,} HEATER VENTS AND DRAINS, AND CIRCULATING WATER SYSTEMS

These systems were modified to reflect the impact of the implementation of the hybrid concept and subsequent reduction in the unit power output capacity. The following items characterize the effects on the IPP plant by the introduction of the hybrid design.

(1) Feedwater flow was reduced from 5,704,000 to 4,548,000 $\mathrm{lb} / \mathrm{hr}$.

(2) Steam flow to the high pressure and intermediate pressure turbines was reduced in accordance with Item 1. Steam flow in the low pressure turbine sections was increased as outlined in Paragraph 2.4.4.

A major portion of the bleed steam system was removed since Extraction Type Feedwater Heaters 1, 2, 3, 5, and 6 in the IPP plant design were replaced by Geothermal Heaters $1,2,3,5,6$, and 7 in the hybrid design. 
(4) The major portion of the heater vents and drains system, as designed for the IPP plant was removed or modified for the hybrid plant. All geothermal vents and drains will be piped either directly to the $\mathrm{H}_{2} \mathrm{~S}$ removal system or to a collection tank where noncondensible gases will be vented to the $\mathrm{H}_{2} \mathrm{~S}$ removal system and the geothermal fluid piped to the reinjection wells.

(5) Heat duty on the circulating water system increased, based on the increase in low pressure turbine flows. This equipment was resized accordingly. No attempt was made to verify the selection criteria for the cooling tower, condenser, air removal system, circulating water pumps, piping, etcetera. Major equipment was sized for the required increase in capacity.

\subsection{ALTERNAT.IVE FEEDWATER HEATING ARRANGEMENTS}

The Roosevelt Hot Springs geothermal resource, as well as most KGRA's in the Western United States, is liquid dominated. Consequently, two major possibilities exist for utilization of the resource for feedwater heating. Heat may be extracted from the liquid directly without a change in phase, or the liquid may be converted to steam by a series of flash devices. In the former, sensible heat transfer takes place in tube and shell liquid to liquid heat exchangers. In the latter, latent heat of vaporization is recovered in what may be termed, "high heat level condensers," or steam to liquid heat exchangers.

\subsubsection{SELECTION CRITERIA}

Normal1y, the thermodynamic cycles associated with the utilization of low-grade energy sources involve large entropy production. The design criteria for the hot and cold brine system was to utilize the geothermal resource in the most efficient manner. Consequently, the 
alternative means for feedwater heating cited above were examined on the basis of available work and the amount of work derived in each case. The difference between the available work and the actual work is related to the entropy production in the cycle. By restricting the feedwater heating cycle to sensible heat transfer, the entropy production in this process can be reduced.

In addition to thermodynamic considerations, other factors which determine the selection criteria for the most economic and desirable alternative are capital costs, operating and maintenance expenses, and reliability. Both the liquid to liquid and steam to liquid feedwater heating designs were examined in light of these other factors as well as their relative thermodynamic characteristics.

\section{5 .2 THERMODYNAMIC COMPARISON}

For purposes of discussion the water to water sensible heat transfer design illustrated in Drawings ME-16 and ME-17 in Section 10 is described as Alternate $A$. The latent heat transfer design illustrated in Drawings ME-9 and ME-10 in Section 10 is described as Alternate B. Maximum available work referenced to condenser circulating water inlet conditions, maximum available work referenced to the geothermal fluid conditions leaving the system, and the efficiency of each alternative were calculated. The entropy production of the flash system (Alternate $B$ ) was significantly higher than that of Alternate A. Relative to available work, the efficiency of Alternate $A$ is approximately 80 percent whereas that of Alternate $B$ is approximately 40 percent. Consequently, the required mass flow of geothermal fluid for Alternate $B$ for an equivalent transfer of heat as in Alternate $A$ is significantly greater than that of Alternate $A$, according to the relationship

$$
\dot{\mathrm{M}}_{\mathrm{A}} \mathrm{N}_{\mathrm{A}} \propto \dot{\mathrm{M}}_{\mathrm{B}} \mathrm{N}_{\mathrm{B}}
$$


where

$$
\begin{aligned}
& \dot{\mathrm{M}}_{\mathrm{A}}=\text { geothermal mass flowrate of Alternate } A \\
& \dot{\mathrm{M}}_{B}=\text { geothermal mass flowrate of Alternate } B \\
& \mathrm{~N}_{A}=\text { efficiency of Alternate } A \\
& N_{B}=\text { efficiency of Alternate } B
\end{aligned}
$$

The factors responsible for the poor efficiency of Alternate $B$ are summarized as follows:

(1) Greater production of entropy resulting in an increased percentage of lost work.

(2) Flash Tank 1 (Refer to Mechanical Flow Diagram ME-9) reduces the geothermal fluid temperature to $426 \mathrm{~F}$, thereby creating a pinch temperature between the hot fluid (geothermal fluid) and the cold fluid (feedwater) of around $67 \mathrm{~F}$.

(3) The temperature of the geothermal brine leaving Feedwater Heater 1 of Alternate $B$ is $212 F$, whereas for Alternate $A$ it is $171 \mathrm{~F}$. While it is true that in Alternate $B$ subcooling sections may be added to Feedwater Heater 1 , the temperature of the geothermal fluid would still remain significantly higher in Alternate $B$ than in Alternate A.

\subsubsection{ECONOMIC CONSIDERATIONS}

In view of the above, selection of Alternate A from a thermodynamic standpoint appears to be highly desirable. However, a comparison of conceptual cost estimates of equipment for both alternates show a substantially higher cost for Alternate A, taking into account cost of geothermal wells, piping, feedwater heaters, and flashtanks. Furthermore, the cost associated with Alternate $A$ is directly proportional to the concentration of impurities in the geothermal fluid. However, this increased 
cost in the overall plant 1 ife and operation does not become a significant factor, and the costs per kilowatt hour for generated power are not significant .

The Roosevelt Hot Springs resource is considered to contain moderately saline fluid. (Refer to Table 2-1.) Moderately saline geothermal fluids would favor Alternate A whereas highly saline geothermal fluids favor Alternate B. Alternate A was selected for this system design verification study based on overall economics and efficient utilization of the geothermal resource. Selection of the proper arrangement for another location should be. made based on site specific criteria.

\subsection{POTENTIAL PROBLEM AREAS}

Although the geothermal resource at Roosevelt Hot Springs was selected for this study, it is recognized that other geothermal sites can be considered, each posing a variety of potential problems.

Application of the hybrid concept imposes unique conditions relative to environmental impact, land use, noise, subsidence and seismic effects, gaseous effluents, liquid effluents, and thermal discharges. Additionally, application of geothermal energy to a conventional power plant poses inherent problem areas relative to the equipment handling the geothermal brine as well as heat exchangers with which the geothermal energy transfer is accomplished.

\subsubsection{HANDLING AND PROCESSING THE GEOTHERMAL FLUID}

Consideration of the geothermal fluid composition indicates that corrosion, scale deposition, fouling, stress corrosion, solids precipitation, and cationic reaction would be present. Dissolved solids as we11 as noncondensible gases have detrimental effects on equipment and performance. Consequently, less efficient utilization of the geothermal energy may be unavoidable and additional costs may be incurred in the prevention of adverse environmental impact. 
Generally, hot geothermal fluid is corrosive in nature. With the exception of silica and its polymers, all of the constituents present in the fluid are simple ionic salts resulting in a solution of electrolytes. Corrosion of equipment processing geothermal fluids is generally associated with the hot electrolyte water solution, the presence of hydrogen sulfide gases, and contamination of the fluid with oxygen.

Normally, undesirable noncondensible gases are present. These are hydrogen sulfide $\left(\mathrm{H}_{2} \mathrm{~S}\right)$, carbon dioxide $\left(\mathrm{CO}_{2}\right)$, ammonia $\left(\mathrm{NH}_{3}\right)$, methane $\left(\mathrm{CH}_{4}\right)$, hydrogen $\left(\mathrm{H}_{2}\right)$, and nitrogen $\left(\mathrm{N}_{2}\right)$. Additionally, scaling of well casings, piping, and heat exchange equipment has been experienced as a result of dissolved solids concentrations in excess of several thousand ppm, including calcium, magnesium, chlorides, etc. Other substances present in solution include silica which poses problems in single or multistage flash systems where geothermal steam is used to drive steam turbine generator sets. 
SECTION 3

PLANT DESCRIPTION

\subsection{GENERAL DESCRIPTION}

This section describes the major systems and equipment for a $715 \mathrm{MW}$ hybrid geothermal/coal fired power plant located at Roosevelt Hot Springs, Beaver County, Utah. The plant description addresses only the plant boundary limits plant. The impact of the hybrid concept on access requirements, land use, coal supply, water supply, structures, buildings, and other such facilities and systems is not described herein. The base case conceptual site plan and plot plan for the hybrid plant is shown on Drawings GA-1 and GA-2 In Section 10 .

The preliminary design for the Intermountain Power Project plant, the reference plant, was modified as required to reflect the changes necessary in order to use geothermal fluids for feedwater heating in the hybrid concept. No attempt was made to optimize the equipment or systems for the hybrid concept, or to analyze the merits or validity of the IPP preliminary design. The estimated life of the hybrid plant was assumed to be 30 years.

The IPP general arrangement drawings for the turbine generator structure, as modified to accommodate the changes in equipment in the hybrid concept, are shown on Drawings GA-3 through GA-6 in Section 10. Drawing GA-7 shows the general arrangement for the $\mathrm{H}_{2} \mathrm{~S}$ removal system.

Since the base case of this study is for the use of geothermal fluids for feedwater heating in order to verify the results and conclusion of the City of Burbank Report, this plant description addresses only the effect of geothermal feedwater heating on the systems. The effect of other uses of geothermal fluids on plant systems is described separately in Sections 4 through 7 . 


\subsection{MAIN BOILER}

Steam will be produced by a conventional drum type, balanced draft, pulverized coal fired boiler. The boiler for the hybrid plant at rated capacity will generate 4,543,000 pounds per hour of main steam at a pressure. of 2487 psia and a temperature of $1000 \mathrm{~F}$ with reheat steam at $1000 \mathrm{~F}$ when burning approximately 650,900 pounds per hour of pulverized coal. The boiler unit includes much of the equipment for handling water, steam, fuel, combustion air, and flue gases. The ratings and expected performance for the main boiler is listed in the Outline Specifications, Paragraph 3.16.4.

\subsubsection{COAL FEED}

Bituminous coal, less than 1-1/2 inches in size, will be fed from the silos to the coal pulverizer for pulverizing, metering, drying, and mixing with preheated primary combustion air. The pulverized coal will be carried by the primary air to the coal burner ports in the boiler furnace for combustion.

\subsubsection{WATER-STEAM FLOW}

High pressure feed water at about 2760 psig and $460 \mathrm{~F}$ will be provided to the boiler unit at the economizer where the temperature of the water will be raised to approximately 620F. The water will flow to the steam drum where it mixes with a water vapor mixture from the waterwalls. The steam will be separated from the water in the steam drum and will flow to the superheater sections of the boiler where its temperature will be increased to and controlled at $1000 \mathrm{~F}$ for the main turbine high pressure section. The water in the steam drum will be recirculated to the waterwalls for additional heat absorption and vaporization.

Most of the steam supplied to the high pressure turbine will be returned to the boiler at reduced pressure and temperature for reheating to $1000 \mathrm{~F}$ for use in the intermediate pressure section of the main turbine. 


\subsubsection{COMBUSTION AIR FLOW}

The combustion air consists of primary air and secondary air. The primary air makes up 20 to 30 percent of the total combustion air, and will be used both for preparing the coal and for transporting the coal to the furnace for combustion. The secondary air provides the additional air necessary to complete combustion of the pulverized coal.

Primary air will be atmospheric air supplied by primary air fans and heated by air heaters to the proper temperature required by the pulverizers and burners. Secondary air, representing about 70 to 80 percent of the air required for proper combustion in the boiler will be atmospheric air supplied by forced draft fans. The air will flow through steam air heaters for preheating and through air preheaters for further heating to the proper temperature for combustion in the boiler.

\subsubsection{FLUE GAS FLOW}

The pulverized coal will mix with hot secondary air and burn in the furnace. The products of combustion (flue gases) will radiate heat to the waterwalls and flow to the backpasses of the boiler, superheater, reheater, and economizer sections, where additional heat will be conducted to the steam and to the incoming water. The flue gases will then leave the boiler and pass through the electrostatic precipitators for particulate removal and then to the air preheater where additional heat will be transferred from the flue gases to the incoming combustion air. The flue gases will then flow through the remaining portion of the draft system for additional cleaning and discharge to the atmosphere.

\subsubsection{COAL SUPPLY SYSTEM}

The coal supply system will include coal feeders, coal pulverizers, valves and piping, coal stoppage safeguards, fire protection equipment, and automatic controls between the coal silo outlet and the coal burner supply piping. 
The coal feeders will feed and meter the coal flow to the pulverizers. Pulverizers will pulverize the coal to the desired fineness of at least 70 percent through a 200 mesh U.S. standard sieve. The pulverizers will also use primary combustion air to meter, classify, dry, and preheat the pulverized coal in preparation for combustion in the furnace. The pulverizers will be capable of providing 370 tons per hour of pulverized coal to the boiler.

\subsubsection{PRIMARY AIR FANS}

The air for drying the pulverized coal, for transporting the coal to the burners, and for partial combustion of the coal will be supplied by two primary centrifugal air fans with backwardly curved blades per boiler unit. The requirements for the fans are given in Paragraph 3.16.10.

\subsubsection{AIR PREHEATERS}

The air preheater is a heat storage device which alternately absorbs and releases the heat as the flue gas and combustion air alternately pass around the heater elements. Combustion air will be heated to the proper temperature for combustion in the boiler by regenerative air preheaters utilizing heat from the flue gases. Secondary combustion air temperature will be increased above $550 F$ and flue gas temperature will be reduced to approximately $260 \mathrm{~F}$.

The air preheater will have automatically operated cleaning devices using air as the cleaning medium as well as having water washing capability. Air heater plugging and corrosion will also be minimized by operation of the air preheaters with average cold end temperature above $155 \mathrm{~F}$. Average cold end temperatures will be maintained above $155 \mathrm{~F}$ by steam air heaters to prewarm the incoming combustion air for air preheater protection. 


\subsubsection{WARM-UP GUNS AND IGNITORS}

The warm-up guns in the boiler will be used during start-ups providing heat input until primary and secondary air temperatures have increased sufficiently to permit operation with pulverized coal. The ignitors will be used for igniting the pulverized coal in the main burners and the oil in the warm-up guns.

\subsubsection{STEAM TEMPERATURE CONTROL}

Main steam and reheat steam temperatures will be automatically controlled at $1000 \mathrm{~F}$. The design steam temperatures will be maintained through the load range from 60 percent to full load operation. Steam attemperation will be used to control main steam temperature during unit operation and reheat steam temperature during operating transients and abnormal operating conditions.

\subsubsection{SOOT BLOWER SYSTEM}

Soot blowers will be provided for cleaning the heat transfer surfaces of the boiler furnace, convection passes and the air preheaters. Compressed air will normally be used as the soot blowing medium, and auxiliary steam will be used as a backup soot blowing medium.

The boiler will have approximately 200 soot blowers, requiring differing air flow rates and operating times to perform the cleaning operation. The cleaning operation will be automatically performed and may be controlled from the main control room. Compressed air will be supplied by a compressor rated at approximately 4500 horsepower, have five stages, and be capable of providing approximately $14,000 \mathrm{scfm}$.

\subsection{DRAFT SYSTEM}

The draft system, shown on Drawings ME-3 and GA-6 in Section 10, will be a balanced draft system consisting of two primary air fans, two forced 
draft fans, two steam air heaters, two air preheaters, electrostatic precipitators, four induced draft fans, flue gas scrubbers with flue gas reheaters, a stack, and associated ducting, dampers, and expansion joints.

Atmospheric air will be conducted by the primary air ducting from the primary air fans through heaters to the coal pulverizers where the air will dry the coal and then transport the coal to the burners for combustion. Additional atmospheric air (secondary air) will be conducted by secondary air ducting from the forced draft fans through the steam air heaters for preheating, then to the air preheaters for further heating to the proper temperature for combustion in the boiler. Flue gases will leave the boiler through flue gas ducting and enter the electrostatic precipitators for particulate removal. The flue gases will then preheat the incoming air in the air preheater and flow, at reduced temperature, to the induced draft fans where it will be circulated to the scrubbers for $\mathrm{SO}_{2}$ removal and additional particulate removal. After leaving the scrubbers, the flue gases will be reheated and discharged through the stack.

\subsection{FORCED DRAFT FANS}

The air flow from the forced draft fans will provide for sufficient secondary combustion air, including the required excess air, and anticipated air heater leakage, to operate the boiler at its maximum continuous rated output of 4,543,000 pounds per hour of main steam. The two forced draft fan requirements are listed in Paragraph 3.16.10.

\subsubsection{INDUCED DRAFT FANS}

The induced draft fans, for the same boiler operating conditions as the forced draft fans, will handle flue gas at 260F. The fan requirements are listed in Paragraph 3.16 .10 . 


\subsubsection{INDUCED DRAFT FAN TURBINES}

Each pair of induced draft fans will be driven by a condensing steam turbine connected to the fan through speed reduction gears. Each steam turbine will normally provide approximately 9,000 horsepower and use approximately 75,000 pounds per hour of steam. The steam will normally be supplied from the last stage of the intermediate pressure section of the main turbine and will exhaust to a separate induced draft fan turbine condenser. Steam will also be supplied from the auxiliary steam system for unit startup and for induced draft fan operation following a boiler trip. If auxiliary steam is not available following a boiler trip, induced draft fan operation may also be maintained by use of the residual heat stored in the boiler to supply steam by way of the main steam line.

\subsubsection{STEAM AIR HEATERS}

The secondary combustion air will be heated in recuperative steam air heaters located at the discharges of the forced draft fans. The steam air heaters will raise the temperature of the combustion air flowing to the air preheaters above $155 \mathrm{~F}$ to prevent excessive cooling and condensation of corrosive vapors on the cold end of the air preheaters. The heating of the combustion air supplied to the air preheater will reduce the variations in flue gas temperatures entering the $\mathrm{SO}_{2}$ scrubber due to variations in ambient air temperatures. This control of flue gas temperature will permit reduced maximum and average water evaporation rates in the scrubber system.

The steam air heaters will be capable of maintaining secondary combustion air temperatures to the air preheater at $90 \mathrm{~F}$. Each steam air heater will use about 24,000 pounds per hour of steam but will be capable of using as much as 48,000 pounds per hour of steam to raise the temperature of the secondary combustion air 93F. The steam will normally be supplied from the last stage of the intermediate pressure turbine. The steam will be condensed in the heater, collected in a hotwell, and then returned to the cycle through the induced draft fan turbine condenser. 


\subsection{EMISSION CONTROL SYSTEM}

The emission control system, as shown on Drawings ME-15 and GA-6 in Section 10 , will be specifically designed to control nitrogen oxide (NOx), $\mathrm{SO}_{2}$, and particulate emissions for which both stack emission and ambient air quality standards have been established. The table below compares estimated emissions from the hybrid power plant with regulations in effect at the time of the IPP plant preliminary design (1976). Emission reductions of $\mathrm{SO}_{2}$ and particulate matter due to these control systems are also shown in the table.

\section{ESTIMATED PLANT EMISSIONS}

Plant Emissions

\section{Estimated Stack Emissions \\ Federal Regulations}

Abated Plant Unabated Plant Emissions
Emissions

\section{(1b/million Btu) (tons/hr)}

Average Coal*

Sulfur dioxide

0.1

1.2

1.33

13.27

Particulates

0.02

0.1

0.22

86.00

Nitrogen oxide

0.07

0.7

Minimum Grade Coal

Sulfur dioxide**

0.2

1.2

2.45

24.53

Particulates***

0.03

0.1

0.37

147.00

Nitrogen oxide

0.7

0.7

*Corresponds to 0.55 percent sulfur and 8.4 percent ash content with higher heating value (wet) of $10,100 \mathrm{Btu} / 1 \mathrm{~b}$.

**Corresponds to 1.0 percent sulfur content with higher heating value (wet) of $10,100 \mathrm{Btu} / \mathrm{lb}$.

$* * *$ Corresponds to 12.5 percent ash content with higher heating value (wet) of $8760 \mathrm{Btu} / \mathrm{lb}$. 
To ensure proper operation of the emission control systems, stack gas monitors will be installed to continuously measure and record $\mathrm{SO}_{2}$ and $\mathrm{NOx}$ emissions as well as plume opacity. These monitors will provide records of plant emissions which will be available to appropriate regulatory agencies.

\title{
3.4.1 PARTICULATE MATTER CONTROL SYSTEM
}

Hot electrostatic precipitators will be provided to remove 99.5 percent of the fly ash resulting from the combustion of coal. In combination with particulate matter removal in the $\mathrm{SO}_{2}$ scrubber, a total of 99.75 percent of the particulates will be removed.

The precipitators will be designed for coal of maximum ash content and the following flue gas conditions:

\author{
$7,912,000 \mathrm{lb} / \mathrm{hr}$ flow \\ $4,536,000$ acfm at $700 \mathrm{~F}$ \\ Design temperature of $700 \mathrm{~F}$ \\ Maximum gas velocity of 6 fps through precipitators
}

Electrostatic precipitators for each boiler will consist of four double-chamber, horizontal gas flow type, installed between the economizer of the boiler and the air preheater. Particles suspended in the flue gas are removed by electrostatically charging the particles through the corona effect of discharge electrodes. Under the strong influence of an electrical field, the charged particles become separated from the gas, and travel to collecting plates. The resulting dust layer is compacted and held in place by electrostatic forces until removed from the collecting plates by rapping. The hoppers, which collect the dust trapped from the collecting plates, will have a 12 hour storage capacity at the design flow and maximum inlet dust loading. 


\section{4 .2 SULFUR DIOXIDE CONTROL SYSTEM}

The $\mathrm{SO}_{2}$ control system, a 1 ime throwaway wet scrubbing process utilizing a horizontal scrubber, will be used to remove 90 percent of the $\mathrm{SO}_{2}$ produced in the boilers and 50 percent of those particulates not collected by the electrostatic precipitator. The additional removal of fine particulates, which have a strong influence on opacity, will ensure that the plant will meet stack opacity regulations.

The flow diagram and elevation shown on Drawings ME-15 and GA-6, respectively, in Section 10 , show the basic design of the scrubber system which will be used for $\mathrm{SO}_{2}$ control. The control system is designed to minimize raw water makeup requirements, meet the objectives of 90 percent $\mathrm{SO}_{2}$ removal, provide reliable operation, and minimize waste products.

The control of $\mathrm{SO}_{2}$ will be achieved through the use of a lime slurry spray flue gas desulfurization system. With this system, the hot flue gas passes through a series of sprays using a slurry containing lime. The slurry spray absorbs the $\mathrm{SO}_{2}$, which is then removed from the system in the form of a sludge for disposal. The scrubbed flue gas is then reheated with steam heaters and discharged up the stack. The scrubber for each unit will be a horizontal type composed of five separate modules, each with five stages. The scrubber will be designed to treat $1.6 \mathrm{million} s \mathrm{sm}$ of flue gas, which consists of the flue gas passed through the electrostatic precipitator as well as leakage into the air heaters. This will remove a minimum of 90 percent of the $\mathrm{SO}_{2}$. In addition, the scrubber will remove approximately 50 percent of the fine particulate matter not removed by the electrostatic precipitators.

\subsubsection{NITROGEN OXIDES CONTROL}

Nitrogen oxides formation occurs in the combustion zone of the boiler resulting from thermal fixation of atmosphere nitrogen and conversion of fuel-bound nitrogen. Combustion modification techniques provide effective 
means of ${ }^{N O} x$ emission control by lowering the peak flame temperature and minimizing oxygen availability for combustion.

Combustion techniques will be selected to ensure that both auxiliary boilers and main steam generators meet applicable state and Federal regulations.

\subsubsection{SUPPLEMENTARY CONTROL SYSTEM}

A supplementary control system will consist of facilities for monitoring and predicting ambient $\mathrm{SO}_{2}$ concentrations, and a 750 foot high stack will be used to enhance plume dispersion and dilution. This system will serve as a backup to the $\mathrm{SO}_{2}$ emission control system and will provide for adjustments in plant operation should very severe meteorological conditions occur.

\subsection{COAL AND LIMESTONE HANDLING SYSTEMS}

The in-plant coal and limestone handing systems will receive, unload, weigh, and sample the delivered coal and limestone; store adequate stockpiles necessary to assure a reliable supply to the plant; supply the required quantity and quality at rates demanded by the plant; and blend different grades when necessary to obtain the desired characteristics.

\subsubsection{COAL HANDLING SYSTEM}

The coal handling system shown on Drawing GA-1 in Section 10 will include train unloading facilities, coal conveyors, sampling and crushing equipment, and dust control equipment. All weigh scales, metering instruments, and controls between the unit train and the boiler coal silos will also be included. The system will be based on the following assumptions: (1) the coal will be delivered five days a week, (2) the coal will be "run-of-mine 8-in." coal (coal with oversize chunks broken up to pass through 
an 8 -in. round hole) with a wet heating value of not less than $8760 \mathrm{Btu} / 1 \mathrm{~b}$, (3) the moisture content will not be greater than 12 percent, and (4) the maximum demand of the boiler will be 326 tons/per hour.

\subsubsection{Train Unloading}

The train will be unloaded by a tandem rotary car dumper capable of unloading two cars at a time. Operation of the car dumper will be from one control panel to make the clamping and rotating sequences for both unloaders simultaneous. After the first car has been properly spotted, positioning will be automatically indexed by a single train positioner. When the tandem rotary car dumper is in operation, indexing will be two cars at a time. When only one rotary car dumper is in operation, indexing will be one car at a time. In the latter case, the rotary car dumper out of service will be disconnected from the unloading controls.

\subsubsection{Unloading, Conveying, Sampling, and Crushing}

Apron feeders will remove the coal from the unloading hoppers and will feed it to belt conveyors for delivery to the weight scales. Self-cleaning magnetic separators will be positioned at the head pulleys of the conveyors to assure an iron-free coal supply to the weigh scales. From the weigh scales, the coal will flow onto conveyors which will transport the coal to the yard surge bin. A primary sampling system will take a portion of the coal stream at the head pulley of the conveyors and the coal rejected from the sampling system will be recycled to the yard surge bin. Coal in the yard surge bin can be fed to the coal crushers by vibrating feeders or it can be diverted to the storage piles through the surge bin overflow chutes.

Coal crushers will size the coal to a 97-100 percent minus 1-1/4 inch product. From the coal crushers, the coal will flow onto belt conveyors which will supply the coal to the boiler coal silo dual cascade belt conveyor system. The transport systems and crusher equipment from the yard surge bin to the boiler coal silos will have the capacity to 
fill the boiler silo in 4 hours or less and maintain full load in the plant when one crusher or one transport system is out of service.

Coal will be diverted from the yard surge bin to storage by opening a yard surge bin overflow chute feeding the conveyors to storage. Conveyors will be used to divert coal to reserve storage and to form the emergency active pile in the event the stacker-reclaimer and the silo coal supply system are both inoperative.

The coal handing system will be able to supply newly delivered coal to the coal silo, and when necessary, a blend of different coal grades can be delivered to the coal silo. Blending will be done by spreading thin layers of the different coals on the active pile with the stacker-reclaimer in the stacking mode and by reclaiming whole vertical sections with the reclaimer bucketwheel when the stacker-reclaimer is in the reclaiming mode. Normally, reclaiming of coal from active storage will be done only when there is no coal in the track hoppers.

\subsubsection{Coal Storage System}

Coal storage will hold sufficient coal to allow the plant to operate at rated capacity for 48 days without coal delivery. Of this total capacity, 3 days storage will be in the active storage pile, 5 days will be in the small reserve pile and 40 days will be in the large reserve pile. The emergency active pile will be formed only when coal is being unloaded from a train and the stacker-reclaimer is out of service.

The boiler coal silo will be designed to store enough coal for 10 hours of full load operation. This will allow one filling cycle per shift with a minimum of 2 hours residual coal before every feeding cycle. 


\subsubsection{Coal Dust Control}

The coal dust control equipment includes dust suppression equipment, dust collection equipment, and dust prevention equipment.

The dust suppression equipment will be a chemicallytreated-water spray system which will include storage tanks, pumps, piping, spray nozzles, and controls. The central portion of the treatment system will be housed in the yard surge bin building. The purpose of the chemical treatment is to improve the wetting characteristics of the water droplets.

The coal dust collection equipment includes dust hoods, enclosures, bag filters, and bag filter blowers. Collected coal dust will be recycled for use as fuel.

The dust prevention equipment includes conveyor enclosures, telescopic chutes, earth berms, and portable surface crusting spray equipment.

\subsubsection{LIME SUPPLY AND HANDLING SYSTEM}

Unloading from truck or rail car to the lime storage bunker will be accomplished by a pneumatic system. A high calcium pebble lime (based on 90 percent availabe $\mathrm{CaO}$ ) will be used for removing $\mathrm{SO}_{2}$ from the flue gases and for raw water softening. Quantities of 1 ime which will be required at an average 75 percent load factor when the generating unit is burning average grade coal, and a maximum continuous requirement for both average and minimum grade coals are 1 isted below. Average and minimum grade coals are listed in Paragraph 3.4 .

The storage bunker will be sized to hold 2,730 tons of lime which will provide 35 days of lime supply for the plant. Lime from the plant 
storage bunker will be transported by means of a pneumatic conveyor to the water treatment storage $b i n$ and to a day tank located near the lime shakers for the $\mathrm{SO}_{2}$ control system. Each day tank, sized to hold 20 tons of lime, will supply $24 \mathrm{hrs}$ of 1 ime to the $\mathrm{SO}_{2}$ scrubber system it serves, assuming full load operation and average grade coal.

\section{LIME REQUIREMENTS}

TONS PER DAY

\begin{tabular}{ccc}
$\begin{array}{c}\text { Lime Required } \\
\text { for Removing SO }\end{array} 2$ & For Water Treatment & Total Lime \\
\hline
\end{tabular}

For average grade

coal and $75 \%$ load

factor

55

5

60

For average grade

coal and maximum

continuous rating

73

7

80

For minimum grade coal

and maximum continuous

rating

133

7

140

\subsection{ASH HANDLING SYSTEMS}

Three separate ash handling systems will convey and prepare bottom ash collected at the bottom of the boiler furnaces, economizer ash collected in economizer hoppers, fly ash collected by the electrostatic precipitators, and the $\mathrm{SO}_{2}$ removed by the flue gas scrubbers in the form of sludge for truck transfer to a solid waste disposal area. 


\subsection{BOTTOM AND ECONOMIZER ASH HANDLING SYSTEM}

The bottom and economizer ash handling system is shown on Drawing ME-12 in Section 10. It includes all the equipment, piping and controls between the economizer hoppers, bottom ash hoppers, mill pyrites storage hoppers, and the dewatering tanks. Water will be used as the cooling and transporting medium for the system.

The system will collect and transport to the dewatering tanks ash collected at the bottom of the boiler (bottom ash), ash collected in the economizer hoppers (economizer ash), and material rejected by the coal pulverizers (mi11 pyrites). The system will be a closed system with no blowdown. Makeup water to the system will provide for water lost by evaporation and moisture absorbed in disposed ash.

\subsubsection{FLY ASH AND SCRUBBER SLUDGE MIXING SYSTEM}

The fly ash and scrubber sludge mixing system is shown on Drawing ME-13 in Section 10. It includes all equipment, piping and controls between the fly ash silo outlet, the scrubber sludge holding silo, and the pug mills.

The system will mix the ash from the fly ash silo with sludge from the scrubber sludge holding silo to produce a mixture suitable for truck disposal. Water from the scrubber water storage tank will be used to wet the fly ash in the event scrubber sludge is not available in sufficient quantity.

\subsubsection{FLY ASH HANDLING SYSTEM}

The fly ash handling system is shown on Drawing ME-14 in Section 10. It includes all the equipment, piping, and controls between the electrostatic precipitator ash feeders and the fly ash silo. Air will be used as the transporting medium for the system. 
The system will collect ash from the electrostatic precipitator ash hoppers and transport the fly ash to the silo at a rate that will permit the ash hopper to be emptied periodically each 8 hour work shift.

\subsection{TURBINE GENERATOR UNIT}

Turbine throttle conditions will be 2400 psig, 1000F/1000F. The turbine generator heat cycle diagram, as shown on Drawing ME-l and the turbine generator heat balance diagram, as shown on Drawing ME-2, both in Section 10 , form the basis for the equipment selection and systems described herein.

The turbine generator will have a capability of 788 MW. Each turbine generator unit will be a single reheat, tandem-compound, $3600 \mathrm{rpm}$, condensing, nonextraction type. The turbine generator capacity was reduced as a result of the flow limitations in the low pressure turbine exhaust stages as described in Section 2.

The turbine for the hybrid plant is a TC4F33.5 machine consisting of one high pressure section receiving steam from the boiler superheater, one intermediate pressure double flow section receiving steam from the boiler reheater, and two low pressure double flow sections receiving steam from the intermediate pressure section and exhausting into the main condenser.

The turbine generator will be housed in the Turbine Generator Building as shown on Drawings GA-3 through GA-6 in Section 10. An enclosure will be furnished for the high pressure and intermediate pressure turbine sections to reduce noise.

\subsubsection{NET PLANT HEAT RATE}

The net heat rate of the plant at any time will be dependent upon the amount of auxiliary power being used within the plant at the time, turbine backpressure, percent plant loading, and other factors. The net heat 
rate for the plant, at full load, is estimated to be $9124 \mathrm{Btu} / \mathrm{kwh}$. This net heat rate does not include the energy required for the operation of the surface and underground water pumps for boiler and cooling tower makeup and plant service water requirements. The low available energy of the geothermal fluid makes this heat rate appear high, whereas the true efficiency of the hybrid plant would be about the same as a conventional plant.

\subsubsection{TURBINE DESIGN CONDITIONS}

The turbine design conditions are listed in the Outline Specifications Paragraph 3.16.

\subsubsection{TURBINE SYSTEMS}

The turbine generator will be provided with all the necessary systems required to provide for a functioning unit. These include:

- Lubrication system

- Lubrication oil purification system

- Turbine gland seal system

- Turbine control system

\subsubsection{GENERATOR}

Each generator will use static excitation and will be capable of a rated output of 845 megavolt-amperes (Mva) at a 0.9 lagging power factor and at an expected terminal voltage of 24 to 26 kilovolts (kV). Power produced by each generator will be carried on forced cooled, isolated phase bus to three, single phase, air/oil cooled generation transformers, where the voltage will be increased to $345 \mathrm{kV}$, and from there, by overhead conductor to 
the plant switchyard. One spare, single phase generation transformer will be provided for the plant. The short circuit ratio will not be less than 0.58 .

\subsubsection{GENERATOR SYSTEMS}

The generator will be provided with all the necessary systems required to provide for a reliable functioning unit. These systems include:

- Generator shaft sealing system

- Generator cooling system

- Excitation system

\subsection{HOT AND COLD BRINE SYSTEM}

The function of the hot and cold brine system is to supply geothermal brine to the feedwater and condensate heaters. The system shown on Drawings ME-16 and ME-17 in Section 10 includes equipment, piping, and controls required. The total geothermal brine flow at 100 percent plant operation will be approximately 4,600,000 pounds per hour.

\subsubsection{MAJOR EQUIPMENT}

The major equipment in the hot and cold brine system includes:

- Three low pressure heaters

- Three intermediate pressure heaters

All the heaters are counterflow straight shell and tube heat exchangers . 


\subsubsection{SYSTEM OPERATION}

During normal operation, geothermal brine will heat feedwater and condensate sequentially in Heaters $7,6,5,3,2$, and 1 , flowing in series through these heaters.

The feedwater and condensate flows on the shell side, and the geothermal brine flows on the tube side of the heaters. This flow arrangement provides easier cleaning and maintenance, and thus gives greater reliability to the system. Each heater will have a bypass connection across the geothermal brine inlet and outlet so as to provide for maintenance and cleaning of a heater when a high differential pressure across the heater is reached.

The system will be designed so that the pressure of geothermal brine in the feedwater heaters is maintained lower than the pressure of the feedwater and condensate under all plant operating conditions. Consequently, leaks in the she 11 and tube geothermal heaters will not result in contamination of the feedwater and a subsequent unit trip. Instead, in the event of a leak, the flow will be from the feedwater (shell) side to the geothermal brine (tube) side.

\subsubsection{DRAINS AND VENTS}

Al1 heater and geothermal brine piping vents will be routed to the $\mathrm{H}_{2} \mathrm{~S}$ removal system. Also, all heater and geothermal brine piping drains will be sent to a collecting tank. The noncondensibles present in the collecting tank will be routed to the $\mathrm{H}_{2} \mathrm{~S}$ removal system, whereas the geothermal brine present in this tank will be sent to the battery limit for reinjection into the wells. This system is shown on Drawing ME-18 in Section 10. 


\subsubsection{PIPING MATERIALS}

All piping for the hot and cold brine system will be made of stainless steel or other material compatible with the composition of the geothermal brine analysis.

\subsection{FEEDWATER AND CONDENSATE SYSTEM}

The function of the feedwater and condensate system is to supply the steam generator with heated feedwater which has been deaerated and chemically treated to maintain a specific water quality. The major equipment in this system is the main steam condenser, eight feedwater heaters, condensate pumps, boiler feed booster pumps, and boiler feed pumps.

\subsubsection{FEEDWATER SYSTEM}

The feedwater system, shown on Drawing ME-5 in Section 10, is the high pressure portion of the feedwater and condensate system, and it will include all the equipment, piping, and controls between the deaerating heater and the boiler.

The three half capacity boiler feed booster pumps will draw condensate from the elevated deaerating storage tank and will discharge it through a single stream to full capacity Intermediate Pressure Geothermal Feedwater Heaters 5, 6, and 7 to the boiler feed pumps. The feedwater from the two boiler feed pumps will discharge through a full capacity High Pressure Heater 8 before entering the steam generator economizer inlet header. Each of the intermediate and high pressure heaters will be provided with an individual full flow motor-operated bypass. Double valves will be provided with a bleedoff between them on each side of the heaters so that the heaters can be isolated and maintained safely while the unit is in operation. 


\subsubsection{Boiler Feed Pumps}

The two boiler feed pumps provided will be four-stage, horizontal, with the first stage double suction and the third and fourth stages flowing in the opposite direction from the second stage. The pumps will take suction from the feedwater outlet of Heater 7.

The normal operating point for each pump (rated unit load) will be 5330 gallons per minute at 6760 feet and $450 \mathrm{~F}$ feedwater with a speed of approximately $5200 \mathrm{rpm}$. The efficiency will be 86.5 percent. The design point corresponding to valves-wide-open and 5 percent overpressure main turbine throttle condition will be 5900 gallons per minute discharge at 7280 feet and $420 \mathrm{~F}$ feedwater with a speed of $5550 \mathrm{rpm}$. Each pump will be driven by a 10,850 horsepower, $5550 \mathrm{rpm}$ condensing steam turbine.

\subsubsection{Boiler Feed Booster Pumps}

The boiler feed booster pumps will take suction from the deaerating storage tank. These half capacity boiler feed booster pumps will have a capacity of approximately 5030 gallons per minute at 1145 feet total head.

\subsubsection{Feedwater Heaters 5,6 , and 7}

There will be three intermediate pressure geothermal feedwater heaters between the boiler feed booster pump and boiler feed pumps. Heaters 5, 6 and 7 will be horizontal hemispherical head type with straight tube construction of stainless steel tubes and carbon steel shell. Heaters 5 , 6 , and 7 will have heating surfaces of $48,300,51,600$, and 56,200 square feet, respectively. 


\subsubsection{Feedwater Heater 8}

There will be one full-flow high pressure feedwater heater between the boiler feed pump and steam generator. Heater 8 will be a horizontal hemispherical head type with U-tube construction of 70-30 coppernickel tubes. It will have a heating surface of 33,300 square feet, and will have integral desuperheating, subcooling, and condensing zones.

\subsubsection{CONDENSATE SYSTEM}

The condensate system, shown on Drawing ME-6 in Section 10, is the low pressure portion of the feedwater and condensate system, and will include all the equipment, piping, and controls between the main steam condenser and the deaerating heater.

During normal operation, two of three half capacity condensate pumps will take suction from the condenser hotwe 11 and will discharge condensate through the gland steam condenser and air ejector condensers connected in parallel. Then the condensate will flow to a single heater train, equipped with individual ful1-flow bypass systems to provide for maintenance. A total of three geothermal water-to-water heaters and one extraction steam deaerating type heaters heat condensate to a temperature of 460F. Motor operated valves as shown on Drawing ME-6 will be provided to enable safe isolation of any heater during maintenance.

The arrangement of the condensate system components will provide for recirculation at low flows to maintain the required minimum flow through the condensate pumps, air ejector condensers, and gland steam condenser. The system will include an additional condenser which will service the induced draft fan turbine, steam air heater, and flue gas reheater.

The system wil1 also provide for condenser hotwell level control, condensate makeup or drawoff and storage, seal injection water for 
sealing pump glands, condensate for the turbine exhaust hood sprays, bearing cooling water system makeup, and condensate for the gland seal steam emergency desuperheater.

\subsubsection{Main Steam Condenser}

The main steam condenser will be a single shell, dual pressure, single pass, deaerating type of surface condenser with divided waterboxes and hotwell. It will condense and deaerate the exhaust steam from the main turbine and the boiler feed pump turbines prior to returning the condensate to the steam generator through the condensate and feedwater system. In addition, the condenser will serve as a heat sink for several other flows, such as air ejector condenser drains, gland steam condenser drain, main steam piping drains, induced draft fan condenser drains, and other miscellaneous flows, drains, and vents.

The main steam condenser will have an effective surface area of 445,000 square feet using $28,100,7 / 8$ inch OD, 70 foot long copper-nickel tubes. The tubes will be designed for a water velocity of 6 feet per second and the hotwell storage will be sized to provide a minimum of 5 minutes of total storage at maximum condensate flow.

\subsubsection{Condensate Pumps}

Three half capacity, vertical, condensate pumps will be provided to draw condensate from the condenser hotwell and pump it through Feedwater Heaters 1, 2, and 3 to Deaerating Heater 4. Each pump is rated at 4450 gallons per minute at 580 feet total head. The speed of the four-stage, motor-driven pump will be $1750 \mathrm{rpm}$.

\subsubsection{Feedwater Heaters 1, 2, and 3}

There will be three low pressure geothermal feedwater heaters between the condensate pumps and the deaerator heater. Each heater 

noncondensible gases.

The heater will deaerate incoming condensate to 0.005 cc/l or less of free oxygen, zero carbon dioxide, and will heat the condensate to the saturation temperature corresponding to the shell pressure.

\subsubsection{Air Remova1 System}

The main steam condenser will be provided with an evacuation system to remove noncondensible gases and air during plant startup, cool down, and normal operation. Noncondensible gases and in-leaking air will be removed continuously to maintain minimum absolute backpressure in the condenser and to minimize concentration of corrosive gases in the condensate system. 


\subsubsection{Air Ejector Condensers}

Condensate will be the coolant used in the air ejector intercondenser and aftercondenser to condense the air-vapor mixture from the main condenser prior to discharge of the air to the atmosphere. Condensate will flow in parallel through the intercondenser and aftercondenser. The drain from these condensers will be returned to the main condenser hotwe 11 .

\subsubsection{Gland Steam Condenser}

Condensate will also be used to condense the steam exhausted from the turbine steam seal system in the gland steam condenser. The gland steam condenser will be connected in parallel with the air ejector condensers, and will be provided with a bypass line to permit the isolation of either or both the gland steam condenser and air ejector condensers. The condensed steam will be returned to the main condenser hotwell.

\subsubsection{Induced Draft Fan Turbine Condenser}

One condenser will serve both induced draft fan turbines, and will also serve the steam air heater and flue gas reheater prior to returning the condensate to the hotwell of the main steam condenser. It will have an effective surface area of approximately 25,200 square feet using $2940,7 / 8-$ inch OD, 90-10 copper-nickel tubes.

\subsection{MAIN AND REHEAT STEAM SYSTEM}

Superheated steam will be generated in the boiler and piped to the high pressure section of the turbine. The steam exhausting from the high pressure section, except for bleed steam to Feedwater Heater 8 and the deaerator will return to the boiler where it will be reheated and piped to the intermediate pressure section. The steam exhausting from the intermediate 
pressure section will go to the two low pressure sections and will exhaust to the main condensers. The boiler feed pump turbine will be supplied from the main steam supply for low loads or from intermediate pressure turbine exhaust steam for higher loads.

\subsubsection{MAIN STEAM}

Steam at 2487 psia and $1000 \mathrm{~F}$ will flow from the boiler superheater outlet header through the main steam lines to the high pressure turbine control valves where it will be 2400 psig and 1000F. Desuperheaters will be provided between the initial and final superheater sections of the boiler for main steam temperature control. Water for the desuperheaters will be furnished from boiler feed pump discharge.

\subsubsection{COLD REHEAT}

Exhaust steam from the high pressure section will return to the boiler for reheating through the cold reheat 1 ines. Bleed steam for Feedwater Heater 8 will be taken from the cold reheat. Spray desuperheaters are provided in each of the cold reheat 1 ines for reheat steam temperature control.

\subsubsection{HOT REHEAT}

Reheated steam at $1000 \mathrm{~F}$ will be piped from the boiler reheater outlet header through the hot reheat 1 ines to the intermediate pressure turbine intercept valves where its temperature will be $1000 \mathrm{~F}$.

\subsubsection{TURBINE STEAM SUPPLY}

For low load operation, steam will be supplied from the main steam line to the boiler feed pump turbine high pressure inlet stop valve. Under normal operation, steam will be supplied to the low pressure inlet stop 
valve from intermediate pressure turbine exhaust extraction steam, with a backup from the auxiliary steam. The boiler feed pump turbines will exhaust to the low pressure main condenser.

\subsection{BLEED STEAM SYSTEM}

In order to improve the cycle efficiency, bleed steam will be extracted from various sections of the turbine and supplied to the following equipment: the shell side of Feedwater Heater 8 , the tube side of the evaporator, the steam air heaters, the flue gas reheaters, and the turbines (for driving the boiler feed pumps and induced draft fans) as shown on Drawing ME-7 in Section 10. Listed below are the sources of bleed steam.

\section{BLEED STEAM SOURCES}

Steam Source

\begin{abstract}
Equipment
Evaporator
\end{abstract}

Boiler feed pump turbines (2)

Induced draft fan turbines (2)

Steam Air Heaters (4)

Flue Gas Reheaters (5)
Cold reheat

Intermediate pressure section exhaust

Intermediate pressure section exhaust

Intermediate pressure section exhaust

Intermediate pressure section exhaust

Intermediate pressure section exhaust 


\subsubsection{DEAERATING HEATER 4}

Bleed steam supply for the Deaerating Feedwater Heater 4 will normally be cold reheat steam. An alternate steam supply will be the auxiliary steam system. The evaporator will discharge into the deareating heater.

\subsubsection{FEEDWATER HEATER 8}

Feedwater Heater 8 will be supplied bleed steam from the cold reheat steam line. The bleed steam block valve will be closed when the heater is being bypassed to prevent the tube side thermal relief valve from opening.

\subsubsection{EVAPORATOR}

Bleed steam for the evaporator, which suplies distilled makeup water for use in the feedwater cycle, will be supplied from the intermediate pressure turbine exhaust steam.

The condensate drains to Heater $8 \mathrm{flash}$ tank. The incoming treated water will be heated in the evaporated blowdown heat exchanger by the evaporator blowdown and then further heated in the evaporator deaerator. The generated steam will be exhausted to Deaerating Heater 4.

\subsubsection{BOILER FEED PUMP TURBINES}

Boiler feed pump turbines will be supplied bleed steam from the intermediate pressure turbine exhaust line with a backup from the auxiliary steam system. Exhaust will be to the low pressure section of the main condenser. Steam will be supplied from the main steam line to the high pressure inlet stop valve for low load operation. 


\subsection{1 .5 INDUCED DRAFT FAN TURBINES}

Bleed steam for induced draft fan turbines will be supplied from the intermediate pressure turbine exhaust line. The line to each turbine will have a supply of auxiliary steam to a separate turbine inlet for operation during start-up. The turbines will exhaust to the induced draft fan turbine condenser.

\subsubsection{STEAM AIR HEATERS}

The steam air heaters will also be supplied bleed steam from the intermediate pressure turbine exhaust line. These air heaters keep the combustion air from going below a minimum temperature to prevent condensation and corrosion in the main air heater. The condensate will drain to the induced draft fan turbine condenser in addition to the drains from low points in the line. Vents will go to the blow-off tank.

\subsubsection{FLUE GAS REHEATERS}

Bleed steam for the steam stack gas reheaters will also be supplied from the intermediate pressure turbine exhaust 1 ine. These gas reheaters keep the flue gas from going below a minimum temperature of $170 \mathrm{~F}$ to prevent condensation and corrosion in the ducts and stack. The condensate will go to the induced draft fan turbine condenser along with the drains from the low points in the lines. The vents will go to the blow-off tank.

\subsubsection{BLEED STEAM DRAINS}

At low points in all external bleed lines drains will be provided for use during start-up and shutdowns. The drains from the heater side of the shutoff valves will discharge to waste, and drains from the turbine side of the shutoff valves will discharge to the main condenser. During normal operation of the unit, the bleed 1 ines will be hot and the drain valves will be closed. 
Steam traps will be provided at the low points of the bleed steam lines to the boiler feed pumps which will not be in service at all loads. Steam traps will also be provided in the low points of the lines to the induced draft fan turbines, steam air heaters, and steam stack gas reheaters.

\subsection{HEATER VENTS AND DRAINS SYSTEM}

The heater vents and drains system, shown on Drawing ME-18 in Section 10, will provide for the Feedwater Heater 8 condensed extraction steam drains, venting the Feedwater Heaters 8 and gland steam condenser, and for draining the gland steam condenser.

\subsubsection{HIGH PRESSURE HEATER SYSTEM}

The extraction steam entering Feedwater Heater 8 will be condensed on the tubes and collected in the bottom of the horizontal shell. The drains will pass through integral drain coolers where it will be cooled to within $10 \mathrm{~F}$ of the incoming boiler feedwater temperature. Heater 8 will drain to a flash tank normally having the same pressure as the deaerator. The Heater 8 drain line will be provided with a bypass line connected directly to the high pressure zone of the main condenser for use during start-up, the period of high contamination.

The water level in the high pressure feedwater heater will be controlled by means of a level controller and control valve system that throttles the drain to the flash tank. Heater 8 will have a second level controller which transmits a signal to indicate the water level in the heater. This signal will actuate four pressure switches to operate a low level alarm, a high level alarm, a high level bypass switch, and a high level trip which will close the turbine nonreturn valves in the event of a flooded heater. 
High Pressure Feedwater Heater 8 will be vented to the Heater 8 flash tank. The shell vent connection will be furnished with an orifice designed to provide proper venting. Stop valves will be provided in the vent lines to isolate the heater. Vent lines will be used to remove air or noncondensible gases which accumulate in the feedwater heaters. a manual drain cooler bypass valve will be installed on Heater 8 to facilitate level control during start-up and to enable complete draining of the heater shell for maintenance.

\subsection{2 .2 HEATER 8 FLASH TANK AND DRAIN PUMPS}

Drains will impinge upon a stainless steel plate. Steam will be separated from the water by means of baffles, and will flow to the deaerator through the balance line. The level in the Heater 8 flash tank will be regulated by means of two controllers. One controller will be used for transmitting high level and low level alarms to the control rooms and automatic start of the standby drain pumps. The other controller will be used to regulate the control valve at the discharge of the two Heater 8 drain pumps .

Flash tank drain pumps will be operated by selector switches in the control room. for normal operation, one of the drain pumps will run on standby and will be started by the level control system of the flash tank. The starting of the standby pump will indicate malfunctioning of the first pump or excessive drain flow, and the standby pump will continue to operate until stopped manually with the selector. Each heater drain pump will have a recirculation line for a minimum flow of 100 gallons per minute for cooling purposes. The drain pumps will discharge into the deaerator for removal of noncondensable gases. 


\subsection{CIRCULATING WATER SYSTEM}

The circulating water system, shown on Drawing ME-8 in Section 10, is required to transfer the heat rejected by the main condensers, the induced draft fan turbine condensers, the cooling water heat exchangers, the brine vent condenser and the water-to-air cooler to the atmosphere. Two separate, parallel systems will be provided for maximum realiability and economy. Each system will include one cooling tower, one circulating water pump, a piping system, one side of the main condenser, one side of the induced draft fan turbine condenser, and one cooling water heat exchanger.

\subsubsection{COOLING TOWERS}

Each mechanically induced draft wet cooling tower will be designed for $155,000 \mathrm{gpm}$ circulating water flow, $114 \mathrm{~F}$ inlet, and $84 \mathrm{~F}$ outlet water temperatues. The cooling towers will reject heat at the rate of 4.56 billion $\mathrm{Btu} / \mathrm{hr}$ under design conditions.

\subsubsection{CIRCULATING WATER PUMPS}

Each circulating water pump will deliver 155,000 gallons per minute at 64.4 feet TDH. The direct driving induction motor will be $3500 \mathrm{hp}$. The pumps will be operable at 20 percent of design flow to facilitate initial fill and start-up of the system.

\subsubsection{COOLING WATER HEAT EXCHANGER}

Two single-pass, full size cooling water heat exchangers will be provided for each unit, each containing $2600,3 / 4$ inch $0 D, 90-10$ copper-nickel tubes. 
Comprehensive data on the concentration of noncondensible gases in the Roosevelt Hot Springs geothermal resource is not available. However, analyses of other geothermal resources in the United States indicate large variations in the concentration of noncondensible gases, specifically, $\mathrm{H}_{2} \mathrm{~S} . \mathrm{H}_{2} \mathrm{~S}$ concentration in these resources varies between no detectable $\mathrm{H}_{2} \mathrm{~S}$ and approximately two to five tenths of one percent, by weight. The Apri1 1977 . Geothermal Resource Investigations Status Report for the East Mesa Test Site, Imperial Valley, California shows a noncondensible analysis of two tenths of one percent noncondensibles, mostly $\mathrm{CO}_{2}, \mathrm{H}_{2} \mathrm{~S}$, and $\mathrm{NH}_{3}$; about ninety percent of which is $\mathrm{CO}_{2}$. Republic Well No. 16-29 which is two or three miles north of the USBR East Mesa field shows a noncondensible concentration of 0.65 percent by weight, of which 91 percent is carbon dioxide, 4 percent nitrogen and 4 percent methane. No hydrogen sulfide was detected.

\subsection{1 $\mathrm{H}_{2} \mathrm{~S}$ CRITERIA}

For the purpose of this report, $\mathrm{H}_{2} \mathrm{~S}$ was assumed to be present in the geothermal fluid. Total sulfur removal capacity of the $\mathrm{H}_{2} \mathrm{~S}$ Removal System was set at approximately 3.09 tons per day based on the following assumed noncondensible flow rates, and on a total geothermal fluid flow of $5,500,000$ pounds per hour.

Gas or Vapor

$\mathrm{H}_{2} \mathrm{~S}$

$\mathrm{CO}_{2}$

Other Noncondensibles

$\mathrm{H}_{2} \mathrm{O}$

Temperature, F

Pressure, psia

Atmospheric Pressure, psia
Moles per Hour

39.40

6.74

95

13.8

12.2 
The $\mathrm{H}_{2} \mathrm{~S}$ removal system requires an overall land area of 8740 square feet, or a 115 foot by 76 foot plan area. This is shown on general arrangement Drawing GA-7 in Section 10.

\subsubsection{PROCESS DESCRIPTION}

The major components of the $\mathrm{H}_{2} \mathrm{~S}$ removal system, shown on Drawings ME-11 and GA-7 in Section 10, provide for removal of sulfur from the gas stream, sulfur liquifaction, sulfur storage, and sulfur loading.

The noncondensible and water vapor mixture enters the knockout drum, where the major portion of the vapor is separated from the noncondensible gases and sulfur from the $\mathrm{H}_{2} \mathrm{~S}$ is put into solution upon contact with the stretford solution. The liquid from the knockout tank is directed to the balance tank, or cooling tower basin. The noncondensible gases then enter the venturi scrubber and absorber where they are again contacted with the Stretford solution. The overhead product, which contains less than 10 parts per million $\mathrm{H}_{2} \mathrm{~S}$ and is odor free, is discharged into the atmosphere.

Dissolved gases in the Stretford solution are flashed in the reaction tank. The flash gas is then vented to atmosphere. Residence time for the sulfur reaction to go to completion takes place in the reaction tank. The overall reaction is

$$
\mathrm{H}_{2} \mathrm{~S}+1 / 2 \mathrm{O}_{2} \longrightarrow \mathrm{S}+\mathrm{H}_{2} \mathrm{O}
$$

The solution flows from the reaction tank to the oxidizer tank where a turbine aerator supplies air from the air blowers for floating off elemental sulfur froth and converting the stretford solution to the oxidized state. Sulfur slurry flows by gravity to the sulfur slurry tank. The oxidized solution flows from the oxidizer to the balance tank, where it is 
circulated over a cooling tower for maintaining proper heat and water balance. Stretford solution from the balance tank is pumped back to the venturi scrubber to complete the cycle.

The sulfur sent to the sulfur slurry tank is agitated gently, deaerated, and kept in suspension prior to being pumped to the sulfur melters and subsequently to the decanter. The sulfur melters are direct steam injectors used to change the state of the crystalline sulfur to a liquid by melting the sulfur crystals at a slurry temperature of approximately $270 \mathrm{~F}$. The sulfur is then removed from the decanter under level control through a steam jacketed line to the molten sulfur storage tank. Steam heating is provided in the sulfur storage tank to maintain a temperature of 270 to $280 \mathrm{~F}$. Upon sufficient accumulation of sulfur in the storage tank, the molten sulfur is pumped to the loading station. Decantered stretford solution flows out of the top of the decanter and returns to the balance tank on backpressure control.

Auxiliary equipment necessary for the performance of the unit consists of a makeup pit for preparing fresh stretford solution and adding makeup chemicals, and an additive injection package for adding diesel oil to the solution to aid in flotation of sulfur crystals in the oxidizer tank.

\subsection{ELECTRICAL SYSTEM}

The electrical system is shown on the conceptual one line diagram, Drawing EE-1 in Section 10. Electrical power generated at $26 \mathrm{kV}$ is raised to $345 \mathrm{kV}$ by the main transformer bank and transmitted overhead to the $345 \mathrm{kV}$ switchyard. The main features of this power system are described in the following paragraphs.

\subsubsection{SWITCHYARD AND SWITCHING STATION}

Power from the generator will be supplied via a 873 MVA main transformer to a $345 \mathrm{kV}$ switchyard by an overhead $345 \mathrm{kV}$ line. The $345 \mathrm{kV}$ 
switchyard will be arranged with a double bus and a breaker-and-a-half scheme and will provide for the following:

- Two positions for outgoing $345 \mathrm{kV}$ transmissions 1 ines

- One position for incoming $345 \mathrm{kV}$ line from the generator

- Future expansion

- Two positions for and two $345 / 69 \mathrm{kV}$ transformer banks for the switching station

The buses will be of the strain or tubular type with galvanized A-frame or post type steel support structures, respectively. The incoming and outgoing lines will also be supported, using galvanized A-frame-type steel supporting structures.

Power to the switching station will be supplied from two $345 / 69 \mathrm{kV}$ tie transformer banks between the switchyard $345 \mathrm{kV}$ buses and the switching station $69 \mathrm{kV}$ buses. The $69 \mathrm{kV}$ switching station will be arranged with a breaker-and-a-half scheme and will provide for the following.

- Two incoming $69 \mathrm{kV}$ positions for the incoming power from the $345 \mathrm{kV}$ switchyard

- Four positions for outgoing $69 \mathrm{kV}$ power lines

- One position for outgoing $69 \mathrm{kV}$ power line to the plant startup transformer

- Future expansion

The buses will be of the strain type with galvanized A-frame steel support structures. The incoming and outgoing 1 ines will also be supported, using galvanized A-frame-type steel supporting structures. 
The electrical equipment and devices will be rated and connected as shown on the one-line diagram.

3.15.2 GENERATOR, BUS, TRANSFORMERS, AND UNIT AUXILIARY

The generator will be a $3600 \mathrm{rpm}$ unit, hydrogen cooled, rated $873,000 \mathrm{KVA}, 0.9$ power factor, $26 \mathrm{kV}, 3 \mathrm{phase,} 60 \mathrm{~Hz}$, wye-connected and 60 pounds per inch hydrogen pressure. Three indoor-type, drawout potential transformers will be mounted in the cubicles below the generator's main bus. The generator neutral will be grounded through a resistance-loaded transformer.

A complete voltage regulating and excitation system will be furnished for operation with the generator. Furnished with the excitation system will be exciter power equipment, voltage regulator, field application equipment, metal enclosed switchgear, etc., and associated controls for the exciter and voltage regulator. The excitation system will have a high speed of response.

Isolated phase bus will be used to connect the generator terminals and the main transformer, with taps for the unit auxiliary transformers and potential transformers.

The generator bus will be rated $26 \mathrm{kV}, 20 \mathrm{kA}$, forced-air cooled with a $65 \mathrm{C}$ rise. The unit auxiliary transformer and potential transformer compartment taps will be rated $26 \mathrm{kV}, 2.0 \mathrm{kA}, 65 \mathrm{C}$ rise.

The main transformer bank will consist of 3 single phase transformers, each rated at 260/291 MVA FOA, 65C rise, 345-26 kV connected wye-delta.

Power for the plant's auxiliaries will be supplied normally from two $30 / 40$ MVA, OA/FA, 3 phase, $26-13.8 \mathrm{kV}$ unit auxiliary transformers; connected delta-wye. 
The start-up and standby power for the plant's auxiliaries will be supplied from the station service transformer rated at $60 / 80$ MVA, OA/FA, 3 phase, 69-13.8 kV, 55C rise and connected wye-wye with a minimum delta tertiary winding.

Each of the above transformers will be connected and grounded in accordance with the one-line diagram.

\subsection{AND $4.16 \mathrm{KV}$ STATION AUXILIARY POWER SYSTEMS}

The normal power supply for all the plant's auxiliaries will be from two $13.8 \mathrm{kV} 2000 \mathrm{~A}$ buses, each furnished power from the unit auxiliary transformers or from the station service transformer.

The start-up and standby power supply for all the plant's auxiliaries will be from two $13.8 \mathrm{kV} 2000 \mathrm{~A}$ buses each normally furnished power from the station service transformer. Each of these four $13.8 \mathrm{kV}$ buses are interconnected and furnish power to the plant's four $13.8 / 4.16 \mathrm{kV}$ unit auxiliary and two station service transformers as shown on the one-1ine diagram.

Motors 5000 horsepower and larger will be supplied power from one of the $13.8 \mathrm{kV}$ buses.

The ten 13.8-4.16 kV unit auxiliary and station service transformers will be connected to furnish power to ten 2000 and/or 3000A 4.16 $\mathrm{kV}$ buses with each bus being supplied normally from one transformer with a standby feeder from one other transformer.

The power equipment for the 13.8 and $4.16 \mathrm{kV}$ station auxiliary power systems will be rated, connected and grounded as shown on the one-1ine diagram.

Motors 250 to 4500 horsepower will be supplied power from one of the $4.16 \mathrm{kV}$ buses. 


\subsubsection{VOLT STATION AUXILIARY POWER SYSTEM}

The twenty-eight $4.16-.48 / .277 \mathrm{kV}$ load center transformers will supply power to the fourteen double-ended 480 volt load centers switchgear assemblies, connected and grounded as shown on the one-1ine diagram.

Motors 100 to 200 horsepower will be supplied power directly from the 480 volt load center switchgear assemblies.

Motors 100 horsepower and below, nonrotating 480 volt loads, such as lighting transformers and equipment with integral controls, will be supplied 480 volt power from the required motor control centers. Each will be supplied power from a 480 volt load center switchgear assembly and each will be furnished with the circuit breaker units and combination circuit-breaker starters as required.

The power equipment for the 480 volt station auxiliary power system will be connected and grounded.

\subsubsection{OTHER ELECTRICAL SYSTEMS}

Other electrical systems, alarms, protection devices, etcetera found normally in coal fired power plants are not described herein since they are not specifically impacted by the hybrid concept.

\subsection{OUTLINE SPECIFICATIONS OF MAJOR EQUIPMENT}

The outline specifications for major equipment items affected by the use of geothermal fluid for feedwater heating are described in the subsequent paragraphs.

\subsubsection{STEAM TURBINE GENERATOR}

The steam turbine generator with a generated power output of 788,000 kiluwatts will be a sinjie extraction, rehert type, it will contain 
one high pressure, one intermediate pressure, and two low pressure sections operating at $3,600 \mathrm{rpm}$. Other design conditions are:

\begin{tabular}{|c|c|}
\hline Steam conditions, psia/F/F & $2,412.2 / 1,000 / 1,000$ \\
\hline Throttle steam flow, $1 \mathrm{~b} / \mathrm{hr}$ & $4,543,000$ \\
\hline Reheater steam flow, $1 \mathrm{~b} / \mathrm{hr}$ & $4,489,000$ \\
\hline Reheater inlet pressure, psia & 482 \\
\hline Reheater inlet temperature, $\mathrm{F}$ & 596 \\
\hline Reheater outlet pressure, psia & 444 \\
\hline Reheater outlet temperature, F & 1,000 \\
\hline H. P. extraction steam flow, $1 \mathrm{~b} / \mathrm{hr}$ & 296,100 \\
\hline H. P. extraction steam pressure, psia & 467.5 \\
\hline H. P. extraction steam temperature, F & 596 \\
\hline I. P. auxiliary steam flow, $1 \mathrm{~b} / \mathrm{hr}$ & 486,700 \\
\hline I. P. auxiliary steam enthalpy, Btu/lb & 1,385 \\
\hline L.P. 1 inlet steam flow, $1 \mathrm{~b} / \mathrm{hr}$ & $1,984,000$ \\
\hline L.P.1 inlet steam pressure, psia & 152 \\
\hline L.P. 1 inlet steam temperature, F & 715 \\
\hline L.P. 2 inlet steam flow, $1 \mathrm{~b} / \mathrm{hr}$ & $1,984,000$ \\
\hline L.P. 2 inlet steam pressure, psia & 152 \\
\hline L.P.2 inlet steam temperature, $F$ & 715 \\
\hline L.P. 1 outlet steam flow, $1 \mathrm{~b} / \mathrm{hr}$ & $1,984,000$ \\
\hline L.P.l outlet steam pressure, psia & 1.4 \\
\hline L.P. 1 outlet steam temperature, F & 113.3 \\
\hline L.P. 2 outlet steam flow, $1 \mathrm{~b} / \mathrm{hr}$ & $1,984,000$ \\
\hline L.P. 2 outlet steam pressure, psia & 0.9 \\
\hline L.P. 2 outlet steam temperature, $F$ & 98.4 \\
\hline
\end{tabular}

\subsubsection{MAIN STEAM CONDENSER}

The main steam condenser will be a single-shell, dual pressure, single pass, deaerating type of surface condenser with divided waterboxes and hotwel1. Other design conditions are: 
Number of Passes

Surface area, $\mathrm{ft}^{2}$

Condenser shell pressures, psia/psia

Tube material/gage/O.D., in/length, ft

Circulating water flow, gpm

Circulating water inlet temperature, $F$

Circulating water outlet temperature, F one

447,600

$1.4 / 0.9$

$90-10 \mathrm{Cu}-\mathrm{Ni} / 20 / 7 / 8 / 70$

282,500

84

114

\subsubsection{FEEDWATER HEATERS}

All feedwater heaters flow geothermal fluid on the tube side except for Heaters 8 and 4. Deaerating Heater 4 is essentially the same as in the IPP plant and is not listed herein.

\section{$3.16 .3 .1 \quad$ Heater 8}

H.P. Heater 8 is of carbon steel construction with desuperheating, condensing and subcooling sections and it is of shell and tube type.

Duty, Btu/hr $\times 10^{8}$

Tube side fluid

Tube side flow, lb/hr

Tube side design pressure, psig

Tube side design temperature, F

Shell side fluid

Shell side flow, lb/hr

Shell side design pressure, psig

Shell side design temperature, $F$

Overall heat transfer coefficient, Btu/hr-ft ${ }^{2}-\mathrm{F}$

Heat transfer surface, $\mathrm{ft}^{2}$
4.04

Feedwater

$4,543,000$

3,720

525

Extraction steam

444,400

600

650

800

33,300 


\subsection{6 .3 .2 Heater 7}

I.P. Heater 7 is of stainless steel tube and carbon steel shell construction, and is a counterflow, shell and tube type exchanger with straight tubes for ease of maintenance.

$\begin{array}{ll}\text { Duty, Btu/hr } \times 10^{8} & 2.7831 \\ \text { Tube side fluid } & \text { Geothermal } \\ \text { Tube side flow, lb/hr } & 4,600,000 \\ \text { Tube side design pressure, psig } & 600 \\ \text { Tube side design temperature, F } & 500 \\ \text { Shell side fluid } & \text { Feedwater } \\ \text { Shell side flow, 1b/hr } & 4,543,000 \\ \text { Shell side design pressure, psig } & 815 \\ \text { Shell side design temperature, F } & 475 \\ \text { Overall heat transfer coefficient, Btu/hr-ft }{ }^{2}-\mathrm{F} & 225 * \\ \text { Heat transfer surface, ft }{ }^{2} & 56,230\end{array}$

\subsubsection{Heater 6}

I.P. Heater 6 is of stainless steel tube and carbon steel shell construction, and is a counterflow, shell and tube type exchanger with straight tubes for ease of maintenance.
Duty, Btu/hr $\times 10^{8}$
2.7831
Tube side fluid
Geothermal fluid
Tube side flow, $1 \mathrm{~b} / \mathrm{hr}$
$4,600,000$
Tube side design pressure, psig
600
Tube side design temperature, F
500
Shell side fluid
Feedwater

*This number allows for buildup of scale on the heat transfer surfaces. 
Shell side flow, lb/hr

Shell side design pressure, psig

$4,543,000$

Shell side design temperature, F

Overall heat transfer coefficient, Btu/hr-ft ${ }^{2}-\mathrm{F}$

Heat transfer surface, $\mathrm{ft}{ }^{2}$
815

475

$225 *$

51,550

\section{$3.16 .3 .4 \quad$ Heater 5}

I.P. Heater 5 is of stainless steel tube and carbon steel shell construction, and is a counterflow, shell and tube type exchanger with straight tubes for ease of maintenance.

Duty, Btu/hr $\times 10^{8}$

Tube side fluid

Tube side flow, $1 \mathrm{~b} / \mathrm{hr}$

Tube side design pressure, psig

Tube side design temperature, F

Shell side fluid

Shell side flow, lb/hr

Shell side design pressure, psig

She11 side design temperature, F

Overall heat transfer coefficient, Btu/hr-ft ${ }^{2}-F$

Heat transfer surface, $\mathrm{ft}^{2}$
2.7831

Geothermal fluid

$4,600,000$

600

500

Feedwater

$4,543,000$

815

475

$225 *$

48,330

$*$ This number allows for the buildup of scale on the heat transfer surfaces. 


\subsection{6 .3 .5 Heater 3}

L.P. Heater 3 is of stainless steel tube and carbon steel shell construction, and is a counterflow, shell and tube type exchanger with straight tubes for ease of maintenance.

$\begin{array}{ll}\text { Duty, Btu/hr } \times 10^{8} & 2.1348 \\ \text { Tube side fluid } & \text { Geothermal } \\ \text { Tube side flow, lb/hr } & 4,600,000 \\ \text { Tube side design pressure, psig } & 600 * \\ \text { Tube side design temperature, F } & 500 \\ & \\ \text { Shell side fluid } & \text { Condensate } \\ \text { Shell side flow, 1b/hr } & 4,400,000 \\ \text { Shell side design pressure, psig } & 400 \\ \text { Shell side design temperature, F } & 475 \\ \text { Overall heat transfer coefficient, Btu/hr-ft }{ }^{2}-\mathrm{F} & 225 * * \\ \text { Heat transfer surface, ft }{ }^{2} & 19,170\end{array}$

\subsubsection{Heater 2}

L.P. Heater 2 is of stainless steel tube and carbon steel shell construction, and is a counterflow, shell and tube type exchanger with straight tubes for ease of maintenance.

$\begin{array}{ll}\text { Duty, Btu/hr } \times 10^{8} & 2.1348 \\ \text { Tube side fluid } & \text { Geothermal fluid } \\ \text { Tube side flow, lb/hr } & 4,600,000 \\ \text { Tube side design pressure, psig } & 600 * \\ \text { Tube side design temperature, F } & 500\end{array}$

* Normal operating pressures are lower than condensate operating pressures.

$t^{*} *$ This number allows for the buildup of scale on the heat transfer surfaces. 
Shell side fluid

Shell side flow, $1 \mathrm{~b} / \mathrm{hr}$

Shell side design pressure, psig

She11 side design temperature, $F$

Overall heat transfer coefficient, Btu/hr-ft ${ }^{2}-F$

Heat transfer surface, $\mathrm{ft}^{2}$
Condensate

$4,400,000$

400

475

$225 *$

18,430

\subsubsection{Heater 1}

L.P. Heater 1 is of stainless steel tube and carbon steel shell construction, and is a counterflow, shell and tube type exchanger with straight tubes for ease of maintenance.

Duty, Btu/hr $\times 10^{8}$

Tube side fluid

Tube side flow, lb/hr

Tube side design pressure, psig

Tube side design temperature, $F$

Shell side fluid

Shell side flow, lb/hr

Shell side design pressure, psig

Shell side design temperature, F

Overall heat transfer coefficient, Btu/hr-ft ${ }^{2}-F$

Heat transfer surface, $\mathrm{ft}^{2}$
2.1348

Geothermal fluid

$4,600,000$

$600 * *$

500

Condensate

$4,400,000$

400

475

$225 *$

23,200

*This number allows for buildup of scale on the heat transfer surfaces. $* *$ Normal operating pressures are lower than condensate pressures. 


\subsubsection{MAIN BOILER}

The main boiler is a pulverized coal furnace with the following ratings and expected performance:

\section{Main Steam Conditions}

Flow, 1b/hr

$4,543,000$

Pressure, psia

2,487

Temperature, $\mathbf{F}$

1,000

Reheat Steam Conditions

Flow, 1b/hr

$4,489,000$

Inlet pressure, psia

482

Inlet temperature, F

596

Outlet pressure, psia

444

Outlet temperature, F

1,000

\section{Feedwater Conditions}

Pressure, psia

2760

Temperature, $\mathbf{F}$

460

Combustion Air and Flue Gas

Secondary air to air preheater, F

80

Excess air, percent

25

Flue gas temperature exiting air preheater, F

260

Pulverized Coal

Fuel flow rate, $1 \mathrm{~b} / \mathrm{hr}$ ( 100 percent operation)

650,900

Above ratings are based upon the use of a coal with an average heating value of $10,030 \mathrm{Btu} / \mathrm{lb}$, wet. The boiler unit will be capable of meeting the above ratings and performing as described herein, provided the fuel characteristics are within the following ranges:

$$
\begin{array}{lr}
\text { Heat ing value, Btu/lb, dry } & 10,600-13,500 \\
\text { Heating value, Btu/1b, wet } & 8,760-12,970 \\
\text { Moisture, percent } & 5-15
\end{array}
$$


Carbon, percent

$$
\begin{array}{r}
53-73 \\
3.6-5.0 \\
1.0-1.2 \\
0.5-1.0 \\
4.4-12.5 \\
.01-.03
\end{array}
$$

Hydrogen, percent

Nitrogen, percent

Sulfur, percent

Ash, percent

Chloride, percent

Ash Analysis Percent

Oxygen, percent

$$
10-20
$$

Phosphorus Pentoxide, $\mathrm{P}_{2} \mathrm{O}_{5}$

$0.04-1.3$

Silica, $\mathrm{SiO}_{2}$

44-73

Ferric Oxide, $\mathrm{Fe}_{2} \mathrm{O}_{3}$

2-11

Alumina, $\mathrm{Al}_{2} \mathrm{O}_{3}$

4-27

Titania, $\mathrm{TiO}_{2}$

$0.2-1.5$

Lime, $\mathrm{CaO}$

$$
\text { 2-13 }
$$

Magnesia, MgO

$0.2-5.0$

Potassium Oxide, $\mathrm{K}_{2} \mathrm{O}$

$0.2-0.5$

Sodium Oxide, $\mathrm{Na}_{2} \mathrm{O}$

$0.2-3.2$

\subsubsection{STEAM AIR HEATER}

There are two half capacity, steam condensing, copper-nickel finned tube construction heaters to heat ambient air when necessary to prevent cold end corrosion of the air preheaters. The design conditions are:

$\begin{array}{ll}\text { Air flow, } 1 \mathrm{~b} / \mathrm{hr} & 2.88 \times 10^{6} \\ \text { Temperature of air in - } & \text { Outdoor ambient } \\ \text { Temperature of air out, F } & 90 \\ \text { Normal steam flow, 1b/hr } & 24,000 \\ \text { Maximum steam flow, 1b/hr } & 48,000 \\ \text { Temperature of steam in, F } & 702 \\ \text { Pressure of steam in, psia } & 147.5\end{array}$




\subsubsection{AIR PREHEATERS}

There are two half capacity regenerative type air preheaters utilizing heat from the flue gases to heat air. The design conditions are:

$\begin{array}{ll}\text { Air flow, lb/hr } & 2,880,000 \\ \text { Temperature of air in, F } & 90 \\ \text { Temperature of air out, F } & 550 \\ \text { Temperature of flue gas in, F } & 800 \text { (approx.) } \\ \text { Temperature of flue gas out, F } & 260 \mathrm{~F}\end{array}$

\subsubsection{FLUE GAS REHEATERS}

There are five one fifth capacity, steam condensing, copper-nickel finned tube construction reheaters to reheat flue gas exiting from the $\mathrm{SO}_{2}$ scrubbers to prevent corrosion of the stack and to provide for adequate plume dispersion. Design conditions are:

$\begin{array}{ll}\text { Flue gas flow, lb/hr } & 1,660,000 \\ \text { Temperature of flue gas in, F } & 116 \\ \text { Temperature of flue gas out, F } & 170 \\ \text { Normal steam flow, lb/hr } & 22,400 \\ \text { Temperature of steam, F } & 702 \\ \text { Pressure of steam in, psia } & 147.5\end{array}$

\subsubsection{PRECIPITATORS}

There are four double-chamber, horizontal gas flow type electrostatic precipitators between the steam generator heat recovery area and the air preheaters. Design conditions are as follows:

Flue gas flow, lb/hr a $700 \mathrm{~F}$

Particulate removal efficiency, percent

Design temperature, F

Maximum gas velocity, fps
$1,978,000$

99.5

700

6 


\subsubsection{SULFUR DIOXIDE CONTROL SYSTEM}

There are five modular sulfur dioxide scrubbers. Each is one-fifth capacity horizontal lime throwaway type using a wet scrubbing process. Design conditions are as follows:

$\begin{array}{ll}\text { Total flue gas flow, } \mathrm{lb} / \mathrm{hr} & 7,480,000 \\ \text { Flue gas temperature, } \mathrm{F}, \text { In/Out } & 280 / 170 \\ \text { Flue gas pressure, psia, In/Out } & 12.42 / 12.2 \\ \mathrm{SO}_{2} \text { removal efficiency, percent } & 90\end{array}$

\subsection{6 .10 FANS}

\subsubsection{Forced Draft Fans and Drivers}

Two half capacity centrifugal type motor driven forced draft fans are provided as follows:

Air flow, $1 \mathrm{~b} / \mathrm{hr}$

Ambient temperature, $F$

Atmospheric pressure, psia

Discharge pressure, inches water

Motor, HP
$2,880,000$

80

$$
12.2
$$

15 above atmospheric

pressure

4,250

\subsubsection{Induced Draft Fans and Drivers}

Four quarter capacity steam condensing turbine driven fans (two fans driven by one turbine) are as follows:

Flue gas flow, $1 \mathrm{~b} / \mathrm{hr}$

Flue gas temperature, $F$

Flue gas pressure at fan suction, in. water

Flue gas pressure at fan discharge, in. water
$1,870,000$

260

$-17$

12 
Two half capacity condensing steam turbines with horizontally split casings at shaft centerlines. The steam inlet and exhaust connections are located in the lower half of the casing. Design conditions are:

$\begin{array}{ll}\text { Turbine steam flow, lb/hr } & 75,000 \\ \text { Steam tempereature in, F } & 702 \\ \text { Steam temperature out, F } & 106.4 \\ \text { Steam pressure in, psia } & 147.5 \\ \text { Steam pressure out, psia } & 1.149 \\ \text { Turbine HP } & 9,000 \text { (each) }\end{array}$

\subsubsection{Primary Air Fans}

Two half capacity motor driven centrifugal type

fans are as follows:

Air flow, 1b/hr

716,500

Outdoor ambient air temperature, $F$

80

Air pressure at fan suction

Atmospheric

Air pressure at fan discharge, inches water

40 above atmospheric

pressure

\subsubsection{ASH HANDLING SYSTEM}

The Ash Handing System comprises three separate systems. One will remove bottom ash, economizer ash, and mill pyrites from the boiler; another will remove fly ash from the precipitators; and the third will mix fly ash and scrubber sludge for disposal.

$$
\text { Capacity, tons/hr }
$$




\subsection{6 .12 COAL HANDLING SYSTEM}

The Coal Handling System is designed to receive, unload, weigh, sample, store, reclaim, crush, and pulverize coal.

Full load operation flow, 1b/hr 650,900

\subsubsection{MAJOR PUMPS}

\subsubsection{Boiler Feed Pumps}

There are two half capacity, multistage, horizontal, condensing steam turbine driven centrifugal pumps to handle boiler feedwater. Design conditions are:

$\begin{array}{ll}\text { Operating pump capacity, gpm } & 5,330 \\ \text { Rated pump capacity, gpm } & 5,900 \\ \text { Operating discharge head, ft } & 6,760 \\ \text { Rated discharge head, ft } & 7,280 \\ \text { Feedwater temperature in, F } & 450 \\ \text { Pump efficiency, percent } & 86.5 \\ \text { Rated brake horsepower/RPM } & 10,850 / 5550\end{array}$

\subsubsection{Boiler Feed Pump Turbines}

There are two half capacity condensing type steam turbines with horizontally split casings at shaft centerline to drive the feed pumps. The steam inlet and exhaust connections are located in the lower half of the casing. Design conditions are:

$\begin{array}{ll}\text { Operating Steam flow into turbine, 1b/hr } & 76,725 \\ \text { Operating Steam temperature in, F } & 702 \\ \text { Operating Steam temperature out, F } & 106.4 \\ \text { Operating Steam pressure in, psia } & 147.5 \\ \text { Operating Steam pressure out, psia } & 1.149\end{array}$




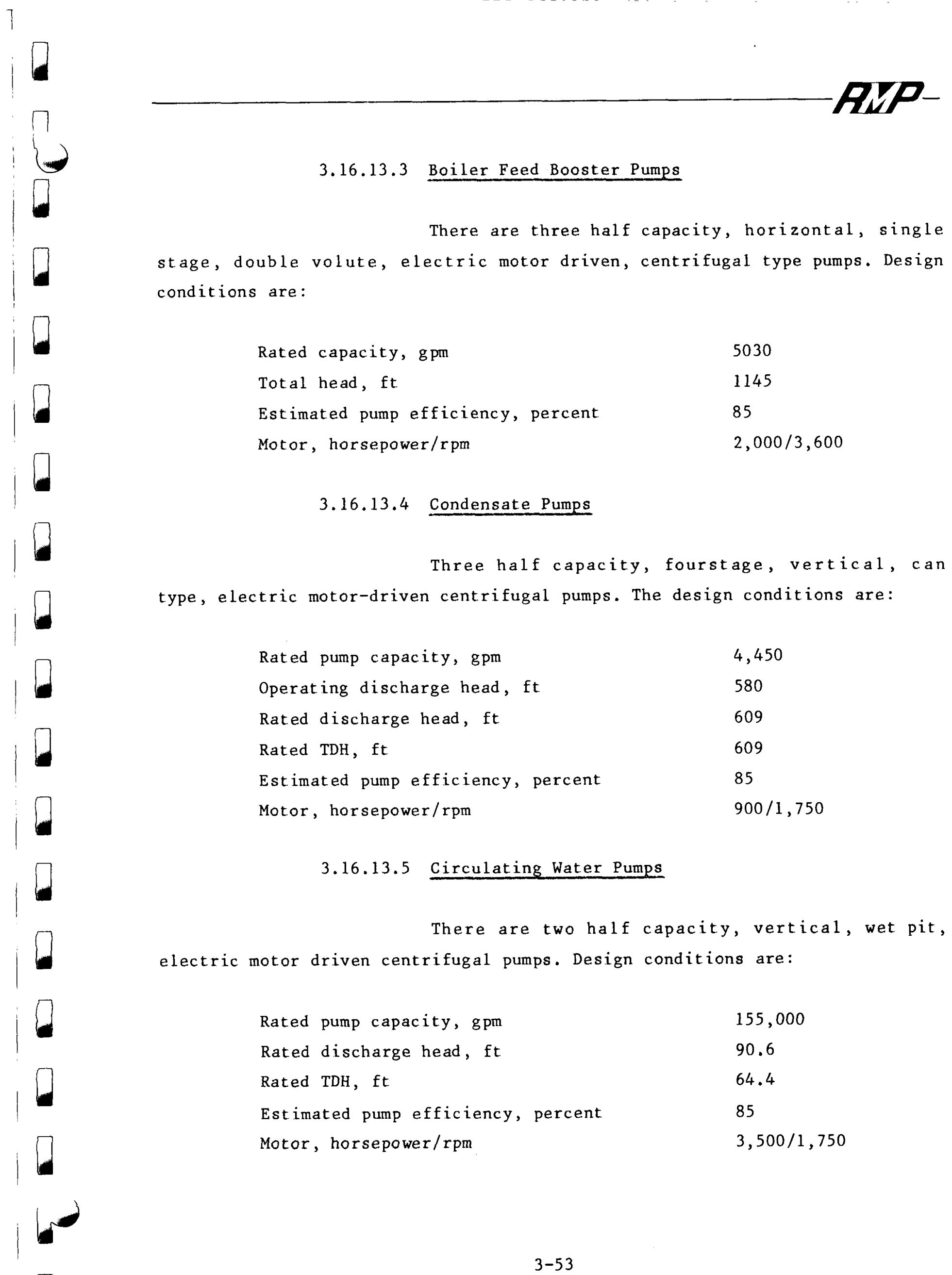


3.16.14 COOLING TOWERS

There are two half capacity, induced draft, multi-cell counterflow cooling towers with the following design conditions:

$\begin{array}{ll}\text { Rated tower capacity, g pm } & 155,000 \\ \text { Water inlet/outlet temperature, F } & 114 / 84 \\ \text { Design wet bulb temperature, F } & 66 \\ \text { Number of cells/tower } & 15 \\ \text { Cell width, ft. } & 42 \\ \text { Cell length, ft. } & 42 \\ \text { Cell height to fan deck, ft. } & 39 \\ \text { Fan stack diameter, ft. } & 21 \\ \text { Fan stack height, ft. } & 14 \\ \text { Number of fans/tower } & 15 \\ \text { Horsepower per fan } & 200 \\ \text { Site elevation above sea level, ft } & 5,500\end{array}$




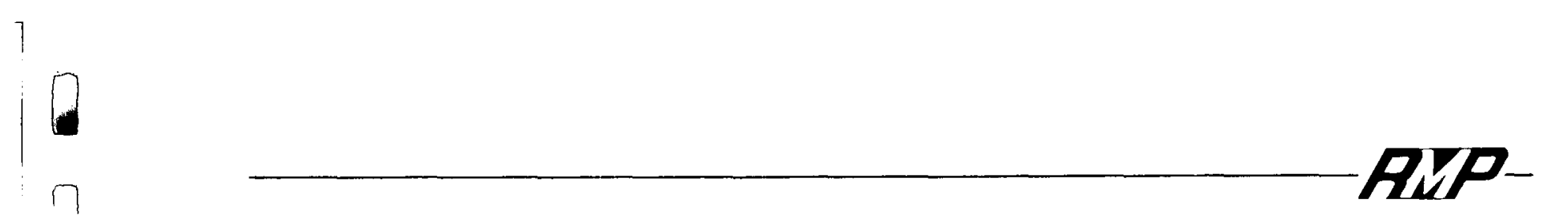

\section{SECTION 4}

MAKEUP WATER

\subsection{GENERAL DISCUSSION}

Cooling tower makeup water and condensate makeup water requirements for the hybrid geothermal/coal fired power plant as described in section 3 were provided from surface and ground water sources near Roosevelt Hot Springs, Utah. It was estimated in the city of Burbank Report that the cost of cooling water for a $750 \mathrm{MW}$ hybrid plant was approximately $0.23 \mathrm{mills}$ per kilowat hour, or about $\$ 1,300,000$ per year. A preliminary review of the possibility of using geothermal fluid for plant makeup water requirements indicated that a study of the available methods by which this could be accomplished was warranted, and could prove to be feasible and economical. The results of this study are described in this section.

The advantages of using spent geothermal fluids for makeup water are significant since the quantity of raw water to be purchased in an area where ground and surface water is scarce and costly is considerably reduced. Likewise, spent geothermal fluid that is not used for makeup water must be reinjected into the ground at additional cost.

Average continuous makeup water requirements at full load for the hybrid plant are estimated at 50,000 pounds per hour for condensate makeup and 4,500,000 to 5,200,000 pounds per hour for cooling tower makeup. The total geothermal fluid flow as described in Sections 2 and 3 for the hybrid plant, at full load is 4,600,000 pounds per hour. Approximately all the geothermal fluid leaving the feedwater and condensate heating system can be treated and used for condensate and cooling tower makeup water. 
Alternative methods for providing makeup water to the plant were investigated in terms of present technology, cost, effect on plant cycle heat rate, operating and maintenance costs.

\subsection{CONDENSATE MAKEUP WATER}

\subsubsection{GENERAL DESCRIPTION}

Condensate makeup water requirements for the hybrid plant at full load are about 50,000 pounds per hour as shown on Drawing ME-2 in Section 10. In a conventional power plant, condensate makeup is normally supplied by either an evaporator system which injects steam directly into the deaerator, or by a makeup demineralizer system which feeds a condensate storage tank or discharges into the condenser hotwell.

Drawing ME-23 in Section 10 shows the geothermal fluid system selected for condensate makeup. Geothermal fluid is evaporated in a conventional tube and shell type evaporator unit, condensed and subcooled in the low pressure Feedwater Heater $1 \mathrm{~A}$, pumped through a mixed bed demineralizer, and sent to the condenser hotwell.

\subsubsection{ALTERNATIVE CONDENSATE MAKEUP ARRANGEMENTS CONSIDERED}

The following four alternative methods for providing condensate makeup were analyzed. Cycle heat balance calculations were performed for each alternative listed.

1. Cold geothermal fluid from the discharge of Feedwater Heater 1 is evaporated in a conventional type evaporator system. Steam from the evaporator would be introduced directly into the feedwater cycle in the deaerator. 
2. Cold geothermal fluid from the discharge of Feedwater Heater 1 is evaporated in a conventional type evaporator system. Steam from the evaporator is condensed in an additional low pressure Feedwater Heater $1 \mathrm{~A}$. The condensate is then pumped through a mixed bed demineralizer to remove any solids, such as silica or other impurities, carried over from the evaporator. The discharge of the demineralizer is then sent to the main condenser hotwe11.

3. Hot geothermal fluid from the well is flashed in a flash tank. Steam from the flash tank is directed to the deaerator and used for condensate makeup.

4. Cold geothermal fluid is flashed at vacuum conditions. The flashed steam is then condensed in an additional low pressure Feedwater Heater 1A, demineralized by a mixed bed demineralizer, and sent to the main condenser hotwell for condensate makeup.

\subsubsection{ANALYSIS AND SELECTION}

Alternative 2 was selected based on the lowest overall cycle heat rate of all alternatives studied, efficient use of geothermmal energy, capital and operating costs, and purest condensate makeup of the alternatives studied. Alternative 1 requires less equipment than Alternative 2, thereby having a lower capital cost, but the high concentration of silica $\left(\mathrm{SiO}_{2}\right)$ in the geothermal fluid results in silica carryover of $0.4 \mathrm{ppm}$ in the steam drum which is in excess of the allowable limit for a 2400 psig 1000F/1000F cycle turbine. Therefore, introduction of the steam to the deaerator without removal of silica is not practicable. Alternative 3 resulted in a higher overall cycle heat rate than Alternative 2, and in addition poses the same silica problem as was the case in Alternative 1. Alternative 4 provided a more desirable arrangement than Alternatives 1 and 3 . The overall cycle heat 
rate was higher than Alternative 2, and the hybrid plant maximum gross kilowat output was reduced since no extraction steam was supplied from the intermediate pressure turbine.

The use of geothermal fluid for condensate makeup water reduces plant raw makeup water requirements by approximately 120 gallons per minute. The extraction steam requirements for the geothermal condensate makeup water system are reduced slightly, but extraction steam flow to the deaerator is increased considerably. The net increase in extraction steam of approximately 45,000 pounds per hour increases the total generating capacity of the hybrid plant.

\subsubsection{SYSTEM DESCRIPTION}

Geothermal fluid at $190 \mathrm{~F}$ and at a rate of 67,800 pounds per hour flows from the outlet of Feedwater 1 , as shown on Drawings ME- 23 and $M E-24$, to the evaporator blowdown heat exchanger where waste heat from the evaporator blowdown is recovered in a tube and shell heat exchanger. The geothermal fluid then enters the evaporator deaerator where most of the dissolved oxygen, $\mathrm{CO}_{2}$, and other noncondensible gases are vented to the $\mathrm{H}_{2} \mathrm{~S}$ removal system. The geothermal fluid is then sent to a tube and shell type evaporator which produces approximately 55,000 pounds per hour of geothermal steam. Since this steam is contaminated with some oxygen, silica, and other dissolved solids, it is condensed and subcooled in Feedwater Heater 1A. It is then pumped through a mixed bed demineralizer.

Clean condensate makeup water, with less than one micro-mho (mmho) conductivity and less than 20 parts per billion silica, is sent to the main condenser hotwell or to the condensate storage tank. 


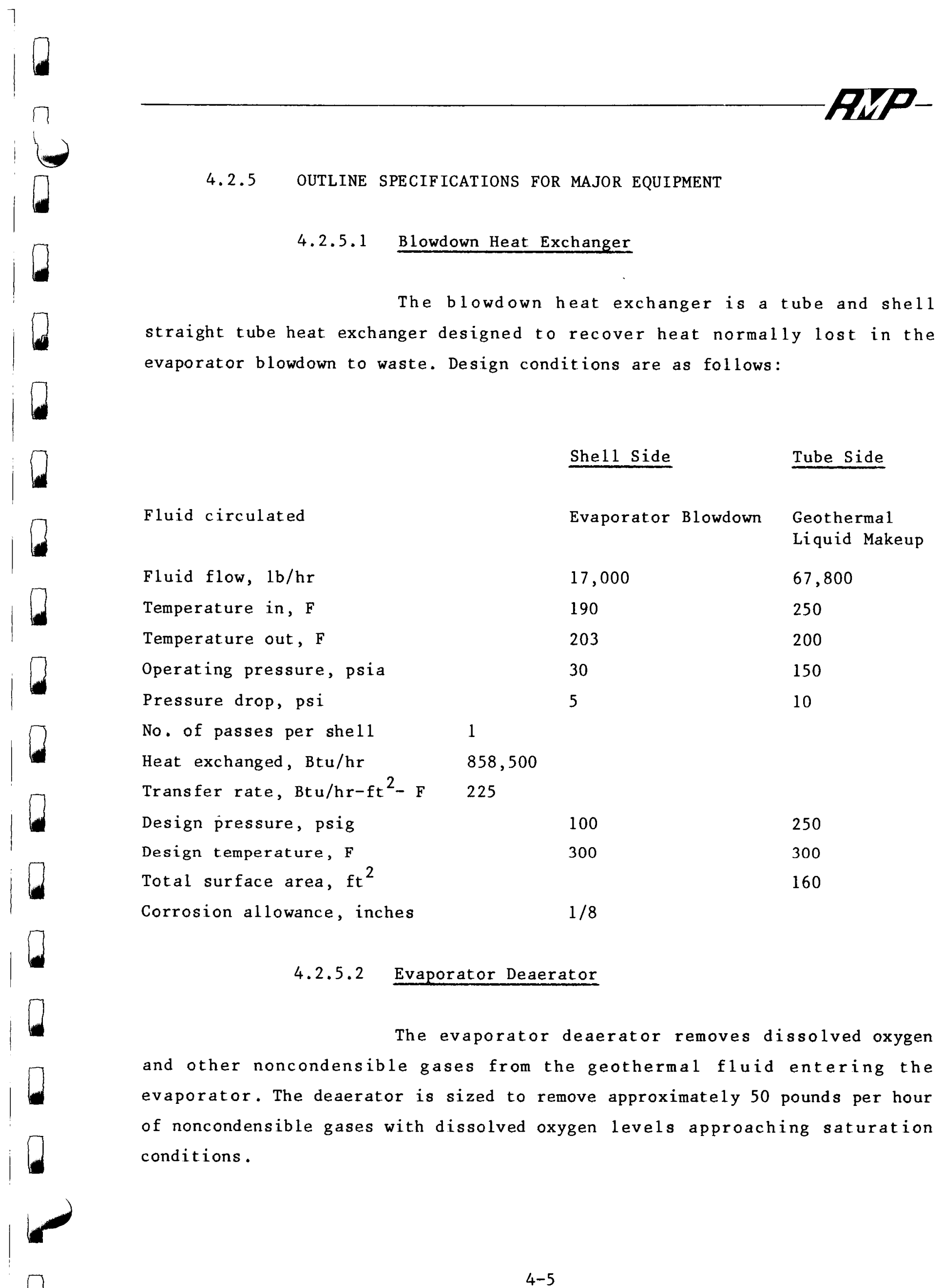




\subsubsection{Geothermal Evaporator}

The geothermal evaporator is a shell and tube straight tube heat exchanger designed to produce steam from geothermal fluid to supply condensate makeup water using extraction steam for heating. Design conditions are as follows:

$\begin{array}{ll}\text { Shell Side } & \text { Tube Side } \\ \text { Geothermal Fluid } & \text { Extraction Steam } \\ 67,800 & 50,942 \\ 215 & 702 \\ 250 & 359 \\ 30 & 148 \\ 10 & 10 \\ & \\ & \\ 100 & \\ 300 & 250 \\ 1 / 8 & 900\end{array}$

\subsubsection{Low Pressure Feedwater Heater 1A}

The low pressure Feedwater Heater $1 \mathrm{~A}$ is a tube and shell $\mathrm{U}$-tube heat exchanger designed to condense and subcool steam produced by the geothermal evaporator. The heater is designed to cool the makeup water to a temperature compatible with that acceptable for introduction to a makeup demineralizer (approximately 115-120F). Design conditions are as follows: 


\begin{tabular}{|c|c|c|c|}
\hline & & Shell side & ube side \\
\hline Fluid circulated & & Steam (Flashed) & Condensate \\
\hline Fluid flow, lb/hr & & 55,350 & $4,290,316$ \\
\hline Temperature in, $F$ & & 250.3 & 114.6 \\
\hline Temperature out, F & & 125 & 129 \\
\hline Operating pressure, psia & & 30 & 350 \\
\hline Pressure drop, psi & & 10 & 10 \\
\hline No. of passes per shell & 2 & & \\
\hline Heat exchanged, Btu/hr & $59,300,000$ & & \\
\hline Transfer rate, Btu/hr-ft ${ }^{2}-F$ & 800 & & \\
\hline Design pressure, psig & & 150 & 400 \\
\hline Design temperature, $F$ & & 300 & 150 \\
\hline Total surface area, $\mathrm{ft}^{2}$ & & & 1600 \\
\hline Corrosion allowance, inches & & $1 / 8$ & \\
\hline
\end{tabular}

The condensate makeup demineralizer consists of two full size trains, and each train has one cation bed, one anion bed and one mixed bed demineralizer. While one train is in service, the other may be in regeneration or in standby. The system has the necessary valves, controls, electrical systems, pumps, chemical storage and injection systems to enable both trains to operate and regenerate automatically on demand. Demineralizer effluent conductivity cells initiate and terminate the regeneration cycles. Design conditions are as follows:

Type

Cation, Anion \& Mixed Bed

Fluid demineralized

Design flow rate, gpm

Design pressure, psig

Design temperature, $F$
Condensate from Geothermal Steam

120

75 
Effluent conductivity, mmo

Silica, ppb

Normal pressure drop, psi

\subsection{COOLING TOWER MAKEUP WATER}

\subsubsection{GENERAL DESCRIPTION}

Cooling tower makeup water requirements for the hybrid plant at full load are about 4,500,000 to 5,200,000 pounds per hour. In a conventional plant, cooling tower makeup water is supplied by either surface or ground water for inland stations or sea water for coastal stations. Cooling towers are normally designed to operate with water containing a wide range of total dissolved solids concentrations. Chemical treatment and blowdown maintain acceptable chemistry and total dissolved solids concentrations during cooling tower operation. In the hybrid geothermal/coal fired power plant, described in this report, nearly all of the cooling tower makeup water requirements can be supplied from spent geothermal fluid.

Geothermal fluid flow for the hybrid plant at full load is approximately $4,600,000$ pounds per hour or about 9,000 gallons per minute. The geothermal fluid leaving the feedwater heaters contains approximately 7,000 to 8,000 parts per million of total dissolved solids and about 400 parts per million silica.

\subsubsection{ALTERNATIVE COOLING TOWER MAKEUP ARRANGEMENTS CONSIDERED}

Alternative methods for providing cooling tower makeup water from spent geothermal fluid were analyzed, and are shown on Drawing ME-30 in Section 10. The three alternatives described below are listed in the order of complexity, capital costs, operating and maintenance costs, and levels of makeup water purity achieved. A geothermal fluid supply of 9,000 gallons per 
minute at 385 psia and $190 F$ is available for cooling tower makeup. In each alternative system, the geothermal fluid is passed through a pressure reducing station and a degasifier. In addition to dissolved solids and silica, the geothermal fluid contains noncondensible gases which are removed by the degasifier. Most of these gases are removed by vents from the feedwater heaters as shown on Drawing ME-16 in Section 10.

1. Cold geothermal fluid from the discharge of Feedwater Heater 1 is passed through a pressure reducing station and a degasifier and introduced directly into the cooling tower.

2. Cold geothermal fluid from the discharge of Feedwater Heater 1 is passed through a pressure reducing station and a degasifier and introduced into a reactor clarifier. Chemicals are injected into the reactor clarifier to remove 90 percent of the silica from the fluid. The geothermal fluid is then passed through gravity filters and introduced into the cooling towers.

3. Cold geothermal fluid from the discharge of Feedwater Heater 1 is passed through a pressure reducing station and a degasifier and introduced into a reactor clarifier. Chemicals are injected into the reactor clarifier to remove 90 percent of the silica from the fluid. The geothermal fluid is then cooled in a heat exchanger and passed through gravity filters and a clearwell.

Cold geothermal fluid is then pumped by a low pressure feed pump, and sulphuric acid (93 percent by weight), is injected into the fluid. The fluid is then passed through a cartridge filter, pumped by a high pressure pump and introduced into the reverse osmosis module. The reverse osmosis module removes 90 percent 
of the total dissolved solids, and produces about 6,000 gallons per minute of clean water which is introduced into the cooling tower. The remaining 3,000 gallons per minute is waste which is filtered and is returned to the geothermal wells for reinjection.

\subsubsection{ANALYSIS AND SELECTION}

Alternative 2 was selected on the basis of meeting cooling tower makeup water purity requirements, cost of equipment and installation, operation and maintenance costs. While Alternative 1 is the least costly to install it does not remove silica whereas Alternative 2 provides for 90 percent silica removal. Removal of silica prevents cooling tower plugging and scale deposition in the piping. It is anticipated that the added cost of the reactor clarifier would be more than compensated for by lower overall cooling tower operating and maintenance costs. Although Alternative 3 produces the best quality water, it is very costly compared to the other two systems.

In all the alternatives studied, the use of geothermal fluid for cooling tower makeup reduces the plant raw water makeup requirement. In Alternative 2, the makeup water requirement is reduced by 9,000 gallons per minute compared to 6,000 gallons per minute in Alternative 3. As a result, these quantities of water used as makeup, will not need to be reinjected back into the ground.

\subsubsection{SYSTEM DESCRIPTION}

As shown on Drawing ME-30, for Alternative 2, geothermal fluid at $189 \mathrm{~F}, 385 \mathrm{psia}$ and at a flow rate of 4,600,000 pounds per hour flows from the outlet of Feedwater Heater 1 to the pressure reducing station. The fluid then flows through a degasifier which removes the noncondensible gases from the liquid. The fluid is then introduced into the reactor clarifier. In the reactor clarifier, chemicals ( 80 percent calcium oxide and magnesium oxide technical grade), are injected to precipitate the silica and to convert it 
into large dense suspended particles which are then separated from the fluid. The clarifier removes 90 percent of silica from the geothermal fluid which is then passed through gravity filters that further remove impurities before the fluid is introduced into the cooling tower.

\subsubsection{OUTLINE SPECIFICATIONS OF MAJOR EQUIPMENT}

\subsubsection{Degasifier}

Three degasifiers are provided, each capable of handling 3000 gallons per minute of geothermal fluid. Each unit is ten feet wide, ten feet deep and about 16 feet high. Air and noncondensible gases are vented from the degasifier and sent to the $\mathrm{H}_{2} \mathrm{~S}$ Removal System.

\subsubsection{Reactor Clarifier}

The reactor clarifier precipitates dissolved minerals and converts the solid matter into large dense suspended particles which are then separated from the water. Design conditions are as follows:

$\begin{array}{ll}\text { Fluid clarified } & \text { Geothermal Fluid } \\ \text { Type of clarifier } & \text { Coagulating and Precipitating } \\ \text { Fluid flow rate, gpm } & 9000 \\ \text { Silica removal, percent } & 90 \\ \text { Calcium oxide injection rate, 1b/hr } & 675 \\ \text { Magnesium oxide injection rate, 1b/hr } & 675 \\ \text { Dimensions, diameter } x \text { height, feet } & 100 \times 18\end{array}$

\subsubsection{Filters}

Ten gravity flow filters are provided for removal of remaining suspended solids from the clarifier effluent stream. Design conditions are as follows: 
No. of filters

Type

Design pressure

Design temperature, $F$

Filter area, $\mathrm{ft}^{2}$ each

Dimensions, diameter $x$ length, ft (each)

Material
10

Multimedia Diatomaceous Earth

Atmospheric

200

400

$10 \times 40$

Cast Concrete

\subsection{SUMMARY}

The amount of geothermal fluid entering the plant is in excess of 9000 gallons per minute when the hybrid plant is at full load. Essentially all of this fluid can be used for condensate and cooling tower makeup water, thereby practically eliminating the need for all but small quantities of fresh water makeup to the plant.

The cost of the equipment described in the preceeding paragraphs is tabulated in Section 8. The net impact of using geothermal fluid for plant makeup in terms of capital, operating, maintenance, and makeup water purchase costs is presented in Section 9. 


\section{SECTION 5}

ADDITIONAL POWER

\subsection{GENERAL DISCUSSION}

As a part of the additional engineering investigations various alternative methods for providing additional power generation using geothermal fluid were investigated for technical and economic feasibility. These are described in this section along with system descriptions and summary.

Existing all geothermal power plants are located in areas where the geothermal resource is steam dominated. The steam is used to drive steam turbine generators to produce electricity. For liquid dominated geothermal resource areas, such as Roosevelt Hot Springs, Utah, the geothermal fluid would be flashed to steam, passed through demisters and sent to the turbines for power generation.

\subsection{ALTERNATIVES CONSIDERED}

Four different concepts for producing additional power from geothermal fluids were considered as described in the subsequent paragraphs. The best of the four concepts was then studied in much greater depth.

\subsubsection{BASE LOADED ALL GEOTHERMAL GENERATING UNIT}

In addition to providing geothermal fluid to the hybrid geothermal/coal fired power plant the construction of an all geothermal generating unit was considered. The unit would be base loaded and consist of a two stage flash tank and demister system to convert the geothermal fluid to steam, a four flow geothermal steam turbine generator set, condensers, air removal system and necessary auxiliary systems. Heat balance calculations indicated that a unit of this type designed for Roosevelt Hot Springs, Utah, 
would have an electric power output capacity of $13 \mathrm{MW}$ for each 1,000,000 pounds per hour of geothermal fluid or approximately $65 \mathrm{MW}$ for 5,000,000 pounds per hour.

Based on the efficiency with which an all geothermal plant utilizes the geothermal resource as compared to the hybrid plant, this concept is not considered economically feasible. Instead 5,000,000 pounds per hour of geothermal fluid could better be used in the operation of another hybrid unit:

The hybrid plant utilizes the geothermal energy much more efficiently than present concepts for all geothermal plants with respect to extraction of available work from the geothermal fluid. The overall efficiency of this all geothermal plant is expected to be about 40 to 50 percent. The overall geothermal efficiency of the hybrid plant described in Sections 2 and 3 is estimated at 80 percent. These efficiency estimates are based on actual work derived from the geothermal fluid as compared to its available work.

Consequently, if the geothermal resource area is located near adequate coal supplies, construction of a base loaded all geothermal plant in addition to a hybrid plant would be less desirable than the addition of a second hybrid unit.

\subsubsection{GEOTHERMAL STEAM IN THE LOW PRESSURE TURBINES}

The second concept considered was the feasibility of introducing flashed geothermal steam to the low pressure sections of the main turbines in the hybrid plant. During off peak periods of operation of the 715 MW hybrid plant at low loads, the geothermal steam may be injected into the low pressure sections of the main steam turbine. Under these conditions, the low pressure turbines are not at maximum steam flow and are capable of accepting additional steam flow from the geothermal flashed steam system. With this additional power, steam flow to the high pressure turbine would be reduced, which in turn would result in a reduction in the firing rate of the 
main boiler while the generator output remains the same. This condition would permit the geothermal resource to make a greater percent contribution in the generation of power.

In this concept the geothermal steam entering the low pressure turbines mixes with the steam from the intermediate pressure turbine, expands through the low pressure turbines and is subsequently condensed in the main condenser. Unfortunately the possibilities of silica and moisture levels in the geothermal steam penalizes this concept with higher operating and maintenance costs and diminished availability. The $2400 \mathrm{psig}, 1000 \mathrm{~F} / 1000 \mathrm{~F}$ cycle requires feedwater and steam purity levels better than those achievable with the use of geothermal steam. Consequently, this concept was not examined in detail.

\subsubsection{GEOTHERMAL STEAM IN ADDITIONAL LOW PRESSURE SECTIONS}

This concept was similar to the second alternative discussed in Paragraph 5.2.2 with the exception that the flashed geothermal steam is sent to an additional steam turbine on the same shaft as the hybrid main turbine generator. Based on the lack of experience by manufacturers with geothermal turbines and the probability of lower reliability and availability than that normally achieved by a conventional steam turbine generator, this concept was not studied in detail. A failure in the system involving either the geothermal turbine or flashed steam system would trip the main hybrid turbine generator unit. Therefore, base load requirements and estimated capacity factors of 85 percent would probably not be met.

\subsubsection{STANDBY ALL GEOTHERMAL UNIT}

The fourth concept considered was a standby all geothermal unit consisting of a $65.4 \mathrm{MW}$ four flow geothermal turbine generator set, dual flash system with demisters, air compressors, condensers, vacuum pumps, and all necessary auxiliaries. This concept appeared to be the most feasible since it does not adversely affect the reliability and availability of the hybrid unit and does not pose any feedwater contamination problems. 
One $715 \mathrm{MW}$ hybrid power plant with geothermal feedwater heating would be base loaded while a 65.4 MW all geothermal unit would be either on minimum load or on standby. At full load, the hybrid power plant net generating capacity is $715 \mathrm{MW}$ and a geothermal fluid flow of about 5,000,000 pounds per hour is required. However, at lower than base loads, the geothermal fluid demand for feedwater heating, makeup water, air preheating, flue gas reheating and plant space heating is proportionately less. As the hybrid plant load is reduced, geothermal fluid becomes available for use in the all geothermal unit for direct power generation.

Since the geothermal efficiency of the hybrid plant is nearly twice as high as the all geothermal unit, geothermal fluid would be used in the all geothermal unit only when the demand for geothermal fluid decreases in the hybrid plant. The curves in Figure 5-1 show the relative power output of the hybrid plant and the all geothermal unit versus total station generation. The curves in Figure 5-2 show geothermal fluid flow to each unit as well as total geothermal flow to the plant versus total station power output.

\subsection{HEAT BALANCE}

The geothermal fluid used for additional power generation is at a temperature of $475 \mathrm{~F}$. Steam is produced by the flashing process for driving the turbine generator. By component sensitivity analysis it was determined that a double flash system is the most practical system to be used for the aforementioned temperature, and therefore this system was incorporated into the design.

Steam is generated by lowering the geothermal fluid pressure below the saturation pressure corresponding to its temperature. The amount of steam generated increases as the flashing stage pressure is decreased. However, as the pressure is decreased the enthalpy drop across the turbine also decreases. The maximum power output is achieved when the flash points are set at temperatures giving equal intervals between the geothermal fluid temperature and the heat sink temperature. 


\section{$1 \ldots \ldots \ldots \ldots \ldots$}

Figure 5-1

TOTAL STATION OUTPUT VERSUS INDIVIDUÁL UNIT OUTPUT

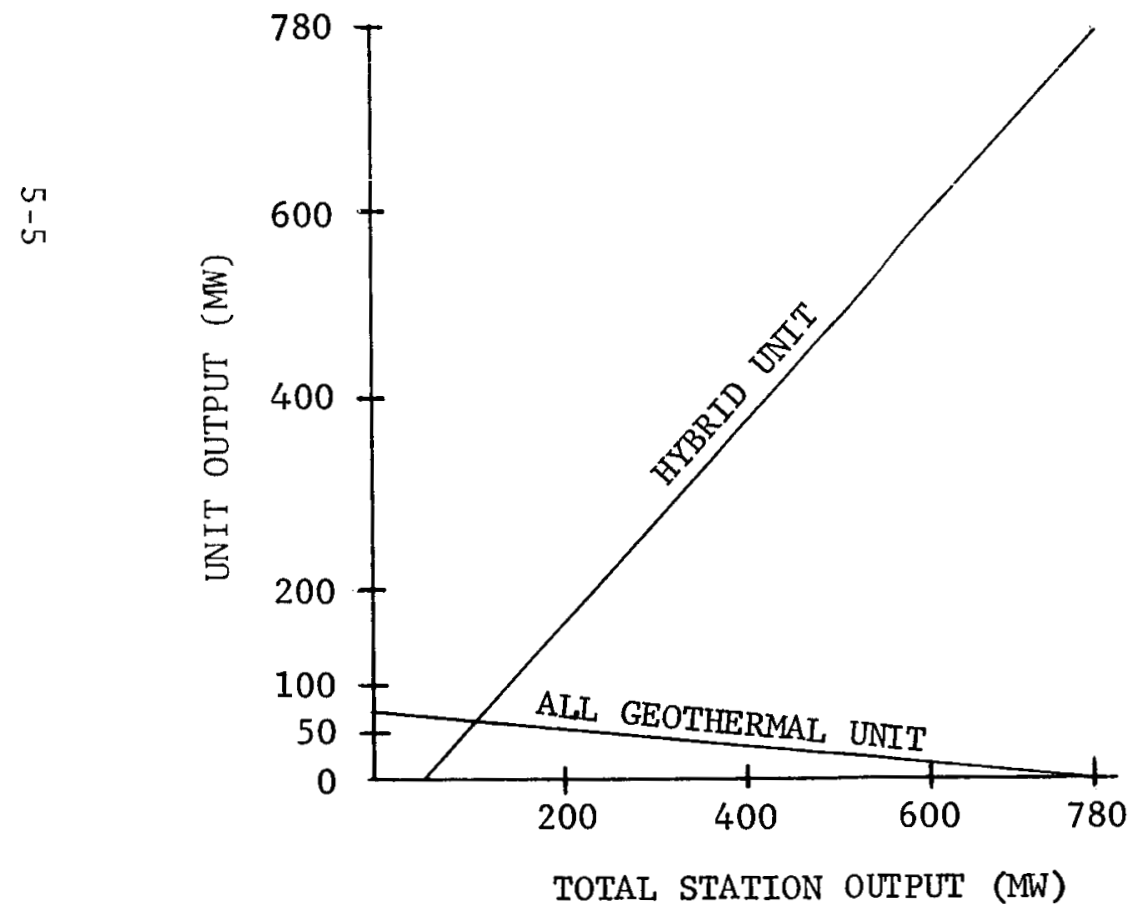

\section{Figure 5-2}

GEOTHERMAL FLUID FLOW VERSUS TOTAL STATION OUT'PUT

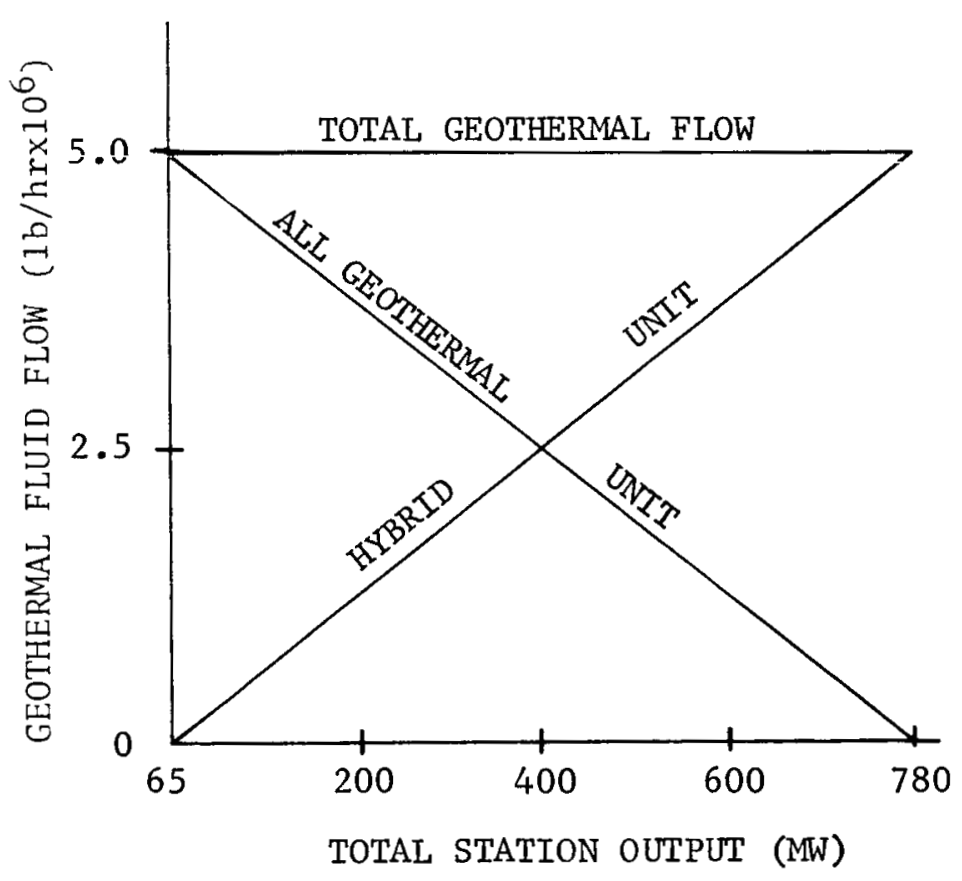


Subatmospheric flash pressures are undesirable for this application and were not considered in this study. Moreover, the large increases in specific volume of steam require large piping and components and plant startup is more complicated.

The heat balance calculations were based on a geothermal fluid flow of 5,000,000 pounds per hour. For the dual flash systems investigated, the first flash occurs at a pressure range of 143 to $160 \mathrm{psia}$, and the second flash occurs at a pressure range of 22.5 to 31 psia. For simplicity in a 11 calculations, it was assumed that 100 percent quality steam is produced and that flashed steam pressure and turbine inlet pressure are the same. The steam flow rate for the high pressure and low pressure turbines ranges from 720,000 to 770,000 pounds per hour and from 526,000 to 550,000 pounds per hour, respectively.

In order to evaluate the most desirable condenser arrangement for the all geothermal unit, heat balance calculations were performed for three arrangements, namely, an air cooled condenser, a conventional water cooled surface condenser, and a barometric direct contact condenser.

Power generation calculations were based on an assumed 76 percent expansion 1 ine efficiency through the turbines. The used energy end points were evaluated corresponding to 6 inches $\mathrm{Hg}$ backpressure for the air cooled condenser case, 3.5 inches Hg backpressure for the surface condenser, and 2.91 inches $\mathrm{Hg}$ backpressure for the direct contact condenser case. The set point at lowest operating backpressure is determined by the outlet cooling water temperature of $114 \mathrm{~F}$. There is a 30 degree temperature rise through the direct contact barometric condenser. The plant output is significantly influenced by the turbine backpressure. A maximum gross generator output of $55.83 \mathrm{MW}$ is expected when operating with an air cooled condenser as shown on Drawing ME-19 in Section 10. This generation is increased to the level of 57.22 MW (gross) when a water cooled surface condenser is used as shown on Drawing ME-21. Total generated output capacity is increased to $65.4 \mathrm{MW}$ when a barometric direct contact condenser is used as shown on Drawing ME-28. About 
81,200 gallons per minute of circulating water are required to condense the are required to condense the steam entering the barometric direct contact condensers at maximum load.

The barometric condenser alternative was selected because it has the lowest turbine backpressure and highest generator output capability for the same geothermal fluid flow. Conceptual piping line diagrams of the air-cooled condenser, surface condenser and barometric condenser alternatives are shown on Drawings $M E-20, M E-22$ and $M E-29$, respectively.

The heat balance calculations assume the steam expansion of both flashes to be independent for each turbine. The condenser operating conditions are estimated for a combined turbine discharge for both surface and direct contact condensers. The turbine configuration is double-flow type with 16.8 inch last stage blades. The geothermal cycle heat rate for additional power is $22,100 \mathrm{Btu} / \mathrm{kwh}$ when a barometric direct contact condenser is used.

\subsection{SYSTEM DESCRIPTIONS}

General arrangements of the entire plant including the 715 MW hybrid and the $65.4 \mathrm{MW}$ all geothermal unit are shown on Drawings GA-8 and GA-9 in Section 10. A more detailed conceptual plan and an elevation of the all geothermal unit are shown on Drawings GA-10 and GA-11, respectively. The main electrical system requirements are shown on the electrical one-line diagram Drawing EE-1.

\subsubsection{MECHANICAL SYSTEMS DESCRIPTION}

At full load operation of the all geothermal unit approximately $5,000,000$ pounds per hour of geothermal liquid at $475 \mathrm{~F}$ and 540 psia enter four 25 percent capacity high pressure geothermal flash tanks. These flash tanks normally operate at 143 psia and contain demister pads to produce 99.8 percent dry steam. The steam generated in these flash tanks is sent via 
common header to the high pressure steam turbine inlet while the concentrated geothermal fluid remaining in the flash tanks is drained into four 25 percent capacity low pressure geothermal flash tanks. These flash tanks normally operate at 22.5 psia and contain demister pads to produce 99.8 percent dry steam. The steam generated in these flash tanks is sent via common header to the low pressure steam turbine inlet while the concentrated geothermal fluid remaining in the tanks is sent to the plant battery limit for disposal.

The steam generated in the high pressure and low pressure geothermal flash tanks goes through the high pressure and low pressure steam turbine and it is then condensed in two half size barometric direct contact condensers. In the condensers the exhaust steam and circulating water are mixed, and this mixture of condensed steam and circulating water is returned to the cooling towers via three half capacity condensate pumps.

Noncondensible gases entering the direct contact condensers will be removed by a vacuum pump system and sent to the $\mathrm{H}_{2} \mathrm{~S}$ Removal System. During system upset and/or shutdown, flash steam may be routed directly from the high pressure and low pressure geothermal flash tanks to the direct contact condensers.

The high pressure and low pressure geothermal flash tanks are provided with relief valves and level control for protection and reliable plant operation. Both direct contact condensers are provided with level controls tied to the control valve located at the discharge header of the condensate pumps and to condensate pump controls.

\subsubsection{ELECTRICAL SYSTEM DESCRIPTION}

The all geothermal electrical power generating unit will be connected into the switchyard and the hybrid power plant's electrical power system as shown on the conceptual one-line diagram, Drawing EE-1 in Section 10. The main required electrical systems and equipment as shown on this one-line diagram include the following: 


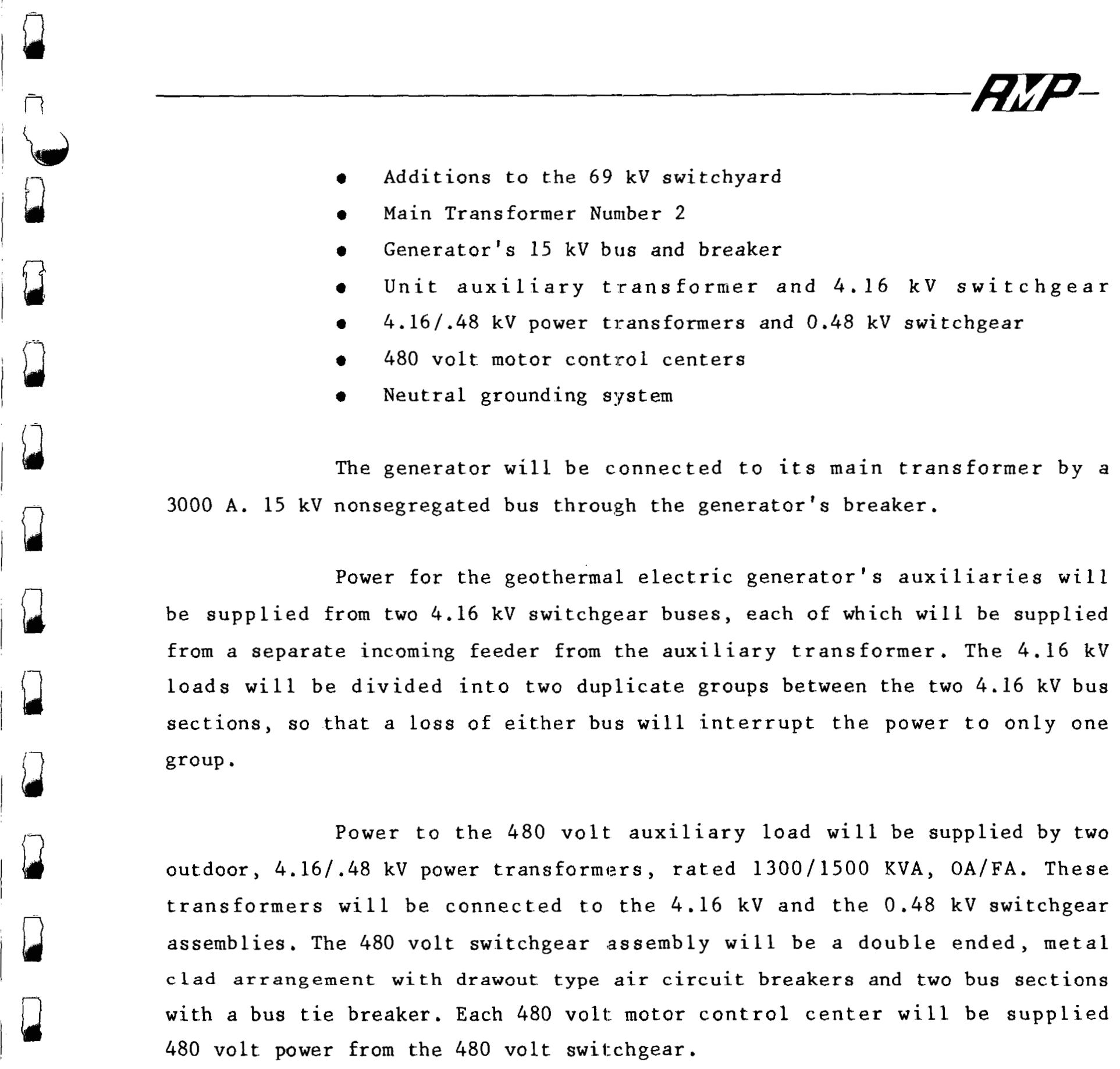

All motor driven auxiliaries, 250 horsepower and larger will be 3 phase squirrel-cage induction motors with a voltage rating of 4000 volt and will be supplied power, together with the $4.16 / .48 \mathrm{kV}$ load center transformers, from the $4.16 \mathrm{kV}$ switchgear. Al1 motor driven auxiliaries from 125 to 200 horsepower will be 3 phase squirrel-cage, 460 volt induction motors and will be supplied power together with the 480 volt motor control centers, from the 480 volt switchgear. All motor driven auxiliaries $1 / 2$ to 100 horsepower, together with all non-rotating loads, will be supplied power from the motor control center. 
The electrical design for the all geothermal electrical power generator will be based on centralized controls, monitoring and protection. The control devices, instruments, and relays will be located on panels in the switchyard and power plant's control rooms. The switchyard oil circuit breakers, geothermal generating unit and main transformer, the auxiliary electrical system and the essential auxiliary motors will be controlled from the control rooms. The noncritical auxiliary loads will be controlled locally at the load or from the motor control centers.

Protection of electrical equipment will be accomplished by means of coordinated relay systems and circuit breaker operations. The generation unit, main transformer and unit auxiliary transformer will be provided with protection systems and devices.

The geothermal electric power generator will be capable of operating with the 345 and $69 \mathrm{kV}$ grid systems. The controls will be able to maintain the required output, frequency, voltage and continuity of service. The geothermal generator will also be provided with an automatic and manual synchronizing system with speed matching, voltage matching, and breaker closing.

\subsection{OUTLINE SPECIFICATIONS OF MAJOR EQUIPMENT}

The outline specifications for major equipment items affected by the use of geothermal fluid in a dual flash all geothermal plant are described in the subsequent paragraphs.

\subsubsection{STEAM TURBINE-GENERATOR}

A condensing, nonextraction, double flow steam turbine generator with a high pressure section and a low pressure section is provided for power generation. Design conditions are as follows: 
Turbine Design Data:

Turbine rating, kw $\quad 65,400$

Speed, rpm 3600

HP turbine last stage bucket, inches 16.5

HP steam flow, $1 \mathrm{~b} / \mathrm{hr} \quad 770,000$

HP steam inlet temperature, F 354.6

HP steam inlet pressure, psia 142.8

HP steam inlet enthalpy, Btu/lb 1193

HP exhaust pressure, psia 1.43

HP exhaust enthalpy, Btu/1b 970.3

LP turbine last stage bucket, inch 23

LP steam flow, lb/hr $\quad 549,900$

LP steam inlet temperature, F 234.3

LP steam inlet pressure, psia 22.5

LP steam inlet enthalpy, Btu/lb 1158.6

LP exhaust pressure, psia 1.43

LP exhaust enthalpy, Btu/1b 1022.9

Generator Design Data:

Rating, $\mathrm{kW}$

65,400

Rating, kVA

72,700

Speed, rpm

3,600

Poles

2

Phases, wye connected

3

Frequency, hertz 60

Power factor $\quad 0.9$

Short circuit ratio $\quad 0.58$

Cooling medium

Hydrogen

Cooling pressure, lb/inch

30

Static exciter:

Rating, kw 190

Volts 250

Amperes $\quad 760$ 
In addition, the following standard accessories are included with the steam turbine-generator unit:

- EHC control system

- Turbine lube oil system

- Hydraulic power unit

- Turbine bypass valves

- Lube oil reservoir

- Hydrogen control system

- $\mathrm{CO}_{2}$ purge system

- Collector assembly

- Excitation potential transformer

- Excitation current transformers

- Excitation cubicle

\subsubsection{HIGH PRESSURE GEOTHERMAL FLASH TANKS}

Four, twenty-five percent capacity, vertical, high pressure geothermal flash tanks with hemispherical end are provided. Design conditions are as follows:

Tank diameter, ft

Tank height, ft

Design fluid flow into tank, lb/hr

Design flashed steam flow, 1b/hr

Design fluid return flow, lb/hr

Design temperature, $F$

Design pressure, psia

Thickness, inch

Material:

She11, Head

Internal
15

$14(\mathrm{~T}-\mathrm{T})$

$1,500,000$

216,000

$1,290,000$

500

250

1.25

Carbon Stee1

Stainless Steel 


\subsubsection{LOW PRESSURE GEOTHERMAL FLASH TANKS}

Four, twenty-five percent-capacity, vertical low pressure geothermal flash tanks with hemispherical ends are provided. Design conditions are as follows:

Tank diameter, ft 17

Tank height, ft

$14(\mathrm{~T}-\mathrm{T})$

Design fluid flow into tank, $1 \mathrm{~b} / \mathrm{hr}$

$1,290,000$

Design flashed steamflow, lb/hr

160,000

Design fluid return flow, $1 \mathrm{~b} / \mathrm{hr}$

$1,130,000$

Design temperature, $F$

400

Design pressure, psia

250

Thickness, inch

1.38

Material:

She11, Head

Carbon Steel

Internals

Stainless Steel

\section{5 .4 CONDENSER}

Two, half capacity, direct contact, barometric type condensers are provided. Design conditions are as follows:

$\begin{array}{ll}\text { HP turbine exhaust flow, lb/hr } & 385,000 \\ \text { LP turbine exhaust flow, 1b/hr } & 275,000 \\ \text { Total exhaust steam flow, 1b/hr } & 660,000 \\ \text { Exhaust steam pressure, psia } & 1.43 \\ \text { HP Exhaust steam enthalpy, Btu/1b } & 970 \\ \text { LP Exhaust steam enthalpy, Btu/lb } & 1022 \\ \text { Circulating water flow, 1b/hr } & 20,000,000 \\ \text { Circulating water inlet temp., F } & 84 \\ \text { Circulating water outlet temp., F } & 114 \\ \text { Design Pressure, psia } & 30 / \text { Full Vacuum }\end{array}$


Storage volume required for

level control (Circulating

water and steam) 1 minute

Construction:

She11

$1 / 8^{\prime \prime} 304 \mathrm{~L}$ SS clad

on $1 / 2$ " $\mathrm{A} 285 \mathrm{C}$

Internals

304 Stainless Steel

Corrosion allowance, inch $\quad 1 / 16$

Dimension, ft 59 (N) $\times 23$ (H) $\times$

$67(\mathrm{~L})$

\subsubsection{CONDENSATE PUMPS}

Three, half capacity, vertical centrifugal, motor-driven condensate pumps are provided to return the mixture of condensate and circulating water from the barometric condensers to the circulating water system. Design conditions are as follows:

$\begin{array}{ll}\text { Rated pump capacity, gpm } & 41,500 \\ \text { Rated pump discharge pressure, ft } & 90 \\ \text { Pump efficiency, percent } & 85 \text { (assumed) } \\ \text { Pump speed, rpm } & 875 \\ \text { Motor horsepower, hp } & 1250\end{array}$

5.5.6 ADDITIONS TO $69 \mathrm{KV}$ SWITCHYARD

The all geothermal generation connection into the $69 \mathrm{kV}$ switchyard will require the installation of the following equipment.

Quantity

Description

Outdoor, $69 \mathrm{kV}, 3$ pole, oil circuit breaker, rated at $1200 \mathrm{~A}, 60 \mathrm{~Hz}, 2500 \mathrm{MVA}$, with $72.5 \mathrm{kV} 3$ pole, group operated $1200 \mathrm{~A}$, isolating switches 


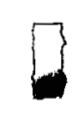

and an outdoor, 3 pole, motor operated, disconnect switch. Each with $61 \mathrm{kA}$ rating.

1

Outdoor, $69 \mathrm{kV}$ potential transformer, with a $40 / .12 \mathrm{kV}$ ratio.

1 Lot

Galvanized steel support structures - of the "A" frame and pedestal type.

2

Indoor control and relay panels complete, for installation in switchyard control room.

1

$69 \mathrm{kV}$ overhead power 1 ine from main transformer to the switchyard.

\subsubsection{MAIN TRANSFORMER NUMBER 2}

Quantity

Description

Outdoor, oil immersed, 3 phase, 2 winding, 60 $\mathrm{Hz}$, power transformer rated $62 \mathrm{MVA}$, FOA, 65C rise, 69 grounding $Y / 40-13.2 \mathrm{kV}$ wye delta connected, with 3-base mounted, $60 \mathrm{kV}$ lightning arresters. 


\subsubsection{GENERATOR'S $15 \mathrm{KV}$ BUS AND $15 \mathrm{KV}$ BREAKER}

Quantity

\section{Description}

1 Lot

Outdoor, $15 \mathrm{kV}, 3000 \mathrm{~A}, 3$ phase, metal enclosed self-cooled, nonsegregated bus and an outdoor, $15 \mathrm{kV}, 600 \mathrm{~A}, 3 \mathrm{phase,}$ metal enclosed nonsegregated bus tap; both with insulated to run from the generator to the main transformer, via the generator breaker with a tap to the unit auxiliary transformer.

1 Outdoor, $15 \mathrm{kV}$ power circuit breaker enclosure with:

- Drawout type, $13.8 \mathrm{kV}, 3000 \mathrm{~A}, 3$ pole generator air circuit breaker, rated 1000 MVA at $13.8 \mathrm{kV}$.

- Drawout type $14.4 / .12 \mathrm{kV}$ generator potential transformers and the generator's surge protection equipment.

\subsubsection{UNIT AUXILIARY TRANSFORMER AND 4.16 KV SWITCHGEAR}

Quantity

\section{Description}

Outdoor, oil-immersed, 3 phase, 2 winding 60 $\mathrm{Hz}$ unit auxiliary transformer rated $6.4 / 8.0$ MVA, OA/FA, with $65 \mathrm{C}$ temperature rise. $13.8 / 4.16 \mathrm{kV}$ - delta-wye connected, solidly grounded. 
Indoor, $5 \mathrm{kV}$ draw out type, metal clad switchgear assembly, rated at 250 MVA at 4.16 $\mathrm{kV}$ with:

- Two - 1200A bus sections.

- Two - incoming $1200 \mathrm{~A}$ air circuit breakers, one per bus section.

- Eight - 1200A outgoing air circuit breakers, four per bus section.

\section{$5.5 .104 .16 / 0.48 \mathrm{KV}$ POWER TRANSFORMER AND $0.48 \mathrm{KW}$ SWITCHGEAR}

Quantity

2

1 Lot

1

\section{Description}

Outdoor, oil immersed, 3 phase, 2 winding, 60 $\mathrm{Hz}$, power transformers, each rated $1300 / 1500$ KVA OA/FA; with $65 \mathrm{C}$ temperature rise. 4.16/.48 $\mathrm{kV}$ - delta-wye connected, solid1y grounded.

480 volt $2000 \mathrm{~A}$, nonsegregated, outdoor, 3 phase, 3 conductor, metal enclosed bus.

Indoor, 480 volt, 3 phase, metal clad drawout type, double ended switchgear assembly, rated $30 \mathrm{kA}$, RMS, SYM, at $0.48 \mathrm{kV}$ with:

- Two - 2000A bus sections.

- Two-2600A incoming air circuit breakers. 
- One-1600A bus tie air circuit breaker.

- Six - outgoing 600A air circuit breakers, three per bus section.

\subsubsection{VOLT MOTOR CONTROL CENTERS}

Quantity

2

\section{Description}

Indoor, 480 Volt, 3 phase, metal-clad, floor mounted, self supported motor control centers, each rated $30 \mathrm{kA}$ RMS, SYM., with: $600 \mathrm{~A}, 3$ conductor bus; 4-225A, frame 3 pole molded case air circuit breakers and ten air circuit breaker - motor starter combinations.

\subsubsection{GENERATOR'S NEUTRAL GROUNDING SYSTEM}

Quantity

\section{Description}

1

$37.5 \mathrm{kVA}, 12 / .24 \mathrm{kV}$ single phase, $60 \mathrm{~Hz}$, neutral grounding transformer with a 240 volt, $197 \mathrm{~A}$, for 30 minutes, secondary.

\subsubsection{MISCELLANEOUS ELECTRICAL SYSTEMS, DEVICES, AND MATERIALS}

The equipment, devices and material for the following electrical systems, for the all geothermal electric power generator will be an addition to the similar system for the coal fired generator and switchyard.

- Electric control and relay panels

- Grounding - switchyard and plant 
- Annunciation and public address

- Communication

- Cathodic protection

- AC single phase power

- Instrument AC systems

- DC system

- Lighting systems, including emergency

- Raceway systems

- Emergency AC power supply

- Power, control and instrumentation cables

- Lighting and surge protection

- Winter protection

- Fire detection and alarm systems

\subsection{SUMMARY}

The most efficient use of geothermal heat for power generation is to use geothermal fluid for feedwater heating in a hybrid plant. The geothermal efficiency in a hybrid plant is approximately twice that obtained in most all geothermal plants. Consequently, for an area like Roosevelt Hot Springs, where large quantities of coal are economically available for use in a hybrid plant, a base loaded all geothermal plant is not desirable. However, it is 
desirable to maintain geothermal well production at system capacity to obtain an acceptable rate of return on the capital cost of the wells and geothermal piping systems. Constant flow is also desirable from an operating and maintenance standpoint.

of the four alternatives examined in this study, the most feasible concept is an all geothermal plant operated in conjunction with the hybrid plant. When the hybrid plant is at full rated load all the geothermal fluid is used for feedwater heating. When the hybrid plant is at less than full rated load, excess geothermal fluid is flashed for power generation in the all geothermal plant. Thus, under all normal operating conditions the geothermal fluid flow is held constant and at maximum system capacity.

A conceptual design cost estimate for the all geothermal plant is presented in Section 8, Paragraph 8.3.1, of this report. An economic analysis of total energy costs for additional power from the all geothermal plant is presented in Section 9, Paragraph 9.3. 
SECTION 6

COAL BENEFICIATION

\subsection{GENERAL DISCUSSION}

This section describes the potential use of geothermal fluids for coal beneficiation in a hybrid geothermal/coal fired power plant. Coal beneficiation, in general, may enhance the design and operation of a power plant by the reduction of ash and sulfur. It also reduces the amount of pollutants to be removed in the emission control system.

Normally, if the run-of-mine coal is dirty and contains extraneous rubble, it is given a simple wash treatment at the mine and shipped to the customer. In the case of coals in the Western part of the United States, this is generally dispensed with since the run-of-mine coal is quite clean. Further, more complex treatments to coal in order to effect significant improvements in its charateristics, such as ash reduction or sulfur removal, is referred to as beneficiation. This may be performed by either the coal supplier or the customer.

Processes for upgrading coal for industrial uses have been developed and used on eastern coals. One process consists of wet physical gravity separation. This process involves a combination of wet jigging, wet screening, further crushing of certain fractions, wet cycloning and centrifuging for extraneous water removal. Another process, considerably more expensive, is heavy media separation. This process uses a high specific gravity liquid, or slurry which behaves as a high gravity liquid, allows floating of the higher grade coal particles and sinking of the still higher gravity waste ingredients. These processes primarily reduce ash content in the coal. 
The hybrid geothermal/coal fired power plant under consideration will be located in a giothermal resource area remotely located from the source of coal. Since fresh water is scarce and costly in many geothermal resource areas in the western states, the availability of the geothermal fluids provides a definite economic advantage. Spent geothermal fluid can be used as the water media for wet physical coal beneficiation, and can be used either hot or cold.

With the advent of strict environmental sulfur compound emissions regulations, the further beneficiation of coal in order to reduce or eliminate sulfur content has been under study during the past few years. Coal chemical treatment processes are being studied and developed as possible alternates to stack gas scrubbing in order to make effluent stack gases pass emission requirements. Some of these processes require handling the coal in a hot slurry form. The geothermal fluid can be advantageously used in place of fresh water.

The western coals, bituminous and sub-bituminous, are generally appreciably lower in sulfur and ash content than eastern coals. Since this study is based on the power plant located in the Roosevelt Hot Springs area, review of Utah coal analyses indicated that sulfur and ash content are low. Accordingly, beneficiation can be considered advantageous for on $1 \mathrm{y}$ a portion of the boiler feed coals.

\subsection{ALTERNATIVES CONSIDERED}

Coal beneficiation to remove both ash and sulfur is essentially a two part process. Processes that are effective in the removal of ash are not particularly effective in the removal of sulfur. Processes that are effective in the removal of sulfur are not effective in the removal of ash. Therefore, in order to accomplish both, a combination process would be more practical. 
In order to achieve mainly ash reduction, the two beneficiation processes considered were the wet physical separation process using water as the media and the heavy media process. The heavy media separation process is applicable to removal of pyrites sulfur from high sulfur eastern coal where the sulfur is primarily in the pyrites form. However, this situation is unlikely to occur in the low sulfur Utah coal where the sulfur is primarily organic. In addition, the heavy media process is more expensive both in capital and operating costs than the wet physical separation process. Therefore, the first process mentioned, based on a combination of water jigging, screening, multi-stage cycloning and centrifuging is considered the most desirable. Both of the processes are in commercial use.

The wet physical separation process will only remove a small percentage of pyrites sulfur, insofar that it is present as separate particles or is imbedded in ash particles. If it is desired to desulfurize western coal of, say 2 percent total sulfur content to below 0.65 percent in order to meet the 1.2 pounds $\mathrm{SO}_{2}$ stack emission per million Btu of coal fired, a costly chemical treatment of the coal in a fine ground state would be required in combination with the wet physical separation process.

The chemical cleaning processes reviewed are all in the developmental stage. Thus, there is no actual commercial operational experience. A comprehensive survey prepared for the Bureau of Mines in March, 1977 entitled "An Analysis of Chemical Coal Cleaning Processes," (See Reference 4) comparing six processes under development, and associated reports (See Reference 5), were reviewed. The six developmental processes all purport to remove 100 percent of the pyritic sulfur and little or none of the organic sulfur. These processes with major operating characteristics are summarized as follows: 


$\begin{array}{ll}\text { Process } & \text { Method } \\ \text { Hagen } & \text { Dry Fe (CO) } \\ & \text { Treatment and } \\ & \text { Magnetic Sep. }\end{array}$

KVB

Battelle

Dry $\mathrm{O}_{2}, \mathrm{~N}_{2}$, NO

$\begin{array}{ll}- & 100 \\ --\quad 100\end{array}$

TRW

Caustic Leach

Acid Leach

Ledgemont

BOM/ERDA

$-100$

$--\quad 100$

$--\quad 100$
Remova1 Percent

Ash Pyritic S Organic S

40

100

0

40

383

PSIA

${ }^{\circ} \mathrm{F}$
Pressure Temperature

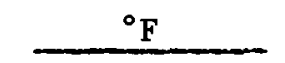

40

25

0

0

40
35

565

15-80

315

1,000
250

482

162-245

266

392

of the six processes, the last three appear to be the furthest advanced. None of these have been fully piloted. The TRW process has been partially piloted. Accordingly, the removal percentages shown can only be construed as claims, in some cases patent claims, and not proven experience.

The Ledgemont process, or a combination with the BOM/ERDA process, is the simplest process and could be expected to reach commercial status within a reasonable period of time. Practically, the chemical treatment process can be used in conjunction with the wet physical separation process where the need is to remove or reduce both ash and sulfur.

\subsection{SELECTION CRITERIA}

Beaver County, Utah, where the Roosevelt Hot Springs geothermal resource is located, is an area where fresh water is scarce with limited and expensive availability for industrial purposes. The heat-depleted geothermal fluid can be reused, in place of fresh water, for the beneficiation of that portion of the coal feed having the higher ash and higher pyrites sulfur content. 
The most feasible beneficiation system is the wet physical separation process, a gravity separation system, consisting of wet jigging, wet screening, multi-stage wet cycloning and centrifugation to effect an ash reduction to a content in the range of 6 to 7 percent. A small portion of exposed pyrites sulfur, approximately 25 percent, would also be simultaneously removed. This particular system of coal beneficiation represents a lower capital and operating cost. It is preferred because the Utah coals are generally of high quality having low ash and low sulfur content such that only a relatively small amount need be processed.

A 1 imited review of the analyses of coal in the areas which would probably supply requirements for the hybrid geothermal/coal fired power plant was made in order to estimate the extent of beneficiation which would be practical. Utah Power and Light operates several power plants in Utah. Analyses of coal used from Carbon County and Emery County, covering a total of 2,455,000 tons of sub-bituminous and 2,867,000 tons of bituminous coal over the period of 1972 through 1976 are summarized in Table 6-1 (See Reference 1). Additional State of Utah coal data from Carbon and Emery Counties was obtained from the Bureau of Mines and is also summarized in Table 6-1 (See Reference 2). Further Utah coal data, contained in the Pennsylvania State University report FE-0390-2, (See Reference 3), for special purpose coals, is also included in Table 6-1, with details shown in Table 6-2.

The average data contained in Table 6-1, and especially the source reports' detailed information, indicates the majority of Utah coal sampled to be low in sulfur and ash content, not requiring sulfur removal. Most Utah coal can be burned with no stack gas scrubbing and meet EPA regulations of 1.2 pounds $\mathrm{SO}_{2}$ per million Btu of fuel fed. A maximum average sulfur content of 0.65 percent in the coal will result in the maximum allowable stack emission of 1.2 pounds $\mathrm{SO}_{2}$ per milliion Btu charged.

The reduction of ash through beneficiation of only the high ash coal, or coal containing above 9 percent ash would appear desirable. This would 
TABLE 6-1

UTAH COAL ANALYTICAL DATA SUMMARY

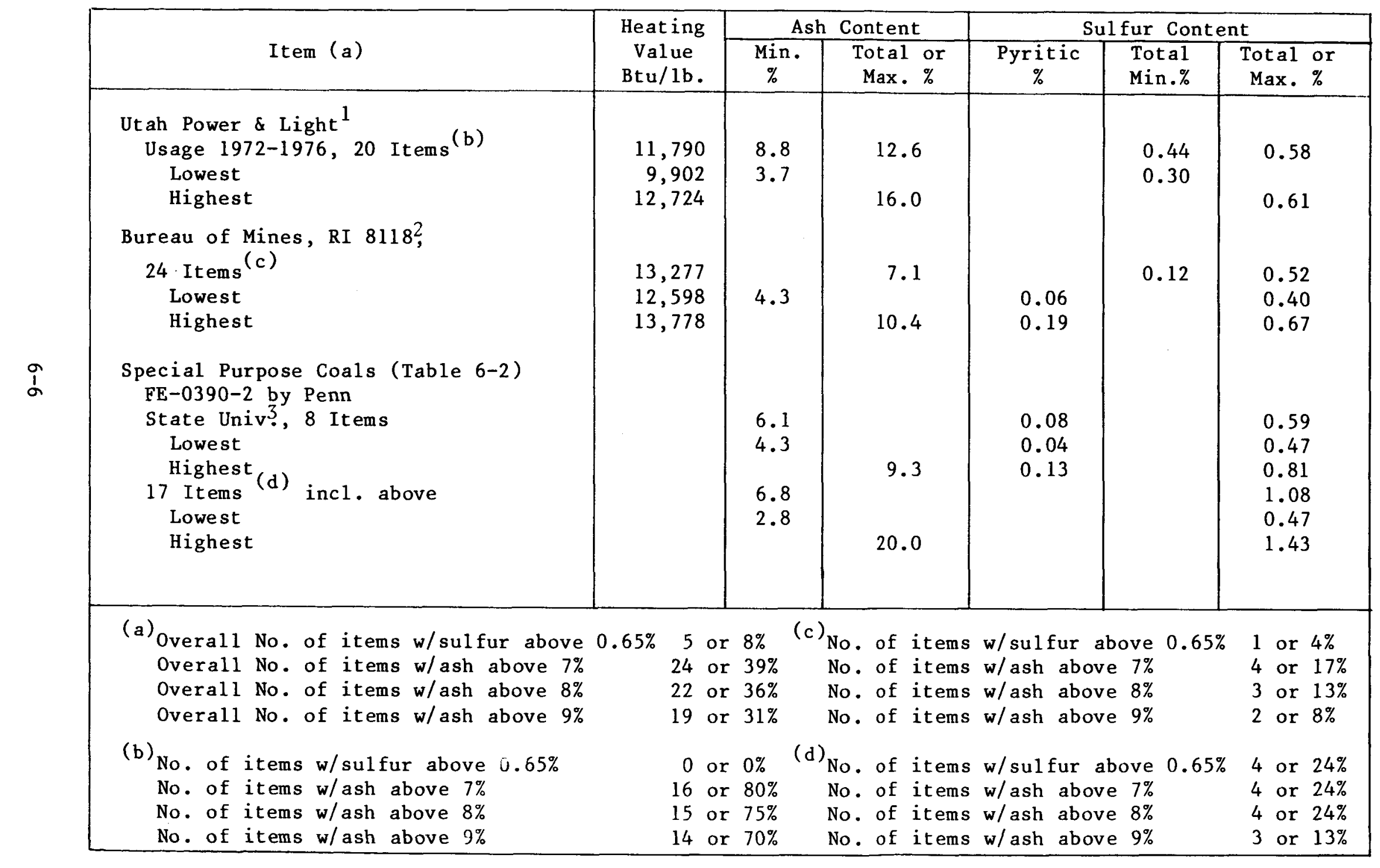


TABLE $6-2$

UTAH COAL FROM EVALUATION

AND DEVELOPMENT OF SPECIAL PURPOSE COALS

\begin{tabular}{|c|c|c|c|c|c|c|c|c|}
\hline \multirow[b]{2}{*}{$\begin{array}{l}\text { POC } \\
\text { No. }\end{array}$} & \multirow[b]{2}{*}{ Seam } & \multirow{2}{*}{$\begin{array}{l}\text { Miles } \\
\text { from } \\
\text { Mil ford }\end{array}$} & \multirow[b]{2}{*}{ Location } & \multicolumn{4}{|c|}{ Sulfur (Dry) } & \multirow[b]{2}{*}{$\begin{array}{c}\text { Ash } \\
(\text { As Rec'd.) }\end{array}$} \\
\hline & & & & $\begin{array}{c}\% \\
\text { Pyr. }\end{array}$ & $\begin{array}{r}\% \\
\mathrm{SO}_{4} \\
\end{array}$ & $\begin{array}{l}\% \\
\text { Org. }\end{array}$ & $\begin{array}{l}\% \\
\text { Total }\end{array}$ & \\
\hline 183 & Alton & 70 & Utah & 0.10 & 0.01 & 0.70 & 0.81 & 6.86 \\
\hline 184 & Castle Gate D & 140 & Helper City & 0.04 & 0.01 & 0.46 & 0.51 & 9.26 \\
\hline 185 & Castle Gate C & 95 & Kane City & 0.05 & 0.00 & 0.47 & 0.52 & 4.94 \\
\hline 186 & Castle Gate B & 95 & Kane City & 0.09 & 0.04 & 0.41 & 0.54 & 6.74 \\
\hline 245 & & 130 & Navaho & & & & 0.86 & 19.97 \\
\hline 247 & & 95 & Kanab & & & & 0.76 & 5.55 \\
\hline 248 & & 70 & Alton & & & & 0.59 & 6.06 \\
\hline 250 & & & Last Chance & & & & 0.60 & 4.39 \\
\hline 252 & & 100 & Kaiparowitz & & & & 0.55 & 10.08 \\
\hline 253 & & 188 & Coalville & & & & 1.43 & 2.82 \\
\hline 255 & & & Castle Valley & & & & 0.50 & 8.37 \\
\hline 256 & & & Spencer & & & & 0.53 & 4.97 \\
\hline 257 & & 140 & Castle Gate & & & & 0.53 & 5.00 \\
\hline 189 & Hiawatha & & Utah & 0.13 & 0.02 & 0.49 & 0.64 & 5.89 \\
\hline 160 & 'D' & 140 & Castle Gate & 0.09 & 0.01 & 0.37 & 0.47 & 6.62 \\
\hline 213 & Hiawatha & 128 & Hiawatha & 0.07 & 0.01 & 0.57 & 0.65 & 4.29 \\
\hline 214 & Hiawatha & 128 & Hiawatha & 0.08 & 0.00 & 0.46 & 0.54 & 4.54 \\
\hline
\end{tabular}


amount to approximately one-third of the coal. Accordingly, a coal beneficiation system, using the wet physical separation process, having a capacity of approximately 3,000 tons per day, should reduce the ash content of coal deliveries having over 8 to 9 percent ash to a range of 6 to 7 percent. The pyrites sulfur of the high ash coal would also be partially removed in the coal beneficiation processing.

\subsection{SYSTEM DESCRIPTION}

The wet physical separation process consisting of wet jigging, wet screening, wet multi-stage cyclone and centrifuge separation system selected is shown on Drawing ME-31 in Section 10. This unit processes coal to separate and discard inerts on the basis of respective specific gravities to produce a quality product with a minimum of loss.

The coal delivery trucks and railroad cars discharge into a 400-ton-capacity receiving hopper. If the coal being received indicates an ash content below 8 to 9 percent, it will be transferred by the apron feeders to belt conveyors to the reserve or active coal piles. However, if the coal being received has an analysis of greater than 8 percent ash content, it will be transferred via apron feeders to reserve storage or to the wet physical separation process. The process is described in the following paragraphs.

The receiving hopper discharges via apron feeder - continually sampled by a primary feed sampler - to a double deck raw coal vibrating screen equipped with geothermal fluid sprays. Here the raw coal is separated into three size fractions. The coarse fractions, $1-1 / 2$ inch plus and $1-1 / 2$ inch by $3 / 4$ inch, from the first and second screens respectively, are sent to a Baum $\mathrm{jig}$. The Baum jig is a U-shaped compartmented box which transmits air induced pulsations to the mixture of coal and water. This causes a prelimnary separation of coal and ash by specific gravity differences. The middings, 1-1/2 inch by $3 / 4$ inch material from the lower screen, may be directed either to the $j i g$ or cyclone circuits as may be required. The raw coal screen undersize slurry flows to the primary liquid cyclone feed sump. 


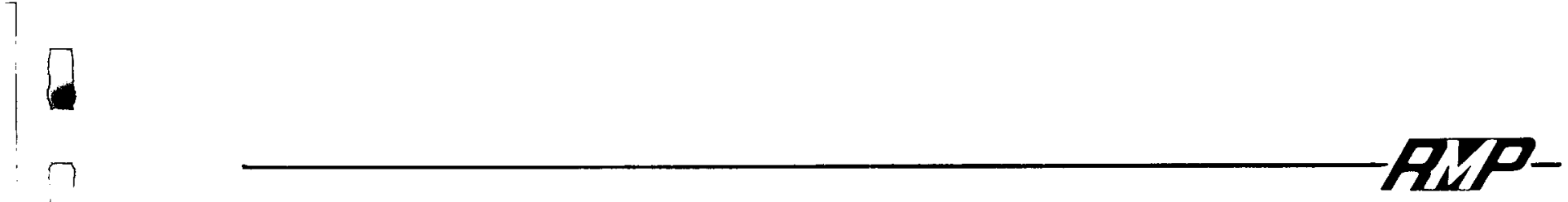

The jig yields a "float" cleancoal product which, after dewatering on a sieve bend screen with 6 mesh:slots, continues onto the vibrating double-deck coarse coal screen. Here, the coarse top-deck oversize material, plus 1-1/2 inch, is sent directly to the washed clean coal conveyor for dispatch to the clean coal active coal pile. The oversize from the bottom screen, minus $1-1 / 2$ inch plus 28 mesh, is directed to the coarse coal centrifuge, where the coal is further dewatered and deposited on the clean coal conveyor. The sieve bend underflow and the vibrating screen underflow are combined and sent to the primary cyclone feed sump.

The $\mathrm{jig}$ middiing product, consisting of locked coal and stone material, is crushed to minus $3 / 4$ inch size by a middlings roll crusher. Crushing to a smaller size causes substantial parting of coal from inert material. The crushed product is directed to a secondary cyclone feed sump. The jig waste product, mostly heavy inert material is discharged and sent to the refuse vibrating screen where the plus $3 / 4$ inch material is dewatered and discharged onto the plant refuse conveyor for transfer to a refuse hopper. The undersize refuse screen material, which contains a fair quantity of coal, flows to the secondary liquid cyclone circuit sump.

The primary cyclone feed sump contents, consisting of the undersize material from the raw coal screen and coarse coal screen, are pumped to a battery of primary cyclones, which yields a low specific gravity clean coal overflow product. This product is delivered to a dewatering fine sieve bend screen having 32 mesh slots which, in turn, feeds a wet fine coal vibrating screen where the minus $3 / 4$ inch plus 9 mesh product is removed and sent for further dewatering to the fine coal centrifuges. The centrifuges discharge the coal to the product conveyor with the other clean coal size fractions. The centrifuge liquid discharge stream returns to the fine clean coal screens.

The underflow high specific gravity primary cyclone product flows to the secondary feed sump where it joins the crushed jig middling product and the refuse screen underflow to form the feed to the battery of secondary cyclones. The overflow low-specific gravity product joins the other 
materials, forming the primary cyclone circuit feed. The secondary cyclone underflow product goes to the plant sump for pumping to the tailings basin. Suspended fine solids, mostly inert material, settles out and may be periodically dredged out for final disposal.

A clean geothermal fluid circuit is provided that treats the primary cyclone clean coal product screen undersize material by means of successive closed circuit classifying and polishing cyclone batteries. Clean geothermal fluid from the classifying cyclones is recovered and flows to the head tank, which provides screen spray fluid and jig dilution fluid. Makeup geothermal fluid is recovered, in part, from the tailings basin.

The geothermal fluid circulating volume through the process approximates 2,000 gallons per minute. On a once-through basis, this would constitute the geothermal fluid requirement. On a recycle basis, as shown on Drawing ME-31, the minimum makeup rate would approximate 150 gallons per minute. Operation would probably dictate an advisable purge rate which would increase this makeup rate. The coal losses from the coal beneficiation plant are estimated to be approximately 2 percent by weight of the clean coal product stream.

The final centrifuged coal would have an average surface moisture content of approximately 8 to 10 percent. No additional drying is required prior to pulverizing and final drying with primary air. Therefore, the use of goethermal heat for coal drying is not required.

The residual geothermal fluid remaining on the coal surface introduces only an additional 2 tons per day average of salts, of which approximately one ton consists of sodium oxide. The sodium oxide originates from both sodium chloride and sodium sulfate. These salts dissociate at the combustion temperature, and the sodium oxide formed causes the slaging problems. While substantial quantities of sodiuum oxide would tend to lower ash fusion temperatures, this addition of one ton of sodium oxide to the total ash quantity of 210 tons per day would have only a negligible effect on the boiler. 


\subsection{OUTLINE SPECIFICATIONS FOR MAJOR EQUIPMENT}

\subsubsection{COAL SAMPLER}

The coal sampling system is a Denver Equipment or equivalent cutter type complete with size reduction and drive. Its purpose is to sample a fraction of the feed, grind it, split a portion out for testing and return the balance to the main stream. Design requirements are as follows:

$\begin{array}{ll}\text { Sampling Ratio } & 40: 1 \\ \text { Splitting Ratio } & 20: 1 \\ \text { Final Sample Rate } & 30 \mathrm{lb} / \mathrm{hr} .\end{array}$

\subsubsection{RAW COAL SCREEN}

The raw coal screen is a two deck unit for separating the raw feed coal into three fractions, coarse, intermediate and fine sizes. Design conditions are as follows:

$\begin{array}{ll}\text { Type } & \text { Vibrating, double deck wet } \\ \text { Capacity, tons per hour } & 200 \\ \text { Size, ft. (W } \mathrm{W} \mathrm{L}) & 6 \times 16 \\ \text { Top screen } & 1-1 / 2 \text { inch, heavy wire mesh, stainless steel } \\ \text { Bottom screen } & 3 / 4 \text { inch, heavy wire mesh, stainless steel } \\ \text { Drive, hp } & 30\end{array}$

\subsubsection{BAUM JIG}

The Baum jig is a rectangular U-shaped compartmented box equipped with an air blower. Air induced pulsations are transmitted to the mixture of coal and water. Separation of the coal into three fractions are effected on the bases of specific gravity. The lighter product, coal having a specific gravity of 1.3 to 1.4 , is floated to the top and discharged out the far end of the jig. Waste material (rubble, ash particles, pyrites sulfur), 
having a specific gravity of approximately 2 and higher, settle to the bottom and is discharged as it accumulates. The middlings, composed of a mixture of coal and inert particles, having specific gravities in the range of 1.5 to 1.9 are discharged at an intermediate level at the end of the jig.

$\begin{array}{ll}\text { Capacity, tons per hour } & 110 \\ \text { Washing Area } & \begin{array}{l}\text { Standard No. } 2 \text { box with } 2 \text { primary } \\ \text { and } 3 \text { secondary cells }\end{array} \\ \begin{array}{l}\text { Elevator motors, hp } \\ \text { Air blower: }\end{array} \\ \begin{array}{l}\text { Capacity, cfm } \\ \text { Pressure, psig }\end{array} \\ \text { Drive, hp }\end{array}$

\subsubsection{REFUSE SCREEN}

The refuse screen is a single deck unit for wet screening and washing the heavy waste stream from the Baum jig. the coarse material discharging off the screen is mainly waste having a near nil coal content. The finer material passing through the screen will have a fair quantity of attached coal particles and is discharged to the cyclone circuits.

Type

Capacity, tons per hour

Size, ft. ( $W \times L)$

Screen

Drive, hp
Vibrating, single deck, wet

30

$3 \times 7$

$3 / 4$ inch, heavy wire mesh, stainless steel $7-1 / 2$

\subsubsection{MIDDLINGS CRUSHER}

The middings crusher is a single roll coarse crusher capable of breaking lumps as large as 6 inches to minus $3 / 4$ inch size. 


$\begin{array}{ll}\text { Capacity, tons per hour } & 20 \\ \text { Size, inches } & 12 \times 24 \\ \text { Drive, hp } & 15\end{array}$

\subsubsection{COARSE COAL SIEVE BEND AND SCREEN}

This combination of sieve bend and vibrating screens is for dewatering and separating the high grade coal from the Baum jig. The coarse, plus $1-1 / 2$ inch, coal off the top deck is sufficiently dewatered that it can be sent to the stock pile. The plus 28 mesh coal off the second deck, being fine and holding water, is sent to a centrifuge for further dewatering. The minus 28 mesh coal-water slurry flows from the bottom of the screen to the cyclone circuits. Design requirements are as follows:

Coarse Coal Sieve Bend

Capacity, tons per hour 80 coal, 190 water

Size 5 feet wide $x 32$ inch

Slots

6 mesh

\section{Coarse Coal Screen}

Type

Capacity, tons per hour

Size, ( $f t$. ( $W \times L)$

Top screen

Bottom screen

Drive, hp
Vibrating, double desk, wet

80 coal

$5 \times 16$

1-1/2 inch heavy stainless steel wire mesh 28 mesh, stainless steel

30

\subsubsection{FINE COAL SIEVE BEND AND SCREEN}

This combination of sieve bend and vibrating screens is for dewatering and separating coal fines from the cyclone circuit streams. 
Fine Coal Sieve Bend

Capacity, tons per hour

Size

slots

Fine Coal Screen

Type

Capacity, tons per hour

Size, ft. (W $x$ L)

Screen

Drive, hp
150

6 feet wide $x 32$ inch

32 mesh

Vibrating, single deck, wet 150

$6 \times 16$

32 mesh, stainless steel

25

\subsubsection{PRIMARY CYCLONE CIRCUIT}

The primary cyclone circuit includes two feed sumps, pump and spare and two primary cyclones for separation of minus $3 / 4$ inch coal into a clean coal overflow and mixed coal and inert underflow. Design requirements are as follows:

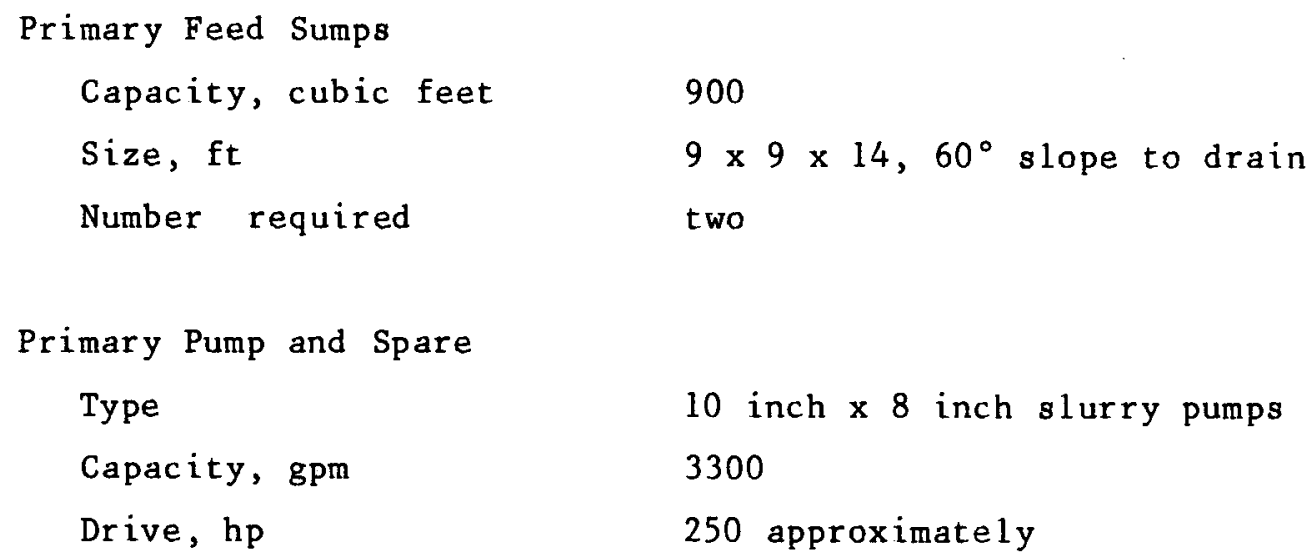

900

$9 \times 9 \times 14,60^{\circ}$ slope to drain

two

Cyclones

Type

Ceramic lined hydroclone

Size

20 inch ID approximately

Number required

two
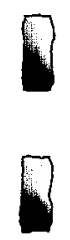
Classifying pump and spare

Type, inch

Capacity, g pm

Drive, hp

Cyclones

Type

Size

Number Required
$10 \times 8$ slurry pump

2800

150 approximately

Ceramic lined

10 inch ID

10

\subsubsection{POLISHING CYCLONE CIRCUIT}

The polishing cyclone circuit includes a feed sump, pump and spare and a battery of polishing cyclones for separation of coal fines into a mixed coal and inert overflow and an inert underflow. Design requirements are as follows :

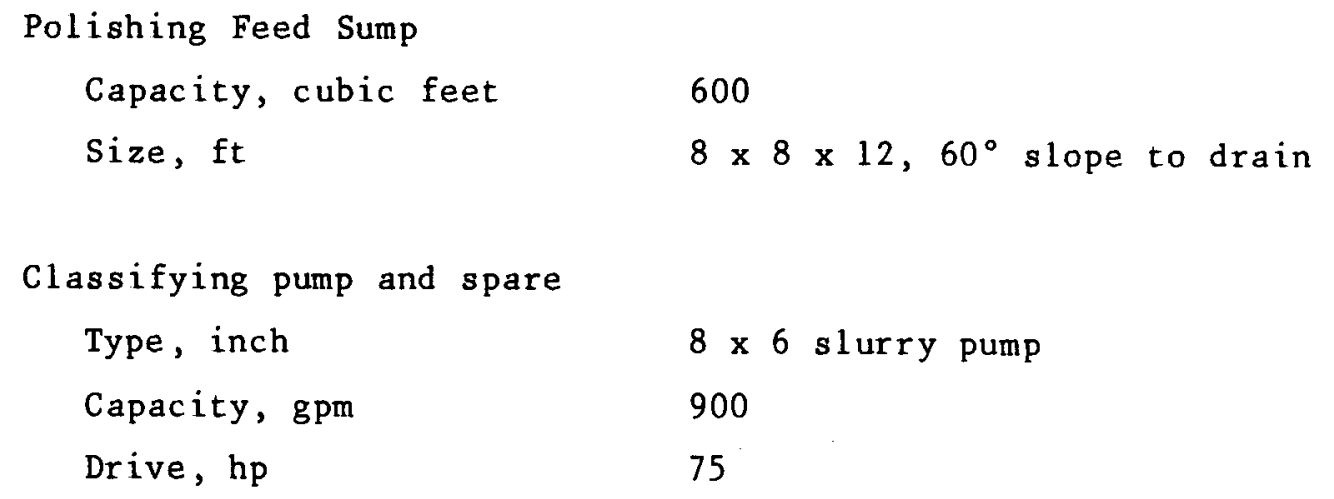

Cyclones

$\begin{array}{ll}\text { Type } & \text { Ceramic lined } \\ \text { Size } & 8 \text { inch ID } \\ \text { Number required } & 4\end{array}$

\subsubsection{COARSE COAL CENTRIFUGE}

The coarse coal centrifuge is used for final dewatering of the 1-1/2 inch $\times 28$ mesh coarse coal. Part of the time dewatering at the coarse 
coal screen may suffice so that the centrifuge may be bypassed. In case of screen blinding the centrifuge can be used for final dewatering. Design requirements are as follows:

$\begin{array}{ll}\text { Capacity, tons per hour } & 20 \\ \text { Size, inch diameter } & 24 \\ \text { Drive, hp } & 15 \\ \text { Number required } & \text { one }\end{array}$

\subsubsection{FINE COAL CENTRIFUGES}

The fine coal centrifuges are provided for final dewatering of the plus 32 mesh coal received from the fine coal screen. Design requirements are as follows:

$\begin{array}{ll}\text { Capacity, tons per hour } & 20 \\ \text { Size, inch diameter } & 36 \\ \text { Drive, hp } & 25 \\ \text { Number required } & \text { two }\end{array}$

6.5.14 GEOTHERMAL HEADTANK

The headtank provides intermediate fluid storage equivalent to twelve minutes of operating requirements. The pumps deliver the water at the pressure required for screen spray operation and to the jig. Design requirements are as follows:

Size, ft (Diameter $\times \mathrm{H}$ ) $12 \times 18$

\subsubsection{REFUSE CONVEYOR AND HOPPER}

The refuse conveyor transports the waste material from the refuse screen to the refuse hopper from which trucks are loaded. Design requirements are as follows: 
Refuse Conveyor

$\begin{array}{ll}\text { Type } & \text { Belt conveyor, } 30^{\circ} \text { trough } \\ \text { Size } & 10 \text { inch wide } x 200 \text { feet long } \\ \text { Drive, hp } & 5\end{array}$

6.5.16 CLEAN COAL CONVEYOR

The clean coal conveyor transfers the cleaned coal to the coal storage conveyor. Design requirements are as follows:

$\begin{array}{ll}\text { Type } & \text { Belt conveyor, } 30^{\circ} \text { trough } \\ \text { Size } & 24 \text { inch wide } \times 100 \text { feet long } \\ \text { Drive, hp } & 15\end{array}$

\subsubsection{PLANT SUMP}

The plant sump is a concrete basin equipped with a sump pump. It receives the slurry underflow from the secondary and polishing cyclones. The slurry is pumped to the tailings pond where the inert fine solids are settled. Design requirements are as follows:

$$
\begin{array}{ll}
\text { Capacity, cubic feet } & 600 \\
\text { Size, ft } & 8 \times 8 \times 12,60^{\circ} \text { slope to drain }
\end{array}
$$

\subsubsection{RECIRCULATING PUMP}

The recirculating pumps is used for recycling clarified geothermal fluid from the tailings pond back to the head tank and for other requirements, such as pump gland water. Design requirements are:

$\begin{array}{ll}\text { Type } & \text { Sump pump, self priming } \\ \text { Capacity, gpm } & 250, \text { approximately } \\ \text { Drive, hp } & 10\end{array}$




\subsection{CONCLUSIONS}

The desirability and economic feasibility of coal beneficiation is highly dependent on the coal characteristics, the site location, and applicable emission standards to be met. Furthermore, in a hybrid geothermal/coal fired power plant, the geothermal fluids will have a bearing on the feasibility of coal beneficiation in that it will supplant the use of fresh water. No reliable assessment of the cost and benefits from coal beneficiation can be made on the basis of generic studies or generalized analysis as it relates to a specific situation.

Based on the coal beneficiation system described in this section, an estimate of capital costs and operating expenses specifically related to the beneficiation of Utah coal was made, and is described in Paragraph 8.2.4, in Section 8, Cost Estimates and Schedule. 
LITERATURE CITED

1. Asbury, J. G., H. T. Kim, and A. Kouvalis. "Survey of Electric Utilty Demand for Western Coal." Report ANL/SPG-1, Argonne National Laboratory, Energy and Environmental Systems Division. Prepared for the U.S. Energy Research and Development Administration under Contract W-31-109-Eng-38, January 1977.

2. Cavallaro, J. A., et. al. "Sulfur Reduction Potential of the Coals of the United States." Report of Investigation 8118, Bureau of Mines, U.S. Department of the Interior, 1976.

3. Spackman, W., et. al. "Evaluation and Development of Special Purpose Coals." Report FE-0930-2, Coal Research Section, The Pennsylvania State University. Prepared for the U.S. Energy Research and Development Administration under Contract E(49-18)-0390, September 1976.

4. Ergun, S., R. R. Oder, L. Kulapaditharom and A. K. Lee. "An Analysis of Chemical Coal Cleaning Processes." Prepared for Bureau of Mines, U.S. Department of the Interior by Bechtel Corporation under Contract J0166191, March 1977.

5. McGraw, R. W. and G. Janik. "MCSS - Implementation at Homer City", Presented at the Third Symposium on Coal Preparation, Louisville, Kentucky, October 17-24, 1977. 
The geothermal heaters are the finned tube type. Geothermal fluid from the well flows inside the tubes while combustion air is allowed to pass around the finned tube surfaces. The system is designed to maintain the combustion air temperatures entering the Ljungstrom air preheaters at $90 \mathrm{~F}$ during the most severe weather conditions when outdoor air temperature will approach 0 F.

\subsubsection{OUTLINE SPECIFICATIONS}

\subsubsection{Geothermal Air Preheaters}

Two half capacity finned tube type geothermal air preheaters are provided. Each heater consists of 16 coils. Each coil is $37-1 / 2$ inches high with 12 foot nominal tube lengths, and has two rows of stainless steel tubes with copper fins. Other design conditions are:

$\begin{array}{lr}\text { Air flow, lb/hr per heater } & 2,820,000 \\ \text { Design air temperature In, F } & 0 \\ \text { Design air temperature Out, F } & 90 \\ \text { Design geothermal liquid temperature In, F } & 475 \\ \text { Design geothermal liquid temperature Out, F } & 100 \\ \text { Normal geothermal 1iquid flow, lb/hr } & 72,550 \\ \text { Maximum geothermal liquid flow, 1b/hr } & 80,000 \\ \text { Pressure drop on air side, in } \mathrm{H}_{2}{ }^{2} & 3 \\ \text { Pressure drop on geothermal liquid side, psi } & 20\end{array}$

\subsection{FLUE GAS REHEATING}

In a conventional coal fired power plant, steam coil flue gas reheaters are provided to raise the temperature of the flue gas leaving the scrubber and prior to leaving the stack. The purpose of reheating is primarily to elevate the flue gas temperatures above the $\mathrm{SO}_{3}$ dew point level to prevent stack corrosion, and secondarily to provide greater stack gas buoyancy for a more desirable plume dispersion. 


\subsubsection{SYSTEM DESCRIPTION}

The maximum total estimated heat load for flue gas reheating is approximately $110,000,000$ Btu per hour. Five one-fifth capacity flue gas reheaters are provided. Each reheater is placed in the discharge duct of one of five flue gas desulfurizatrion system modules. Each reheater raises the flue gas temperature from $116 \mathrm{~F}$ to $170 \mathrm{~F}$ before it enters the stack. Use of geothermal fluid for flue gas reheating replaces approximately 112,000 pounds per hour of extraction steam.

As shown on Drawings ME-26 and ME-27 in Section 10, flue gas is supplied to the $\mathrm{SO}_{2}$ scrubber modules by four 25 percent capacity induced draft fans at an approximate pressure of +12 inches of water. Flue gas leaving the $\mathrm{SO}_{2}$ scrubber modules enters the geothermal flue gas reheaters. The geothermal reheaters are of finned tube construction. Geothermal liquid from the wells flows inside the tubes while flue gas is allowed to pass around the finned tube surfaces. The system is designed to heat the flue gas at full load up to $170 \mathrm{~F}$.

\subsubsection{OUTLINE SPECIFICATIONS}

\subsubsection{Geothermal Flue Gas Reheaters}

Five twenty percent capacity geothermal flue gas reheaters are provided. Each reheater consists of 14 coils. Each coil is 37-1/2 inches high with 12 foot nominal tube lengths, and has two rows of stainless steel tubes with outside copper fins. Other design conditions are:

$\begin{array}{lc}\text { Flue gas flow, lb/hr per reheater } & 1,660,000 \\ \text { Flue gas temperature In, F } & 116 \\ \text { Flue gas temperature Out, F } & 170 \\ \text { Geothermal liquid temperature In, F } & 475 \\ \text { Geothermal liquid temperature Out, F } & 200 \\ \text { Geothermal liquid flow, 1b/hr per reheater } & 74,340\end{array}$




\subsection{PLANT SPACE HEATING}

Normal plant space heating requirements vary substantially from season to season and sometimes from one year to the next. Conventional heating systems are designed to provide adequate space heating during the most severe climate conditions. For the purpose of estimating the heating requirements of the hybrid plant, space heating is provided by a hot water system. Design temperature of $O F$ is assumed for buildings and enclosed facilities. The design temperature will be determined for the specific site during the preliminary design phase.

\subsubsection{SYSTEM DESCRIPTION}

The average winter space heating load for the above mentioned design condition for the entire plant is estimated at 7,000,000 Btu per hour. Maximum load under the design conditions is estimated at $12,000,000$ to $14,000,000$ Btu per hour. Use of geothermal fluid for plant space heating, therefore, replaces approximately 12,000 pounds per hour of extraction steam.

The plant space heating system is a centralized hot water system. Chemically treated hot water is circulated through thermally insulated piping to individual air heating units located throughout the plant. Water leaving the individual air heating units is returned to the central system where it is passed through shell and tube heat exchangers, heated from $180 \mathrm{~F}$ to $200 \mathrm{~F}$ using geothermal liquid, and returned to the air heaters. A reservoir of approximately 2000 gallons capacity is provided for water expansion and makeup water requirements.

Geothermal fluid from the we $11 \mathrm{~s}$ at $475 \mathrm{~F}$ is piped to the tube side of the two half capacity heat exchangers. The geothermal fluid leaves the heat exchangers at $200 \mathrm{~F}$ and is returned to the hot and cold brine system. Figure 7-1 shows the Plant Heating System, and as can be seen from this figure, the hot water system temperature regulates the flow of geothermal 


\section{$\therefore \ldots \ldots \ldots \ldots$}

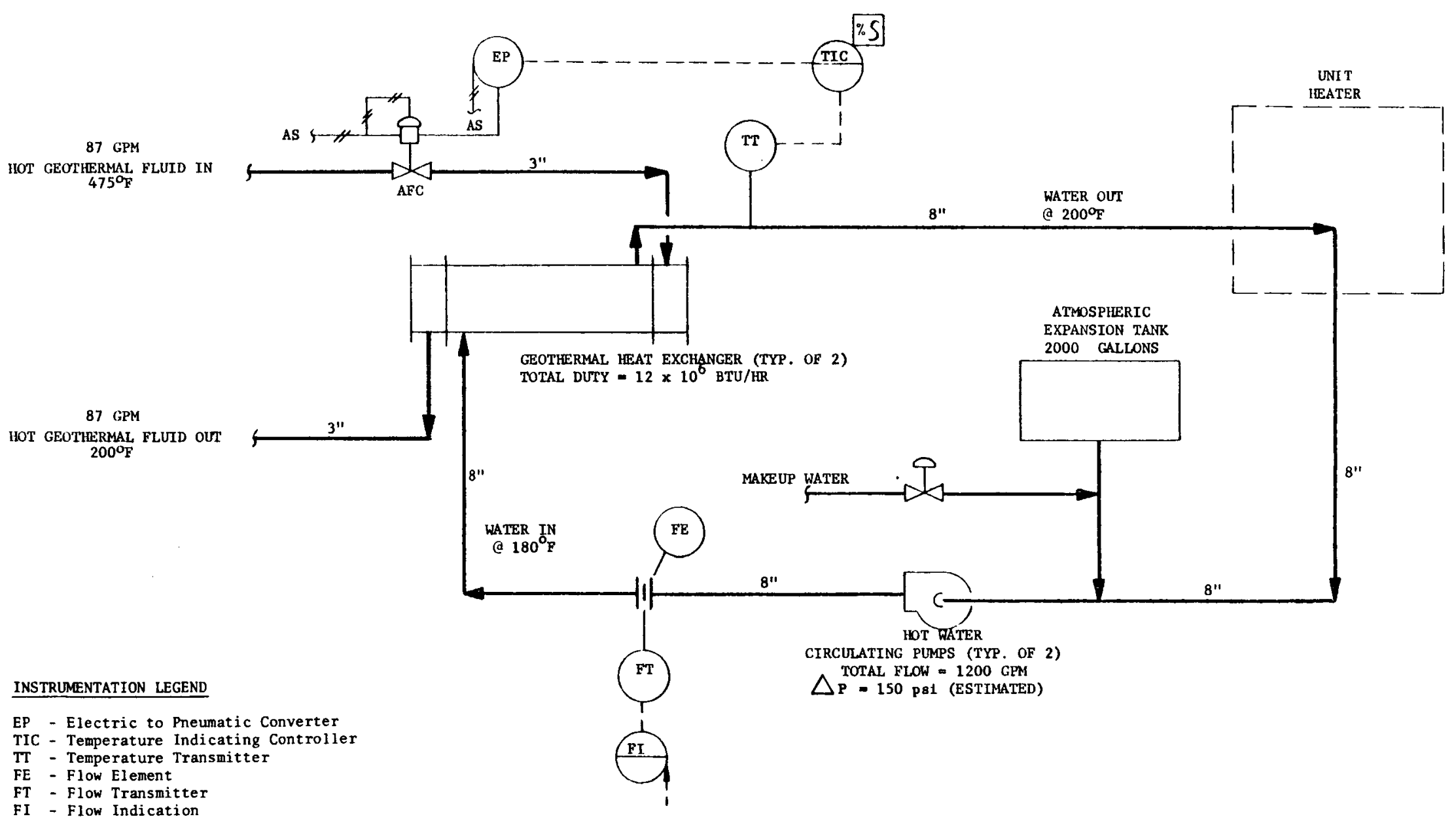

FIGURE 7-1 - CONCEPTUAL DIAGRAM 
fluid to the heat exchangers. Thus, a constant temperature of $200 \mathrm{~F}$ is maintained in the hot water supply header when this system is in operation.

\subsubsection{OUTLINE SPECIFICATIONS}

\subsubsection{Geothermal Heat Exchanger}

The geothermal heat exchanger is a straight tube, tube and shell type heater with all stainless steel 304 construction. Geothermal fluid flows in the tubes while the hot water flows on the shell side. Design conditions are as follows:

\section{Shell Side Tube Side}

Fluid circulated

Fluid flow, lb/hr per heater

Temperature in, $\mathbf{F}$

Temperature out, F

Operating pressure, psig

Pressure drop, psi

No. of passes per shell

Heat exchanged, Btu/hr

Transfer rate, Btu/Ft ${ }^{2}-\mathrm{hr}-\mathrm{F}$

Design pressure, psig

Design temperature, $F$

Total heat transfer area, $\mathrm{Ft}^{2}$

Corrosion allowance, inches
Treated Water Geothermal Fluid

600

43.5

180

475

200

200

150

550

15

15

1

$6,000,000$

135

200

650

500

500

\subsubsection{Expansion Tank}

One 2000 gallon atmospheric expansion tank is provided to accommodate thermal expansion and provide transient makeup requirements for the hot water system. Tank design conditions are as follows: 
Working fluid

Operating temperature, $\mathrm{F}$

Operating pressure

Design temperature, $F$

Design pressure, psia

Capacity, gallons

Insulation

Corrosion allowance, inches
Water

200

Atmospheric fusion

300

14.7

2,000

Yes

$1 / 4$

\subsubsection{Hot Water Circulating Pumps}

Two full capacity hot water circulating water pumps are provided to circulate the hot water in the plant space heating system. Design and operating conditions for each of two pumps are as follows:

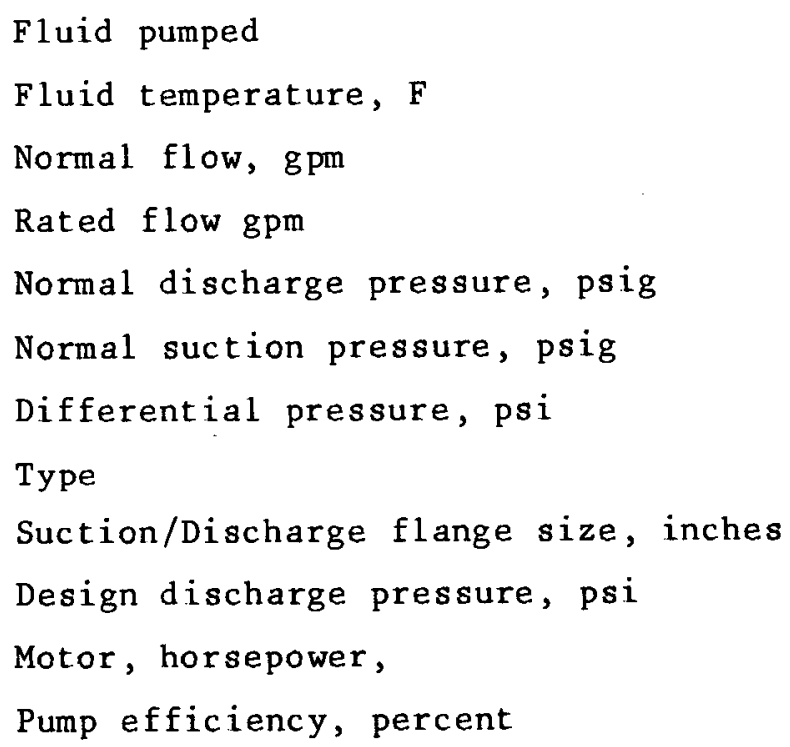

Water

180

600

600

150

0

150

Centrifugal

$6 / 6$

175

75

82

\subsection{SUMMARY}

The total contribution of geothermal heat for combustion air preheating, flue gas reheating and plant space heating may vary between $181,000,000 \mathrm{Btu}$ per hour and $241,000,000 \mathrm{Btu}$ per hour, depending upon the 
outside air temperature. Total geothermal fluid flow in the three systems varies between 120,000 and 155,000 pounds per hour. The heat input to the hybrid plant resulting from these systems is equivalent to a savings in coal of between 8 and 10.5 tons per hour which converts to an approximate annual cost savings of $\$ 1,000,000$ to $\$ 1,400,000$ based on 1976 coal cost figures. Escalated fuel costs and corresponding fuel savings, equipment, operating and maintenance costs are incorporated in the total energy costs in Section 9, Paragraph 9.3. 
SECTION 8

COST EST IMATES AND SCHEDULE

\subsection{COST ESTIMATE AND SCHEDULE CRITERIA}

In the preparation of the base case conceptual design cost estimates presented herein, Parsons relied heavily on the Intermountain Power Project Cost Estimate taking into consideration the differences in plant size, generating capacity, and effects of using geothermal fluids as a heat source. To a lesser extent, the cost estimate presented in the City of Burbank Report was used primarily in the areas of geothermal well and coal costs. No attempt was made to verify or validate the above mentioned cost estimates since specific detailed breakdown of costs were not available, nor was it within the scope of this study.

The conceptual design cost estimates for additional power, makeup water, coal beneficiation, and other geothermal systems were developed from vendor budgetary prices and respective installation cost estimates, as well as Parsons current cost estimating practices and procedures. All costs for the remaining systems in the plant which were affected either in size, capacity, or design, by these geothermal systems, were derived from the IPP cost estimate as in the base case cost estimate.

The basis for the overall plant schedule presented herein is the preliminary schedule developed for the IPP plant, input from Environmental Research \& Technology, Inc. on the environmental aspects, and Parsons experience on similar type projects. The preliminary schedule prepared by Parsons was used in the preparation of the economic analyses for the hybrid plant, but was not used in the cost estimate since the cost estimate reflects costs as of January 1976. 


\subsection{COST ESTIMATE}

The conceptual design cost estimate of the hybrid geothermal/coal fired power plant is presented in several parts. First, in the base case, the total installed capital cost comprised of direct and indirect costs was prepared to include only the impact of the geothermal feedwater heating aspects of the hybrid plant. The other parts reflect the cost impact of the additional investigations on the total installed cost of the hybrid plant and is presented in Paragraphs 8.2.2 through 8.2.5. The cost estimate is formatted the same as in the City of Burbank Report, and is comparable but does not include the well costs which were estimated by the City of Burbank.

\subsubsection{GEOTHERMAL FEEDWATER HEATING}

Cost estimates of geothermal equipment for the hybrid plant are based on manufacturers budgetary estimates, whereas costs developed for the remaining portion of the plant are based on the IPP Project Cost Estimate, Section 4, Tables 4-1 and 4-2. The hybrid plant is limited to approximately 715 MW net power generation, whereas the IPP plant net capacity was $750 \mathrm{MW}$. Equipment costs for which the IPP Project Cost document was used as a base required adjustments to reflect either a decrease or increase in size or capacity. The introduction of the geothermal heat source also affected the size and capacity of a number of major pieces of equipment and systems in addition to the variation in plant capacity. The IPP Project Cost Estimate is a cost estimate for a four unit $3000 \mathrm{MW}$ coal fired power plant. Various systems included in the parsons conceptual cost estimate were partially accounted for in the IPP Project Cost Estimate as common facilities. Individual consideration was given for each system or equipment, for which a "common facilities" entry was provided, to determine the estimated cost for a one unit plant.

\subsubsection{Basis of the Cost Estimate}

The costing bases for this conceptual design cost estimate are as follows: 
(1) The total plant net electrical power output is approximately 715,000 kilowatts.

(2) Major equipment costs, as discussed above, were developed from equipment manufacturer cost estimates or were extrapolated and factored from the IPP project capital cost estimate. Equipment and system cost estimates obtained by extrapolation and factoring were developed, taking into account price versus capacity or price versus size relationships, using Parsons estimating procedures. Extrapolation and factoring were based on ratios of IPP versus the hybrid plant for one or more of the following factors:

- Coal Feed Rate

- Steam Flow

- Feedwater Flow

- Condensate Flow

- Circulating Water Flow

(3) The costing basis is as of January 1976, unescalated.

\subsubsection{Included in the Cost Estimate}

The costs for the following items are included in the cost estimate:

(1) Site clearing, grading, excavation, and piling as required.

(2) Bulk materials and the labor of installation. 
(3) Mechanical and electrical equipment, vessels, tanks, structures, conduit, wire, busways, cable, heating, ventilating, and air conditioning, water supply system, waste management systems, miscellaneous site systems, miscellaneous plant electrical systems, coal handing systems, fire protection, plumbing, roofing, painting and related items, and the labor of installation.

(4) Contractor's insurances, overhead and fee.

(5) Indirect costs such as project management and administration, engineering overheads, public relations, legal services, project field engineering and inspection, surveying, construction facilities and other items as listed in the estimate under the heading of "Indirect Costs."

\subsubsection{Excluded From the Cost Estimate}

The costs for the following items have been excluded from the cost estimate:

(1) Quality assurance requirements on materials, equipment and construction over and above those normally obtained on an industrial project

(2) Licenses, fees and royalties

(3) Fuels, lubricating oils and related items

(4) Spare parts 
Tests other than those normally provided by a construction contractor

(6) Insurance coverage over and above that which is norma11y required for engineering and construction

(7) Escalation and contingencies

(8) Geothermal wells

\subsubsection{Cost Estimate Summary}

The estimated total constructed capital cost for the hybrid plant, considering geothermal feedwater heating only (base case), including direct and indirect costs is $\$ 385,841,000$, in January 1976 dollars, or approximately $\$ 540$ per installed kilowatt of net generating capacity. Table 8-1, the cost estimate summary for the hybrid plant, identifies the major items and their respective estimated costs as well as the total indirect costs. The items included in indirect costs and the estimated costs associated with them are shown on Table 8-2.

Contingency was not included in the cost estimate, but based on the available information and degree of accuracy of the estimate, Parsons believes a contingency of 25 percent should be included in the total plant costs.

\subsubsection{MAKEUP WATER}

The conceptual design cost estimates for the hybrid plant makeup water requirements are presented in two parts. First, the total installed capital cost of a condensate makeup water system was prepared to include the impact of using geothermal fluid for makeup water. Secondly, the total installed cost of a cooling tower makeup water system was developed to include the use of geothermal fluid as makeup water. 
Table 8-1

\section{COST ESTIMATE SUMMARY - BASE CASE}

\section{JANUARY 1976 DOLLARS}

ITEM

ESTIMATED COST

Land and Land Rights

$\$ \quad 329,000$

Structures and Improvements

$69,293,000$

Main Boiler

$52,957,000$

Draft System

$13,330.000$

$\mathrm{H}_{2} \mathrm{~S}$ Removal System

$2,645,000$

$\mathrm{SO}_{2}$ Scrubber System

$39,517,000$

Electrostatic Precipitators

$20,248,000$

Feedwater and Condensate System

$17,903,000$

Industrial Waste Water and Oil Systems

$1,180,000$

Coal Handling System

$6,120,000$

Ash Handling System

$2,631,000$

Piping

$5,511,000$

$5,267,000$

Instrumentation and Controls

$32,781,000$

Circulating Water and Cooling Water Systems

$11,507,000$

Accessory Electric Equipment

$8,371,000$

Auxiliary Equipment and Mechanical Systems

$4,352,000$

Insulation

912,000

Miscellaneous Power Plant Equipment

$3,860,000$

SUBTOTAL

$\$ 298,714,000$

Indirect Costs (from Table 8-2)

$\$ 87,127,000$

TOTAL ESTIMATED COST (One Unit)

$\$ 385,841,000 *$

*The total estimated cost does not include the costs of the geothermal wells. The City of Burbank estimates the cost of geothermal wells at $\$ 6,090,000$. 
Table 8-2

BASE CASE

INDIRECTS

Project Management and Administration

$\$ 3,187,000$

Engineering Overheads

$16,815,000$

239,000

Project Field Engineering and Inspection

$3,136,000$

547,000

Construction Facilities

$6,243,000$

Construction Services

$8,185,000$

Construction Equipment, Tools and Supplies

$10,336,000$

Field Office Costs

$10,485,000$

Preliminary Operations and Testing

$7,109,000$

Payroll Expense

$8,334,000$

Insurance

State and Local Taxes

$1,225,000$

418,000

Other Construction Costs

836,000

Preliminary Costs - Prior to Detailed Design

$4,058,000$

General Contractor's Fee

$5,974,000$

TOTAL INDIRECT COSTS

$\$ 87,127,000$ 


\subsubsection{Condensate Makeup}

8.2.2.1.1 Basis of the Cost Estimate. The costing basis for this conceptual design cost estimate is the same as for the base case, defined in Paragraph 8.2.1.1, except as follows:

(1) Total condensate makeup water system capacity is 120 gallons per minute.

(2) Major equipment costs were based on budgetary estimates supplied by equipment manufacturers. Installation estimates were factored from other similar projects estimated previously.

8.2.2.1.2 Cost Estimate Summary. The estimated total constructed cost for the condensate makeup water system, including direct and indirect costs is $\$ 940,000$, in January 1976 dollars. This cost is about $\$ 400,000$ higher than the cost of the condensate makeup water system for the base case. Table 8-3, the cost estimate summary for the condensate makeup water system identifies the major items and their respective estimated costs as we 11 as the total indirect costs. Indirect costs comprise approximately 29 percent of the total direct costs.

\subsubsection{Cooling Tower Makeup}

8.2.2.2.1 Basis of the Cost Estimate. The costing basis for this conceptual design cost estimate is the same as for the base case, defined in Paragraph 8.2.1.1, except as follows: 
Table 8-3

CONDENSATE MAKEUP WATER SYSTEM

COST ESTIMATE SUMMARY

JANUARY 1976 DOLLARS

ITEM

ESTIMATED COST

Equipment Foundations \& Supports

Blow-Down Heat Exchanger

Evaporator Deaerator

Evaporator

Low Pressure Feedwater Heater 1-A

Condensate Makeup Demineralizer

Pumps

Piping

Electrical

Instrumentation \& Controls

Insulation

SUBTOTAL

Indirect Costs

ESTIMATED COST - NEW EQUIPMENT

ESTIMATED COST - REPLACED EQUIPMENT

TOTAL ESTIMATED COST INCREASE
$\$ 25,000$

12,000

17,000

110,000

110,000

230,000

11,000

125,000

50,000

15,000

20,000

$\$ 725,000$

$\$ 215,000$

$\$ 940,000$

$(540,000)$

$\$ 400,000$ 
(1) The total cooling tower makeup system capacity is 9000 gallons per minute.

(2) Major equipment costs were based on budgetary estimates supplied by equipment manufacturers. Installation estimates were factored from other similar projects estimated previously.

\subsection{Cost Estimate Summary. The estimated} total constructed cost for the cooling tower makeup water system, including direct and indirect costs is $\$ 2,320,000$, in January 1976 dollars. This figure is in addition to the estimated costs for the base case. Table 8-4, the cost estimate summary for the cooling tower makeup water system, identifies the major items and their respective estimated costs as well as the total indirect costs. Indirect costs amount to about 29 percent of the total direct costs.

\subsubsection{ADDITIONAL POWER}

The conceptual design cost estimate for the all geothermal plant is presented in a similar format to those previously discussed.

\subsubsection{Basis of the Cost Estimate}

The basis for this conceptual design cost estimate is the same as for the base case, defined in Paragraph 8.2.1.1, except as follows :

The total all geothermal power plant net electrical power output is approximately 65,400 kilowatts.

(2) The costs for the turbine generator unit and the accessory electric equipment were based on budgetary quotations supplied by the equipment manufacturers. 
Table 8-4

COOLING TOWER MAKEUP WATER SYSTEM

COST ESTIMATE SUMMARY

JANUARY 1976 DOLLARS

ITEM

ESTIMATED COST

Equipment Foundations \& Supports

Clarifier

Degasifier

Gravity Filter

Transfer Pumps

Piping

Electrical

Instrumentation \& Controls

Insulation

SUBTOTAL

Indirect Costs

TOTAL ESTIMATED COST INCREASE
535,000

$\$ \quad 75,000$

550,000

240,000

460,000

155,000

150,000

85,000

50,000

20,000

$\$ 1,785,000$

$\$ 2,320,000$ 
Costs for condensers, flash tanks, condensate pumps, piping and instrumentation and controls were factored from other similar projects estimated previously.

\subsubsection{Cost Estimate Summary}

The estimated total constructed cost for the all geothermal plant including direct and indirect costs is $\$ 30,432,000$, in January 1976 dollars. This figure takes into consideration the cost savings provided by common systems between the hybrid plant and the all geothermal plant. Total constructed cost for the all geothermal plant per installed kilowatt capacity is $\$ 465$. Table 8-5, the cost estimate summary for the a 11 geothermal plant, identifies the major items and their respective estimated costs as well as the total indirect costs. The items included in indirect costs and their respective estimated costs are shown on Table 8-6.

\subsubsection{COAL BENEFICIATION}

\subsubsection{Basis of the Cost Estimate}

The costing bases for this cost estimate is the same as for the base case defined in Paragraph 8.2.1.1, except as follows:

(1) The total capacity of the coal beneficiation system is 3000 tons per day.

(2) The total system cost was factored from previous Parsons cost estimates for similar coal benefication plants.

(3) The coal analysis provided by the IPP Preliminary Engineering and Feasibility Study, Part 2 Volume 1 as well as average coal analyses for the Western United States. 
Table 8-5

ALL GEOTHERMAL PLANT

COST ESTIMATE SUMMARY

JANUARY 1976 DOLLARS

ITEM

ESTIMATED COST

Structures \& Improvements

$\$ 700,000$

Equipment Foundations \& Supports

$1,500,000$

Turbine-Generator Unit

$12,000,000$

Condensers

High Pressure Flash Tanks

$1,800,000$

330,000

Low Pressure Flash Tanks

380,000

Condensate Pumps

$1,050,000$

Piping

$3,000,000$

Accessory Electric Equipment

$2,100,000$

Instrumentation \& Controls

700,000

SUBTOTAL

$\$ 23,560,000$

Indirect Costs (From Table 8-6)

$6,872,000$

TOTAL ESTIMATED COST

$\$ 30,432,000$ 
Table 8-6

ALL GEOTHERMAL PLANT

INDIRECTS

Project Management and Administration

$\$ 251,000$

Engineering Overheads

Public Relations and Legal Services

Project Field Engineering and Inspection

Surveying

$1,326,000$

20,000

247,000

43,000

Construction Facilities

492,000

Construction Services

646,000

Construction Equipment, Tools and Supplies

815,000

Field Office Costs

827,000

Preliminary Operations and Testing

561,000

Payroll Expense

657,000

97,000

State and Local Taxes

33,000

Other Construction Costs

66,000

Preliminary Costs - Prior to Detailed Design

320,000

General Contractor's Fee

471,000

TOTAL INDIRECT COSTS

$\$ 6,872,000$ 


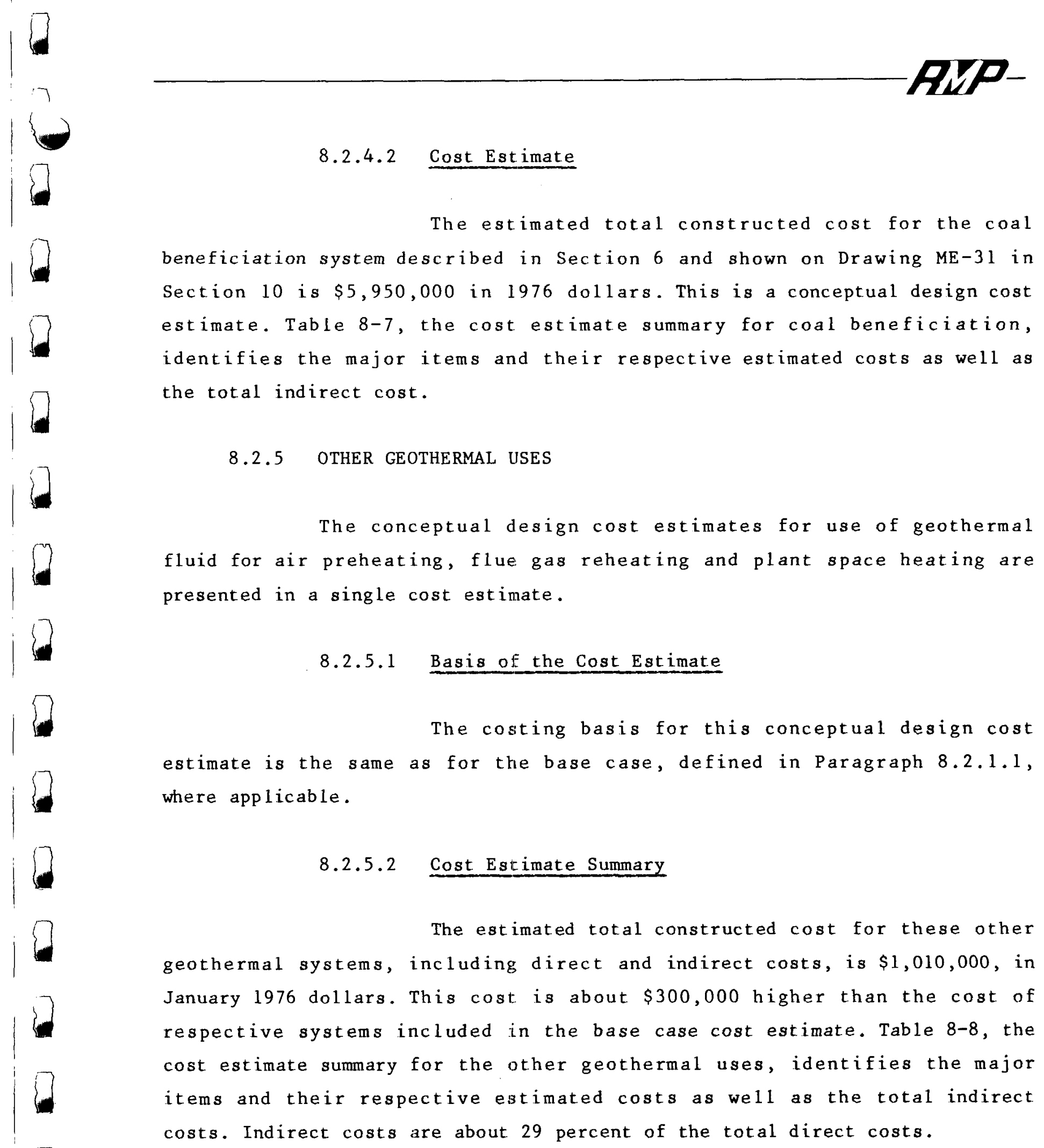


Table $8-7$

COAL BENEFICIATION SYSTEM

COST ESTIMATE SUMMARY

JANUARY 1976 DOLLARS

Equipment Foundations \& Supports

$\$ 840,000$

Coal Sampling Circuit

70,000

Screens

240,000

Baum Jig and Middlings Crusher

170,000

Cyclone Circuits

585,000

Centrifuges

240,000

Head Tank and Pumps

60,000

Piping

600,000

Conveyors, Chutes and Hoppers

155,000

Plant Sump and Tailings Basin

620,000

Building-Control Room

700,000

Inst rumentation and Controls

300,000

SUBTOTAL

$4,580,000$

Indirect Costs

$1,370,000$

TOTAL ESTIMATED COST

$\$ 5,950,000$ 
Table 8-8

OTHER GEOTHERMAL USES

COST ESTIMATE SUMMARY

JANUARY 1976 DOLLARS

ITEM

ESTIMATED COST

Equipment Foundations \& Supports

$\$ 75,000$

Air Preheating

Geothermal Air Heaters

120,000

Flue Gas Reheat

Geothermal Flue Gas Reheaters

275,000

Plant Space Heating

Geothermal Heat Exchanger

40,000

Piping

100,000

Electrical

80,000

Instrumentation \& Controls

50,000

Insulation

40,000

SUBTOTAL

780,000

Indirect Costs

230,000

ESTIMATED COST - NEW EQUIPMENT

$\$ 1,010,000$

ESTIMATED COST - REPLACED EQUIPMENT

$(710,000)$

TOTAL ESTIMATED COST INCREASE

$\$ 300,000$ 


\subsection{SCHEDULE}

The overall objective of the preliminary plant design and construction schedule is to produce an engineering, procurement, and construction plan that defines major project schedule parameters including determination of the total time required for plant construction and identification of pacing items.

Figure 8-1 shows a preliminary plant design and construction schedule, by months, for a $715 \mathrm{MW}$ hybrid geothermal/coal fired power plant. This schedule does not reflect the time required for site selection, surveys, and land acquisition, or for development of offsite facilities such as geothermal wells, coal mines, and road to the plant site.

The schedule identifies the time periods, major milestones, and interface points for the plant engineering, procurement, and construction activities. Major features of the preliminary schedule are:

- Environmental studies, analyses, preparation of environmental reports, and obtain permits will cover a period of approximately 33 months.

- Major portion of engineering and design will be completed in approximately 36 months.

- Procurement activities will overlap engineering and design to permit purchase of long-lead time items.

- Initial site grading and earthwork will begin prior to obtaining final construction permits. 
- Construction will cover a period of approximately 60 months.

This schedule forms the basis for the economic analyses presented in Section 9. 


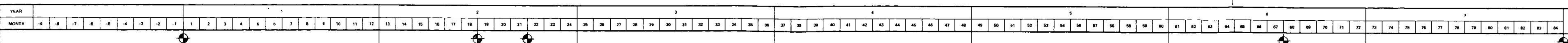

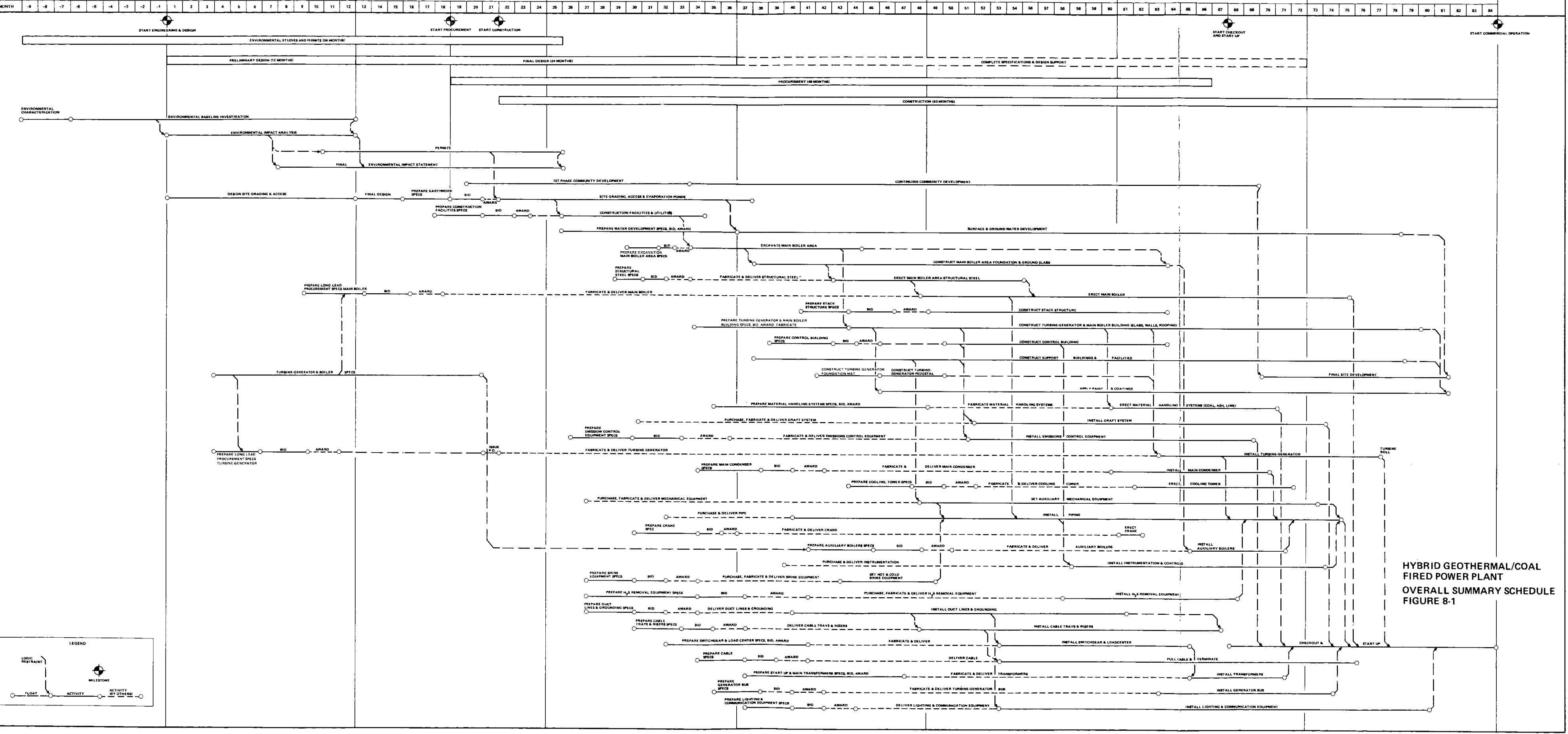




\section{SECTION 9}

ECONOMIC ANALYSIS

\subsection{GENERAL DISCUSSION}

The economic analysis of the hybrid geothermal/coal fired power plant was conducted in three parts. First, the total energy cost per kilowat and its equivalent annual cost in 1976 dollars were calculated taking into account only the geothermal feedwater heating aspects of a hybrid plant. This total energy cost is inclusive of the generating plant capital cost, plant operating and maintenance (O\&M) costs, geothermal we11 capital and O\&M costs, fuel and cooling water costs, and transmission costs to victorville, California. Second, the impact of additional uses of geothermal heat in the hybrid plant on the total energy cost was estimated. These other uses include makeup water, air preheating, flue gas reheating, and plant space heating. Third, the cost impact of using a dual flash steam system for additional power. Use of geothermal fluids for coal beneficiation was considered separately. The cost impact of coal beneficiation on total plant cannot be made without an in-depth analysis of cost impact on the emission controls system and other systems. This was not a part of this study.

In order to develop total energy costs on the same economic base as the City of Burbank Report, economic factors assumed in the Parsons analysis are, with just one exception, the same as those adopted by the City of Burbank. These factors are as follows:

\begin{tabular}{lc} 
& Percent \\
\cline { 2 - 2 } Capacity Factor & 85 \\
Inflation Rate & 5 \\
O\&M Escalation Rate & 5 \\
Coal Cost Escalation Rate & 8 \\
Bond Interest Rate & 6
\end{tabular}




$\begin{array}{lr}\text { Plant Economic Life } & 30 \text { Years } \\ \text { *Construction Time } & 5 \text { Years } \\ \text { Seismic Factor } & 1.0\end{array}$

* Construction time was assumed in the City of Burbank Report to be four years. However, Parsons schedule of 5 years has only a small impact on the total energy costs.

\subsection{GEOTHERMAL FEEDWATER HEATING}

9.2.1 CAPITAL COSTS

Capital costs used in this analysis for the hybrid plant are based on the Parsons prepared conceptual design cost estimate described in Section 8 . The total capital cost, estimated at $\$ 385,841,000$ in 1976 dollars for the plant within the battery limits was converted to dollars per year equivalent annual cost and corresponding mills per kilowat hour in 1976 dollars, taking into account interest during construction, inflation, 30 year economic life, and the cost of money. Figure 9-1 is the cash flow curve on which interest during construction calculations were based.

A fixed charge rate of 8.30 percent for all plant capital costs was assumed. This rate is identical with that adopted in the IPP cost analysis. Capital costs for the geothermal wells, as well as transmission costs, were extracted from the City of Burbank Report.

\subsubsection{OPERATING AND MAINTENANCE COSTS}

Operating and maintenance costs for the hybrid plant were modified from those provided in the IPP Project Cost Estimate. Since the IPP costs were based on a four unit $3000 \mathrm{MW}$ plant, they were modified to reflect a single unit $715 \mathrm{MW}$ hybrid plant. Also taken into consideration was the 

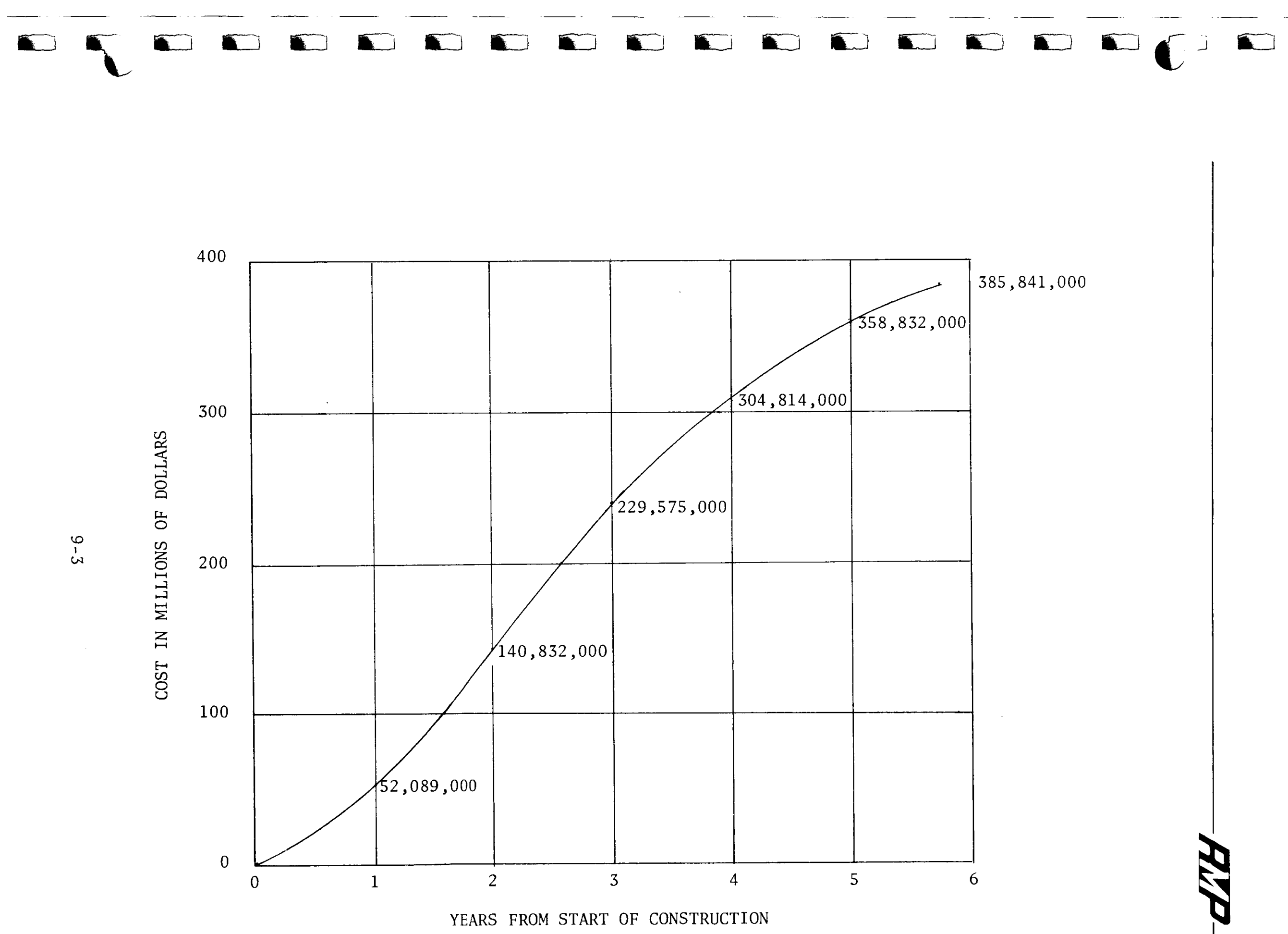

FIGURE 9-1, CASH FLOW DURING CONSTRUCTION 
non-linearity characteristics of scaling down as well as the inherent increase in the operating and maintenance costs due to increased complexity of the hybrid systems in the plant. Equivalent annual costs in 1976 dollars and mills per kilowatt hour costs were calculated using the economic factors defined in Paragraph 9.1.

\subsubsection{COAL COST}

The cost of coal assumed for this analysis is $\$ 20$ per tonne or $\$ 18.18$ per ton in 1976 dollars. These figures include the cost of coal at the minemouth and the cost to purchase, construct, operate and maintain a coal haul railroad to the plant. Total annual fuel costs in 1976 dollars and equivalent mills per kilowatt hour are based on an escalation rate of 8 percent per year.

\subsubsection{TOTAL ENERGY COSTS}

Total energy costs that include capital costs operating and maintenance expenses, fuel costs, transmission costs, and community development costs, are expressed in terms of average annual costs and base year (1976) costs.

Table $9-1$ is a tabulation of base year costs in 1976 dollars for the hybrid plant as estimated by Parsons and the City of Burbank; and for an all coal fired plant located at Roosevelt Hot Springs as estimated by the City of Burbank. Total energy costs for the hybrid plant estimated by Parsons is only slightly more than one-half mill per kilowatt hour higher than the Burbank estimate. Differences in plant capital cost estimates as well as the total contribution of geothermal heat to the plant primarily account for the fact that the Parsons total energy cost estimate is 3.6 percent higher than that estimated by Burbank. However, both estimates compare favorably with the Burbank estimate of total energy costs for the all coal fired power plant. 
TABLE 9-1

ANNUAL COST SUMMARY FOR 715 MW HYBRID PLANT

BASE YEAR (1976) COSTS

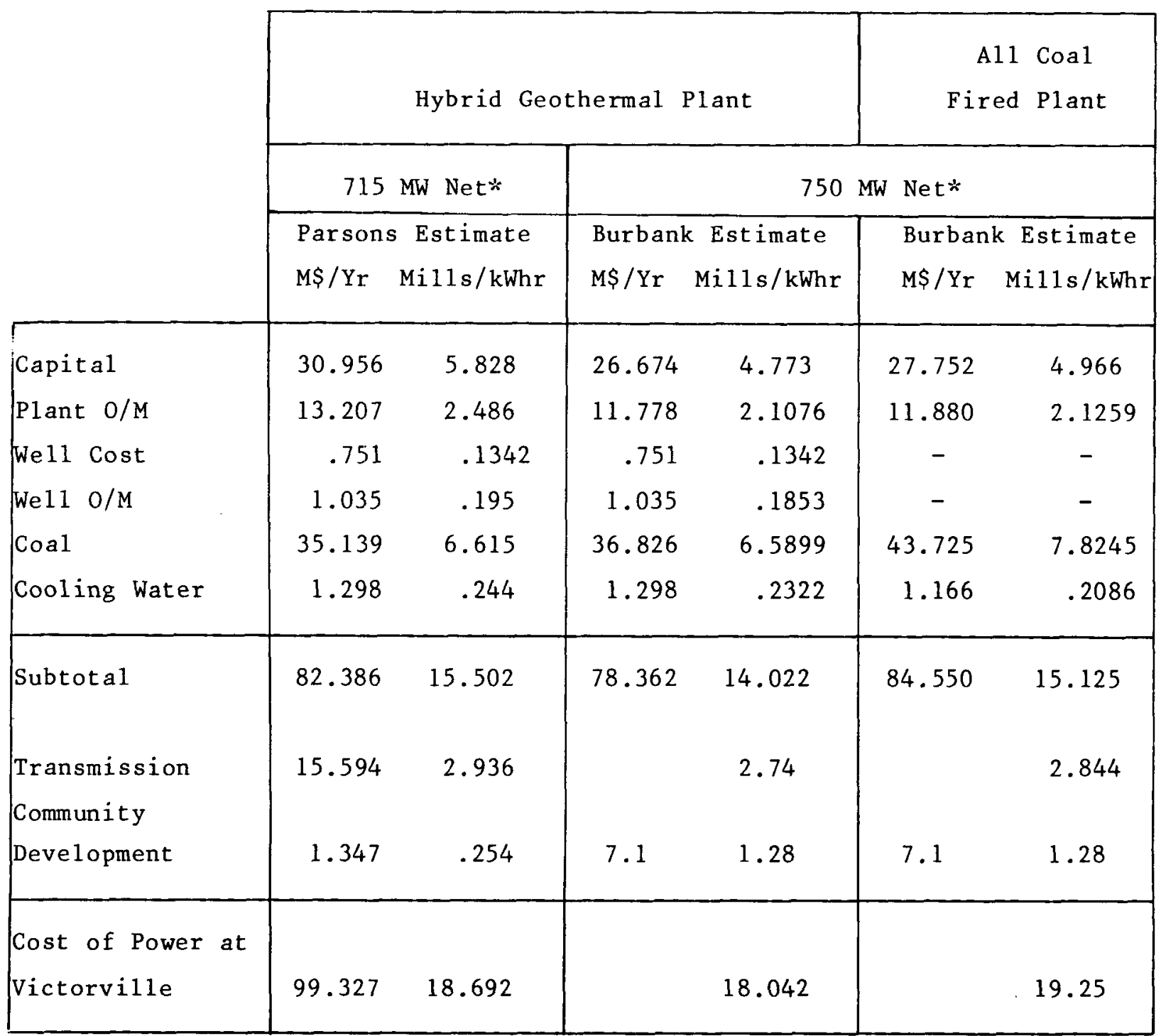

*Factoring of costs is not linear with respect to plant electrical generating capacity. 
Table 9-2 is a tabulation of average annual costs, also in 1976 dollars, for the hybrid plant as estimated by Parsons and Burbank; and for an all coal fired plant located at Roosevelt Hot Springs as estimated by Burbank. The Burbank estimates for both the hybrid and the all coal fired plant were based on ERDA costing methods. The Parsons estimate of 20.67 mills per kilowatt hour is 1.0 percent higher than that estimated by Burbank. Again, this increase is primarily due to the differences in estimated total capital costs and geothermal heat contribution to the plant between the Parsons and Burbank investigations. Both the Parsons and Burbank estimates for total energy cost, delivered to Victorville, for the hybrid plant compare favorably to the Burbank estimate for the all coal fired plant also located at Roosevelt Hot Springs.

\subsection{MAKEUP WATER AND OTHER GEOTHERMAL USES}

The economic analysis for the implementation of geothermal fluid systems for condensate and cooling tower makeup water, air preheating, flue gas reheating and plant space heating includes capital costs, operating and maintenance costs, and fuel savings, where applicable. The economic factors used in this portion of the analysis are identical to those 1 isted in Paragraphs 9.1 and 9.2

\subsubsection{CAPITAL COSTS}

Capital costs are based on Parsons conceptual design cost estimates described in Section 8, Paragraphs 8.2.2, and 8.2.5. The estimated total increase in plant capital costs for condensate and cooling tower makeup water, air preheating, flue gas reheating, and plant space heating, inclusive, is $\$ 3,020,000$, in January, 1976 dollars. This was converted to equivalent annual costs and corresponding mills per kilowat hour. Base year (1976) annual costs and average annual costs, expressed in 1976 dollars are presented in Tables 9-3 and 9-4, respectively. 
TABLE 9-2

ANNUAL COST SUMMARY FOR 715 MW HYBRID PLANT

AVERAGE ANNUAL COSTS

1976 DOLLARS

\begin{tabular}{|c|c|c|c|c|c|c|}
\hline & \multicolumn{4}{|c|}{ Hybrid Geothermal Plant } & \multicolumn{2}{|c|}{$\begin{array}{c}\text { A11 Coal } \\
\text { Fired P1ant }\end{array}$} \\
\hline & \multicolumn{2}{|c|}{$715 \mathrm{MW} \mathrm{Net*}$} & \multicolumn{4}{|c|}{750 MW Net* } \\
\hline & $\begin{array}{l}\text { Parsons } \\
\text { MS/Yr }\end{array}$ & $\begin{array}{l}\text { Estimate } \\
\text { Mills/kWhr }\end{array}$ & $\begin{array}{l}\text { Burbank } \\
\text { M\$ / Yr }\end{array}$ & $\begin{array}{l}\text { Estimate } \\
\text { Mills/kWhr }\end{array}$ & $\begin{array}{l}\text { Burbank } \\
\text { M\$ / Yr }\end{array}$ & $\begin{array}{l}\text { Estimate } \\
\text { Mi11s/kWhr }\end{array}$ \\
\hline Capital & 14.203 & 2.670 & 11.548 & 2.0664 & 12.019 & 2.1507 \\
\hline Plant $\mathrm{O} / \mathrm{M}$ & 13.207 & 2.486 & 11.778 & 2.1076 & 11.880 & 2.1258 \\
\hline We11 Cost & .309 & .0581 & .325 & .0581 & - & - \\
\hline Well $0 / M$ & 1.035 & .195 & 1.035 & .1853 & - & - \\
\hline Coal & 61.814 & 11.637 & 64.781 & 11.5925 & 76.917 & 13.7642 \\
\hline Cooling Water & 1.298 & .244 & 1.298 & .2322 & 1.166 & .2086 \\
\hline Subtota 1 & 91.866 & 17.290 & 90.765 & 16.2421 & 101.982 & 18.2493 \\
\hline $\begin{array}{l}\text { Transmission } \\
\text { Community }\end{array}$ & 16.616 & 3.128 & & 2.94 & & 3.12 \\
\hline Development & 1.347 & .254 & 7.1 & 1.28 & 7.1 & 1.28 \\
\hline $\begin{array}{l}\text { Cost of Power at } \\
\text { Victorville }\end{array}$ & 109.829 & 20.672 & & 20.46 & & 22.65 \\
\hline
\end{tabular}

*Factoring of costs is not linear with respect to plant electrical generating capacity. 


\subsubsection{OPERATING AND MAINTENANCE COSTS}

The estimated average operating and maintenance cost for condensate and cooling tower makeup water, air preheating, flue gas reheating, and plant space heating in 1976 dollars in excess of those estimated for the base case is $\$ 496,000$. Base year (1976) equivalent annual costs, average annual costs in 1976 dollars, and the corresponding mills per kilowatt hour figures are provided in Tables 9-3 and 9-4, respectively.

\subsubsection{COAL COST}

The total consumption of coal in the hybrid plant decreases with the addition of geothermal fluid systems for air preheating, flue gas reheating and plant space heating by approximately 70,000 tons per year. This converts to savings of $\$ 1,252,200$ and $\$ 2,203,000$ per year expressed in base year (1976) and average annual costs, respectively.

\subsubsection{MAKEUP WATER}

The condensate and cooling tower makeup water systems have been sized to provide for all station makeup water requirements. Therefore, the cost of makeup water is entirely accounted for by the addition of capital, operating and maintenance costs to the total cost of power. As compared to the base case economic analysis of total energy costs, Tables 9-3 and 9-4 show that cooling water costs do not exist in Case 2, whereas Case 1 shows $0.244 \mathrm{mills}$ per kilowatt hour.

\subsubsection{TOTAL ENERGY COST}

Tables 9-3 and 9-4 show the base case energy costs bereakdown as Case 1. Case 2 is the energy costs breakdown for Case 1 with the addition of geothermal fluid systems for condensate and cooling tower makeup water, air preheating, flue gas reheating, and plant space heating. Case 3 is the energy costs breakdown for Case 2 with the addition of the all geothermal plant. Case 3 is discussed in Paragraph 9.4 . 
Total energy costs for the base case (Case 1) are 18.692 and 20.672 mills per kilowatt hour expressed in base year (1976) and average annual costs, respectively, whereas the corresponding energy costs for Case 2 are 18.364 and $20.132 \mathrm{mills}$ per kilowatt hour. The decrease is primarily the result of the elimination of fresh water requirements to the plant, and the reduction in coal consumption with the use of geothermal heat rather than extraction steam to preheat combustion air, reheat flue gas, and for plant space heating.

\subsection{ADDITIONAL POWER}

\subsubsection{CAPITAL COSTS}

Capital costs are based on conceptual costs estimates described in Section 8, Paragraph 8.2.3. The estimated total increase in capital costs for the all-geothermal $65.4 \mathrm{MW}$ power plant is $\$ 34,800,000$ in 1976 dollars, taking into consideration interest during construction and inflation. This was converted to equivalent annual costs and corresponding mills per kilowatt hour. Base year (1976) annual costs and average annual costs, expressed in 1976 dollars are provided in Tables 9-3 and 9-4, respectively.

\subsubsection{OPERATING AND MAINTENANCE COSTS}

The estimated average operating and maintenance cost for the all geothermal plant, in addition to the estimate for the base case, is $\$ 534,000$. Base year (1976) equivalent annual costs, average annual costs in 1976 dollars, and the corresponding mills per kilowatt hour figures are provided in Tables 9-3 and 9-4, respectively. 


\subsubsection{COAL COST}

The total coal consumption in the hybrid plant decreases with the addition of the all geothermal plant by 1.62 percent, based on the expected capacity factor of 85 percent of the hybrid plant. The decrease in coal consumption amounts to a cost savings of $\$ 548,000$ and $\$ 964,400$ per year expressed in base year (1976) and average annual costs, respectively.

\subsubsection{WELL OPERATING AND MAINTENANCE COSTS}

The increase in geothermal well operating and maintenance costs is estimated at 10 percent. This increase is due to the fact that the well capacity factor required to accommodate the all geothermal plant increased about 15 percent above that required for the hybrid plant alone.

\subsubsection{TOTAL ENERGY COST}

Total energy costs for Case 3 , which take into account all the geothermal uses investigated and implemented in this study except for coal beneficiation, are higher than those Case 2. However, the total energy costs for Case 3 are still lower than those estimated by the City of Burbank for the all coal fired reference plant as shown on Tables 9-1 and 9-2. Tables 9-3 and 9-4 show the total energy costs for Case 3 are 18.845 and $20.294 \mathrm{mills}$ per kilowatt hours, expressed in base year (1976) annual costs and average annual costs, respectively. These compare to corresponding estimates of total energy costs of 18.692 and 20.672 mills per kilowatt hour for the base case (Case 1) and 18.364 and $20.132 \mathrm{mills}$ per kilowatt hour for Case 2.

\subsection{COAL BENEFICIATION}

The order-of-magnitude capital cost for the coal beneficiation system described in Section 6 is estimated to be $\$ 5,950,000$. The total cost of beneficiating the coal in dollars per ton, including capital costs and operating and maintenance costs is esitmated at $\$ 1.43$ and $\$ 1.13$ per ton of 
clean coal in Base Year (1976) Costs and average annual costs, respectively. These costs include the reduction of ash and sulfur content in the coal.

Assuming an 85 percent capacity factor for the coal beneficiation system and the availability of corresponding amounts of coal which would require beneficiation to maintain the system at maximum process capacity, this would amount to an additional first year coal cost of $\$ 1,350,000$ and $\$ 1,060,000$ expressed in Base Year (1976) and average annual costs, respectively. 
TABLE 9-3

ANNUAL COST COMPARISON SUMMARY

BASE YEAR (1976) COSTS

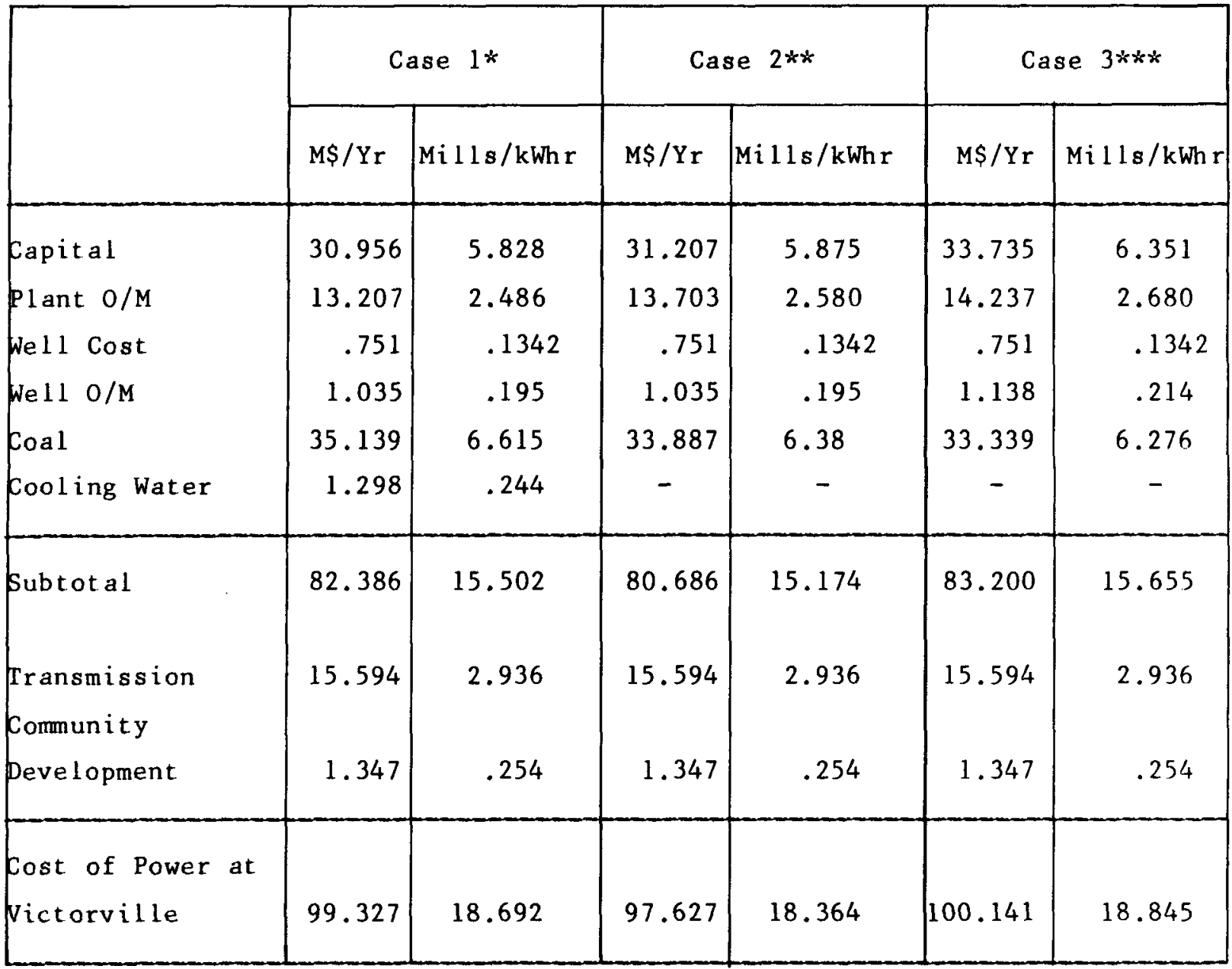

*Case 1 = Hybrid plant with geothermal feedwater heating only.

$*$ Case 2 = Case 1 plus makeup water, air preheating, flue gas reheating, and plant space heating.

$* * *$ Case $3=$ Case 2 plus additional power. 
TABLE $9-4$

ANNUAL COST COMPARISON SUMMARY

AVERAGE ANNUAL COSTS

1976 DOLLARS

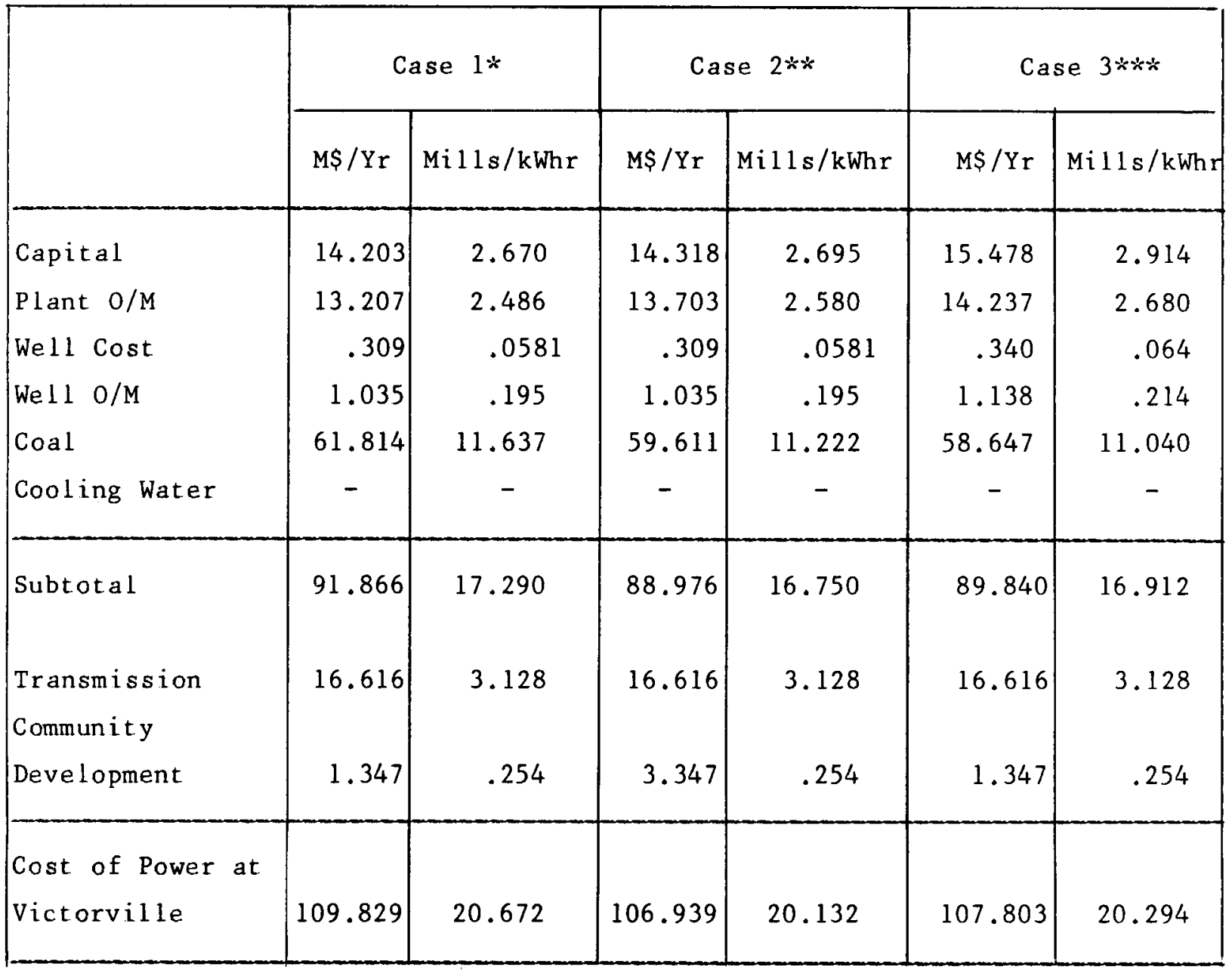

*Case 1 = Hybrid plant with geothermal feedwater heating only.

**Case 2 = Case 1 plus makeup water, air preheating, flue gas reheating, and plant space heating.

$* * *$ Case $3=$ Case 2 plus additional power. 


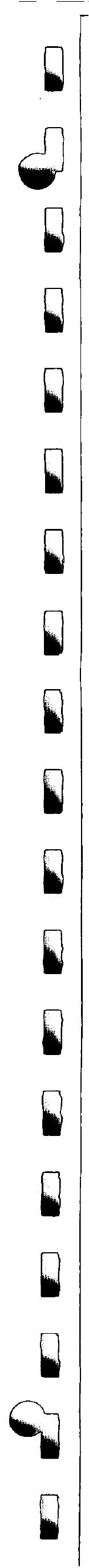


SECTION 10

DRAWINGS

\subsection{DESCRIPTION OF DRAWINGS}

The drawings prepared for this study and referred to in the text are included in this section. The drawings are found in the numerical sequence listed below:

10.1.1 GENERAL ARRANGEMENT DRAWINGS

GA-1 Conceptual Site Plan and General Arrangement - Base Case

GA-2 Conceptual Plot Plan - Base Case

GA-3 General Arrangement Turbine Generator Bay Units $1 \& 2$ Plan-Ground Floor E1. 5500'-0"

GA-4 General Arrangement Turbine Generator Bay Units $1 \& 2$ Plan-Mezzanine Floor E1. 5528'-3'

GA-5 General Arrangement Turbine Generator Bay Units $1 \& 2$ Plan-Turbine Deck E1. 5556'-6"

GA-6 General Arrangement Elevation

GA-7 General Arrangement $\mathrm{H}_{2} \mathrm{~S}$ Removal System

GA-8 Conceptual Site Plan and General Arrangement

GA-9 Conceptual P1ot Plan 
GA-10 Enlarged Conceptual Plan of Turbine-Generator and Flash Tanks

GA-11 Conceptual Elevation of Turbine-Generator and Flash Tanks

10.1.2 MECHANICAL AND PROCESS DRAWINGS

ME-1 Mechanical Turbine Generator Heat Cycle Diagram

ME-2 Turbine Generator Heat Balance Diagram 100\% Load

ME-3 Flow Diagram Forced and Induced Draft System

ME-4 Mechanical Line Diagram Piping and Instrument Index

ME-5 Piping Line Diagram Feedwater System

ME-6 Piping Line Diagram Condensate System

ME-7 Piping Line Diagram Bleed Steam System

ME-8 Piping Line Diagram Circulating Water System

ME-9 Flow Diagram Hot and Cold Brine System-Steam to Water

ME-10 Piping Line Diagram Hot and Cold Brine System (Flash Steam System)

ME-11 Flow Diagram $\mathrm{H}_{2} \mathrm{~S}$ Removal System

ME-12 Flow Diagram Bottom and Economizer Ash Handling System 
ME-13 Flow Diagram Fly Ash and Scrubber Sludge Mixing System

ME-14 Flow Diagram Fly Ash Handing System

ME-15 Flow Diagram $\mathrm{SO}_{2}$ Scrubber Process Balance

ME-16 Flow Diagram Hot and Cold Brine System (Water to Water) - Base Case

ME-17 Piping Line Diagram Hot and Cold Brine System (Water to Water) - Base Case

ME-18 Piping Line Diagram Heater Vents and Drains System

ME-19 Heat Balance Data Additional Power Generation (Air Cooled Condenser Alternative)

ME-20 Piping Line Diagram Additional Power Generation (Air Cooled Condenser Alternative)

ME-21 Heat Balance Data Additional Power Generation (Water Cooled Condenser Alternative)

ME-22 Piping Line Diagram Additional Power Generation (Water Cooled Condenser Alternative)

ME-23 Turbine Generator Overall Heat Balance Diagram - 100\% Load

ME-24 Flow Diagram Hot and Cold Brine System (Water-to-Water)

ME-25 Piping Line Diagram Hot and Cold Brine System (Water-to-Water) 
ME-26 Flow Diagram Air Preheater Services and Stack Reheat

ME-27 Piping Line Diagram Air Preheater Services and Stack Reheat

ME-28 Heat Balance Data Additional Power Generation (Barometric Condenser)

ME-29 Piping Diagram Additional Power Generation (Barometric Condenser)

ME-30 Flow Diagram Cooling Tower Makeup

ME-31 Flow Diagram Typical Wet Physical Coal Beneficiation

10.1.3 ELECTRICAL DRAWINGS

EE-1 Conceptual - One Line Diagram 
:

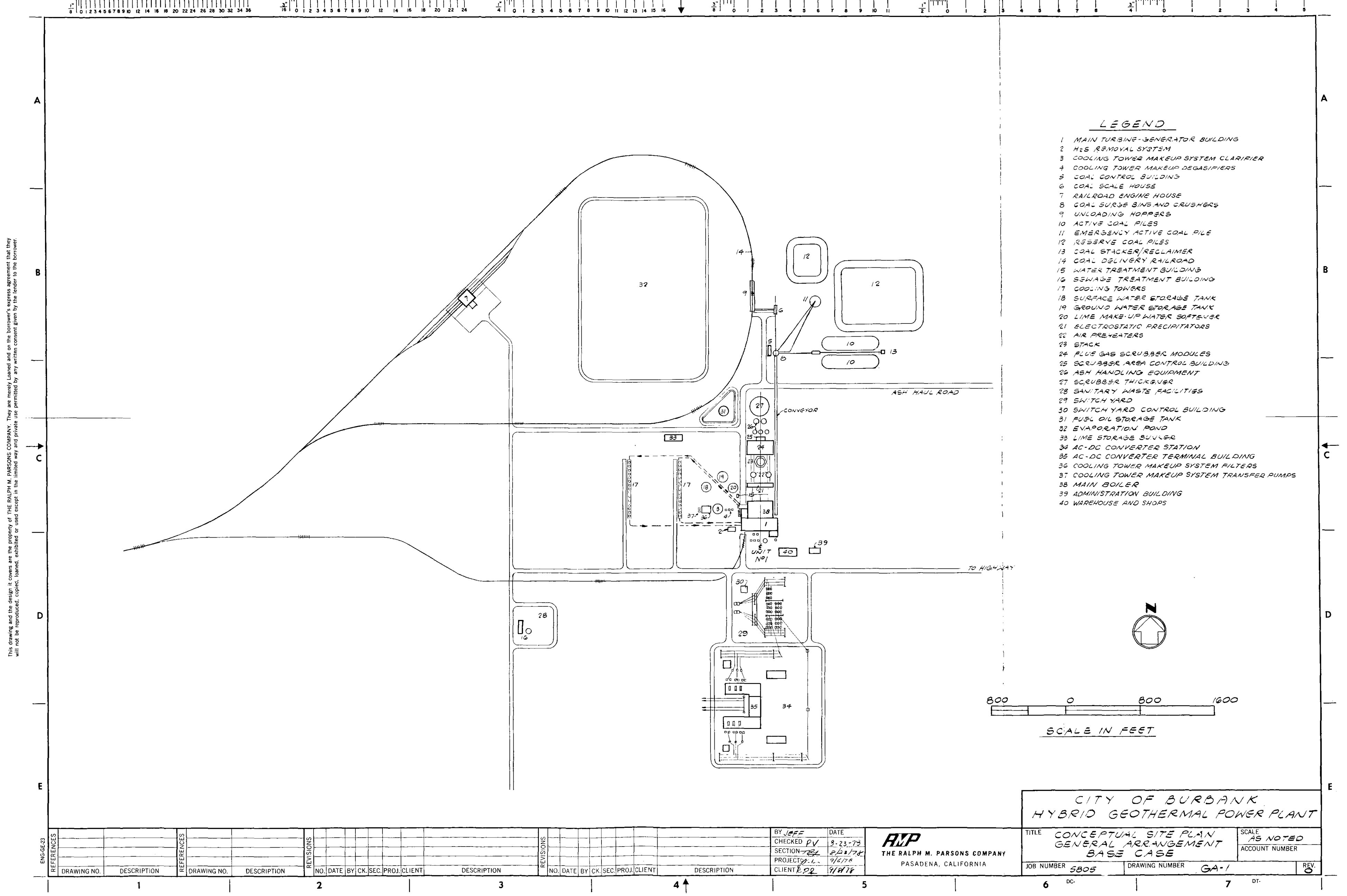




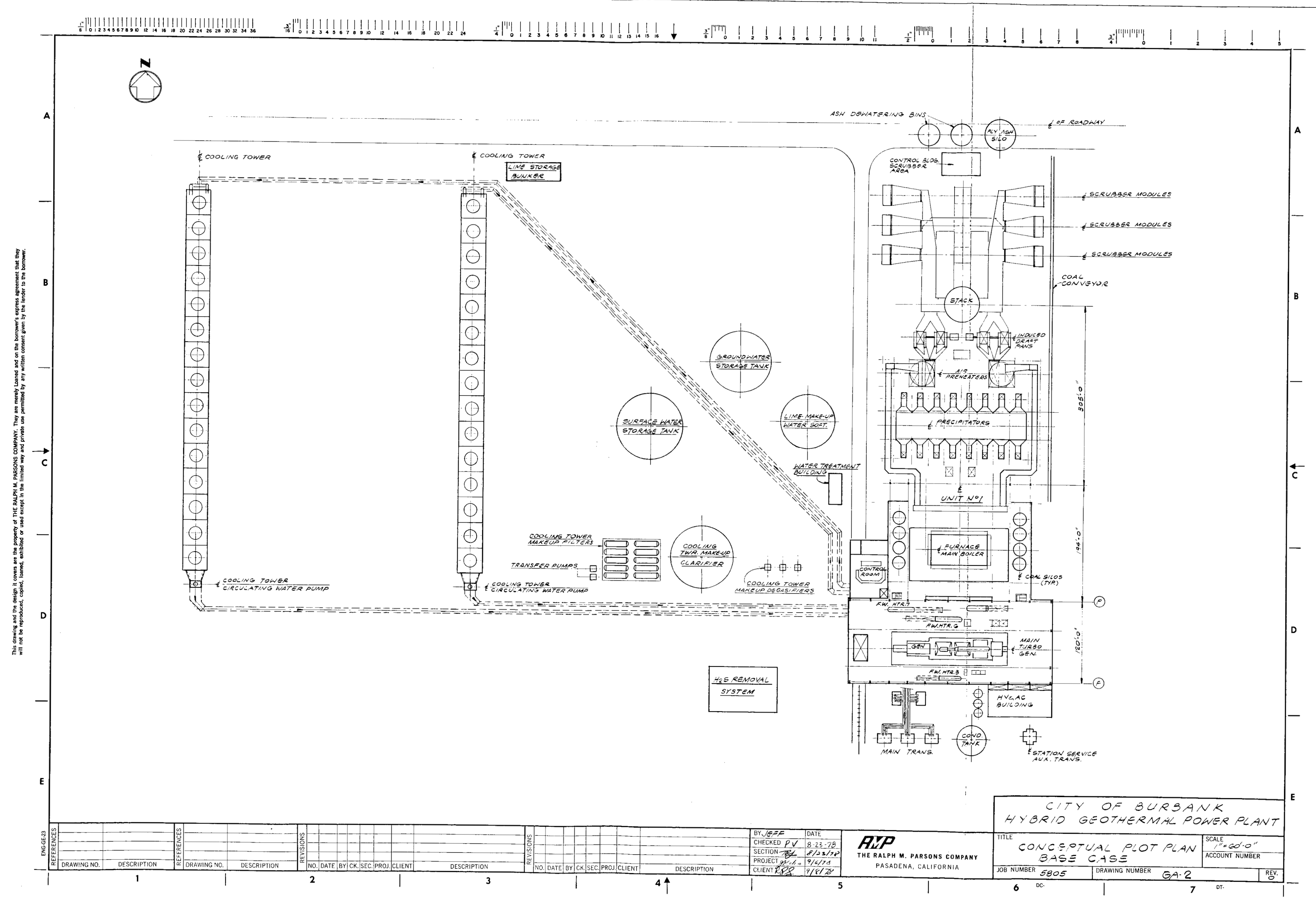




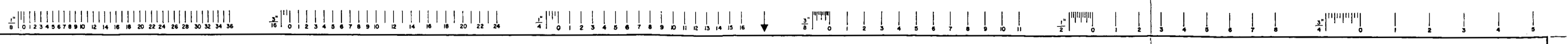

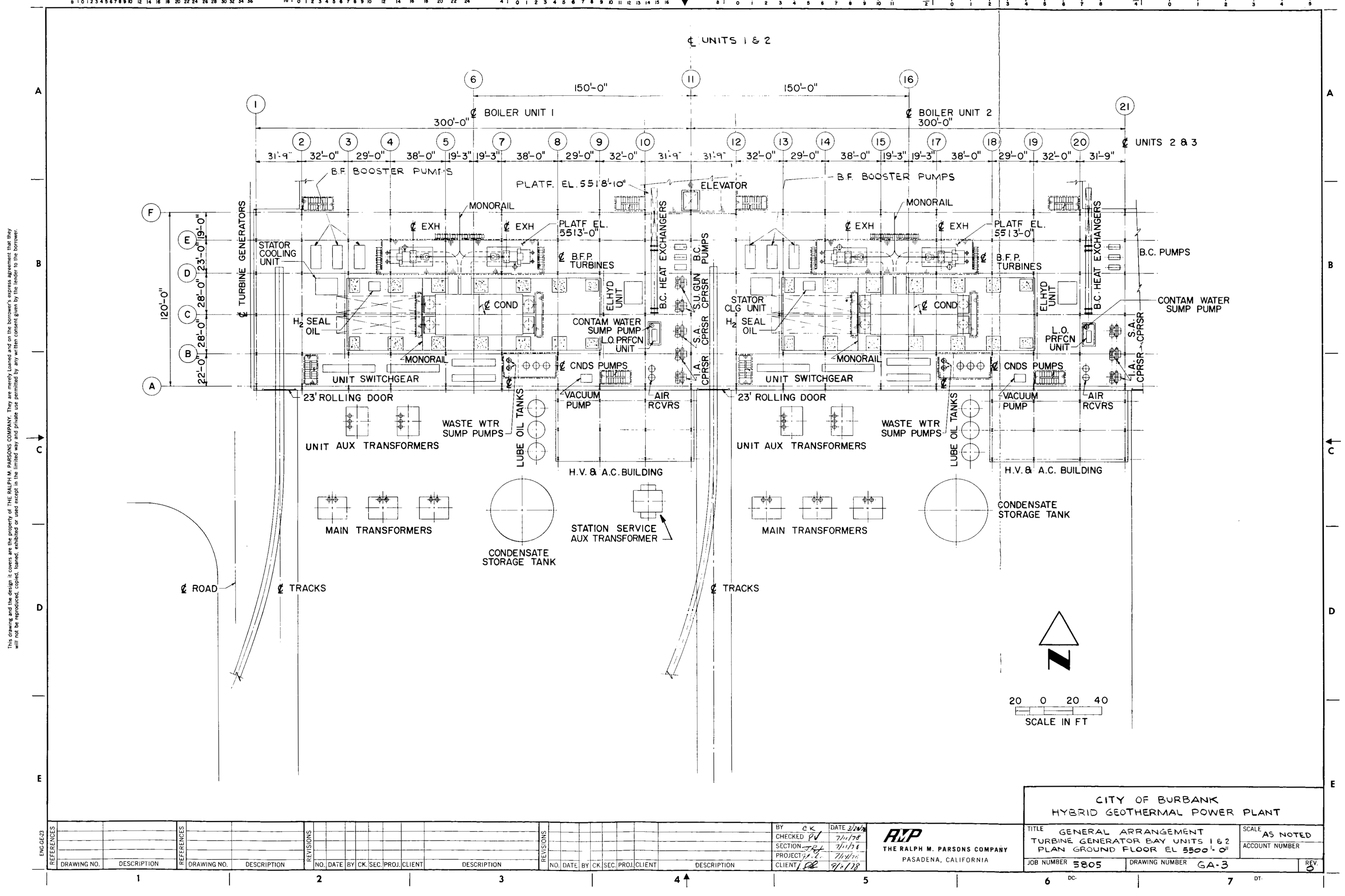




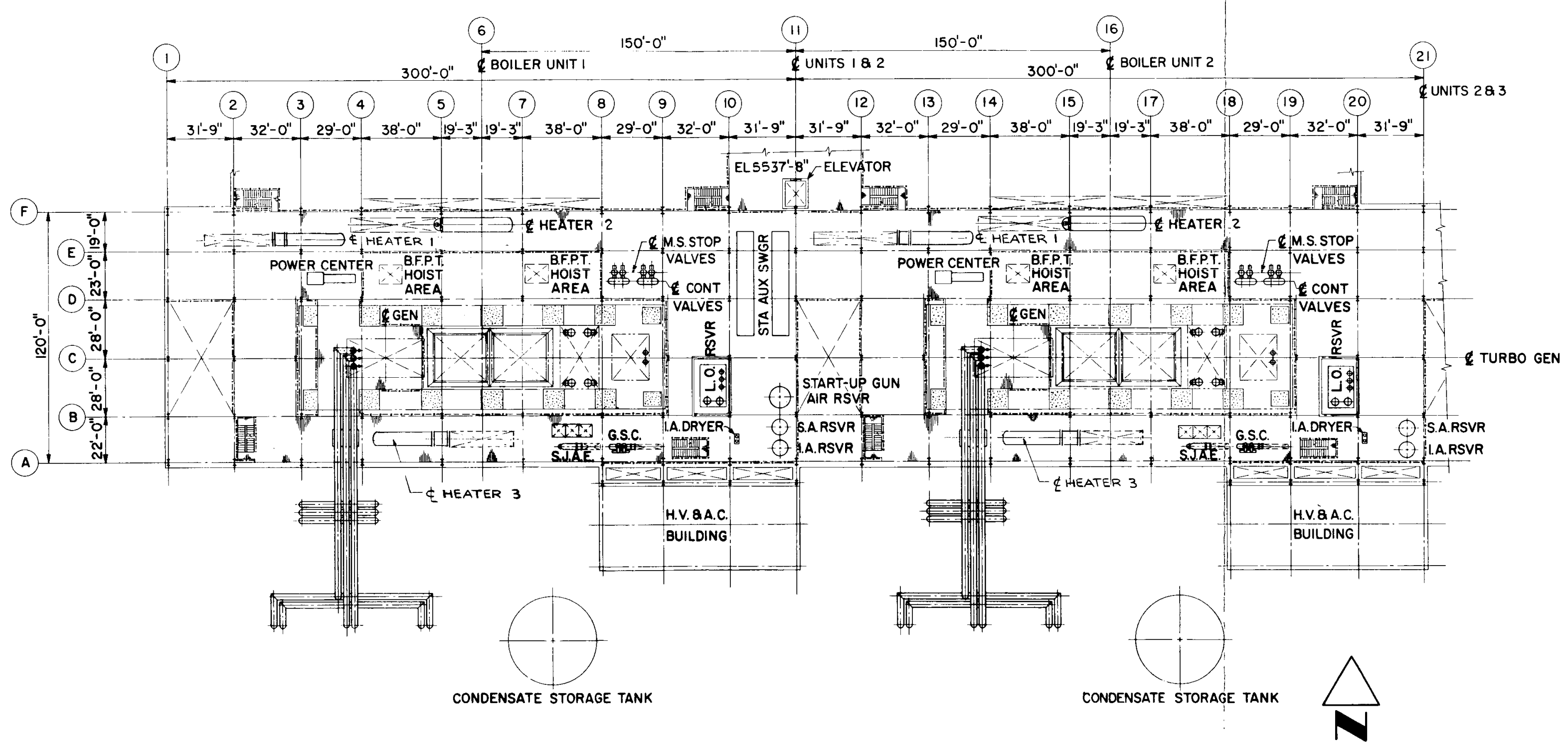

$20 \quad$\begin{tabular}{lll}
20 & 20 & 40 \\
\hline & $\quad$ & 20
\end{tabular}

SCALE IN FT

CITY OF BURBANK

CITY OF BURBANK
HYBRID GEOTHERMAL POWER PLANT

ALP

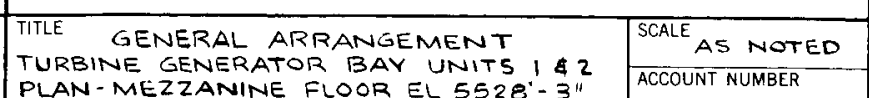


站叫叫!

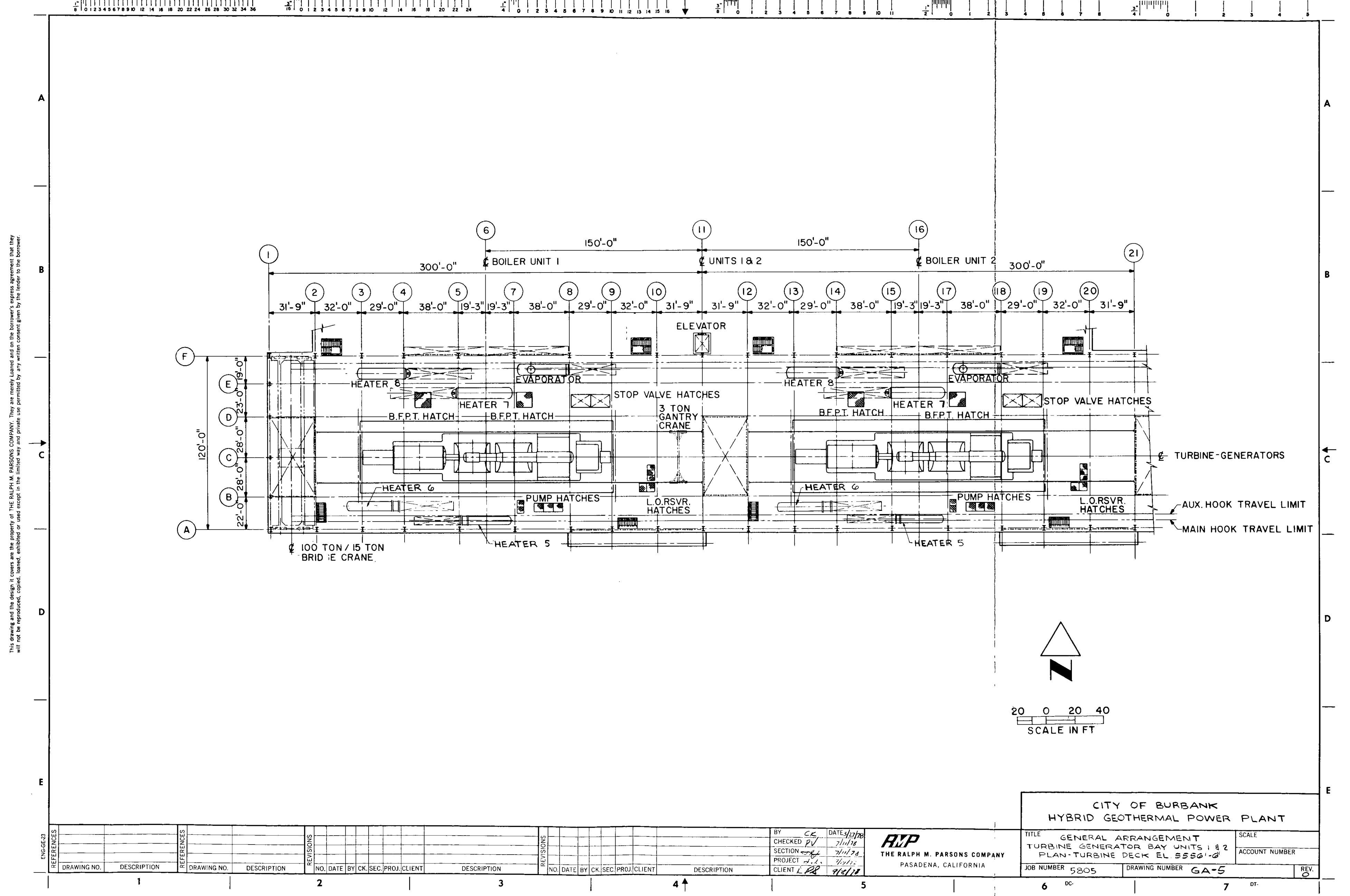




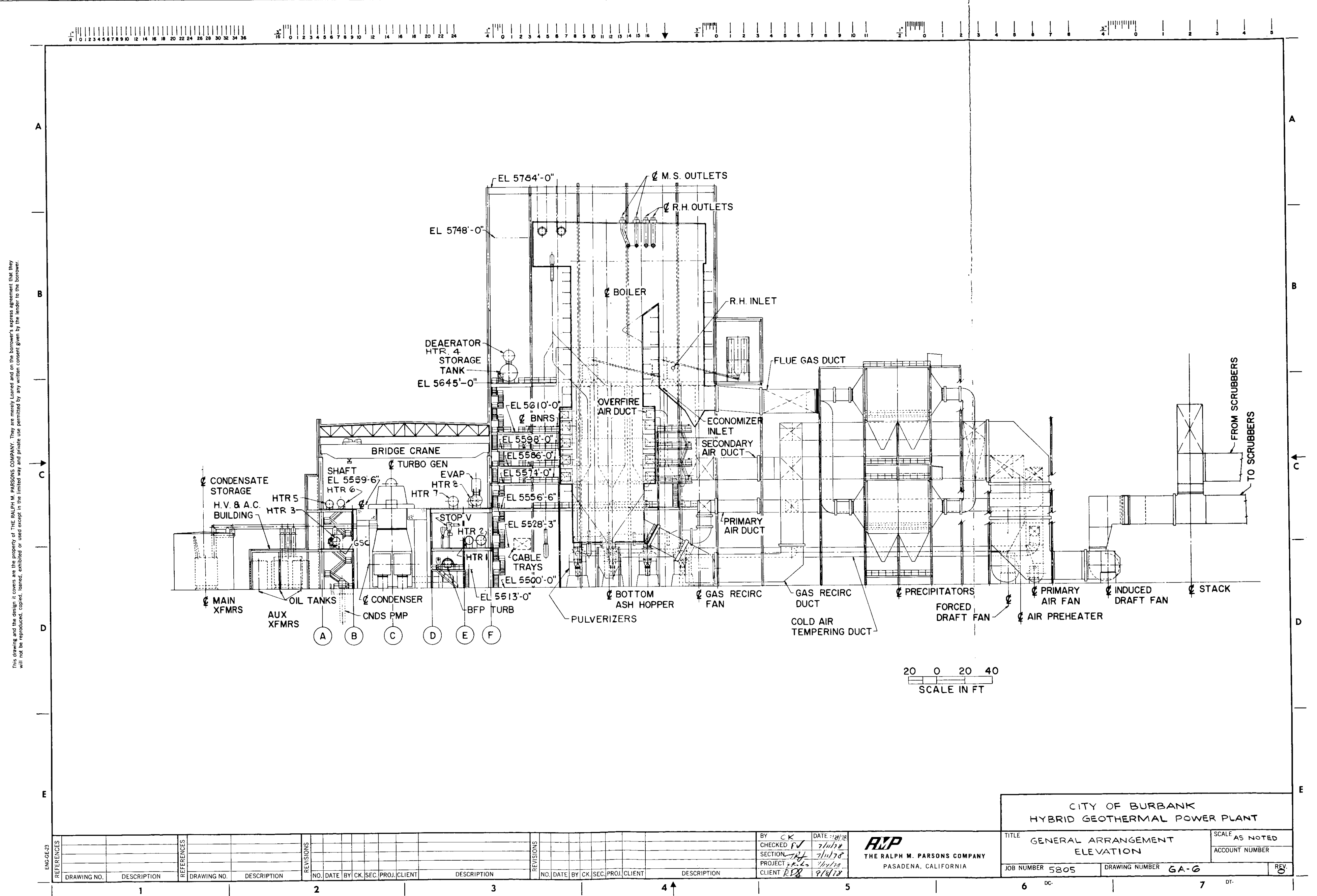




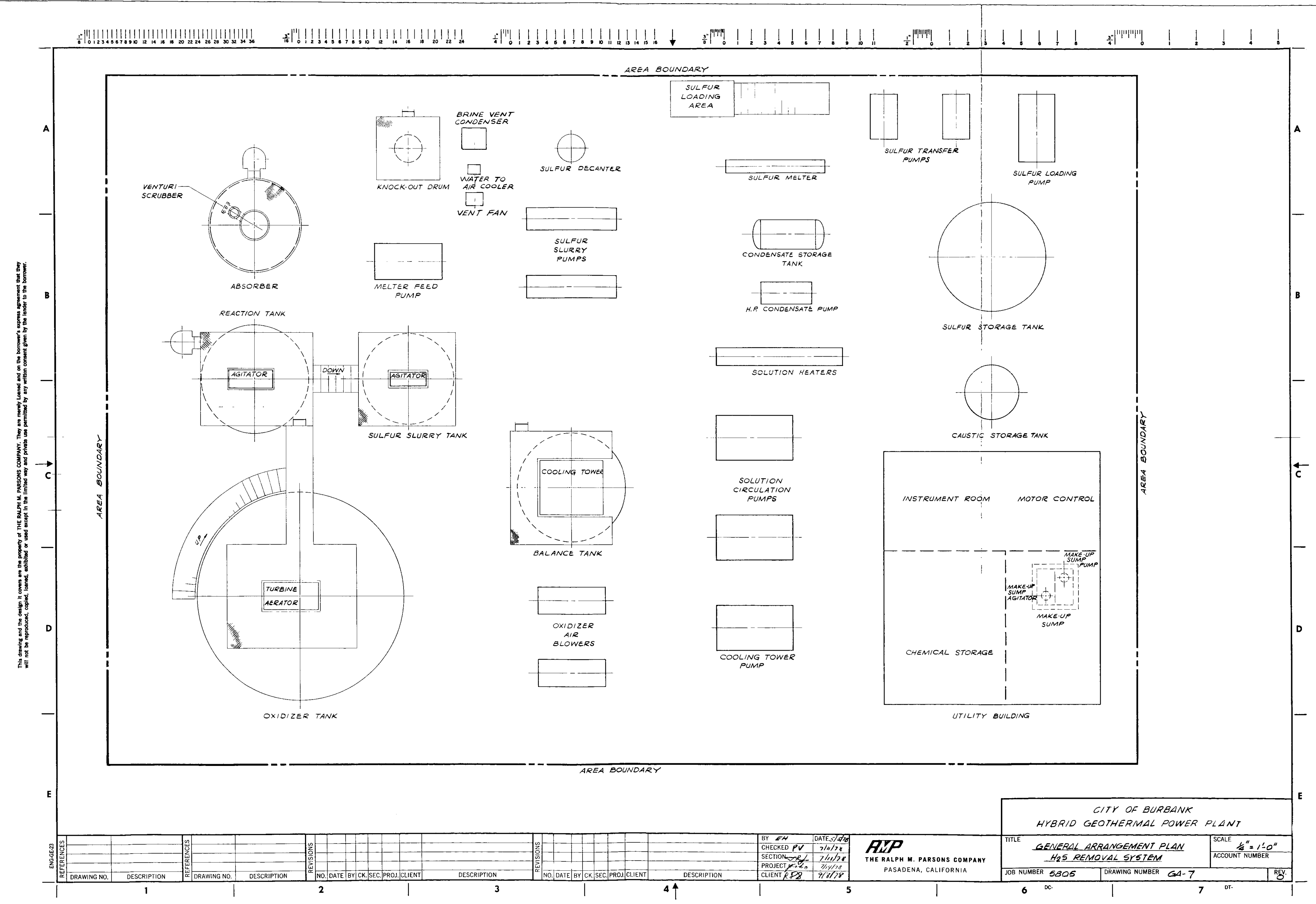




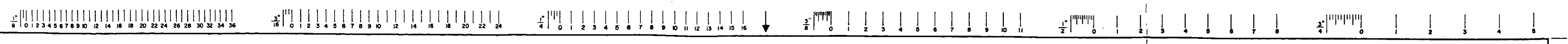

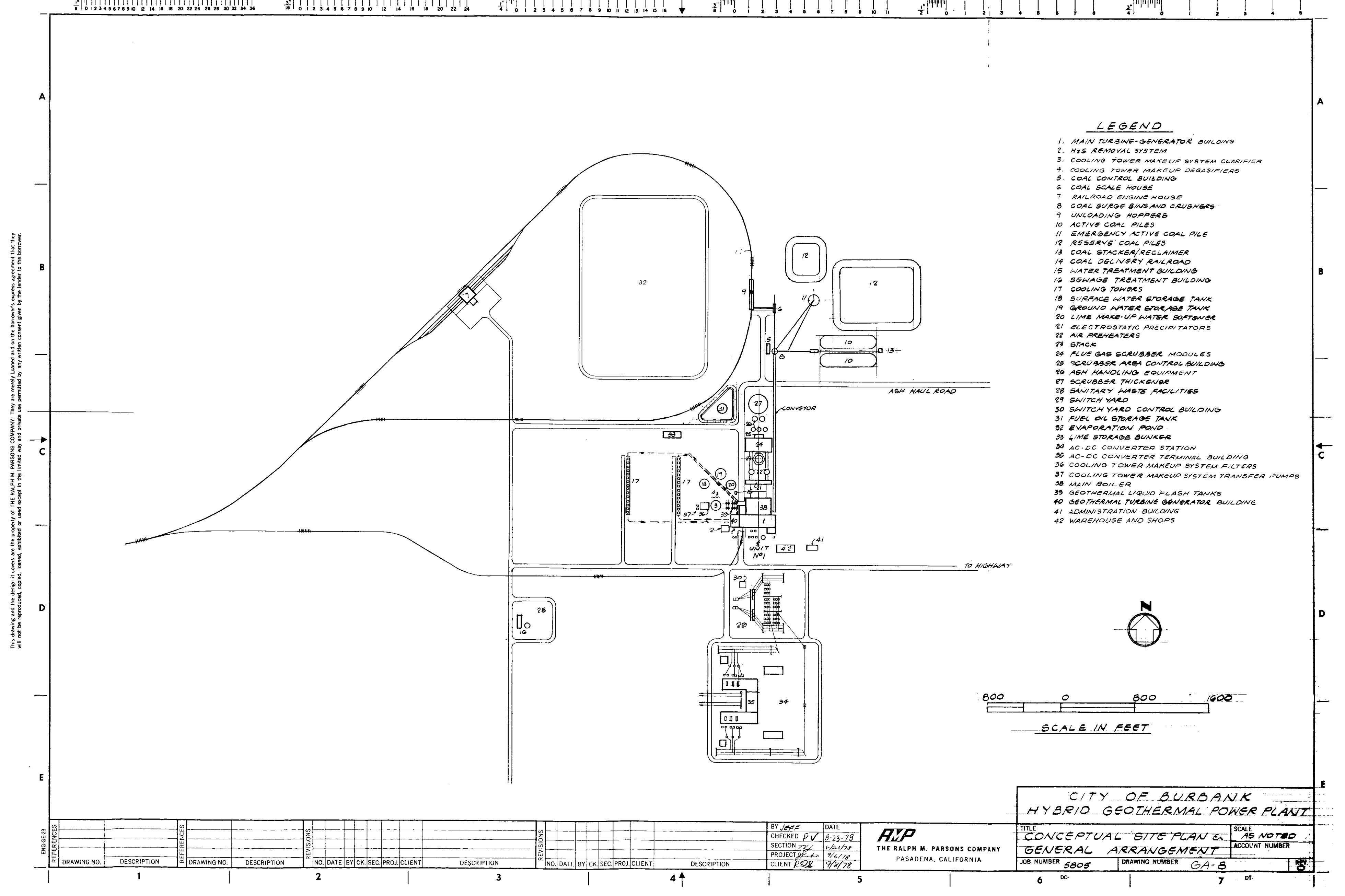




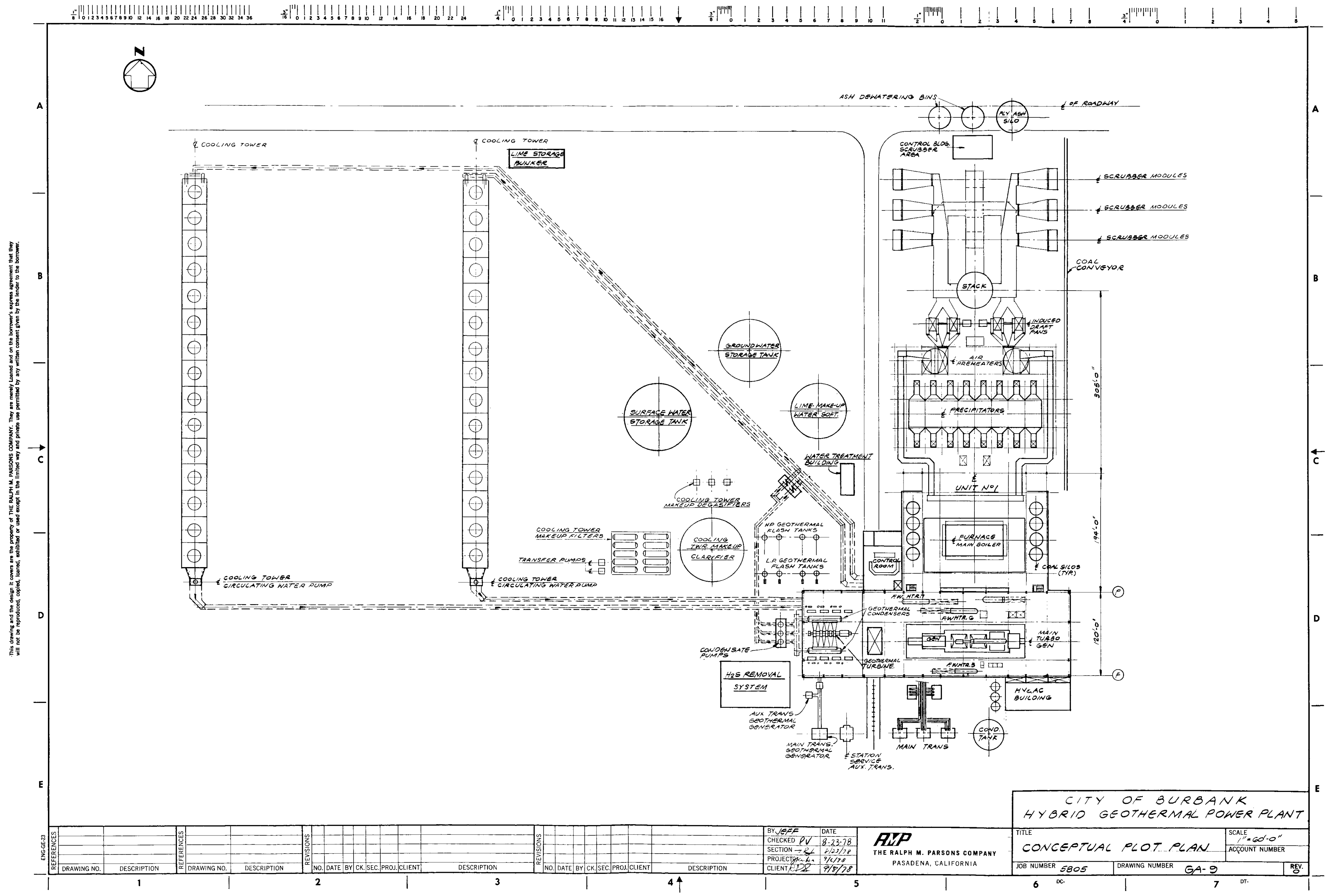




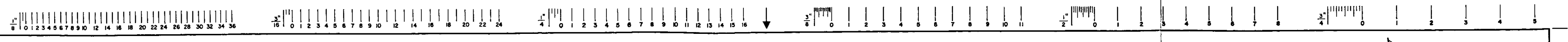

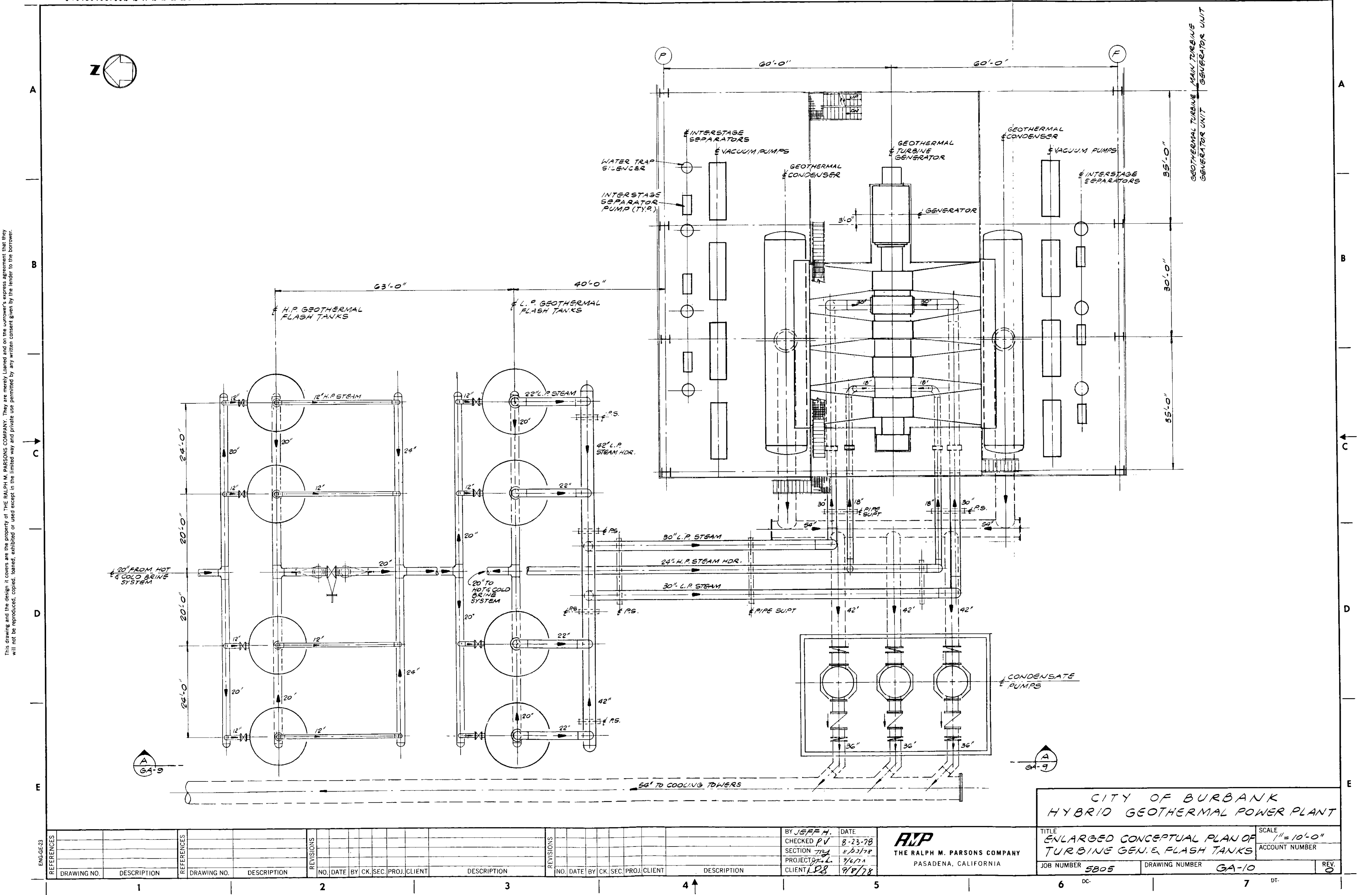




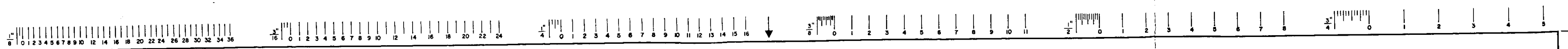

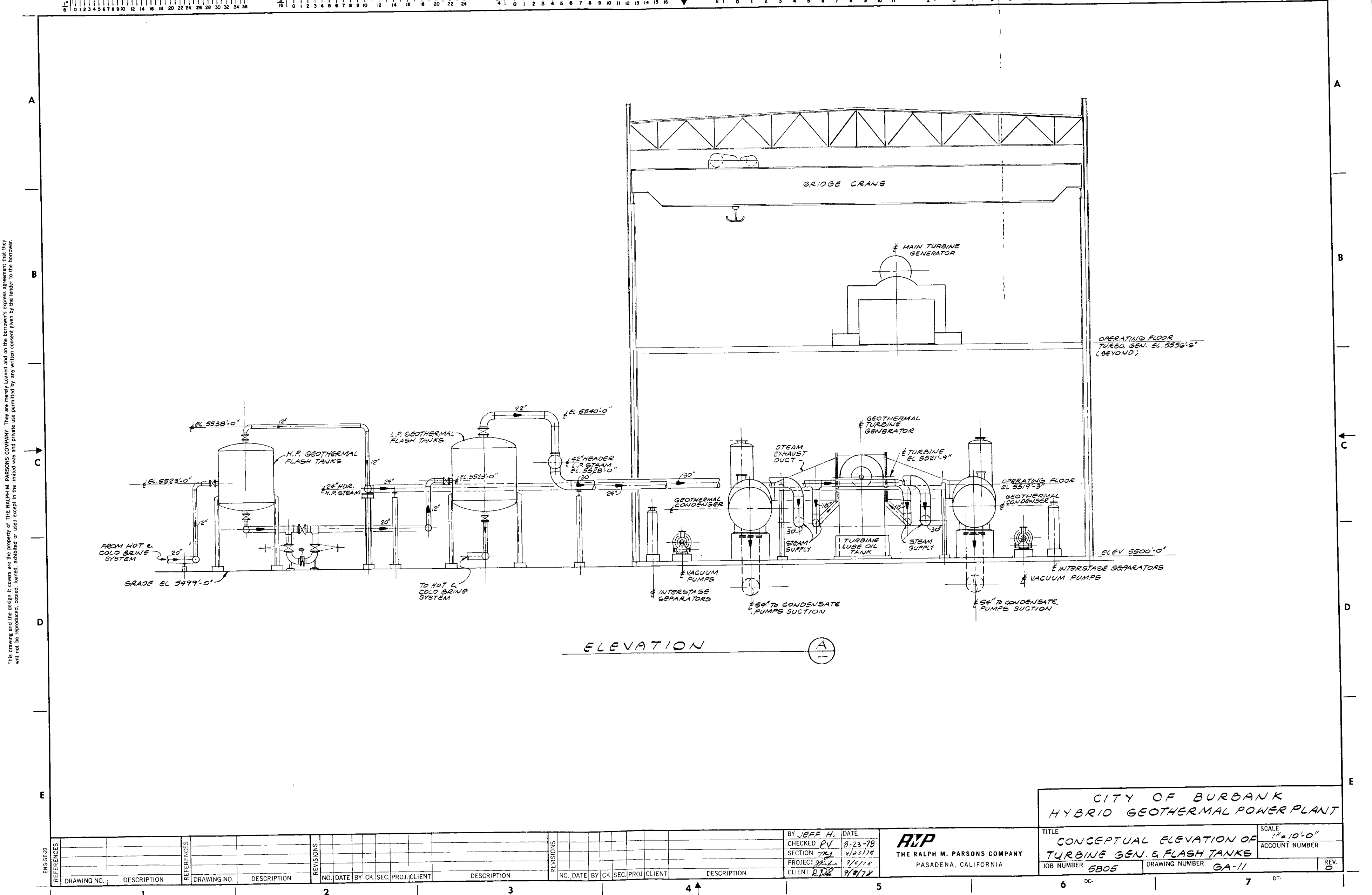




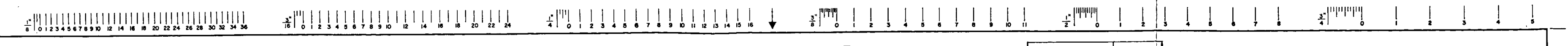

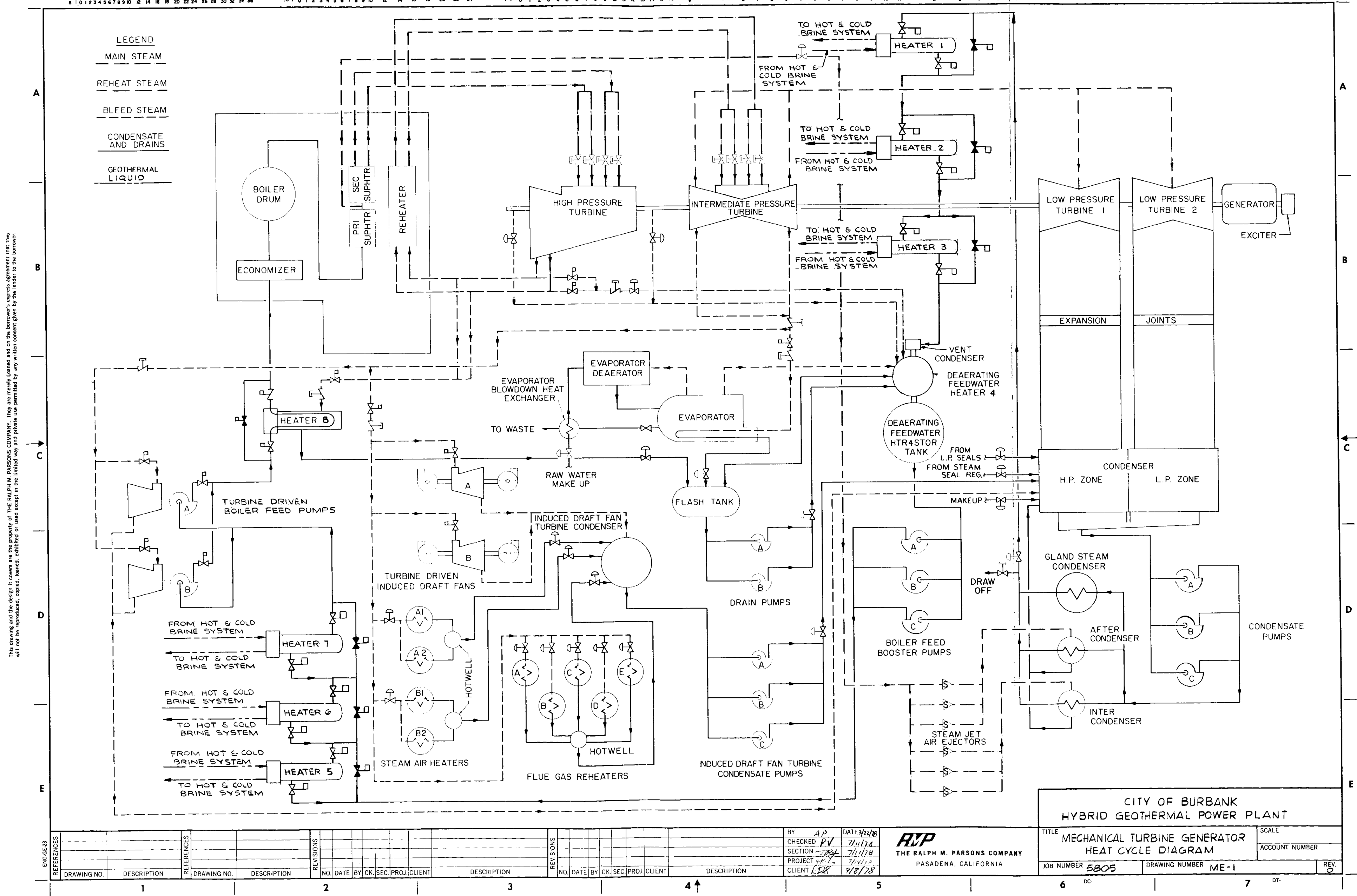




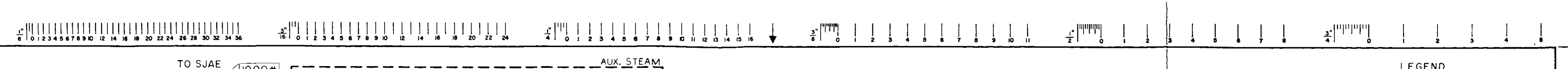

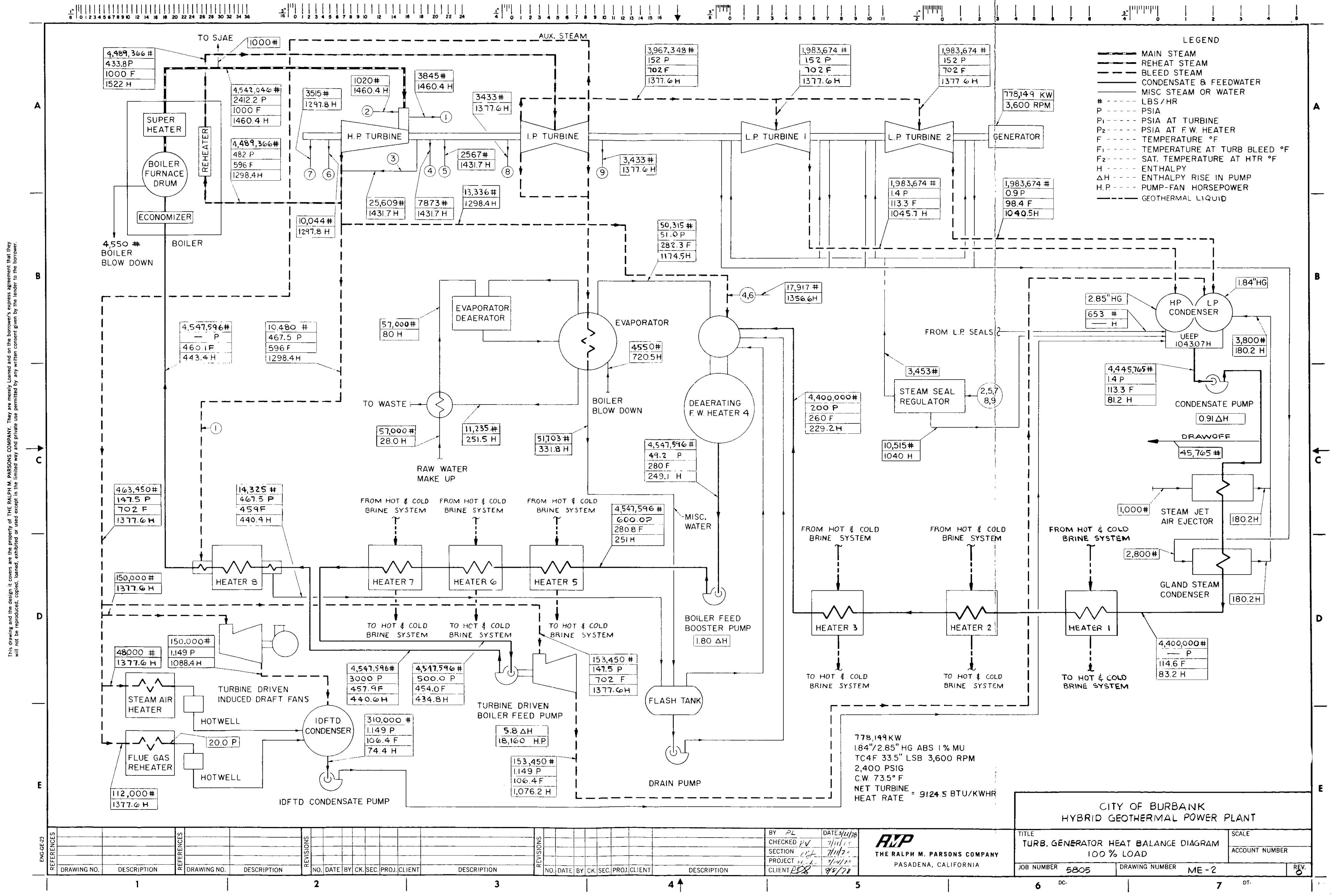




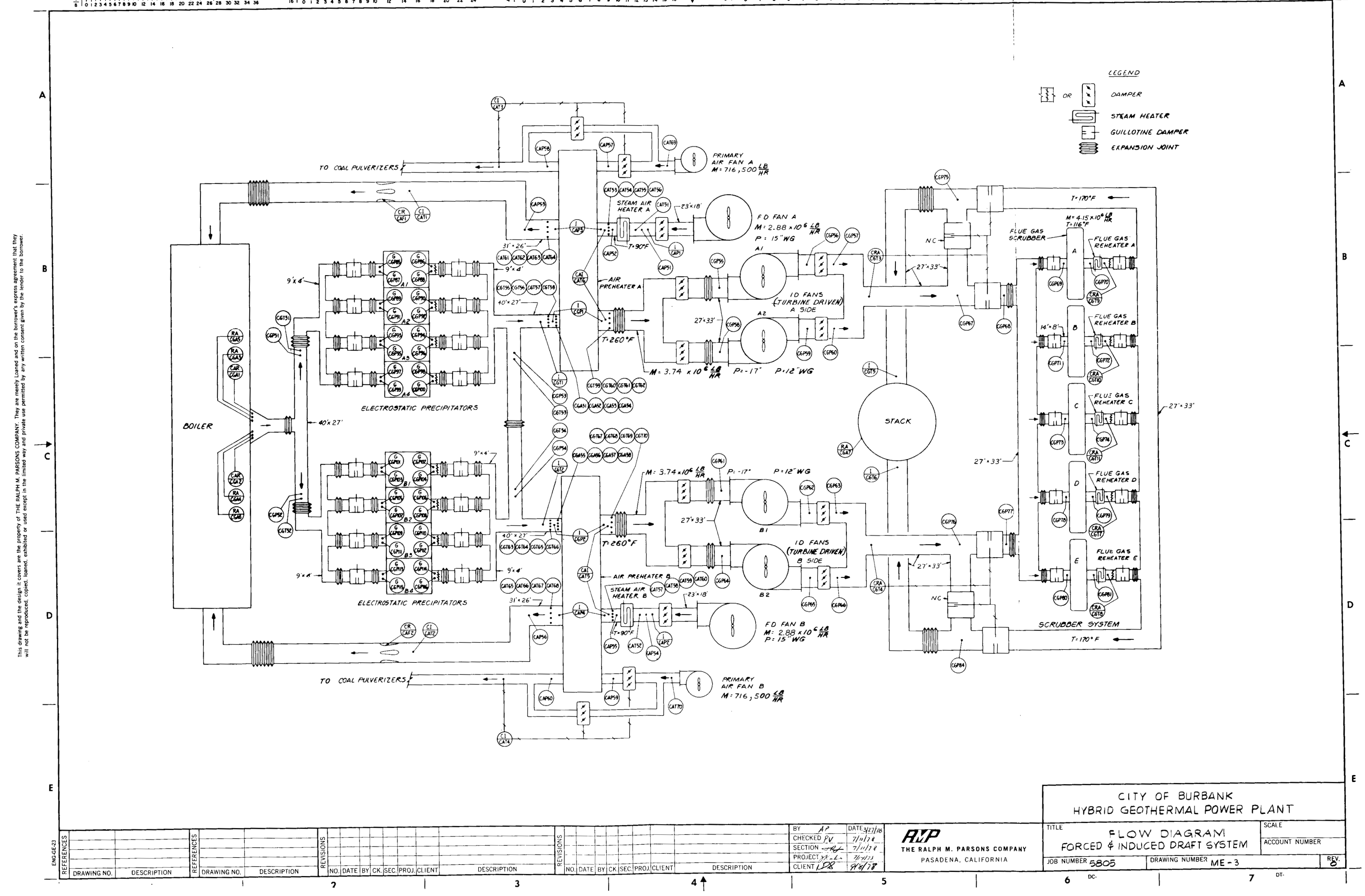




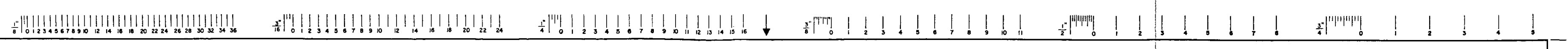

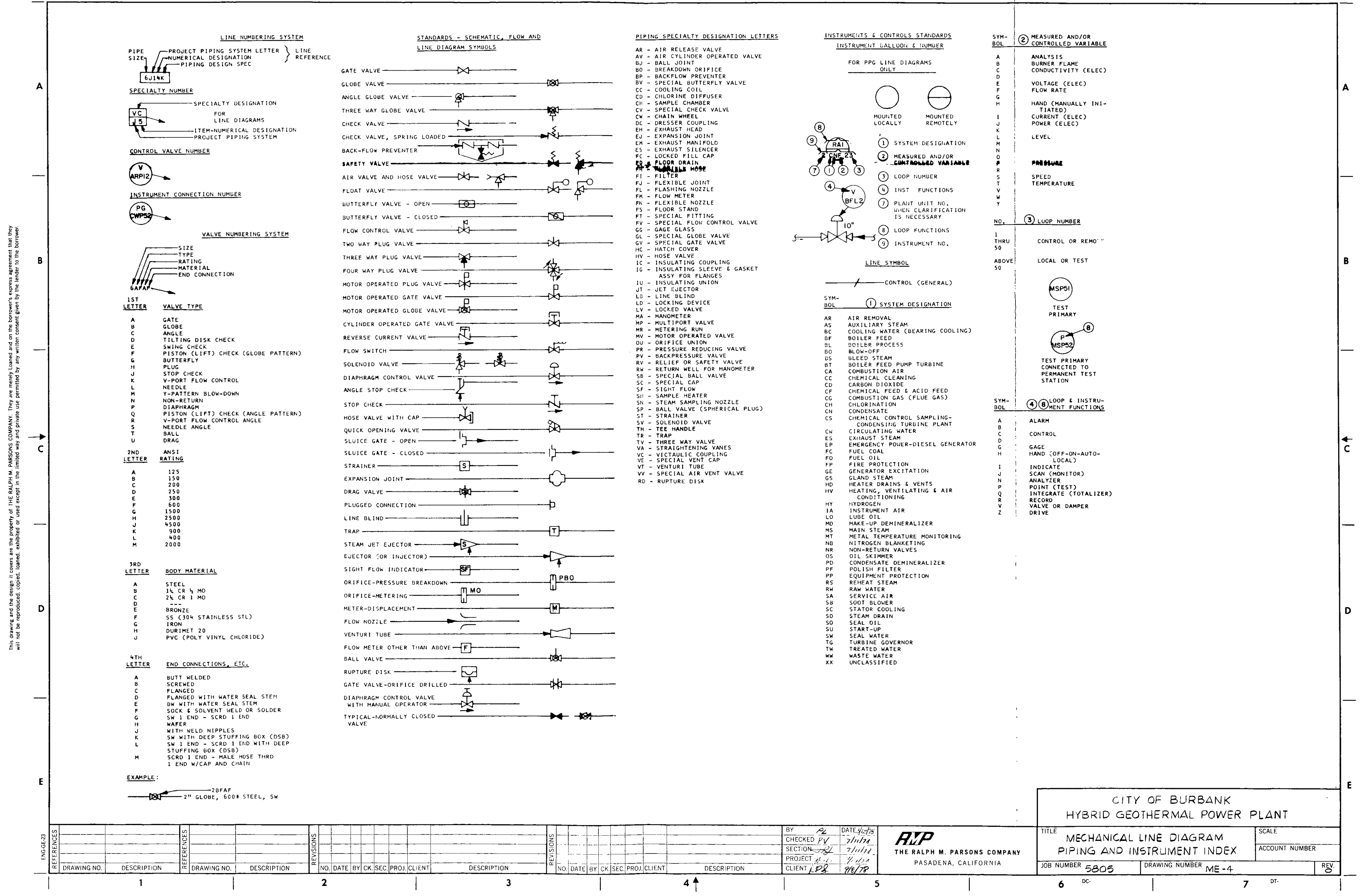


:

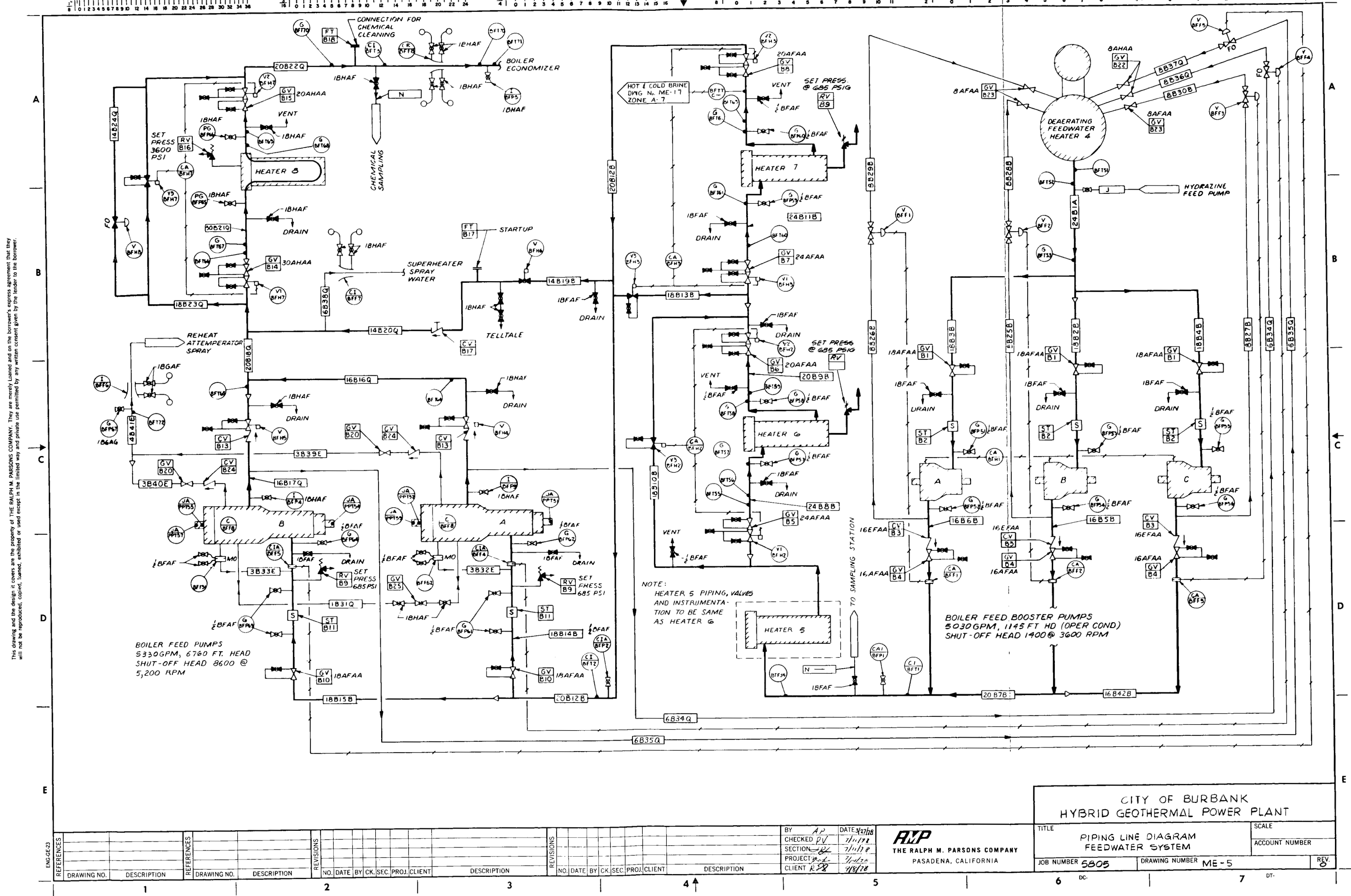


:4!!!!!!!!!!!!!!!!!!!!!!!!!!!!!

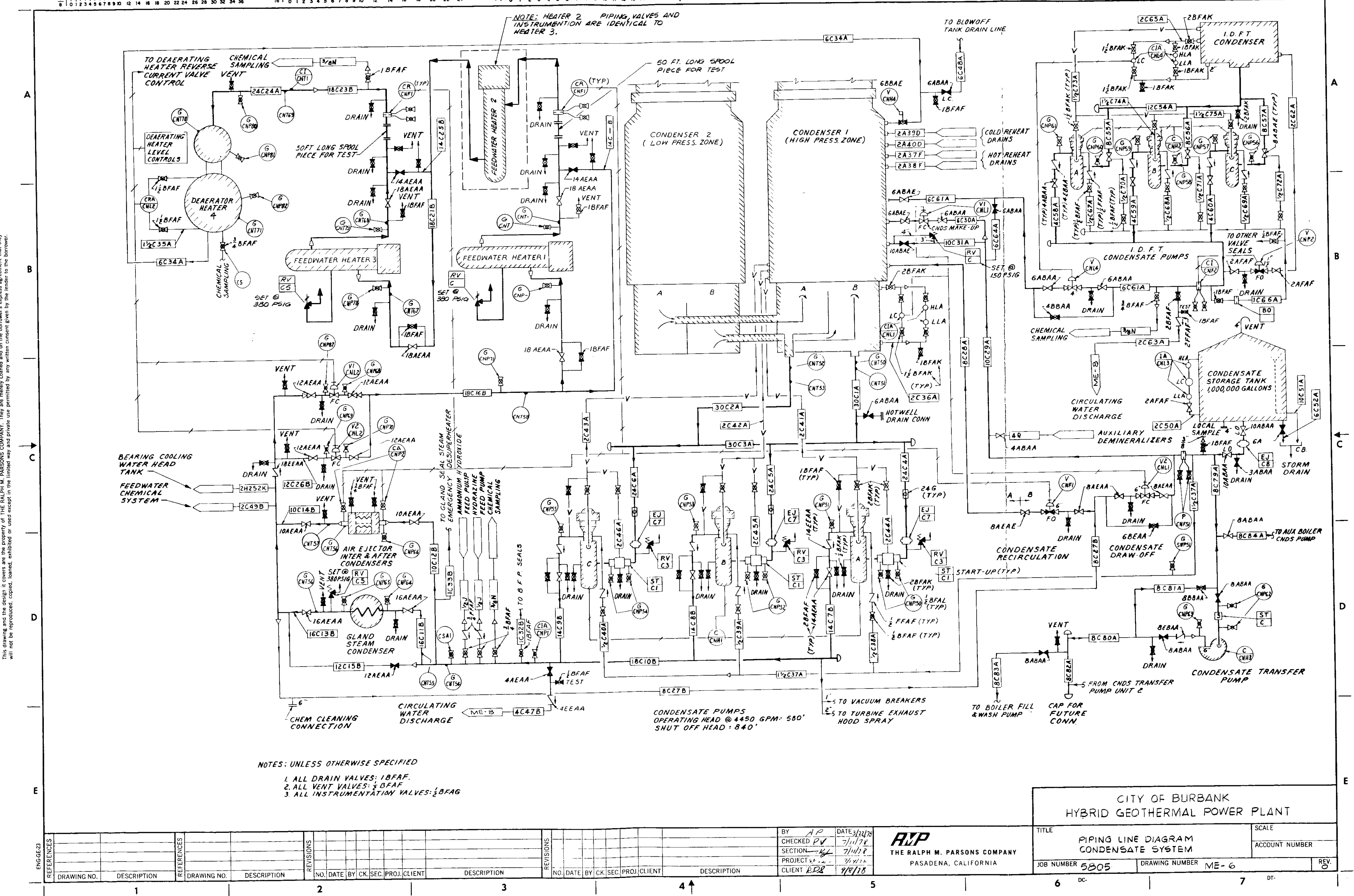




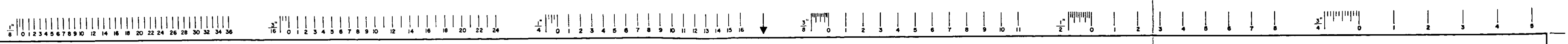

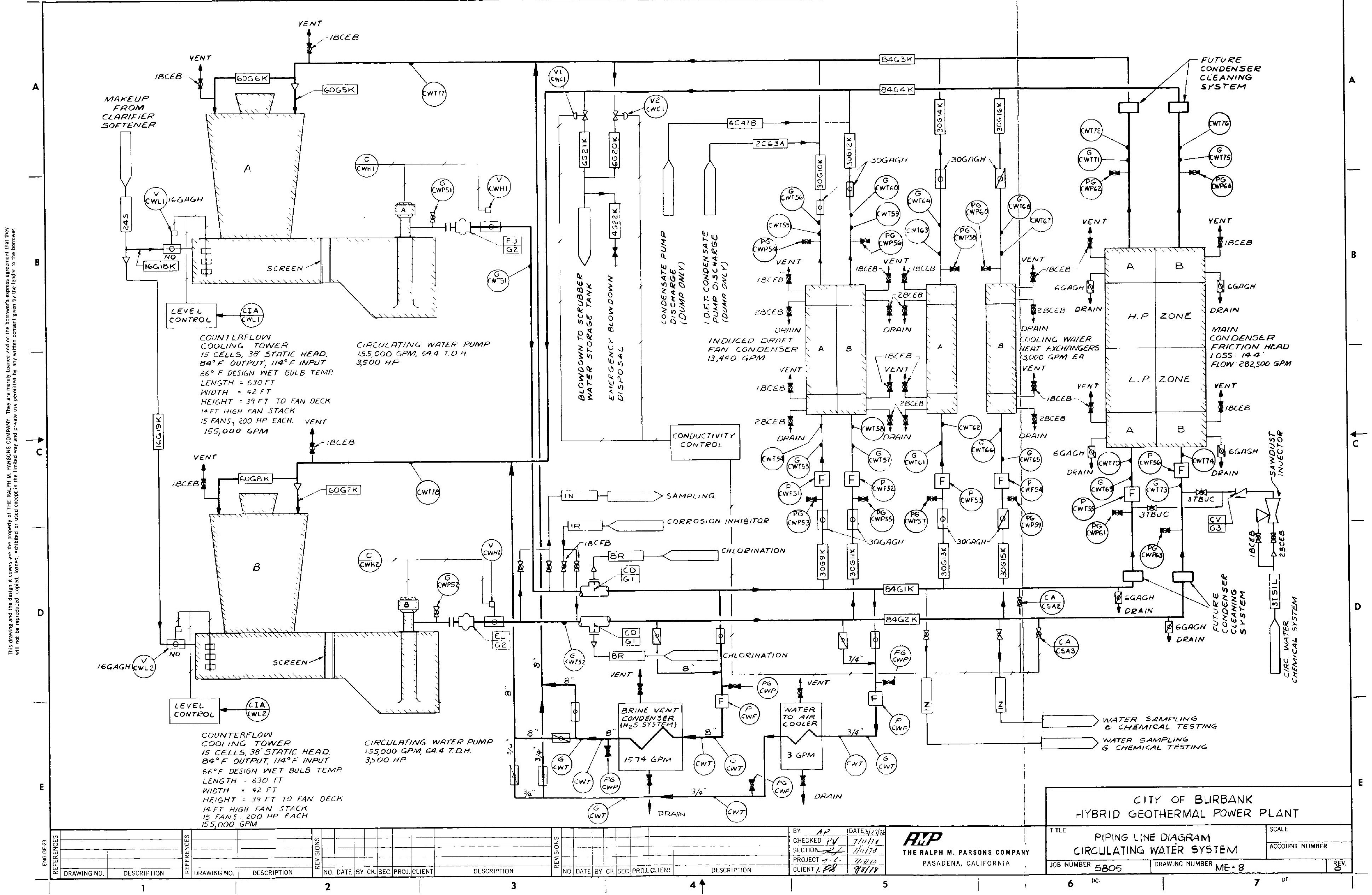




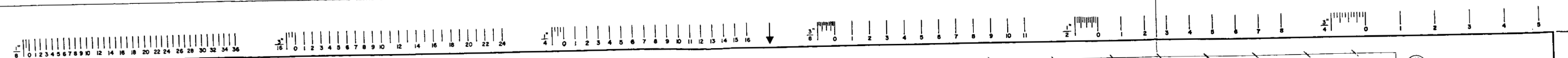

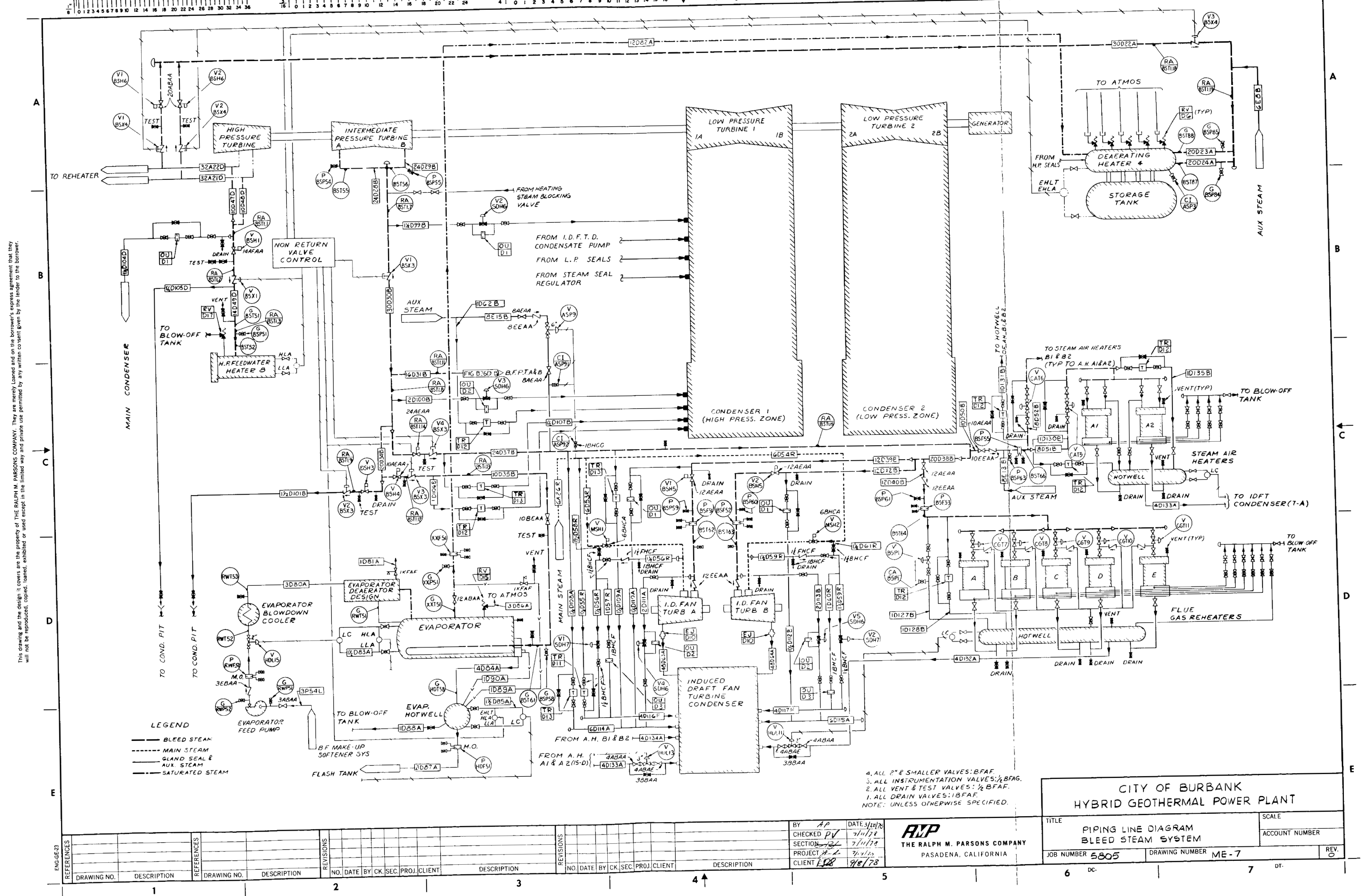




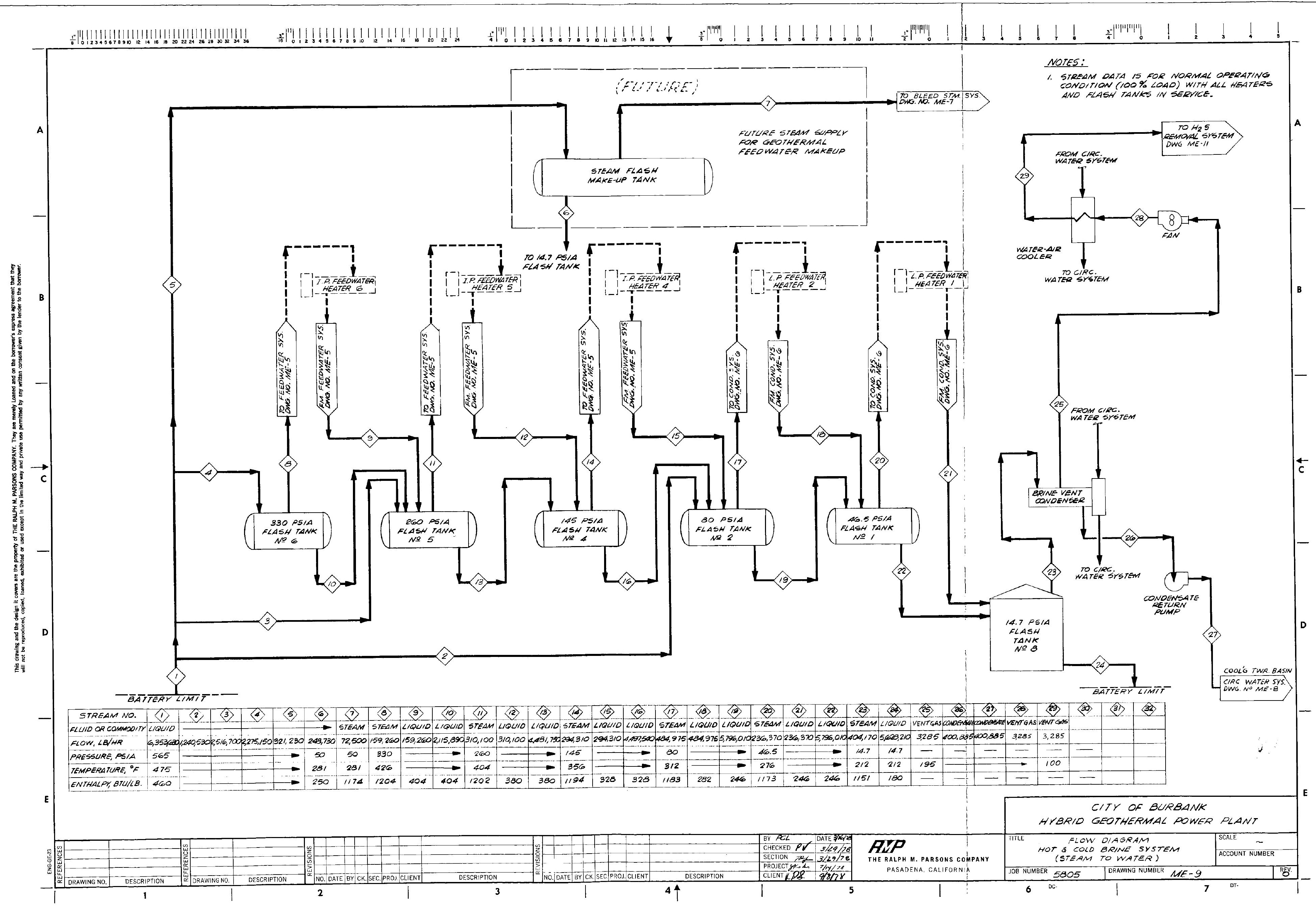




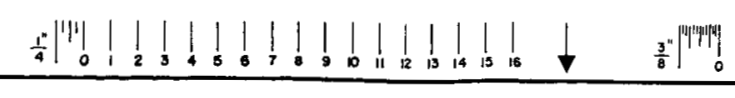

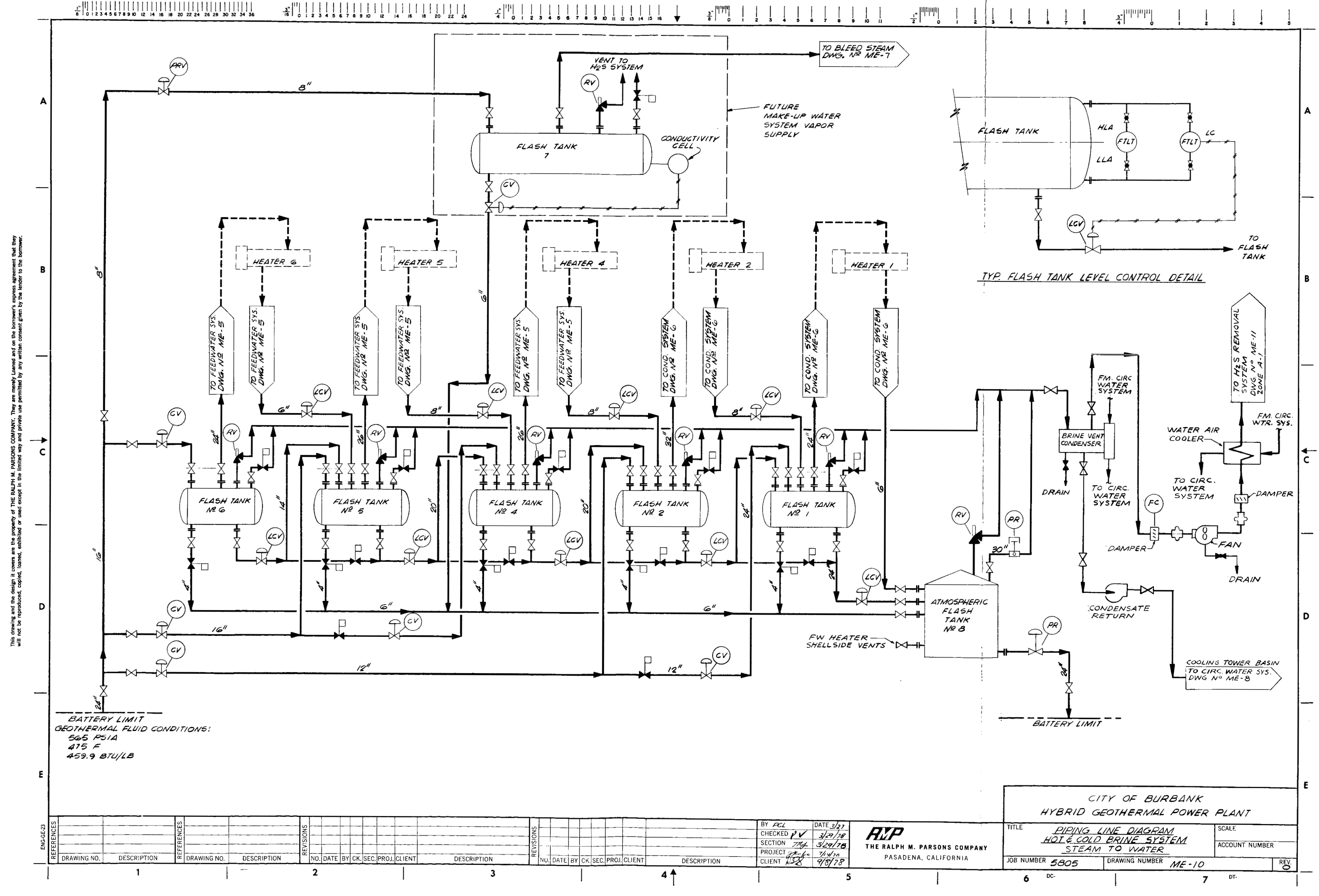




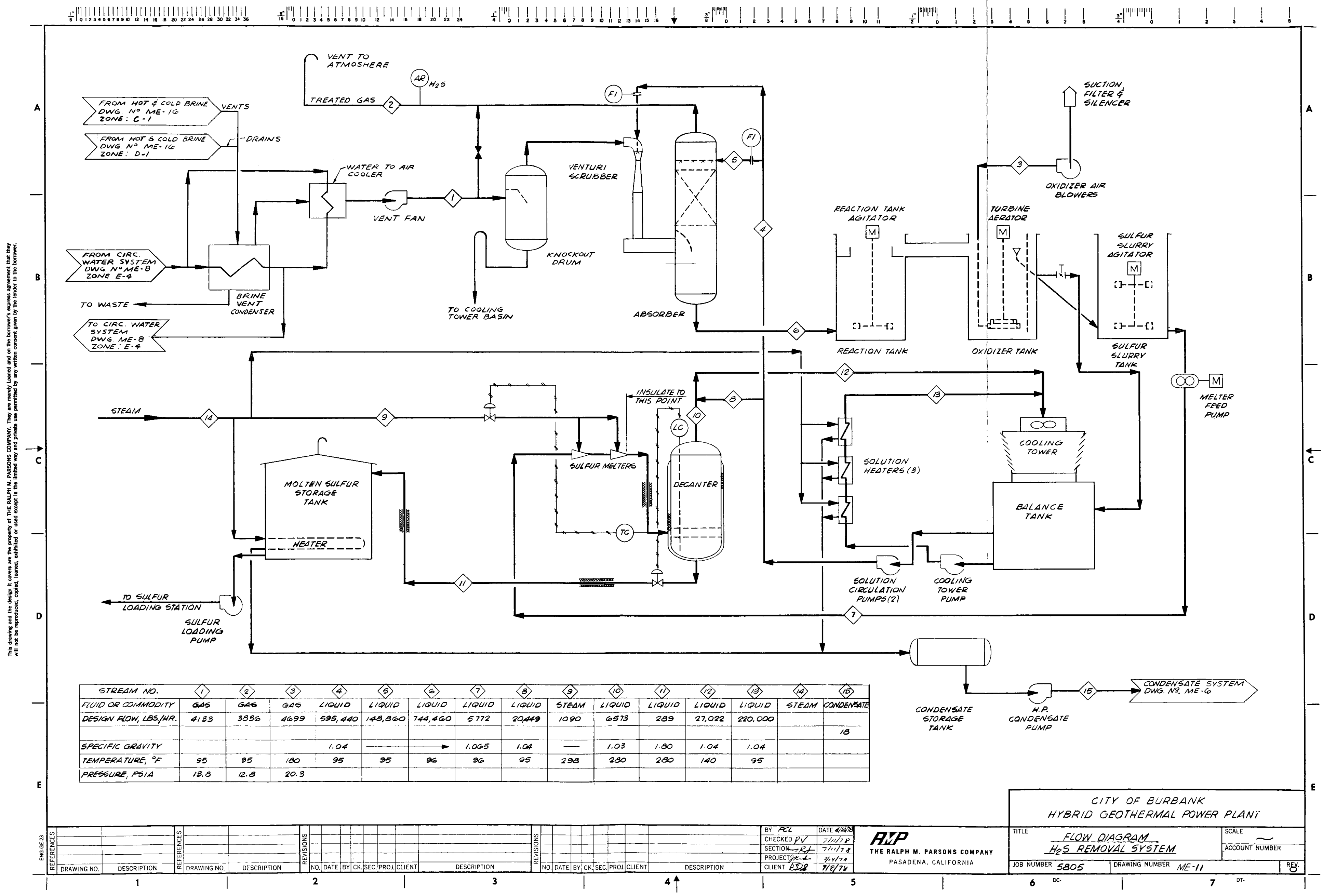




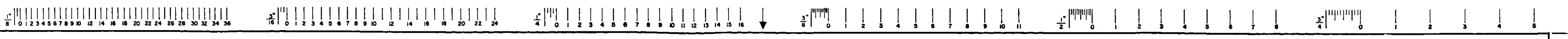

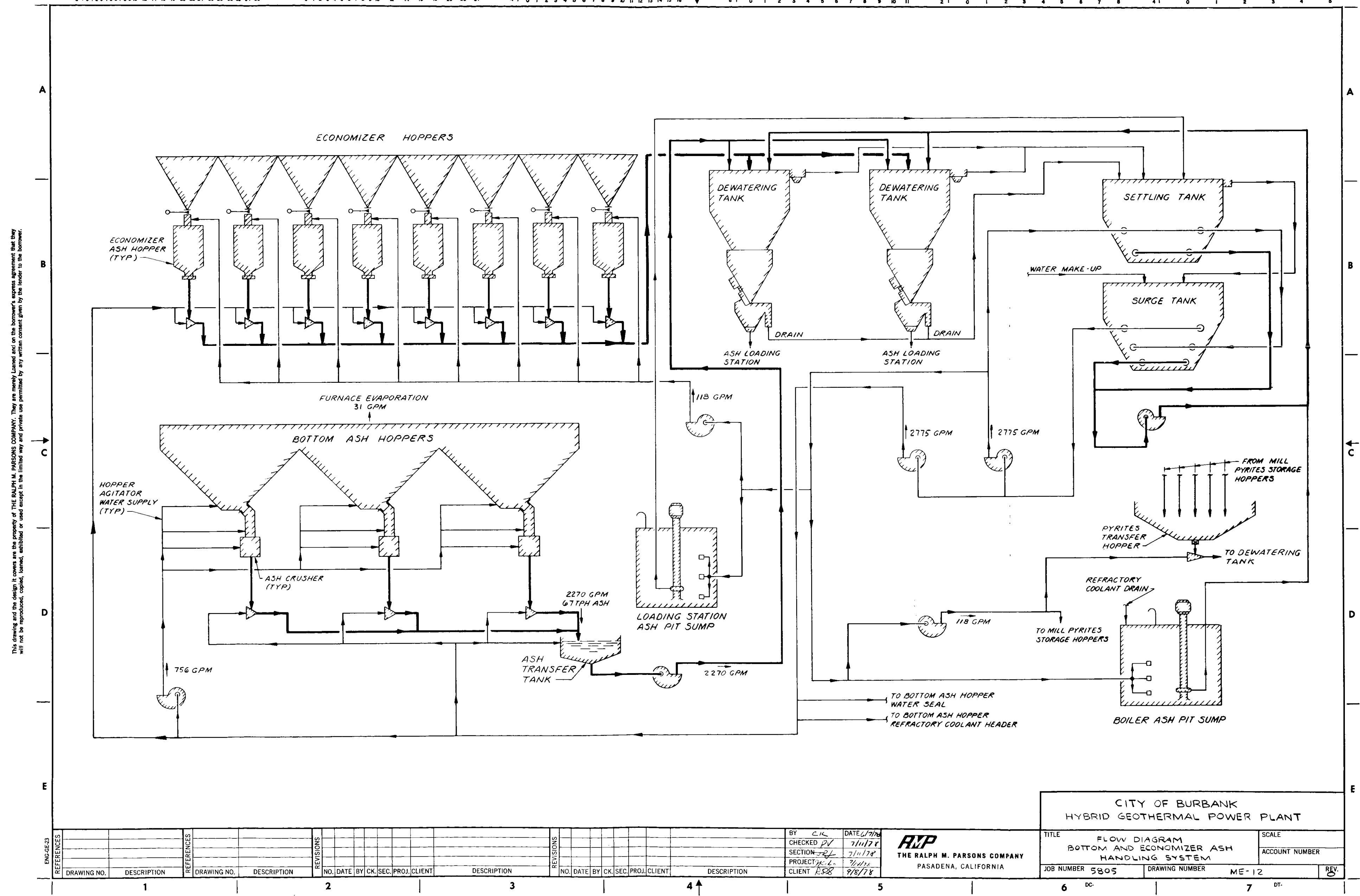




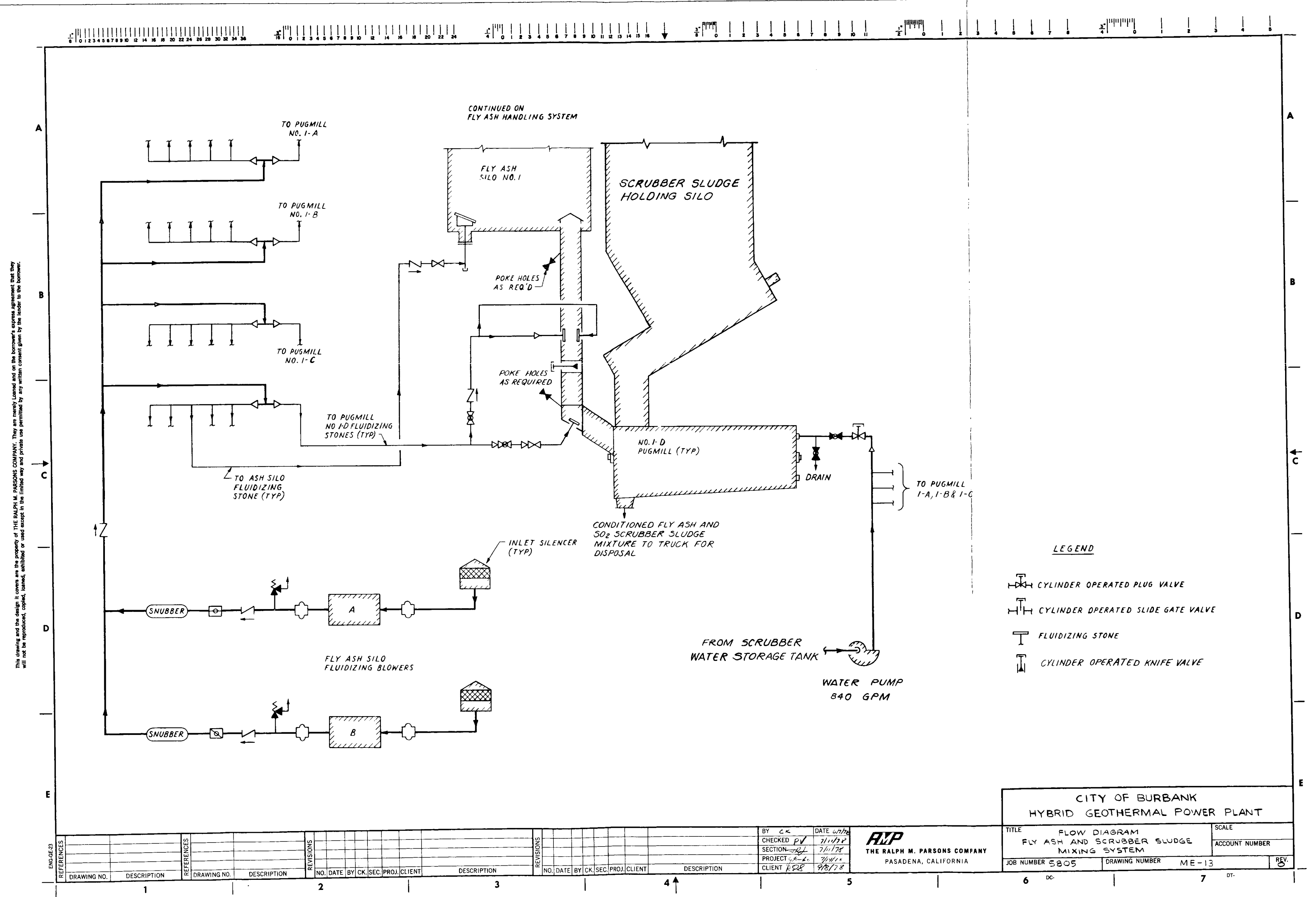




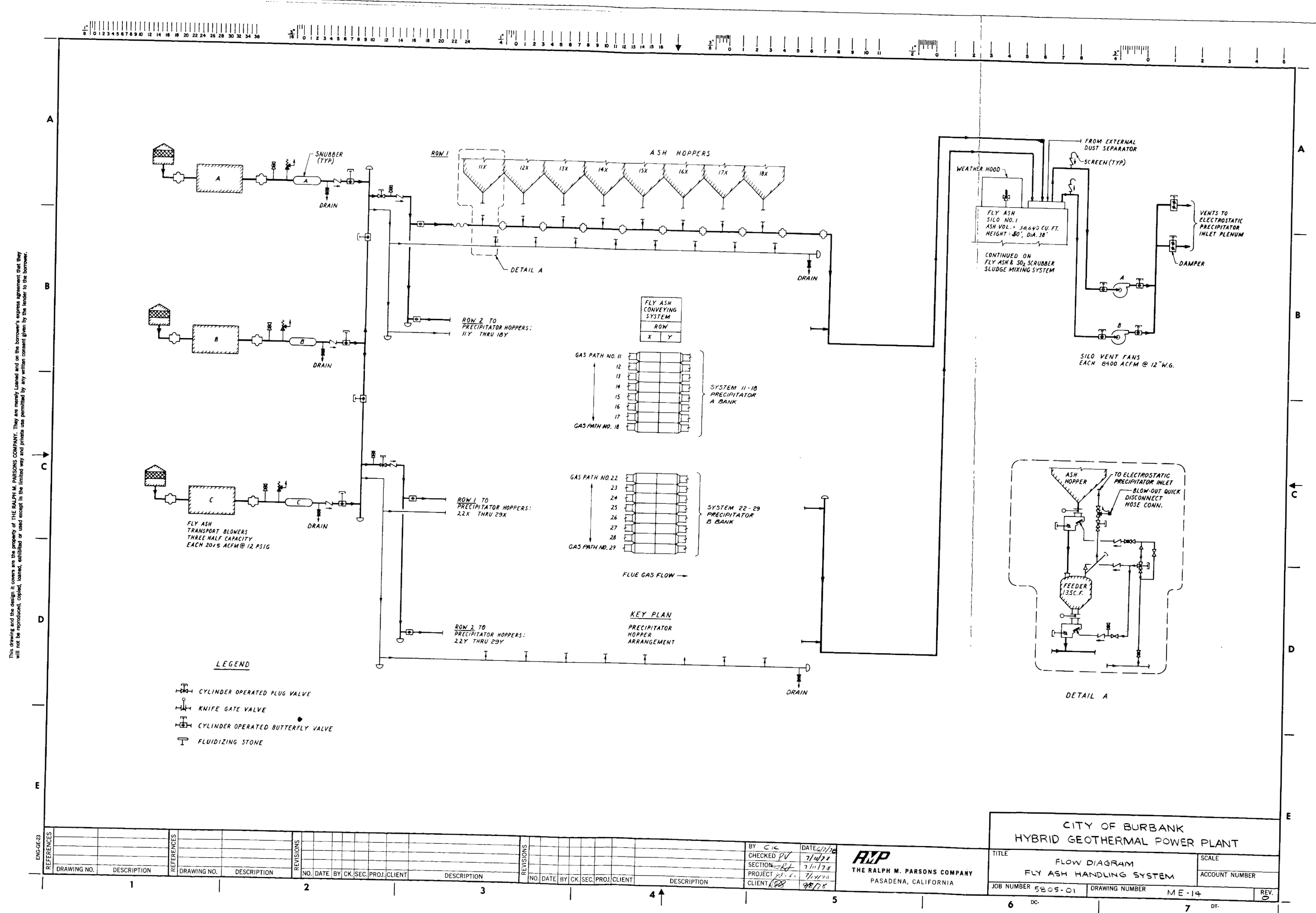




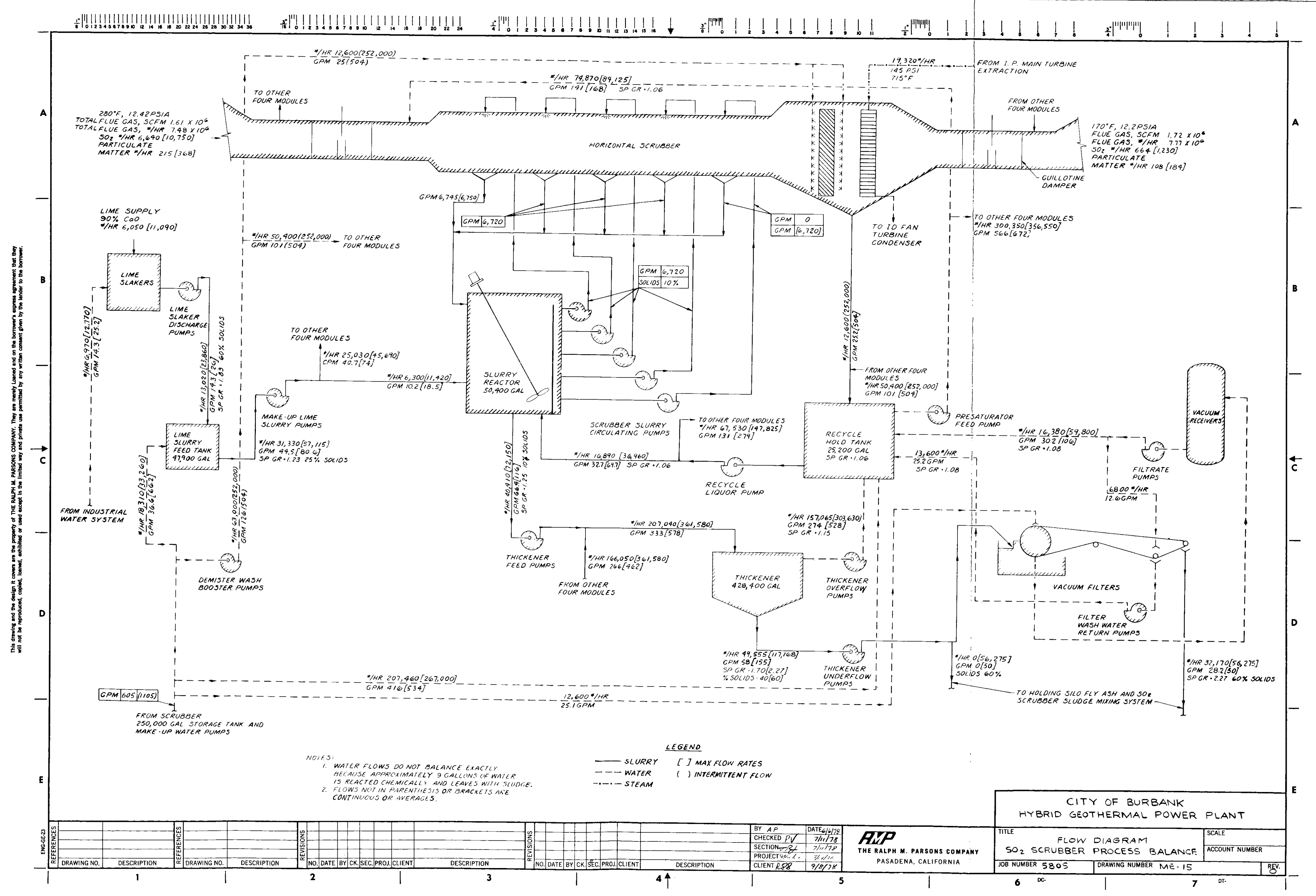


(4)

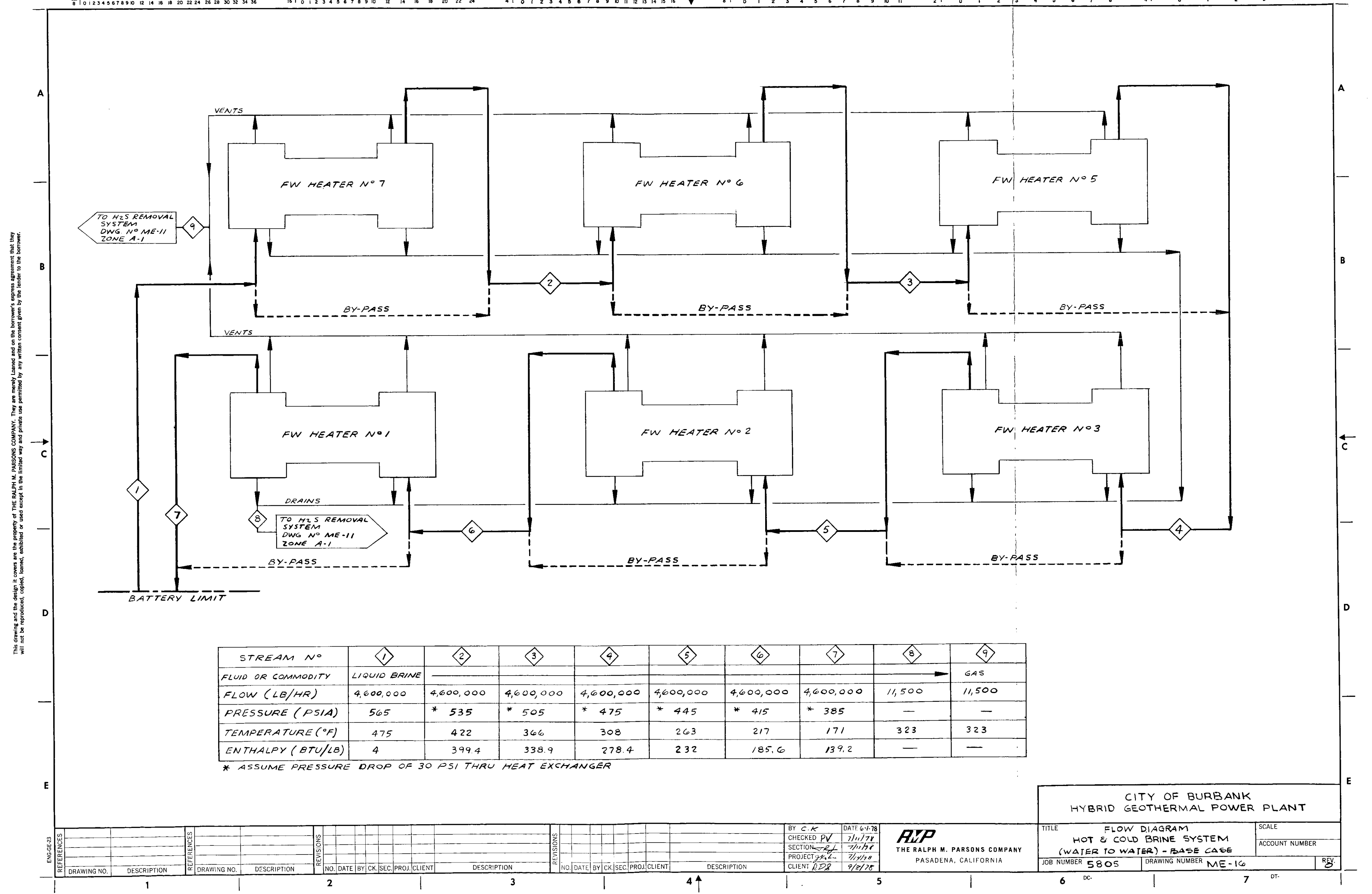




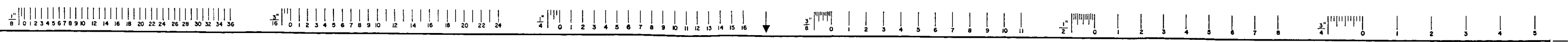

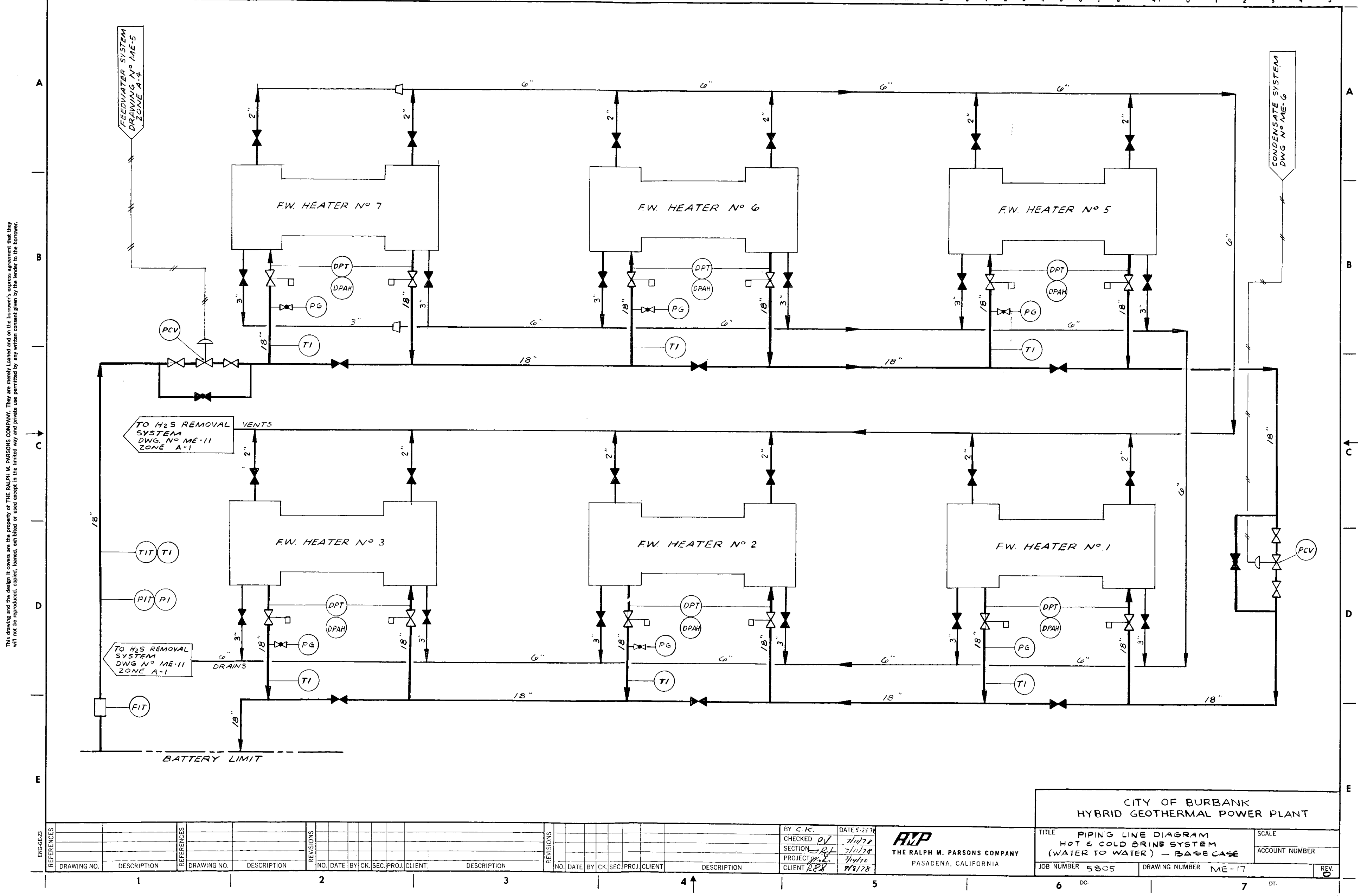




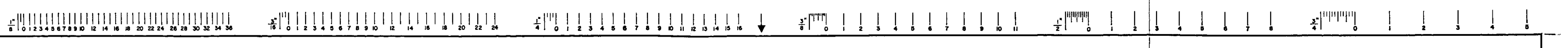

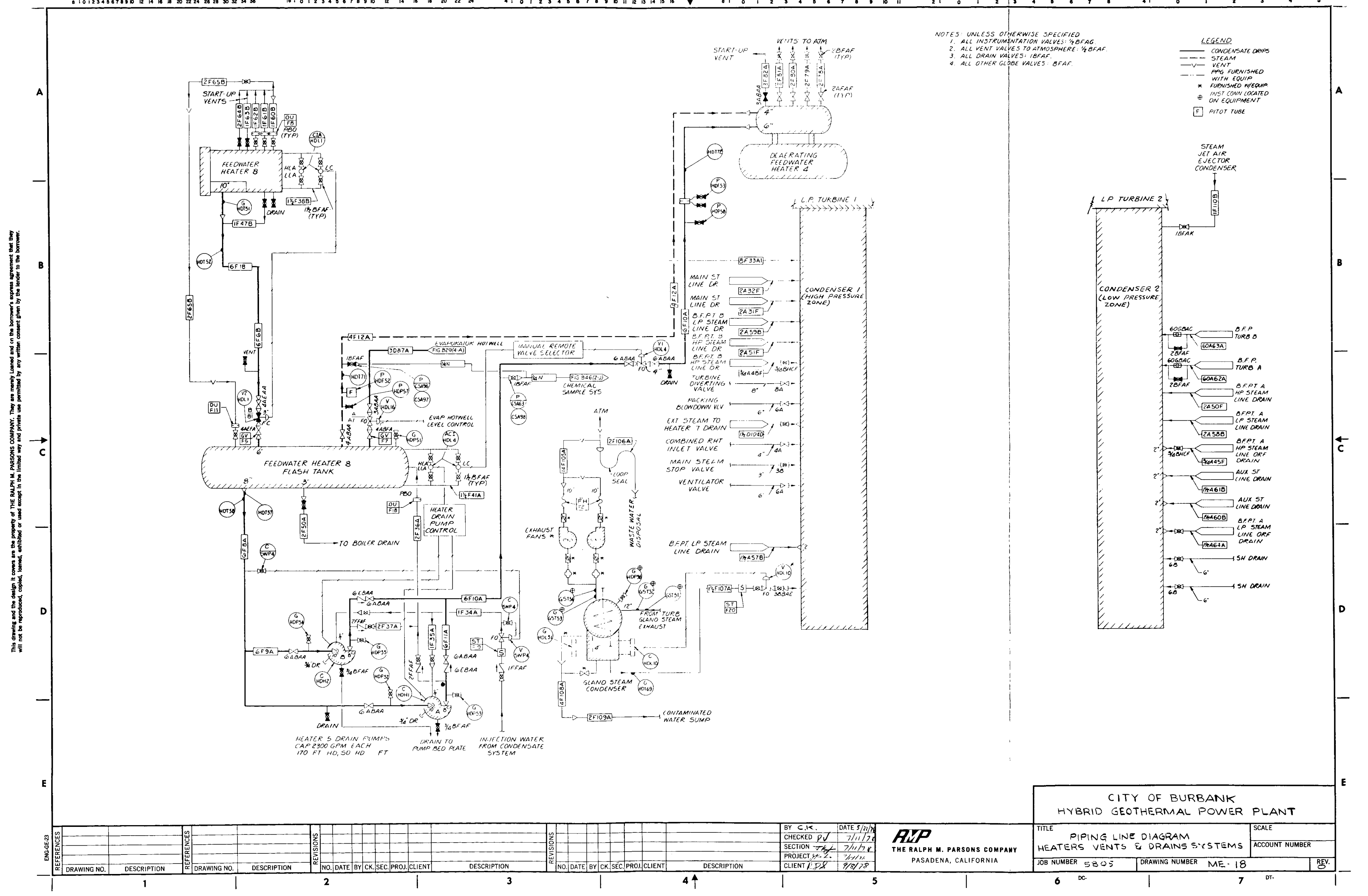




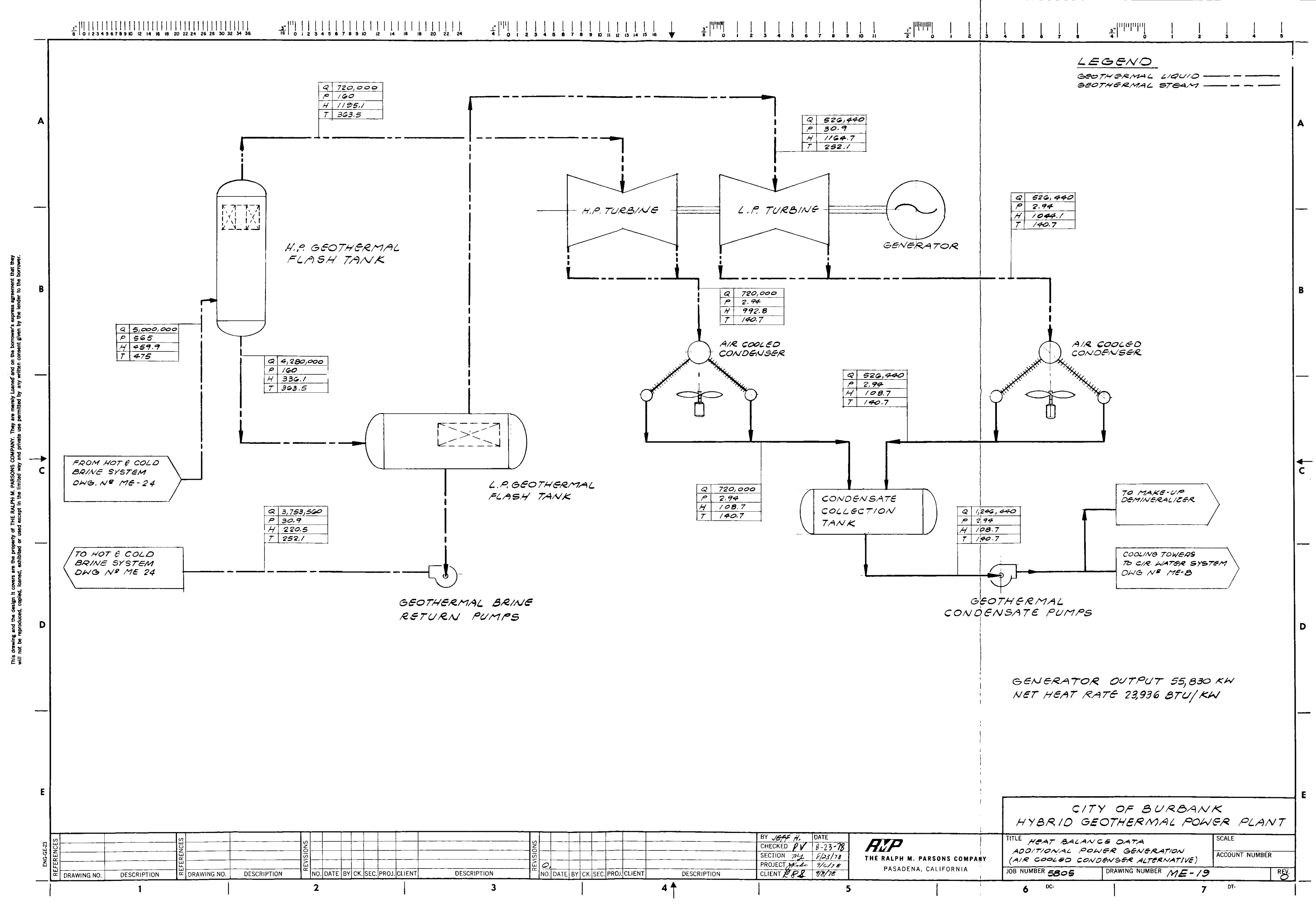




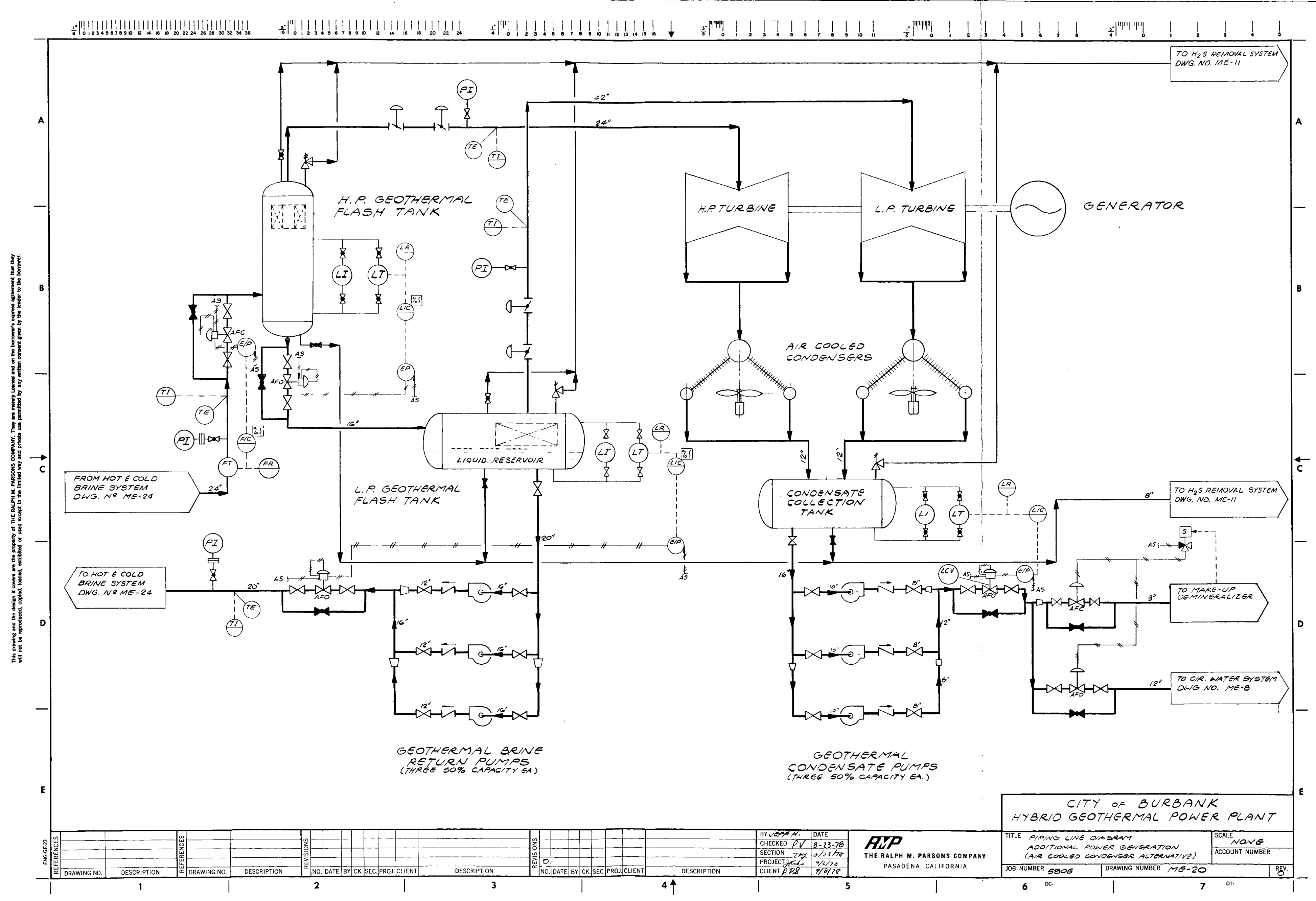




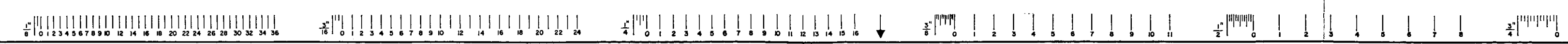

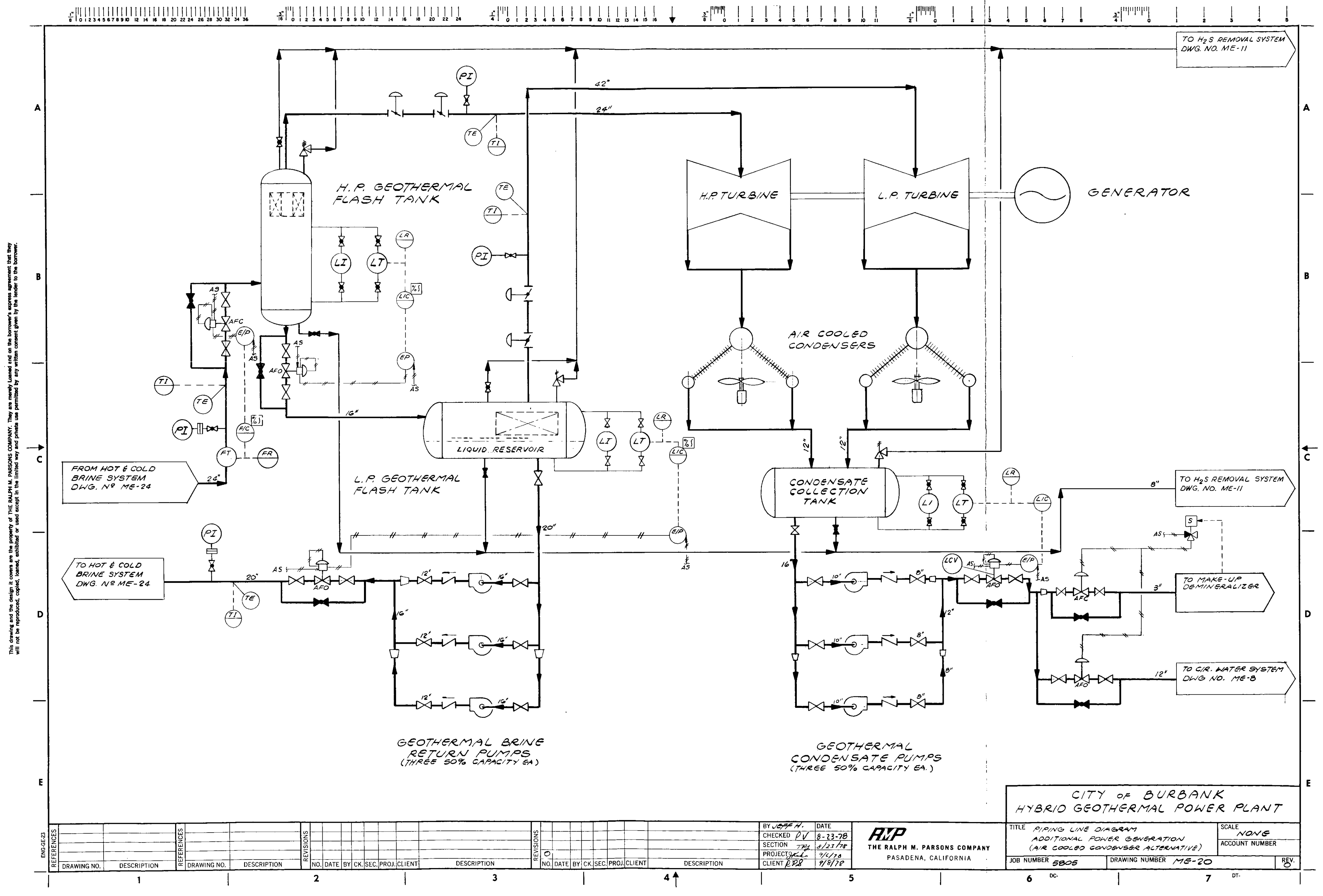




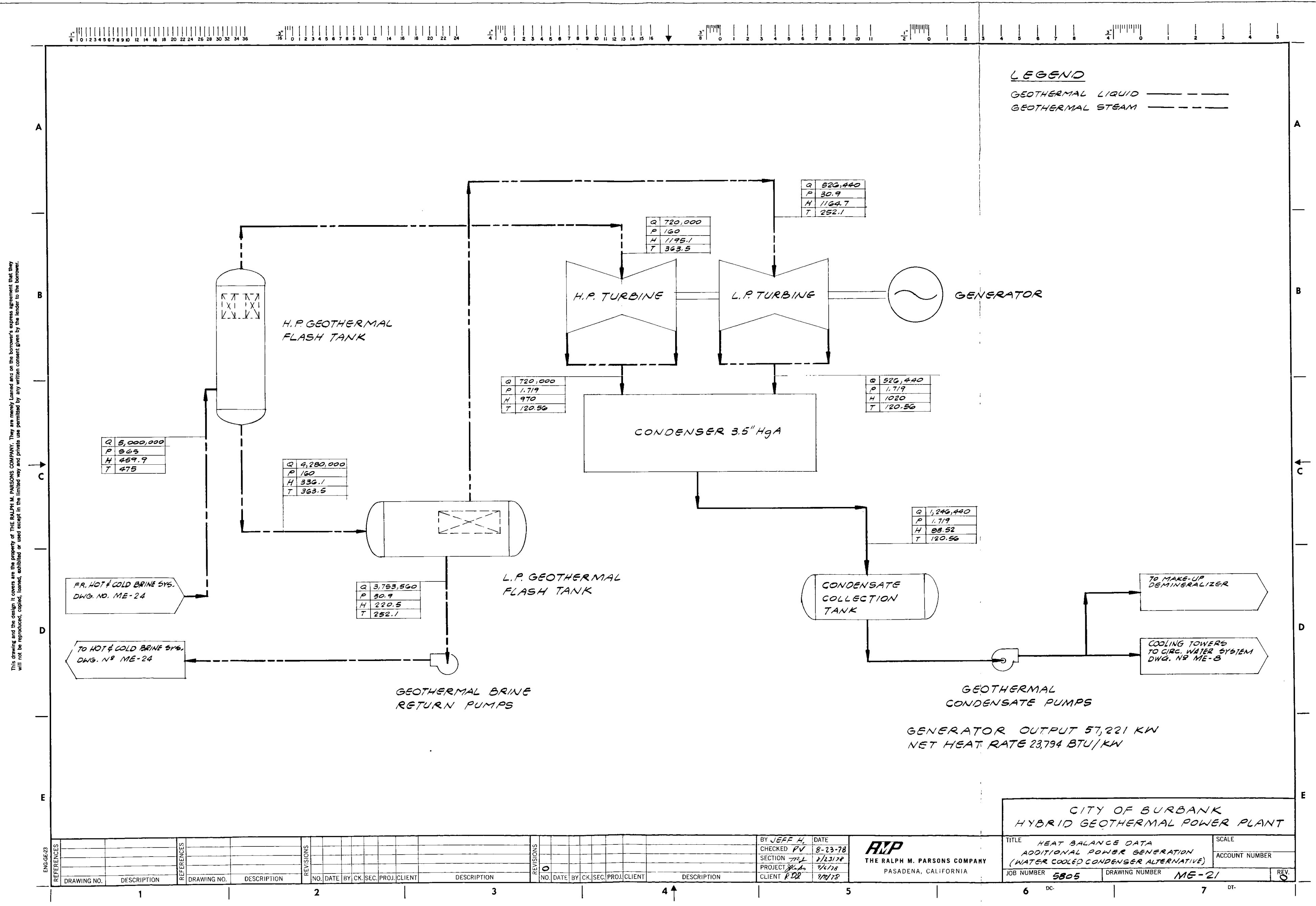


:

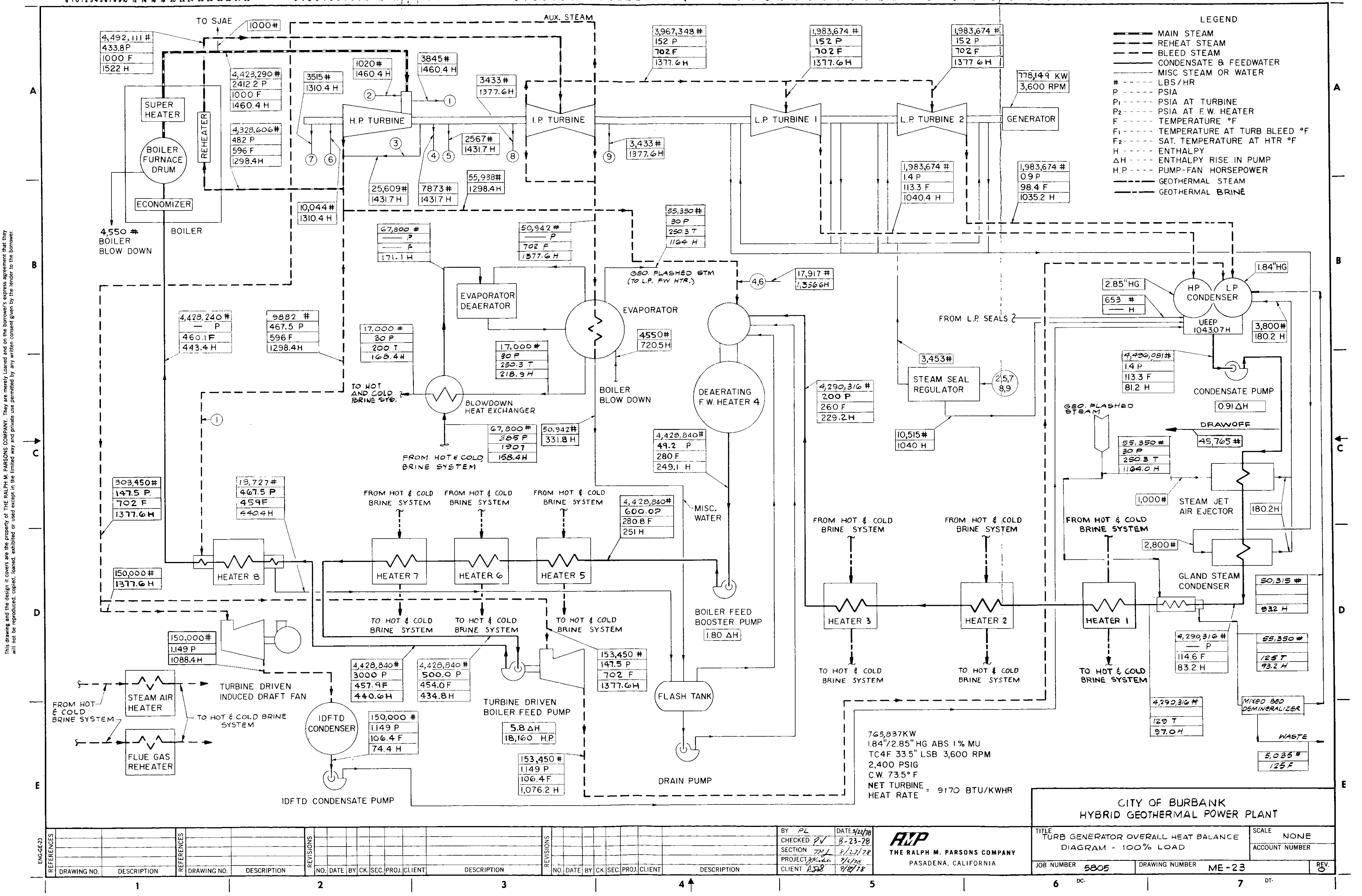




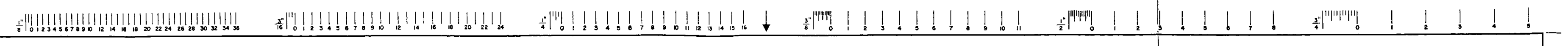

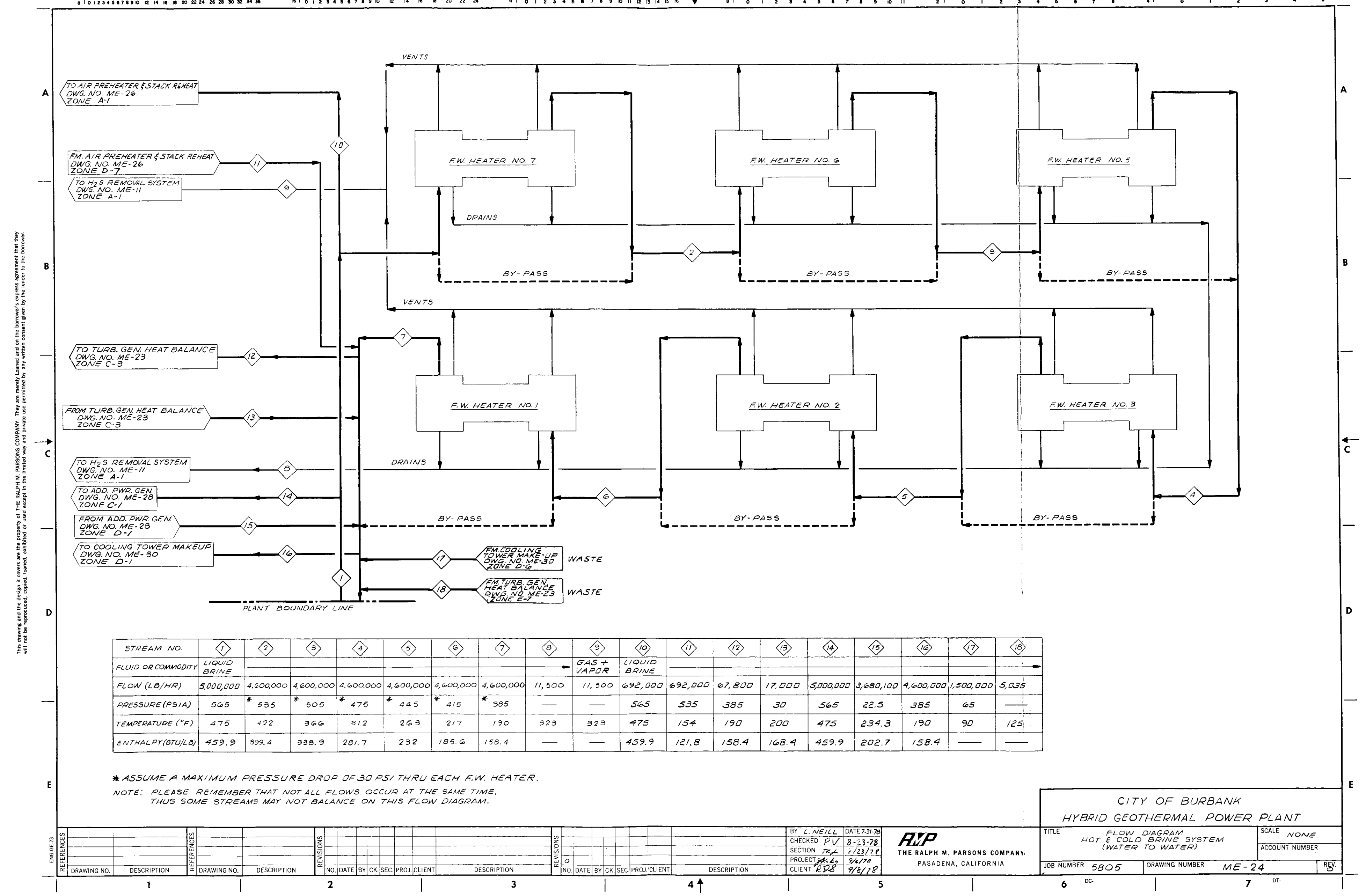




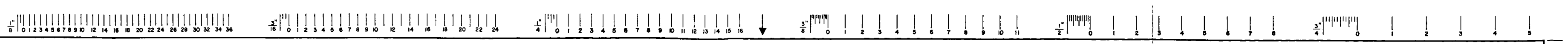

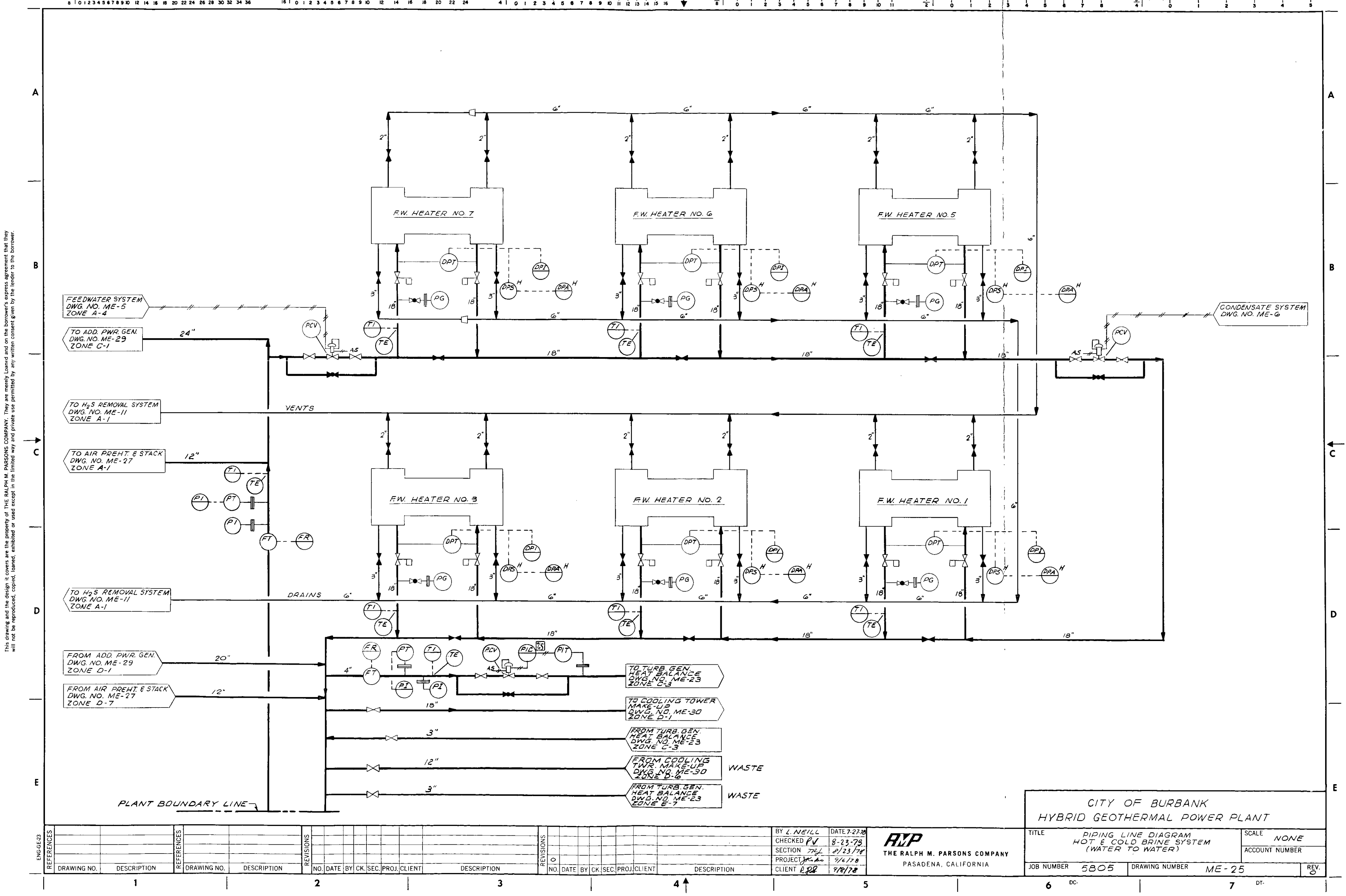




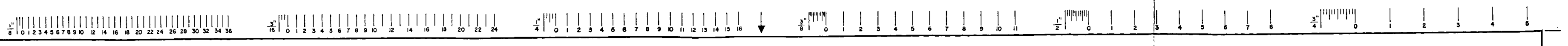

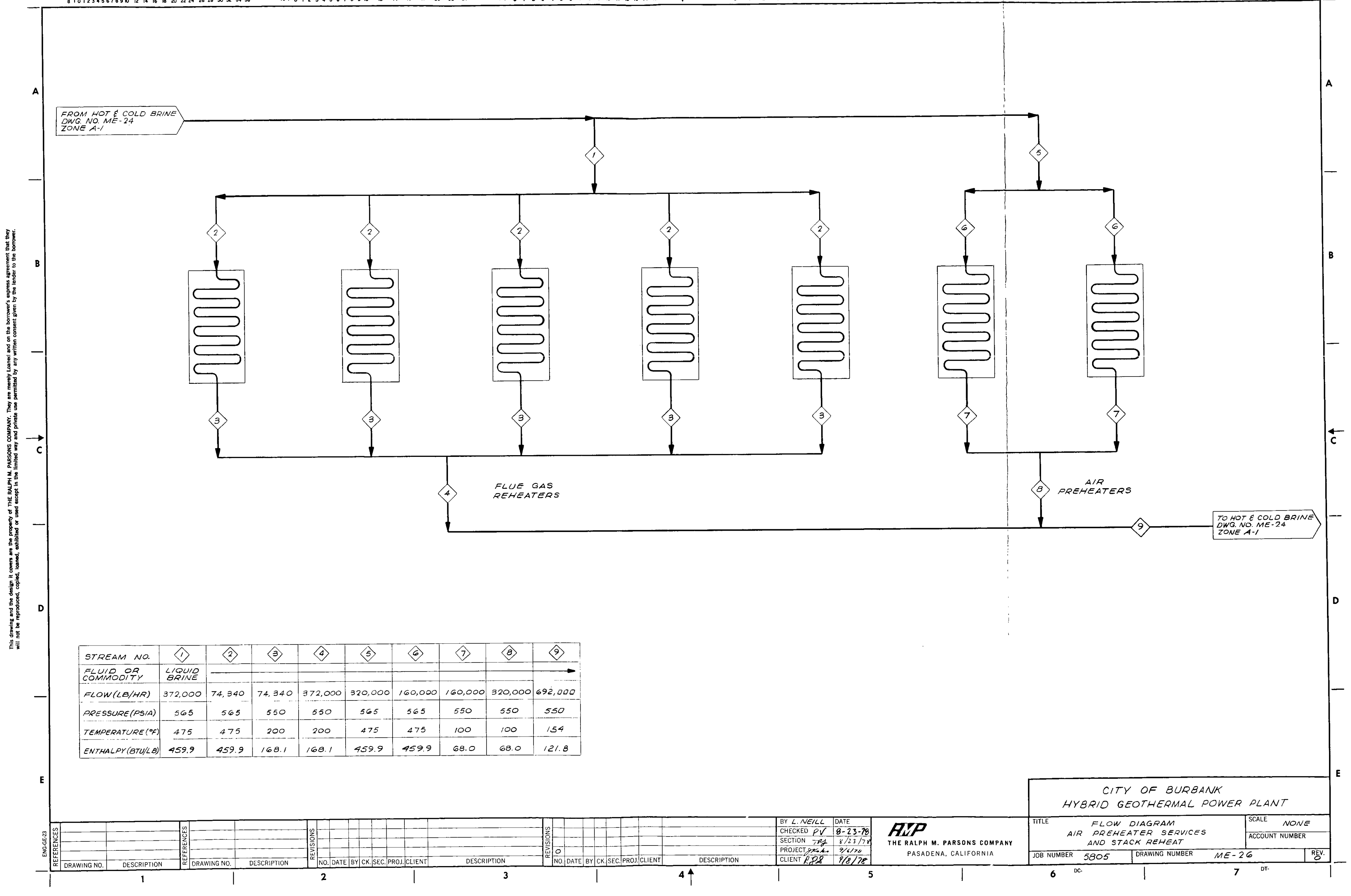




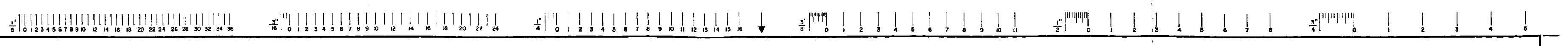

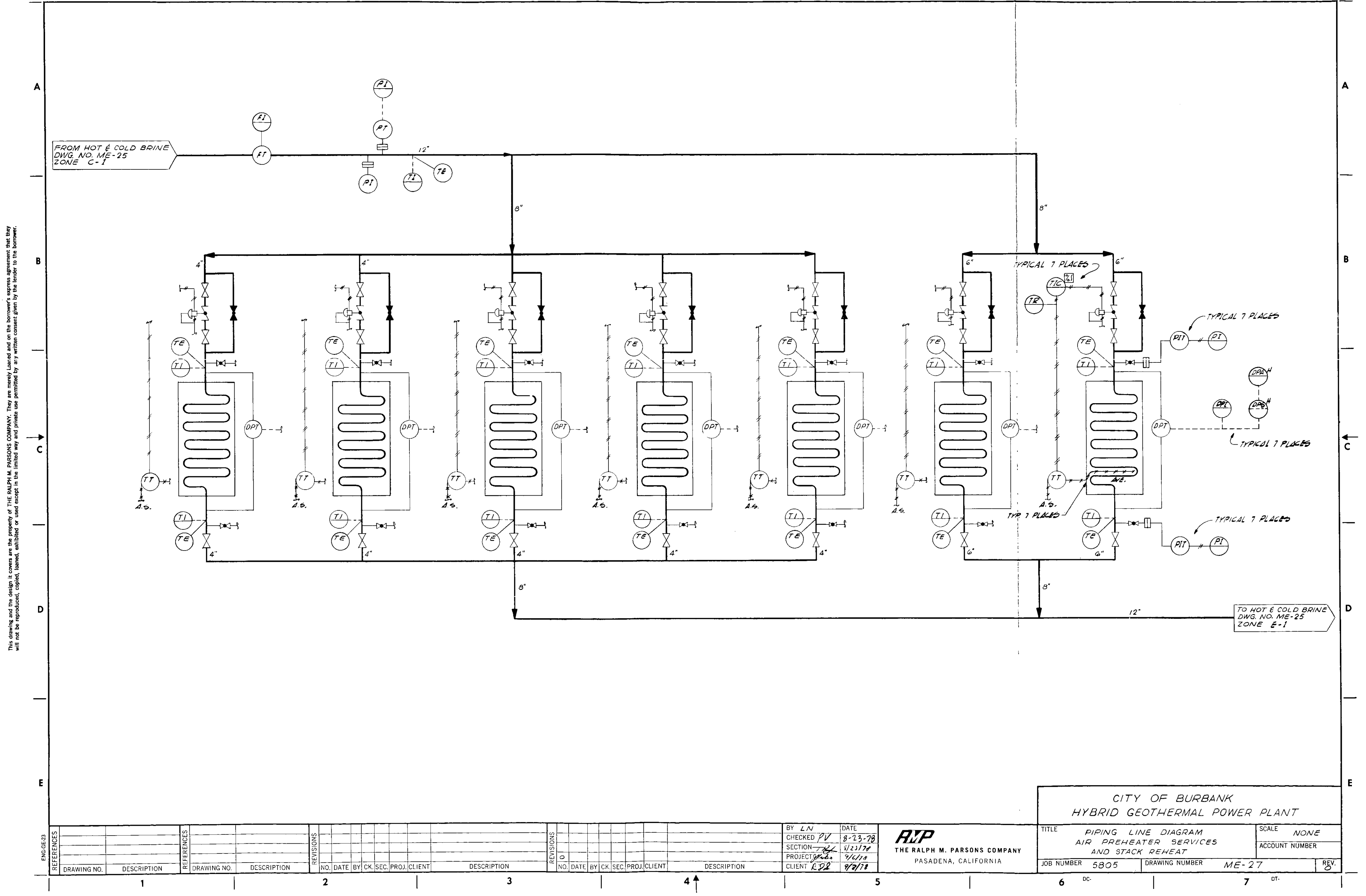




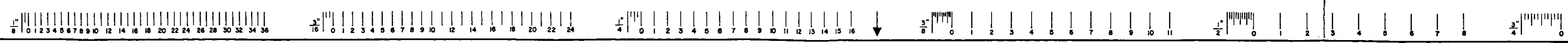

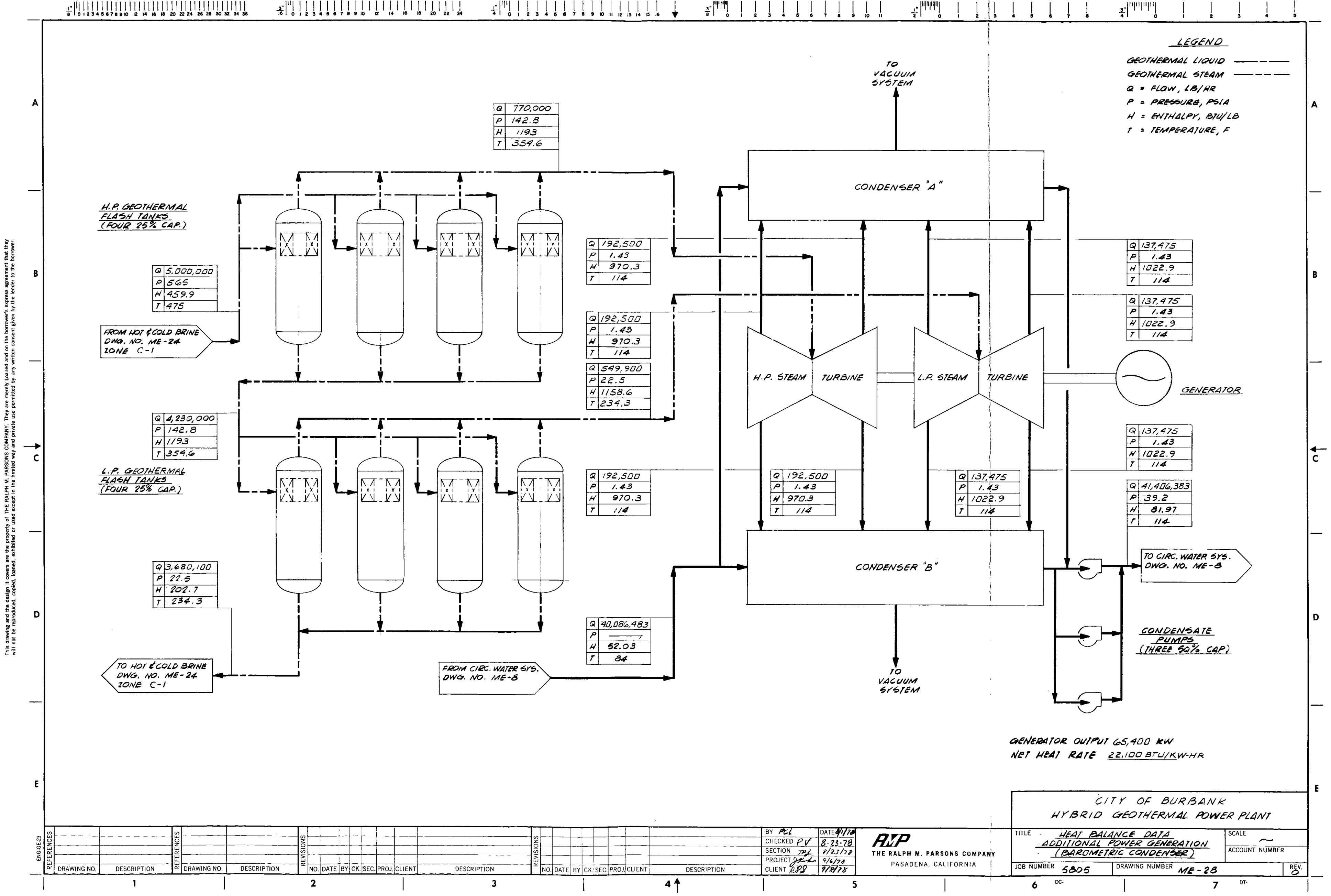


:

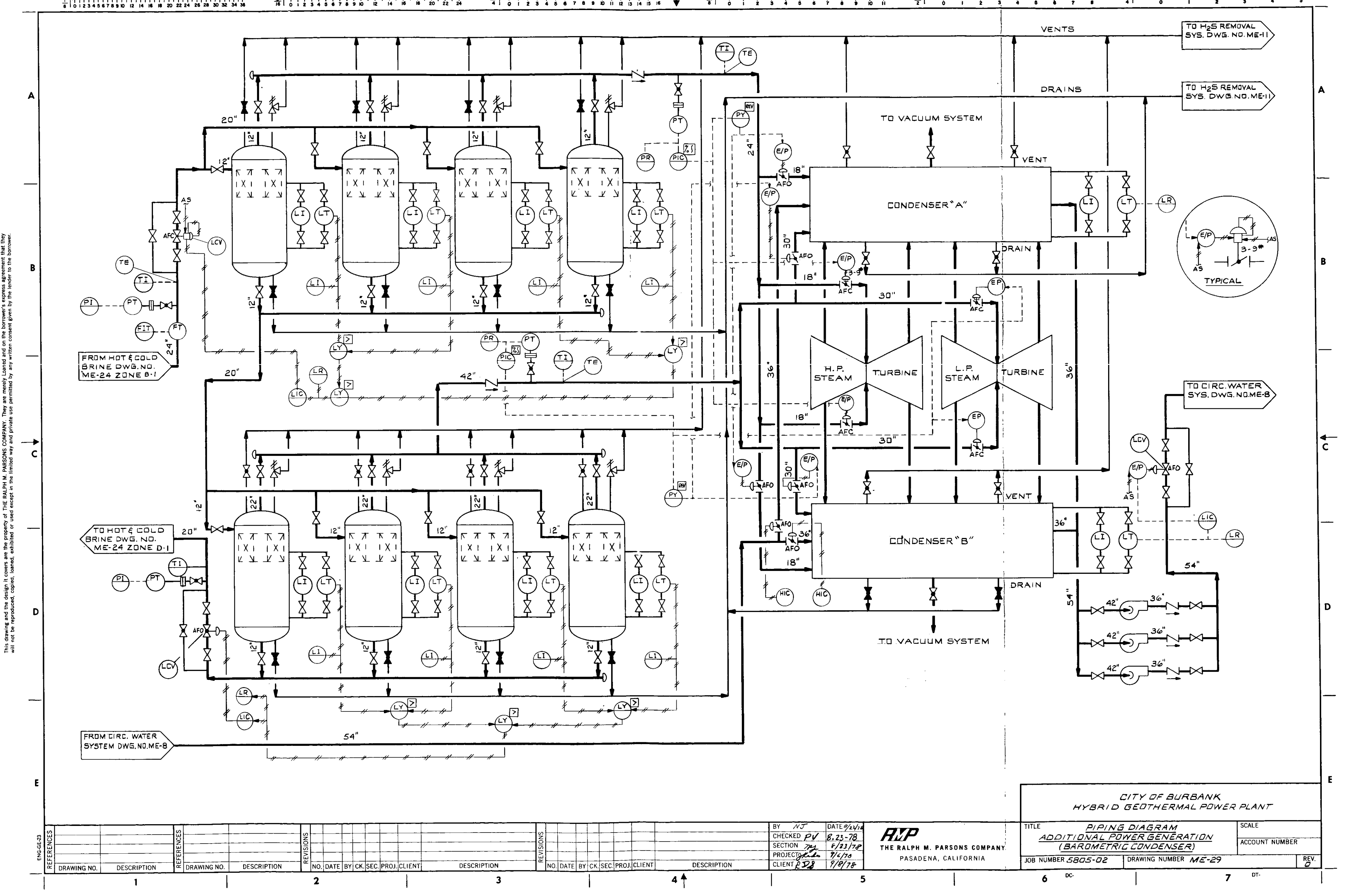


ำ

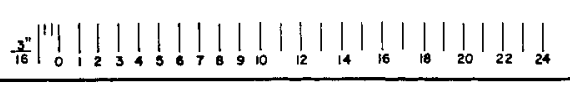

:

fm!m! ! ! ! ! ! ! ! ! !

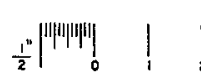

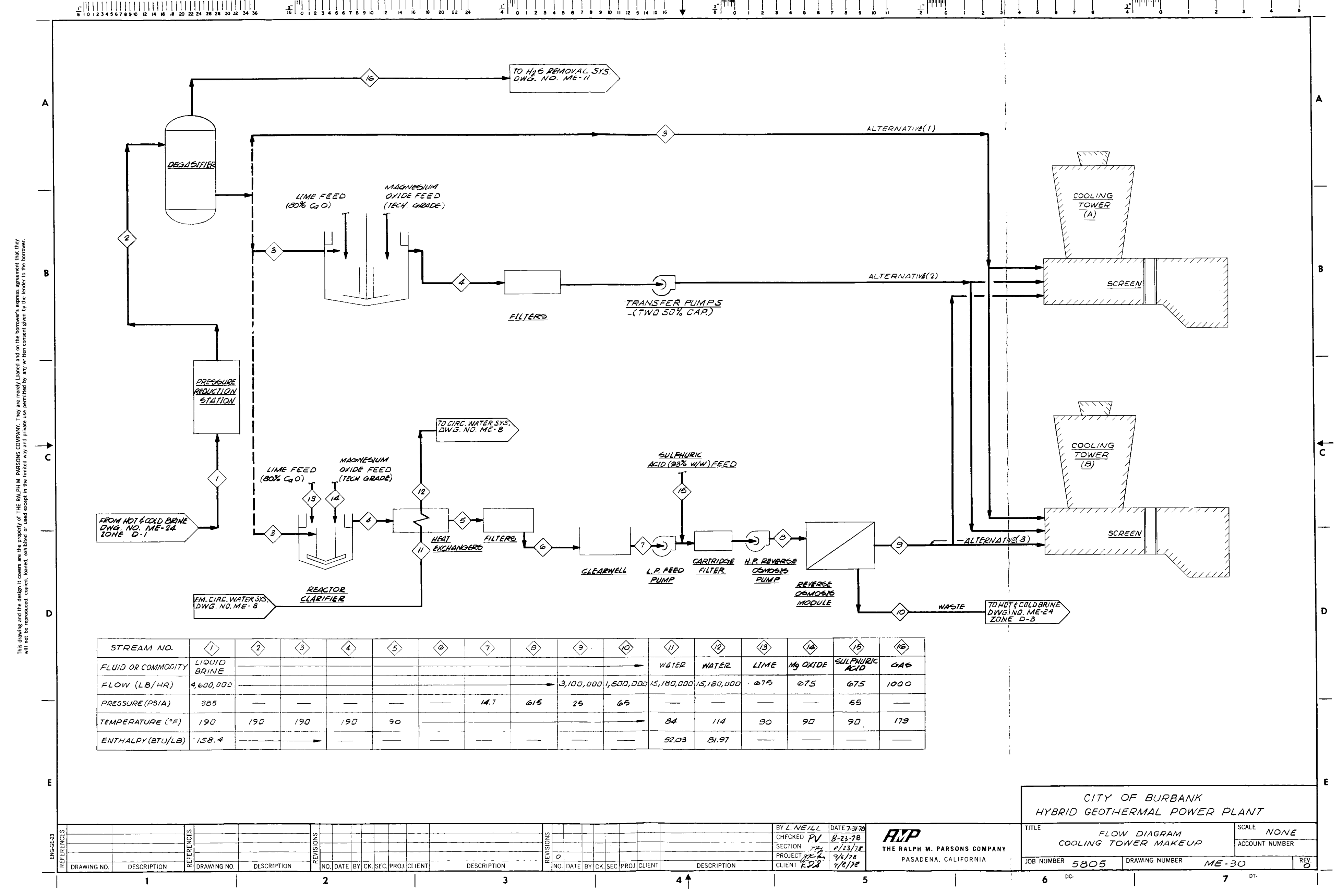




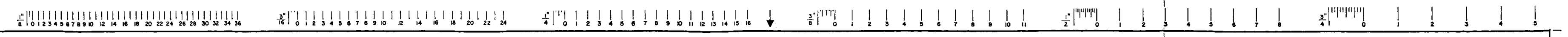

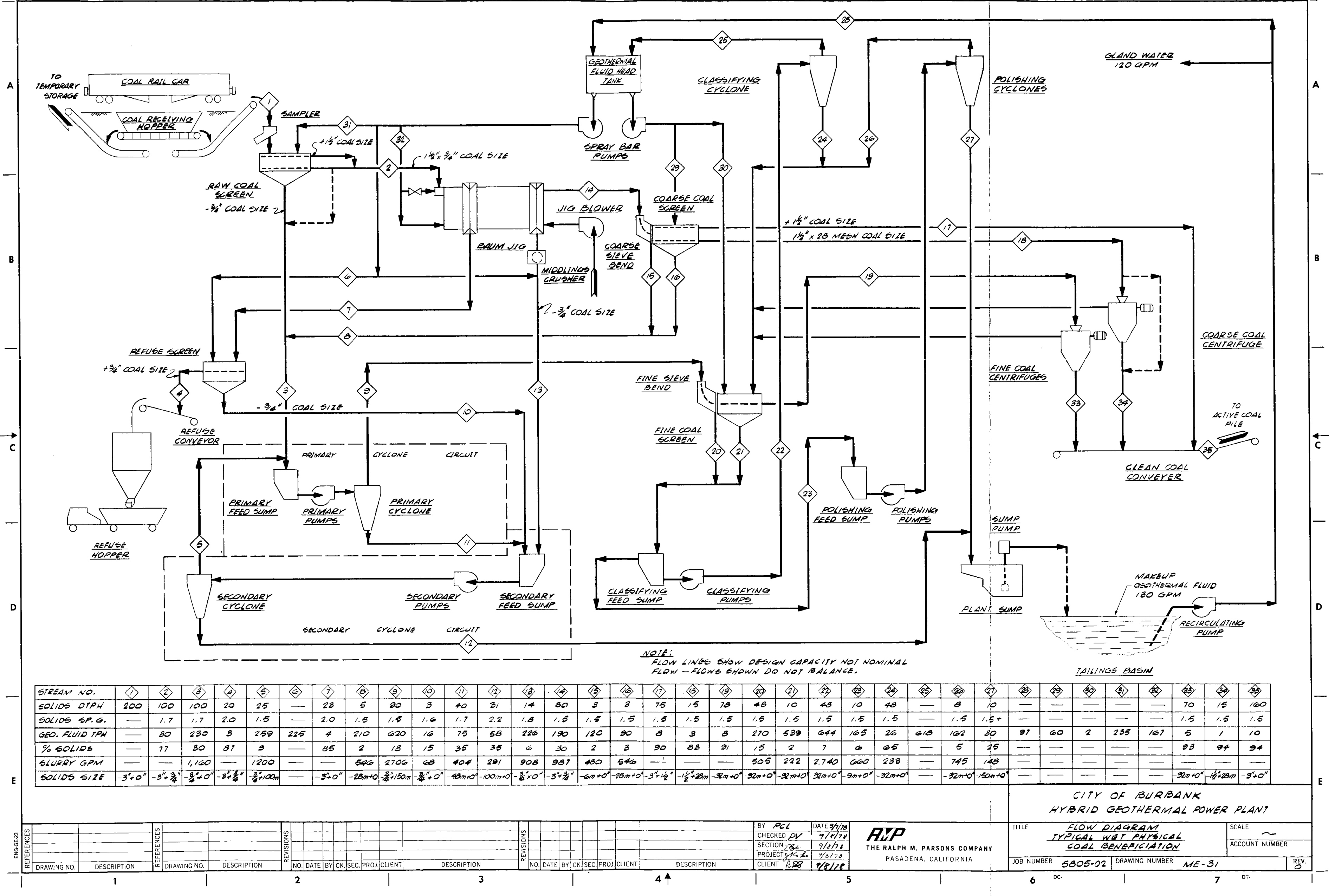




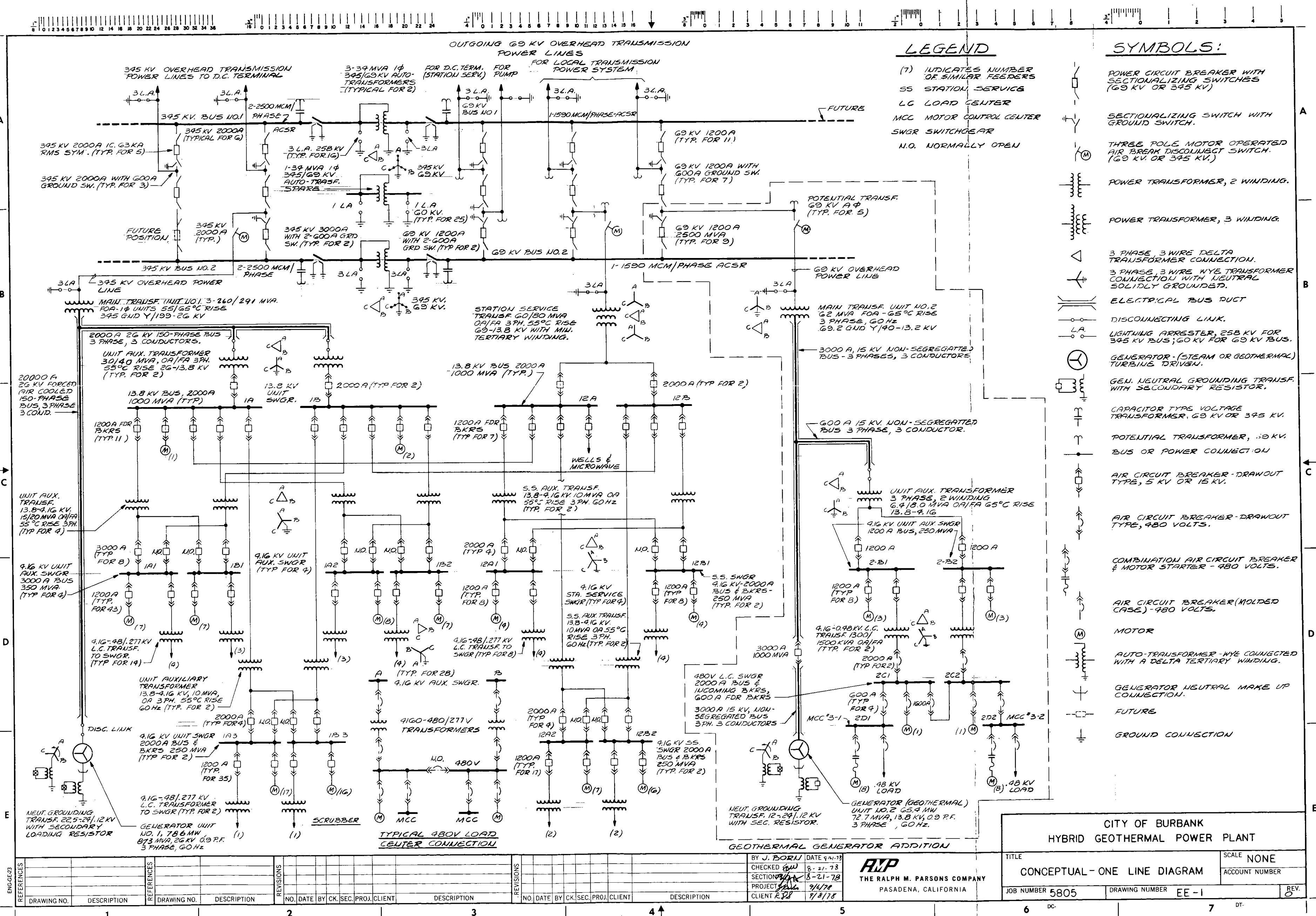




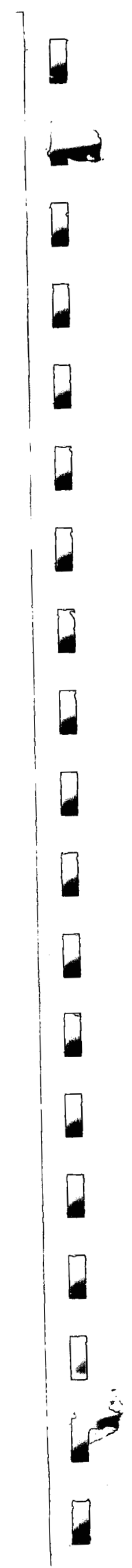




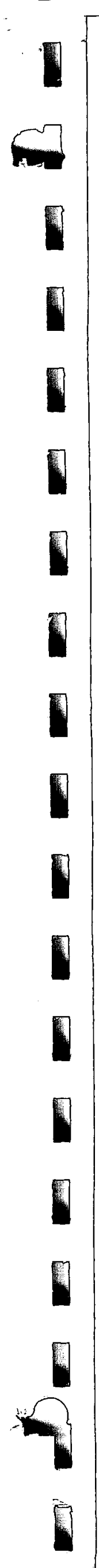

